Simone Policena Rosa

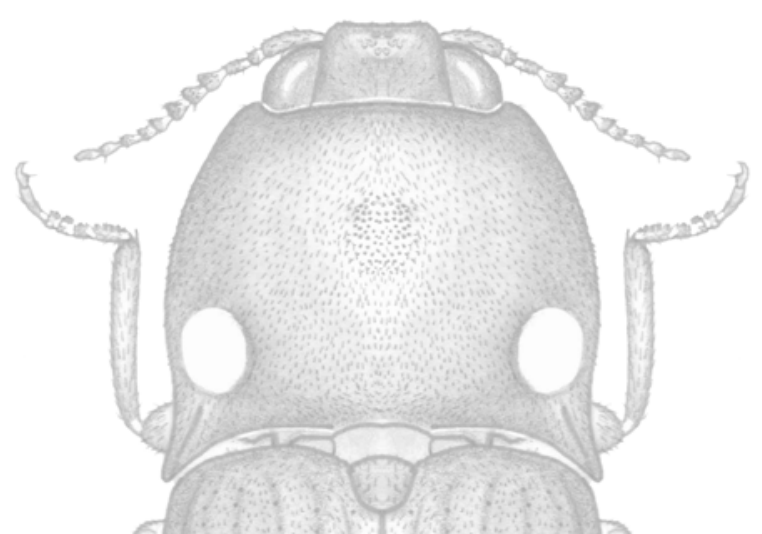

Análise Filogenética e Revisão Taxonômica da Tribo Pyrophorini

Candèze, 1863 (Coleotera, Elateridae, Agrypninae) 
Simone Policena Rosa

\section{Análise Filogenética e Revisão Taxonômica da Tribo Pyrophorini Candèze, 1863 (Coleotera, Elateridae, Agrypninae)}

Tese apresentada ao Instituto de Biociências da Universidade de São Paulo, como parte dos requisitos necessários para a obtenção do título de Doutor em Ciências, na área de Zoologia.

Orientadora: Profa. Dra. Cleide Costa 


\section{FICHA CATALOGRÁFICA}

\section{Rosa, Simone Policena}

Análise filogenética e revisão taxonômica da tribo Pyrophorini Candeze, 1863 (Coleoptera, Elateridae, Agrypninae)

$$
\mathrm{xii}+241 \mathrm{p} \text {. }
$$

Tese (Doutorado) - Instituto de Biociências da Universidade de São Paulo. Departamento de Zoologia.

1. Filogenia 2. Taxonomia 3. Elateridae 4. Pyrophorini. I. Universidade de São Paulo. Instituto de Biociências. Departamento de Zoologia

Comissão Julgadora:

Prof(a). Dr(a).

Prof(a). Dr(a).

Prof(a). Dr(a).

Prof(a). Dr(a).

$\operatorname{Prof}(a) . \operatorname{Dr}(a)$. 
Para Michael Ladenthin 


\section{AGRADECIMENTOS}

À Dra. Cleide Costa, pelos ensinamentos, amizade e apoio à minha formação que, por incontáveis vezes, excedeu o âmbito desta tese. Também pelo exame dos exemplares de Hifo pacificus do ISNB (Bruxelas).

Ao Dr. Sergio Ide (IBSP), por seus conselhos, sugestões e correções no decorrer deste trabalho.

Ao Michael Ladenthin, por toda a sua ajuda e dedicação, amor e compreensão, por tudo.

Aos amigos: Gláucia Marconato e Janice Muriel por me acolherem nos dias mais difíceis; Peterson Lopes e Antônio Macedo, pelas inúmeras vezes que me ajuraram com o TNT, como o NDE e com muito mais. Fernando Domenico, Guilherme Ide, Maurício Rocha, Ilana Fischberg, Carine Chamon, Yana Teixeira, Cristiano Moreira, José Luiz Birindelli, também pela ajuda e atenção em todas as vezes que precisei (e que não foram poucas...). A todos, pela amizade.

Ao Airton A. Cruz, pela formatação geral e do índice.

Aos funcionários do Museu de Zoologia (USP), pelo apoio, amizade e imensa solicitude e gentileza que sempre me dedicaram.

Às funcionárias da biblioteca do Museu de Zoologia, por toda a gentil atenção e paciência durante todos esses anos.

Ao Prof. Dr. Carlos Roberto F. Brandão, antigo diretor, e ao Prof. Dr. Sérgio A. Vanin, atual diretor do Museu de Zoologia da USP, por permitir meu acesso às instalações e recursos do museu.

Ao CNPq e ao Instituto de Biociências da Universidade de São Paulo pela concessão da bolsa de estudo e recursos. 


\section{RESUMO}

A tribo Pyrophorini (sensu Costa, 1975) comprende 144 espécies e 19 gêneros descritos que ocorrem na região Neotropical, sul da região Neártica e na Oceania. São tradicionalmente considerados como um gupo monofilético, compartilhando como suposta sinapomorfia a presença de órgãos bioluminescentes. No presente estudo é apresentada a análise cladística para a tribo, baseada na morfologia dos adultos, que resultou em oito hipóteses filogenéticas alternativas. Os cladogramas mais parcimoniosos demonstram que Pyrophorini (sensu Costa, 1975) não é monofilética, porque inclui, entre os descendentes de seu ancestral exclusivo, seis gêneros de Heligmini: Meroplinthus Candéze, 1891, Coctilelater Costa, 1975, Agnostelater Costa, 1975, Paraphileus Candèze, 1881, Euplinthus Costa, 1975 e Compsoplinthus Costa, 1975. A presença de um par de órgãos luminescentes sobre o pronoto é confirmada como sinapomorfia para a tribo, mas esta condição foi perdida três vezes independentemente e adquirida paralelamente pelo menos uma vez no grupo interno.

Os gêneros Pyrearinus Costa, 1975, Deilelater Costa, 1975, Lygelater Costa, 1975 e Ptesimopsia Costa, 1975 foram subdivididos em grupos de espécies que foram incluídos como táxons terminais na análise e resultaram merofiléticos, levando ao reconhecimento de quatro novos gêneros: Gênero $B$ gen n., Gênero $C$ gen n., Gênero D gen n. e Gênero $E$ gen n.. Para uma espécie não descrita também é erigido o Gênero $A$ gen n.. É reafirmada a hipótese de monofilia entre os gêneros da Oceania e da região Neotropical, cuja disjunção é, provavelmente, devida à tectônica da Gondwana, durante o Mesosóico. O cladograma de consenso aponta as seguintes relações filogenéticas para a tribo Pyrophorini sensu novo: ((Noxlumenes (Nyctophyxis + Cryptolampros $))+($ Gênero A gen. n. (Pyrophorus (Fulgeochlizus (Meroplinthus (Ptesimopsia paralella (Ptesimopsia (Hapsodrilus (Pyroptesis Sooporanga $))))+(($ Gênero B gen. n., Pyrearinus, (Phanophorus + Hypsiophthalmus $))+$

(Gênero C gen. n. (Gênero D gen. n. (Coctilelater (Agnostelater (Paraphileus (Euplinthus 
(Campsoplinthus (Hifo (Opselater, grupo melanurus, Lygelater, L. bifossulatus, Deilelater,

(Photophorus + Ignelater ), (Gênero E gen. n. $(V$. sirius comb. n. ( $V$ gemmiferus +

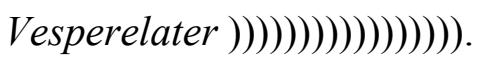

É proposta uma nova composição para a tribo Pyrophorini, que passa a incluir 159 espécies e 30 gêneros divididos em duas subtribos, Nyctophyxina Costa, 1975 e Pyrophorina Candèze, 1863. É apresentada uma revisão taxonômica para esses gêneros, incluindo caracteres novos do metanoto, do mesoventrito e da genitália masculina e ilustrações para grande parte dos caracteres. 


\section{ABSTRACT}

The tribe Pyrophorini (sensu Costa, 1975) comprises 144 species and 19 genera that occur in Neotropical, Southern Neartic and Australian Regions. They have been traditionally recognized as a monophyletic group, sharing as a presumed synapomorphy the bioluminescent organs. I present here a cladistic analysis of the tribe, based on the adult morphology. This study resulted in eight alternative phylogenetic hypotheses. The most parsimonious cladograms show that Pyrophorini (sensu Costa, 1975) is paraphyletic, because it includes, among the descendants of its most recent ancestor, six genera of Heligmini: Meroplinthus Candèze, 1891, Coctilelater Costa, 1975, Agnostelater Costa, 1975, Paraphileus Candèze, 1881, Euplinthus Costa, 1975 and Compsoplinthus Costa, 1975. The presence of a pair of bioluminescent organs on pronotum is corroborated as synapomorphy for the tribe, but this condition was lost three times independently and it was acquired homoplastically at least once in the internal group.

The genera Pyrearinus Costa, 1975, Deilelater Costa, 1975, Lygelater Costa, 1975 and Ptesimopsia Costa, 1975 were subdivided in species groups that were included as terminal taxa in the analysis; they resulted polyphyletic. Four new genera were recognized: Genus $B$ gen n., Genus $C$ gen n., Genus $D$ gen n. and Genus $E$ gen n. For an undescribed species is also proposed the Genus $A$ gen $\mathbf{n}$. The monophyly of the Oceanic and Neotropical genera is confirmed, their disjunction is, probably, due to the tectonic of Gondwana, during the Mesozoic. The consensus cladogram show the following phylogenetic relationships for the tribe Pyrophorini sensu novo: ((Noxlumenes $($ Nyctophyxis + Cryptolampros $))+($ Gênero A the gen. n. (Pyrophorus (Fulgeochlizus (Meroplinthus (Ptesimopsia paralella (Ptesimopsia (Hapsodrilus (Pyroptesis Sooporanga $))))+(($ Gênero $B$ gen. $\quad$ n., Pyrearinus, (Phanophorus + Hypsiophthalmus)) + (Gênero $C$ gen. n. (Gênero D gen. n. (Coctilelater (Agnostelater (Paraphileus (Euplinthus (Campsoplinthus (Hifo (Opselater, group melanurus, 
Lygelater, L. bifossulatus, Deilelater, (Photophorus + Ignelater), (Gênero E gen. n. (V. sirius comb. n. $($ V gemmiferus + Vesperelater $)))))))))))))))))$.

A new composition is proposed for the tribe Pyrophorini, including now 159 species and 30 genera subdivided in two subtribes, Nyctophyxina Costa, 1975 and Pyrophorina Candèze, 1863. Taxonomic revisions of all genera, including new characters mainly of the metanotum, mesoventrite, aedeagous and illustrations for most of them are also given. 


\section{ÍNDICE}

AGRADECIMENTOS $\mathrm{V}$

RESUMO vi

ABSTRACT viii

1 INTRODUÇÃO 1

1.1 Considerações gerais sobre a família Elateridae .................................................. 1

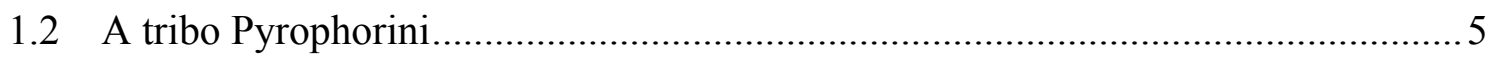

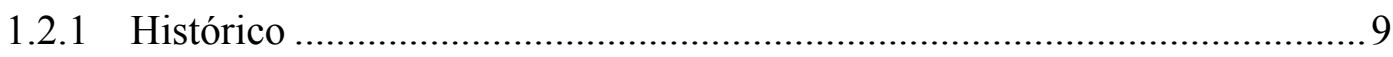

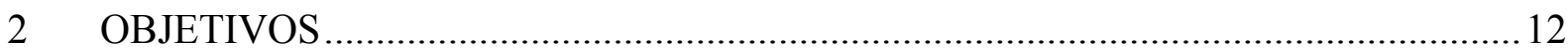

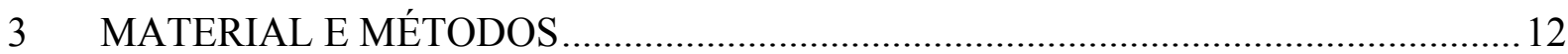

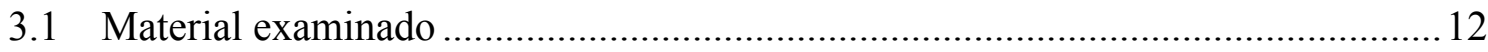

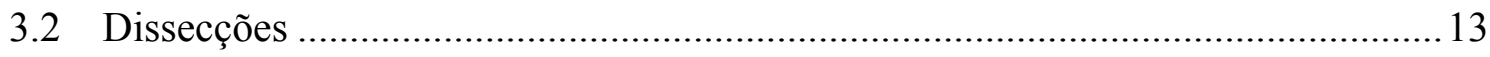

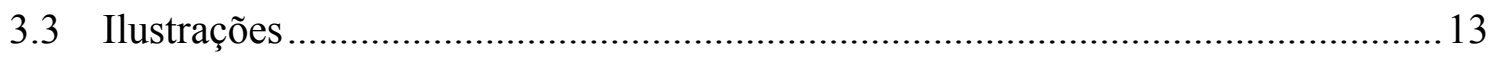

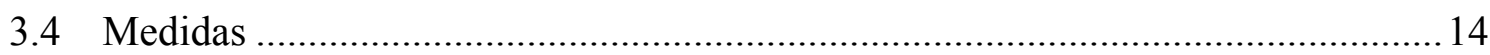

3.5 Distribuição geográfica e lista de material examinado....................................... 15

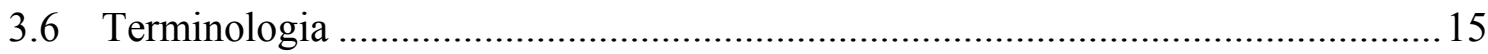

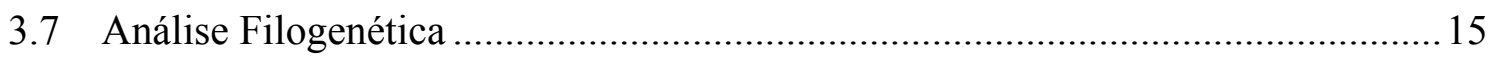

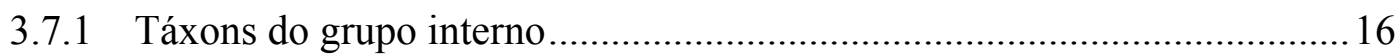

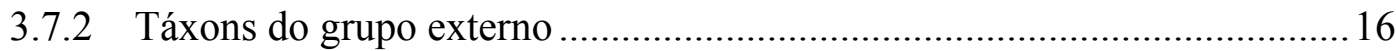

3.7.3 Codificação dos caracteres e construção da matriz ...................................17

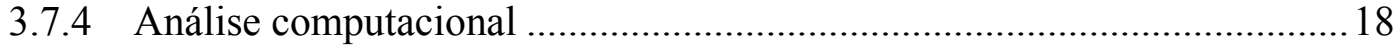

Análise da matriz de dados ................................................................. 18

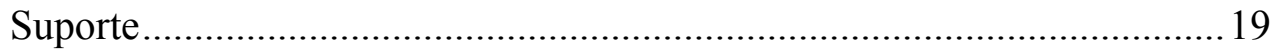

Ponderação sucessiva a posteriori ...........................................................20

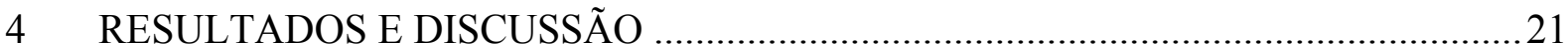

4.1 Lista de caracteres e e distribuição dos estados......................................................21

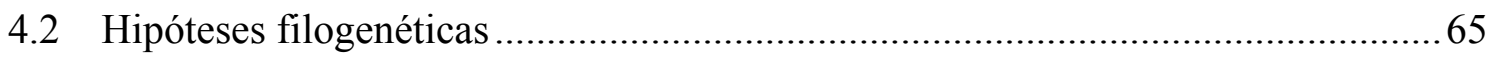




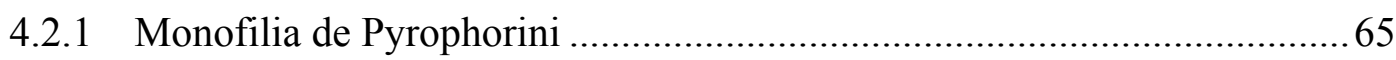

4.2.2 Relações filogenéticas entre Pyrophorini e outros Agrypninae...................67

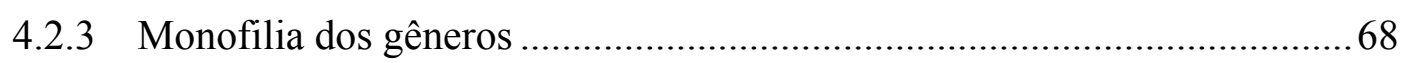

4.2.4 Relacionamentos filogenéticos dentro de Pyrophorini .............................. 71

4.2.5 Suporte de Bremer .............................................................................. 75

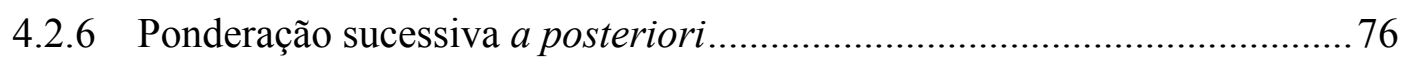

4.2.7 Conclusões sobre as hipóteses de filogenia de Pyrophorini e suas implicações para a taxonomia da tribo. ................................................... 76

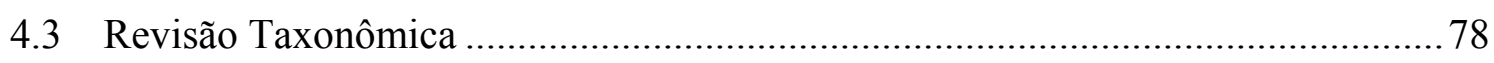

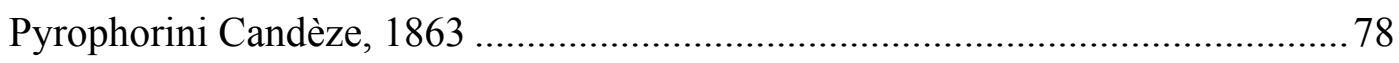

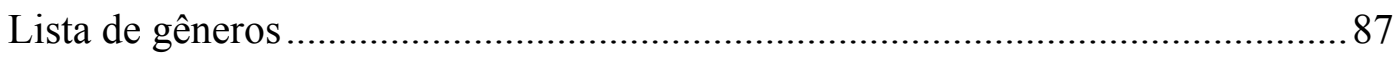

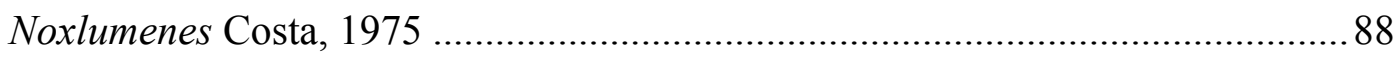

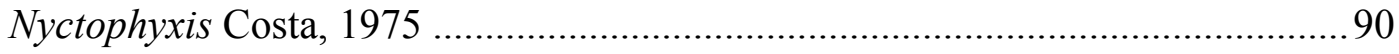

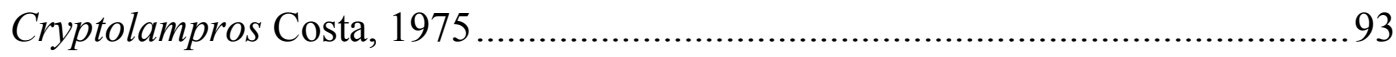

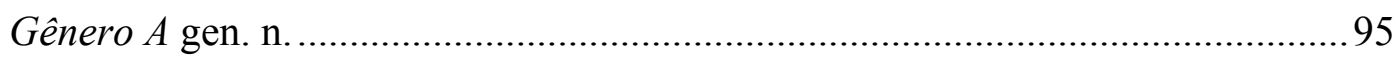

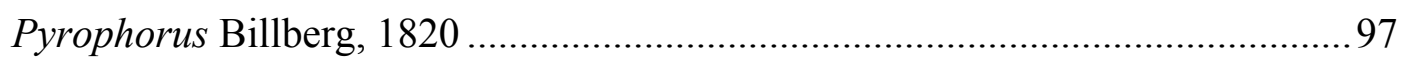

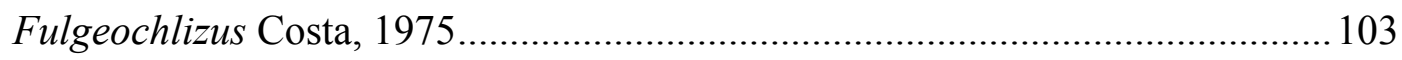

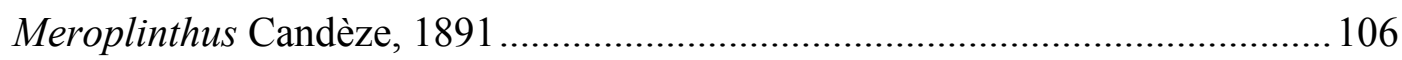

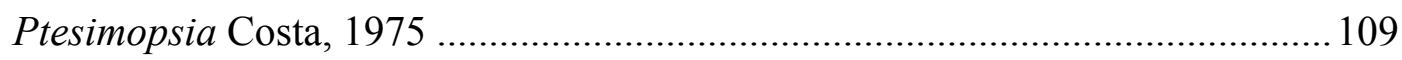

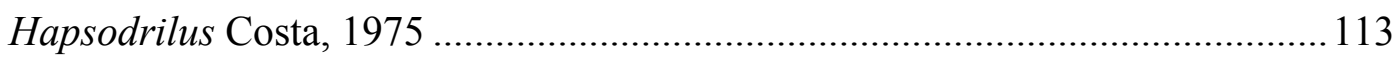

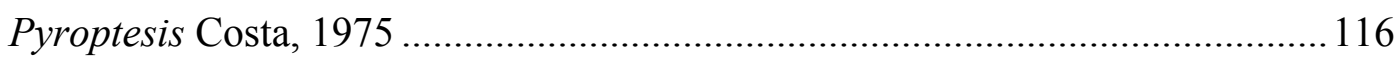

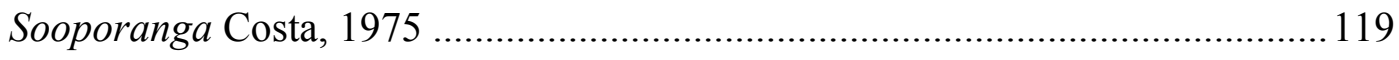

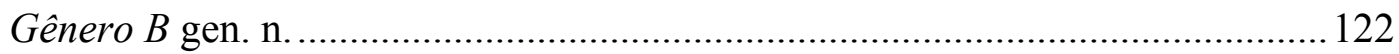

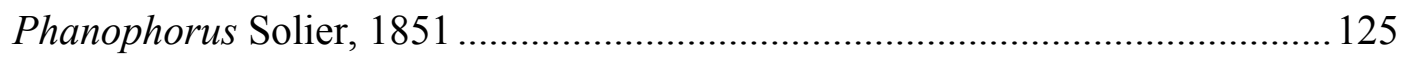

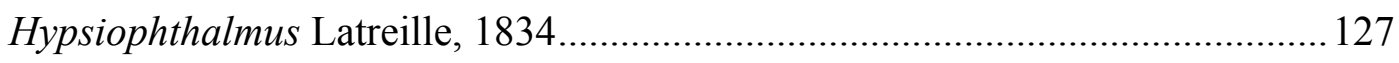

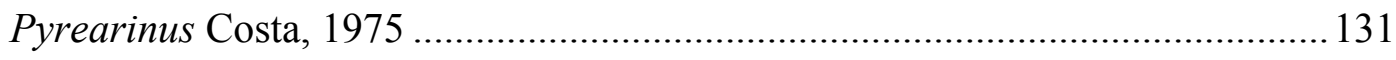

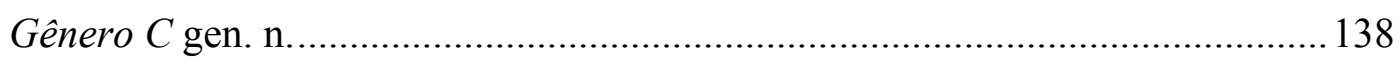


Gênero D gen. n.

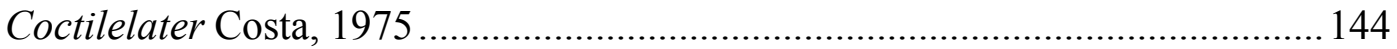

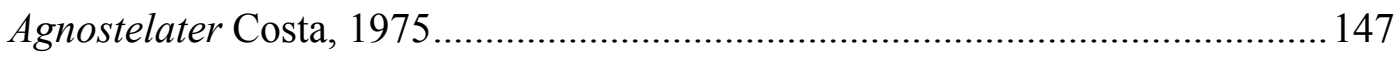

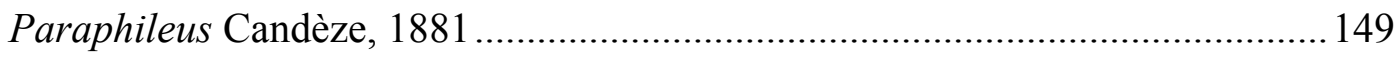

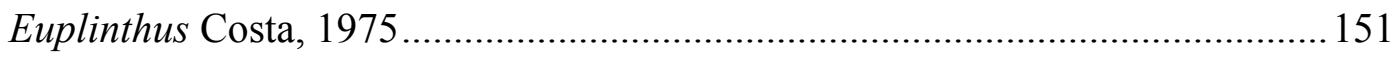

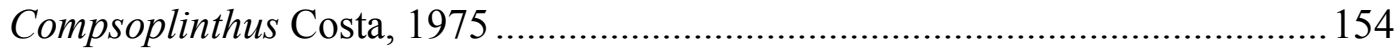

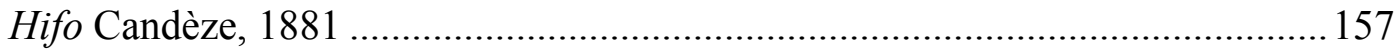

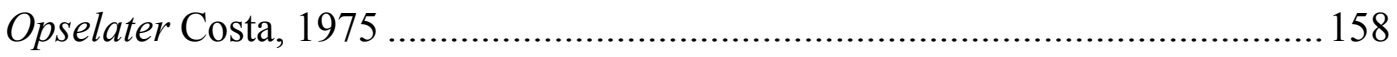

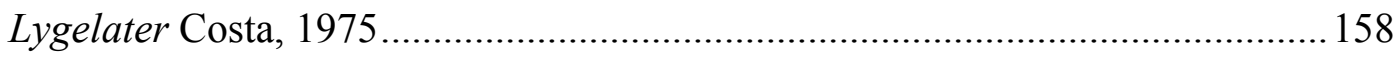

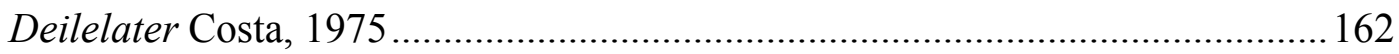

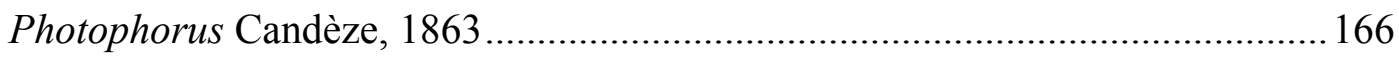

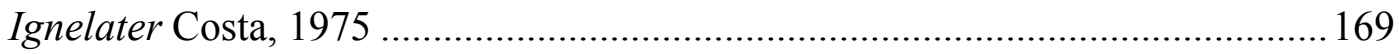

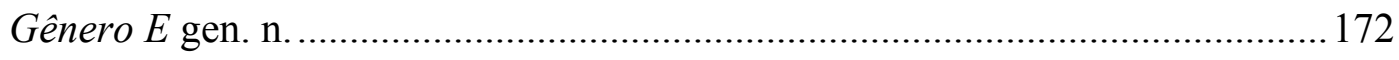

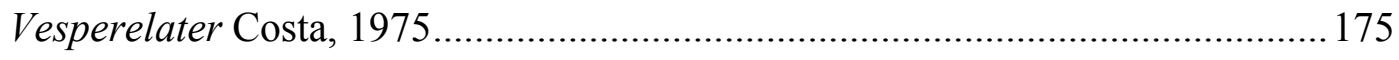

4.4 Considerações biogeográficas sobre a disjunção entre os gêneros Neotropicais

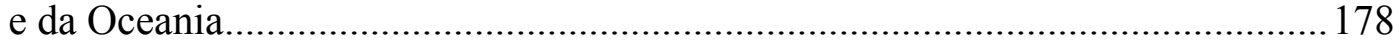

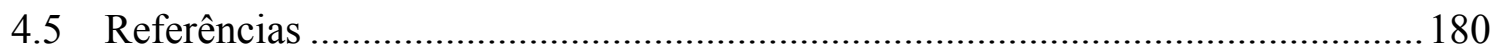

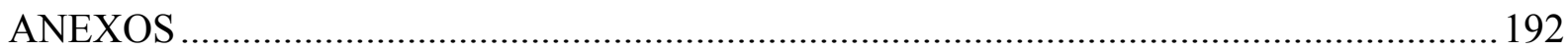




\section{INTRODUÇÃO}

\subsection{Considerações gerais sobre a família Elateridae}

A família Elateridae é cosmopolita e compreende cerca de 400 gêneros e 9000 espécies (Calder, 1998). No Brasil são popularmente chamados de tem-tem, tec-tec e saltamartim (Lenko \& Papavero, 1996), nomes atribuídos principalmente devido à capacidade de saltar que esses insetos possuem. Este salto, provavelmente um mecanismo de defesa, é normalmente acompanhado de um estalo e seu processo envolve um deslizamento muito rápido do processo prosternal para dentro da cavidade mesoventral (Evans, 1972). Os adultos podem ser facilmente distinguidos de outros coleópteros pela seguinte combinação de características: labro exposto, ângulos posteriores fortemente projetados, prosterno longo, procoxa globular com trocantins ocultos, placas metacoxais bem desenvolvidas e com quatro ventritos anteriores conatos. A maioria dos adultos é saprófaga ou fitófaga. Noturnos ou diurnos, podem ser coletados sob pedras, troncos, cascas de árvores e folhiço ou vagando sobre a vegetação e muitos são atraídos pela luz. As larvas são alongadas, cilíndricas, deprimidas ou vermiformes, forte ou fracamente esclerotizadas, com labro fusionado à cápsula cefálica fortemente esclerotizada e com lábio e maxilas conatos formando o hipóstoma. As larvas podem ser saprófagas, fitófagas ou predadoras e são encontradas escavando no solo ou em madeira semi-decomposta, sob troncos, pedras, musgos, liquens ou folhiço e em bromeliáceas e ninhos de insetos sociais (Costa et al., 1988; Calder, 1996). Várias larvas que se alimentam de tubérculos, raízes, bulbos, sementes e brotos provocam danos à agricultura, principalmente nas regiões temperadas (Booth et al., 1990).

Aproximadamente 142 espécies de elaterídeos são bioluminescentes: Balgus schnusei (Heller, 1914), da subfamília Thylacosterninae, ocorre no Peru e na Guiana Francesa e Campyloxenus pyrothorax Fairmaire 1860, única espécie de Campyloxeninae, do Chile e da Argentina (Costa, 1975b; 1984a). Ambas são pouco conhecidas e nada se sabe sobre bioluminescência nos imaturos dessas espécies. Pyrophorini (Agrypninae) encerra os demais 
140 elaterídeos bioluminescentes, chamados popularmente de vaga-lumes ou pirilampos e é o grupo estudado no presente trabalho.

Elateridae tem sido considerada como um grupo supostamente monofilético desde as primeiras classificações para Coleoptera, inicialmente como tribo dentro do grupo Sternoxi (Latreille, 1804, 1825) e finalmente como família (Lacordaire, 1857), status que mantém até hoje. A maioria dos gêneros que constituem a família parece realmente formar um grupo monofilético, mas os limites de Elateridae não estão completamente definidos, e alguns gêneros permanecem taxonomicamente instáveis. Esses gêneros são particularmente aqueles que relacionam os elaterídeos às outras famílias do complexo elateróide, Cerophytidae, Throscidae, Eucnemidae e Cebrionidae, as quais compartilham com Elateridae o mecanismo de estalo e salto, ou que parecem tê-lo perdido secundariamente (Calder et al., 1993; Lawrence et al., 1995).

As primeiras análises cladísticas com base em caracteres morfológicos incluindo representantes elaterídeos foram realizadas por Lawrence (1987), Calder et al. (1993), Muona (1995), Lawrence et al. (1995) e Beutel (1995) e embora não tenham sido conduzidas especificamente para testar a monofilia de Elateridae e definir seus limites, essas análises chegaram a importantes conclusões e têm influenciado a classificação atual de Elateridae. Recentemente, Sagegami-Oba et al. (2007) conduziram uma análise com base em seqüências parciais do nucleotídeo $28 \mathrm{~S}$ do DNA ribossômico com a finalidade de testar a monofilia de Elateridae.

Calder et al. (1993) e Muona (1995) fizeram a análise filogenética das famílias do complexo elateróide e ambas as análises sugeriram que a família Elateridae é parafilética, pois inclui Throscidae ou parte dessa família. Esses autores discordam em relação aos grupos de Throscidae que deveriam estar entre os descendentes da linhagem ancestral exclusiva de Elateridae: para Calder et al. (1993) Elateridae deveria incluir apenas Thylacosterninae, 
enquanto que os resultados de Muona (1995) sugeriram que Elateridae deve incluir totalmente a família Throscidae, como indicada no clado ((Thylacosterninae, Lissominae) Throscinae).

Sagegami-Oba et al. (2007), na primeira análise filogenética baseada em dados moleculares para Elateridae, incluíram 77 elaterídeos representando 9 das 12 subfamílias propostas por Stibick (1979), resultando na hipótese de monofiletismo para a família. Lissominae e Thylacosterninae não foram representados na análise, mas os autores reconheceram a necessidade de incluí-los devido a sua proximidade filogenética com certos grupos de Elateridae.

As subfamílias elaterídeas foram definidas principalmente com base nas características larvais (Hyslop, 1917, 1923; Zacharuck, 1962; Dolin, 1978) e esta classificação mostrou-se estável mesmo depois de acrescentados os estudos sobre venação alar (Dolin, 1975) e das estruturas torácicas (Gur'yeva, 1974).

Apenas recentemente as relações filogenéticas entre as subfamílias de Elateridae começaram a ser estudadas dentro da metodologia cladística. Nove subfamílias estão representadas na análise de Calder et al. (1993) que resultou no cladograma de consenso estrito formado pelo clado (((Pityobiinae + Agrypninae) $($ Cardiophorinae + Elaterinae $))+$ Denticollinae) numa politomia com Lissominae, Semiotinae, Tetralobinae, Cerophytidae e Eucnemidae. A filogenia molecular de Sagegami-Oba et al. (2007) resultou numa hipótese distinta da de Calder (1993) mas parcialmente congruente às propostas de Hyslop (1917), Stibick (1979) e Ohira, 1962. Segundo os resultados obtidos por Sagegami-Oba et al. (2007) Elateridae é monofilética e encontra-se dividida em quatro grupos maiores: o primeiro ramo mais basal é Elaterinae (incl. Melanotinae), o segundo é Agrypninae seguido de Denticolinae (incl. Hypnoidinae, Oxynopterinae e Pityobiinae) como grupo irmão do clado Cardiophorinae + Negastriinae.

A classificação de Elateridae apresentada em Lawrence \& Newton (1995) é uma tentativa de síntese e conciliação dos resultados obtidos nos trabalhos mais relevantes das 
últimas sete décadas (Emden, 1932; Fleutiaux, 1947; Nakane e Kishii, 1956; Crowson, 1961; Laurent, 1961, 1966; Ohira, 1962; Burakowski, 1973, 1975; Stibick, 1979; Costa \& CasariChen, 1993; Calder et al., 1993, Muona, 1995). Nesta classificação Elateridae encontra-se dividida em 15 subfamílias: Cebrioninae, Tetralobinae, Thylacosterninae, Lissominae, Semiotinae, Pityobiinae, Oxynopterinae, Agrypninae, Denticollinae, Negastriinae, Diminae, Elaterinae, Cardiophorinae, Hemiopinae, e Physodactylinae. Outras três subfamílias, Eudicronychinae, Anischiinae e Subprotelaterinae, são consideradas incertae sedis. O gênero Campyloxenus, originalmente incluído em Agrypninae, foi excluído dessa subfamília por Costa (1975b) e incluído em Campyloxeninae.

Agrypninae, que inclui Pyrophorini, é cosmopolita e a maior subfamília elaterídea, com cerca de 115 gêneros e 2.300 espécies que compartilham como sinapomorfias a presença de cerdas na superfície da base ventral externa das garras tarsais e a perda da célula anal na asa posterior (Crowson, 1961; Calder et al., 1993). Pityobiinae aparece como grupo irmão de Agrypninae na análise filogenética conduzida por Calder et al. (1993) e na filogenia molecular de Sagegami-Oba et al. (2007), discutida anteriormente, Agrypninae é o grupoirmão do clado (Denticolinae (Cardiophorinae + Negastriinae)).

Desde Candèze (1857) o grupo “Agrypnides” passou por diversas modificações, ora sendo considerado por alguns autores como subfamília, ora sendo incluído como tribo de Pyrophorinae. Stibick (1979) afirmou que Pyrophorinae não é o nome mais antigo válido para o grupo e, embora Agrypninae também não o seja, sugeriu este último, pois ele preservaria a estabilidade do nome. Atualmente, o nome Agrypninae é o nome mais empregado, sendo Pyrophorini citado como tribo desta subfamília, mas alguns autores ainda se referem à subfamília como Pyrophorinae (Sagegami-Oba et al. 2007).

A subfamília Agrypininae compreende as tribos Agrypnini, Hemirhipini Conoderini, Pseudomelanactini, Tetralobini; Pyrophorini e Heligmni e Anaissini (Costa, 1975b; Golbach, 1984; Calder, 1998; Johnson, 2002). 


\subsection{A tribo Pyrophorini}

A tribo Pyrophorini (sensu Costa, 1975b) compreende 19 gêneros e 144 espécies descritas de elaterídeos conhecidos popularmente como vaga-lumes ou pirilampos, distribuídos nas subtribos Pyrophorina, Hapsodrilina e Nyctophyxina. Com a exceção do gênero Hifo, todos possuem um par de vesículas ou manchas bioluminescentes, localizadas posteriormente sobre o protórax. A maioria das espécies também possui um órgão luminescente abdominal de formato variável, localizado numa fenda mediana do esternito I. Distribuem-se principalmente pela região Neotropical, do sul dos Estados Unidos até o norte da Argentina, com apenas dois gêneros, Hifo e Photophorus, na Oceania (Costa, 1975b).

Os adultos de Pyrophorini são noturnos e fitófagos e podem ser capturados à noite, durante o vôo que precede a cópula. A larvas predadoras vivem no solo, em madeira apodrecida, dentro de cupinzeiros ou sob pedras. As larvas descritas de várias espécies de Pyrophorina e Hapsodrilina não apresentam diferenças morfológicas significativas, elas são caracterizadas por: corpo dorso-ventralmente achatado, amarelado com cabeça, pronoto e prosterno mais escuros, suturas craniais largamente separadas na região anterior e convergentes na região posterior, mandíbulas sem dente e nono segmento abdominal bifurcado com pequenos tubérculos pilosos. Somente a larva de Pyrearinus termitilluminans pode ser facilmente distinguida das demais, pois possuem várias autapomorfias, prováveis adaptações à vida dentro de galerias superficiais de cupinzeiros (Casari-Chen \& Costa, 1986; Costa, 1982). Larvas das espécies de Nyctophyxina ainda não são conhecidas.

Os vaga-lumes elaterídeos são noturnos e fitófagos, alimentam-se de frutos e exsudados de plantas (Hogue, 1993). As larvas podem ser encontradas em madeira apodrecida, cupinzeiros, no solo e sob pedras. Elas são predadoras de isópteros, colêmbolas e larvas de outros insetos e, como todos os Elateridae, possuem digestão parcialmente extra-oral (Costa, 1975b). O tempo de vida desses insetos é relativamente longo, o estágio larval, em condições favoráveis, geralmente varia de 11 a 31 meses, mas espécimes de Fulgeochlizus 
bruchi criados no laboratório do Museu de Zoologia da USP levaram cerca de seis anos para atingir o estágio adulto. O período pupal varia de 19 a 48 dias e os adultos, em laboratório, sobrevivem por aproximadamente três meses (Costa, 1975b; Casari-Chen \& Costa, 1986).

A função da bioluminescência no comportamento desses insetos é pouco conhecida. Ela foi sugerida pela maioria dos autores como um fator importante na corte sexual, possibilitando o encontro de machos e fêmeas de uma mesma espécie. Os machos voam com as lanternas protorácicas e abdominal "acesas" enquanto as fêmeas repousadas sobre a vegetação respondem ao sinal por meio da luz emitida por suas lanternas protorácicas (Lloyd, 1971; Viviani, 1987; Bechara, 1988, Rosa, 2004). As espécies de Pyrophorina e Hapsodrilina produzem luz esverdeada em todos os estágios de desenvolvimento (CasariChen \& Costa, 1986). Os adultos emitem luz esverdeada por meio das vesículas ou manchas luminescentes protorácicas e luz amarelada por meio do órgão luminescente abdominal, visível apenas durante o vôo (Seliger \& McElroy, 1965; Colepicolo-Neto et al., 1986). A luz surge lentamente e intensifica-se gradualmente até atingir seu máximo, persiste por tempo considerável e então se apaga lentamente. Adultos e larvas não emitem luz espontaneamente durante o dia, a menos que sejam manuseados ou perturbados (Seliger \& McElroy, 1965; Harvey, 1952).

Colepicolo-Neto et al. (1986) estudaram o espectro bioluminescente de duas espécies de Hapsodrilina e dez de Pyrophorina. Seus estudos revelaram que machos e fêmeas de uma determinada espécie não apresentam diferenças significativas no espectro da luz emitida pelos órgãos protorácicos ou pelo órgão abdominal, e concluíram que a cor da bioluminescência não desempenha um papel na corte sexual. Permanece, portanto, a questão sobre que fator relacionado à bioluminescência teria importância para o reconhecimento do parceiro sexual nesses elaterídeos. No entanto, os experimentos desses e de outros autores (Barros \& Bechara, 1998; Timmins et al., 1999 apud Costa et al., no prelo) com larvas de Pyrearinus termitilluminans sugerem que a bioluminescência nas larvas pode ter a função 
primária de eliminar o excesso de oxigênio no organismo desses insetos por meio de enzimas antioxidantes, como a superóxido dismutase (SOD) e a catalase

Dubois (1886) estudou o alcance da luz produzida por Pyrophorus e por meio de experimentos concluiu que estes insetos utilizam a luz para se guiarem no escuro, tanto durante a marcha, por meio da luz emitida pelos os órgãos protorácicos, quanto durante o vôo, por meio da luz emitida pelo órgão abdominal.

As larvas de Pyrearinus termitilluminans, que habitam as galerias superficiais de cupinzeiros de Cornitermes sp. na região Centro-Oeste do Brasil (Costa, 1982) utilizam a bioluminescência para atrair pequenos insetos alados dos quais se alimentam (Redford, 1982). A emissão de luminescência pelas larvas e adultos quando perturbados sugere que ela também funciona como um mecanismo de defesa (Viviani, 1987; Bechara, 1988), no entanto larvas mantidas em laboratório passam longos períodos sem iluminar, mesmo quando são estimuladas (Casari-Chen \& Costa, 1986).

A forma e a localização das vesículas luminescentes do pronoto e do órgão abdominal já havia sido apontada por Costa (1975b) como importantes caracteres taxonômicos, fato que é corroborado pelo presente trabalho. Colepicolo-Neto et al. (1986) em seus experimentos concluíram que as diferenças no pico do comprimento de onda podem ter uma importância taxonômica auxiliar para os gêneros Pyrearinus e Hapsodrilus, mas não para Pyrophorus, nos quais as diferenças não são suficientes para discriminar suas espécies. Esses autores também afirmaram que todas as larvas estudadas puderam ser identificadas através do pico do comprimento de onda.

Parece haver diferenças significativas no padrão de emissão de luz nas larvas de várias espécies. Pyrophorus punctatissimus emite luz em manchas arredondadas laterais e em zonas transversais dorsais e ventrais (Costa, 1970). Em Pyrearinus micatus a emissão de luz ocorre por meio de duas manchas arredondadas pequenas no protórax e uma série de pontos laterais e medianos nos segmentos abdominais e Opselater pyrophanus emite luz apenas na 
região do protórax, enquanto que um espécime de Pyrearinus brevicollis criado em laboratório emitiu luz apenas no estágio de pupa farada (Costa, 1978). Pyroptesis gilvus apresenta luz intensa no protórax e, apenas após um longo período de estímulo, também emite luz fraca em forma de faixas transversais nos segmentos abdominais. As pupas também emitem luz, em geral de forma difusa, no protórax e nos segmentos abdominais. A pupa de Fulgeochlizus bruchi emite luz por meio de uma estreita faixa externa nos hipômeros e nos ângulos externos dos segmentos abdominais que correspondem, no adulto, a manchas amareladas, similares ao par de manchas luminescentes do protórax (Casari-Chen \& Costa, 1986).

Recentemente três espécies de Pyrophorini foram estudas citogeneticamente (Schneider et al., no prelo): Pyrearinus candelarius, Pyrophorus divergens e $P$. punctatissimus. A análise das células espermatogoniais evidenciou o número diplóide $2 \mathrm{n}=15$ nessas espécies de Pyrophorini, em contaste com o número 2n = 17 em Conoderus malleatus. O sistema de determinação de sexo é XO e quase todos os cromossomos são acrocênticos. A diferença mais significativa foi encontrada nas células diplotênicas e está relacionada ao número de bivalentes com dois quiasmata: Pyrearinus cadelarius possui 1 bivalente, Pyrophorus divergens possui 2 bivalentes e em P. punctatissimus há 4 bivalentes.

Do exposto acima, pode-se concluir que vários caracteres, obtidos a partir de estudos bioquímicos, etológicos, citogenéticos e da morfologia das larvas podem ser potencialmente informativos para o estudo das relações filogenéticas das espécies e gêneros de Pyrophorini, No entanto, a ausência desses dados para a maioria das espécies, representando um maior número de gêneros, não permite que esses possam ser empregados em análises cladísticas. Os dados morfológicos dos adultos, por outro lado, nesse momento, parecem ser a melhor fonte de informação filogenética para o grupo, dado o número expressivo de espécimes representantes de quase todas as espécies e gêneros descritos nas coleções zoológicas. 


\subsubsection{Histórico}

Pyrophorus foi erigido por Billberg (1820) para agrupar as espécies de Elater Linnaeus, 1758, da América, que possuíam um par de órgãos bioluminescentes na região posterior do pronoto.

Latreille, 1834 erigiu o gênero Hypsiophthalmus para um vaga-lume elaterídeo da Argentina, descrito por Eschscholtz (1829) no gênero Pyrophorus, que se destacava das demais espécies deste gênero pelos olhos muito grandes no macho. Solier (1851) estabeleceu Phanophorus para uma espécie de vaga-lume elaterídeo descrita para o Chile, Elater perspicax Guérin-Méneville, 1830.

Candèze (1863) estabeleceu a subtribo "Pyrophorites" para incluir Pyrophorus e Photophorus, um novo gênero da Oceania que também possui um par de órgãos bioluminescentes no protórax. Nesse mesmo trabalho transferiu as espécies de Phanophorus e de Hypsiophthalmus para o gênero Pyrophorus.

Em 1881, Candèze erigiu os gêneros Hifo para Hifo pacificus, da Oceania, e Paraphileus para a espécie brasileira Aphanobius thoreyi Germar, 1844, e os colocou, apesar da ausência de órgãos bioluminescentes, na subtribo "Pyrophorites", devido à similaridade geral externa entre elas e certas espécies de Pyrophorus, principalmente com relação à forma da fronte e dos tarsos. Este mesmo autor, em 1891, elevou o status de "Pyrophorites" para tribo, à qual acrescentou um novo gênero, Meroplinthus, e transferiu outros três, Heligmus Candèze, 1865, Ischius Candèze, 1857 e Pyrapractus Fairmaire, 1884, todos eles incluindo espécies não bioluminescentes.

Champion (1895) citou Pyrophorini e três de seus gêneros com espécies na América Central: Pyrophorus, Alampes e Ischius.

Schwarz (1906) descreveu Hifoides e Alampoides e os colocou na tribo Pyrophorini, para a qual transferiu Campyloxenus Fairmaire, 1860, Alampes Champion, 1895 
e Mocquerysia Fleautiaux, 1899, juntamente com os gêneros anteriormente incluídos na tribo por Candèze (sup. cit.).

Hyslop (1917) sugeriu uma nova classificação para Elateridae, baseada na morfologia das larvas, na qual arrolou Pyrophorini como subtribo (Pyrophorina). Este mesmo autor, em 1921, notou que Ischius Candèze, 1857 era nome pré-ocupado e propôs o nome Pyrischius para a espécie Ischius gerstaeckeri Candèze, 1857.

Schenkling (1927) catalogou Mocquerysia e Pyrapractus em Denticollinae e elevou o status da tribo para subfamília, Pyrophorinae, incluindo todos os gêneros até então propostos para o grupo.

Blackwelder (1945) seguiu a classificação proposta por Hyslop (1917) e listou para Pyrophorina 9 gêneros com distribuição Neotropical: Pyrophorus, Campyloxenus, Alampes, Alampoides, Hifoides, Paraphileus, Meroplinthus, Pyrischius e Heligmus.

Ao revisar os Pyrophorina da região Neotropical, Costa (1975b) elevou seu status novamente para tribo da subfamília Pyrophorinae, excluiu as espécies não bioluminescentes e erigiu novos gêneros para espécies novas ou para re-agrupar as espécies descritas, a maioria delas arroladas em Pyrophorus. Foram erigidos os gêneros Nyctophyxis, Noxlumenes e Cryptolampros, agrupados na subtribo Nyctophyxina; Sooporanga, Pyroptesis, Hapsodrilus e Ptesimopsia, incluídos na subtribo Hapsodrilina e os gêneros Fulgeochlizus, Opselater, Ignelater, Lygelater, Deilelater e Vesperelater que, juntamente com Phanophorus e Hypsiophthalmus, revalidados por Costa (1975b), e Pyrophorus foram incluídos na subtribo Pyrophorina.

Neste mesmo trabalho, Costa excluiu Hifo e Photophorus, ambos da Oceania, considerando-os incertae sedis e sugeriu a possibilidade de convergência da bioluminescência de Photophorus com a dos gêneros neotropicais. Costa (1984b) apresentou uma redescrição de Hifo pacificus Candèze, 1881 e observou que tanto Hifo como Photophorus compartilhavam das seguintes apomorfias de Agrypninae: garras tarsais com cerdas basais, 
asa posterior sem célula anal e ovipositor sem stylus articulado. Além disso, observou que Hifo possuía um órgão luminescente abdominal. Considerando a bioluminescência como sinapomorfia para os Pyrophorini, a autora re-alocou Hifo e Photophorus em Pyrophorini.

Para os gêneros excluídos de Pyrophorini, Costa (1975b) erigiu a tribo Heligmini, para o qual também estabeleceu novos gêneros: Agnostelater e Coctilelater, incluídos em Alampina juntamente com Alampes e Alampoides; Arcanelater e Euplinthus, ambos incluídos em Euplinthina junto com Paraphileus e Compsoplinthus (Compsoplinthina). A subtribo Heligmina foi erigida para agrupar Heligmus, Meroplinthus e Pyrischius e a subfamília Campyloxeninae para Campyloxenus.

Golbach (1994) citou para a Argentina 13 gêneros de Heligmini e de Pyrophorini e apresentou uma chave para os gêneros dessas tribos baseada, em parte, na chave proposta por Costa (1975b). Johnson (2002) catalogou para os Estados Unidos (Flórida e Arizona) os gêneros Deilelater, Ignelater e Vesperelater.

Sagegami-Oba et al. (2007) fizeram a análise filogenética da família Elateridae, baseada em seqüências parciais do DNA ribossomal $28 \mathrm{~S}$, na qual incluíram entre os táxons terminais Pyrophorus e Phanophorus. O cladograma de consenso das 25 árvores obtidas na análise de parcimônia indicou que esses gêneros formam um grupo monofilético com os gêneros de Conoderini. 


\section{OBJETIVOS}

- Testar a monofilia do grupo e propor uma hipótese de relacionamento filogenético entre os gêneros empregando a metodologia cladística.

- Redescrever os gêneros de Pyrophorini, acrescentando caracteres morfológicos que possam auxiliar na diferenciação desses gêneros.

- Averiguar a existência de padrões na distribuição geográfica para compreender melhor a disjunção entre os gêneros Neotropicais e da Oceania.

\section{MATERIAL E MÉTODOS}

\subsection{Material examinado}

Foram estudados 2.219 exemplares, pertencentes ao Museu de Zoologia da Universidade de São Paulo, São Paulo (MZSP) ou provenientes de empréstimos obtidos nas seguintes instituições: American Museum of Natural History, New York (AMNH); Bernice P. Bishop Museum, Honolulu (BPBM); California Academy of Science, California (CASC); California Insect Survey, Berkeley (CISC); Canadian National Collection of Insects, Ontario (CNC); Carnegie Museum of Natural History, Pennsylvania (CMNH); Cincinnati Museum of Natural History, Cincinnati (CNHM); Departamento de Zoologia da Universidade Federal do Paraná, Curitiba (DZUP); Deutsches Entomologisches Institut, Eberswalde (DEIC); Faculdad de Humanidades y Ciencias, Montevideo (FHCM); Field Museum of Natural History, Chicago (FMNH); Forschungsinstitut und Natur-museum Seckenberg, Frankfurt (SMFD); Fundação Instituto Oswaldo Cruz (FIOC); Fundación Miguel Lillo, Universidad nacional de Tucumán, Tucumán (IMLA); Institut Royal des Sciences Naturelles de Belgique, Bruxelles (ISNB); Instituto Biológico, São Paulo (IBSP); Museo del Instituto de Zoología Agricola, Maracay (MIZA); Museu Anchieta, Porto Alegre (MAPA); Museu de Ciências Naturais, Fundação Zoobotânica do Rio Grande do Sul, Porto Alegre (MCNZ); Museu Nacional da 
Universidade Federal do Rio de Janeiro, Rio de Janeiro (MNRJ); Muséum National d'Histoire Naturelle, Paris (MNHN); Museum of Comparative Zoology, Cambridge (MCZ); Museum of University of Helsinki, Helsinki (MZHF); Naturhistoriska Riksmusset, Stocklolm (NHRS); Texas A \& M. University, Texas (TAMU); The Natural History Museum, London (BMNH); United States National Museum, Washington (USNM).

\subsection{Dissecções}

Para o estudo das genitálias e outras peças anatômicas dissequei espécimes, quando disponíveis, representantes de várias localidades. A dissecção foi feita de acordo com o seguinte procedimento: imersão do inseto em uma mistura de água e hidróxido de potássio ou hidróxido de sódio, fervida por alguns minutos; transferência do inseto para água fria, separação das peças, cortadas pelas regiões pleurais ou membranosas, e limpeza com auxílio de estiletes. Quando necessário, a peça era novamente fervida para a retirada completa da musculatura. As genitálias masculinas de difícil limpeza também eram fervidas em uma solução de água e hidróxido de sódio e posteriormente clarificadas em uma de mistura fervente de água e água oxigenada. Em seguida as peças eram passadas por água e acondicionadas em microtúbulos contendo álcool 70\% e glicerina ou tubos com apenas álcool $70 \%$. Os microtúbulos foram alfinetados com o exemplar e os tubos foram colocados em potes de vidro rotulados e estão depositados na coleção úmida do Museu de Zoologia da USP.

\subsection{Ilustrações}

Para serem desenhadas as peças muito pequenas e delicadas foram colocadas em líquido de Hoyer (goma arábica cristalizada/água destilada/ hidrato de cloral/glicerina neutra bidestilada) sobre uma lâmina escavada devidamente rotulada. Peças maiores e fortemente esclerotizadas, tais como antenas, esternos torácicos, etc., eram secas e acomodadas na posição desejada sobre massa de modelar. 
As ilustrações foram feitas com o auxílio de câmara clara acoplada ao estereomicroscópio ou microscópio ambos. Foram ilustradas apenas as genitálias femininas de alguns gêneros, mas essas são suficientes para representar todas as variações possíveis desta estrutura nos táxons do grupo interno.

\subsection{Medidas}

As estruturas foram medidas no estereomicroscópio equipado com ocular micrométrica, com régua milimetrada ou a partir das ilustrações.

O índice ocular foi calculado dividindo-se a maior largura entre os olhos na região ventral, subtraída a largura intra-ocular, por ela mesma. Esse índice geralmente é calculado na face dorsal (Calder, 1996), mas neste estudo foi necessário medi-lo na região ventral devido à variação da forma da fronte nos gêneros ou grupos de gêneros.

O comprimento dos élitros e do pronoto foi medido na região mediana e a largura do protórax foi medida em sua maior largura, que pode ser na região metade do pronoto se este for mais ou menos retangular, ou na região posterior se ele for trapezoidal.

A proporção da região posterior ao dente no processo prosternal em relação ao processo foi calculada tomando-se o comprimento total dessa estrutura, da margem anterior da procoxa até o seu ápice.

Nos gêneros que apresentam forma da fronte retangular ou subquadrada foi calculada a razão entre o seu comprimento, medido na região mediana, e sua maior largura entre os olhos.

O comprimento da antena foi medido em relação ao comprimento do pronoto, até os ápices dos ângulos posteriores. Quando o comprimento da antena ultrapassava esse limite foram comparados os antenômeros que atingem os ângulos posteriores. Por exemplo, em algumas espécies de Opselater as antenas das fêmeas ultrapassam os ângulos posteriores a partir do $11^{\circ}$ antenômero enquanto que nos machos, ultrapassam a partir do $9^{\circ}$ antenômero. 


\subsection{Distribuição geográfica e lista de material examinado}

As informações sobre as localidades dos espécimes foram obtidas nos rótulos do material examinado e na literatura. Quando possível foi discriminada a quantidade de machos e fêmeas examinados, caso contrário, foi dado apenas o número de exemplares.

\subsection{Terminologia}

Para as medidas e descrição de todos os caracteres, exceto genitálias e asas posteriores, sigo a terminologia apresentada nos trabalhos de Costa (1975b, 1978), Calder (1996) e Lawrence et al. (1999). Para as principais veias da asa posterior adotei a terminologia proposta por Kukalová-Peck \& Lawrence $(1993 ; 2004)$ e para a descrição das genitálias masculina e feminina Lawrence \& Britton (1994) e Calder (1996). A terminologia utilizada para o trato genital feminino baseia-se nos trabalhos de Williams (1945), Becker (1956, 1958) e Calder (1996).

\subsection{Análise Filogenética}

A análise cladística foi realizada conforme a metodologia proposta por Hennig (1966), posteriormente discutida e aprimorada por vários autores (e.g. Nelson \& Platnick, 1981; Kitching et al., 2000; Amorim, 2002)

A polarização dos caracteres foi obtida pelo enraizamento posterior à análise simultânea dos grupos internos e externos. O enraizamento foi feito entre Tibionema abdominalis e os demais táxons. Os caracteres informativos apenas para os grupos externos também foram codificados (Nixon \& Carpenter, 1993). A escolha dos táxons terminais, a codificação dos caracteres em geral e a análise numérica da matriz de dados são descritos a seguir. Maiores detalhes sobre a codificação de alguns caracteres são discutidos na lista de caracteres. 


\subsubsection{Táxons do grupo interno}

Ao todo foram incluídos 36 táxons terminais no grupo interno inicial, dos quais 20 correspondem aos gêneros atuais de Pyrophorini assumidos a princípio como monofiléticos baseando-se em caracteres exclusivos, tradicionalmente atribuídos para esses grupos, ou seja, em prováveis autapomorfias. No entanto, alguns desses gêneros apresentaram importantes variações nos estados de um mesmo caráter que sugeriram que algumas espécies ou grupos de espécies pudessem constituir linhagens monofiléticas distintas daquelas associadas à espécietipo do gênero. Esses gêneros, então, foram subdivididos e os grupos de espécies (Anexo 1) foram incluídos como táxons terminais na análise. Nos cladogramas e no texto o grupo que inclui a espécie-tipo do gênero é referido pelo nome do gênero. Nos demais grupos, aqueles que incluem mais de uma espécie são referidos pelo nome do grupo e os grupos que incluem apenas uma espécie é referido pelo nome da espécie.

\subsubsection{Táxons do grupo externo}

Os 18 táxons terminais elegidos como grupos externos são espécies e gêneros representantes dos grupos supostamente mais próximos filogeneticamente da tribo Pyrophorini, que apresentam caracteres comparáveis e um número razoável de exemplares que puderam ser dissecados.

Dentro de Agrypninae, tomando-se por referência a classificação tradicional (Costa, 1975b; Stibick, 1979) foram selecionados espécies e gêneros representantes de cinco tribos: Hemirhipus lineatus (Olivier, 1790) (Hemirhipini); Lanelater sp. e Lacon ruber (Perty, 1830) (Agrypnini); Conoderus fuscofasciatus (Eschscholtz, 1829) e Aeolus octoguttatus Candèze, 1859 (Conoderini); Heligmus obscurus Costa, 1975; Alampes vestitus Champion, 1895; Alampoides tesselatus (Candèze, 1863), Agnostelater Costa, 1975, Coctilelater Costa, 
1975, Meroplinthus Candèze, 1891, Paraphileus Candèze, 1891, Euplinthus Costa, 1975, Compsoplinthus Costa, 1975 (Heligmini) e Anaissus tarsalis Candèze, 1857 (Anaissini).

Heligmini foi a tribo mais amostrada na análise, não apenas por constituir tradicionalmente o grupo irmão de Pyrophorini, mas principalmente porque durante este estudo observou-se que alguns gêneros de Heligmini compartilhavam caracteres com certos grupos e gêneros de Pyrophorini que sugeriam que o grupo interno não fosse monofilético. É possível, mas não indubitavelmente, que órgãos luminescentes também ocorram em algumas dessas espécies, como em Euplinthus ophthalmicus que possui um par de manchas amareladas próximas dos ângulos posteriores, similares às vesículas encontradas em espécies de Opselater e de Lygelater.

O único táxon terminal externo não Agrypninae é Tibionema abdominalis (Guérin-Méneville, 1838), pertencente à subfamília Pityobiinae, grupo-irmão de Agrypninae segundo a análise filogenética de Calder et al. (1993).

\subsubsection{Codificação dos caracteres e construção da matriz}

As hipóteses de homologia primária (De Pinna, 1991) foram construídas com base na similaridade de forma e de topologia das diferentes condições de uma mesma estrutura, a partir do exame direto da morfologia externa e da genitália dos espécimes pertencentes à espécie-tipo e à maioria das espécies que compõem cada um dos gêneros, exceto Hifo pacificus, cujos dados foram obtidos da literatura (Costa 1984b) e pela comunicação pessoal da Dra. Cleide Costa (MZSP) que examinou recentemente, tendo em mãos os caracteres levandados neste estudo, os dois exemplares-tipos depositados na coleção do Institut Royal des Sciences Naturelles de Belgique.

Foram codificados caracteres binários e multiestados, todos não ordenados. $\mathrm{Na}$ medida do possível, procurou-se codificar caracteres quantitativos ou qualitativos que 
apresentassem variação discreta entre os estados, mas em muitos casos as diferenças entre os estados de caracteres são muito sutis. Nos casos em que a modificação observada em uma estrutura estava condicionada a presença da estrutura optou-se pela codificação separada das duas observações (Strong \& Lipscomb, 1999; Lee \& Bryant, 1999).

A matriz (Tabela 1) foi editada no programa Nexus Data Editor (PAGE, 1998) empregando-se algarismos arábicos para representar cada um dos estados das séries de transformação. O número não indica a ordem nem a polarização do estado, uma vez que esses foram obtidos somente após a análise. A subdivisão dos gêneros descrita anteriormente (item 3.1.1) foi necessária devido às variações significativas dentro de cada gênero, que sugeriam o não monofiletismo dos mesmos. Outras variações observadas entre as espécies e, em alguns casos, intraespecíficas de um táxon terminal foram codificadas como polimórficas e estão representadas na matriz pelos estados separados por uma barra (/). Somente estados autapomórficos que fazem parte de uma série de transformação em caracteres multiestados foram incluídos na análise. Na matriz o sinal de interrogação corresponde a dado ausente ou não aplicável. Na discussão da lista de caracteres o hífen (-) refere-se a estados não aplicáveis em determinado táxon, por este não apresentar a estrutura ao qual se aplica o caráter, e o sinal de interrogação (?) significa que a condição do caráter não pode ser observada no táxon, seja pela ausência de exemplares para estudo ou pela perda da estrutura em exemplares muito danificados.

\subsubsection{Análise computacional}

\section{Análise da matriz de dados}

A análise dos 62 caracteres informativos foi feita com o programa Tree Analysis Using New Technology, TNT 1.0 (Goloboff, Farris \& Nixon, 2003) com a busca heurística "traditional search", na qual a construção inicial dos cladogramas é feita com o algoritmo de 
Wagner (Farris, 1970), em 5.000 réplicas com adição seqüencial aleatória de táxons, exceto para Tibionema abdominalis, que é sempre o primeiro a ser adicionado. Dez árvores mais parcimoniosas por replicação foram salvas após terem seus ramos permutados por meio do algoritmo TBR (tree bisection-reconnection). Os cladogramas mais parcimoniosos encontrados então foram submetidos novamente a permutação de ramos pelo TBR. Esse último procedimento pode recuperar as árvores igualmente mais parcimoniosas, mas com topologia distinta, caso essas não tenham sido salvas na busca anterior. Todas as buscas foram executadas com o comando "collapse trees after the search" ativo sob a regra 1 (Coddington \& Scharff, 1994), que colapsa os ramos com comprimento mínimo igual a zero.

O critério de escolha entre as milhares de hipóteses alternativas resultantes da análise da matriz de dados foi a parcimônia, princípio empregado em várias áreas do conhecimento científico atual e que prenuncia como melhor a explicação que requer o menor número de hipóteses ad hoc relacionadas a uma determinada observação. Em análises filogenéticas, as hipóteses ad hoc que devem ser minimizadas são as homoplasias, portanto a hipótese geral mais parcimoniosa é aquela que requer o menor número de transições na distribuição do conjunto de caracteres, ou seja, o cladograma (ou cladogramas) com menor número de passos (Farris, 1983; Amorim, 2002).

Uma vez que a análise resultou em várias hipóteses igualmente parcimoniosas, fez-se o cladograma de consenso estrito, que apresenta somente as hipóteses de relacionamento filogenético que ocorrem em todos os cladogramas mais parcimoniosos. No presente trabalho, o cladograma de consenso estrito é utilizado apenas como uma síntese das hipóteses concordantes. As hipóteses alternativas também são apresentadas e discutidas.

\section{Suporte}

Para o cálculo do suporte de Bremer (Bremer, 1994) foram salvas as árvores subótimas com números de passos sucessivamente maiores (20) que o das árvores mais 
parcimoniosas até que todos os clados dessas últimas tenham se colapsado no consenso estrito de cladogramas ótimos e subótimos.

\section{Ponderação sucessiva a posteriori}

Foi utilizado o índice de adaptabilidade (“fit", Goloboff, 1993) para dar peso diferencial aos caracteres segundo suas contribuições com hipóteses de homoplasia para as árvores obtidas na análise cladística inicial. Esse índice (f) é calculado em função de uma constante de concavidade (k), e da quantidade de passos extras $(\mathrm{p})$ de cada caráter, resultantes da análise filogenética inicial, com a fórmula $f=k /(e+k)$. Após a atribuição dos pesos foi realizada uma nova análise, e então, sucessivamente, os caracteres foram novamente ponderados, até que o número de passos do cladograma mais parcimonioso se estabilizou (Farris, 1969).

Os índices de consistência e de consistência reescalonado, mais comumente utilizados para este fim, foram preteridos porque têm a desvantagem de atribuir maior peso aos caracteres multiestados. Por exemplo, um caráter binário com três surgimento homoplástico na hipótese final terá índice de consistência 0,33 , enquanto que um caráter com oito estados e três eventos homoplásticos terá índice de consistência 0,70 . Se considerarmos esses índices para a atribuição de peso, o caráter multiestado terá peso maior, embora contribua com tantos eventos homoplásticos quanto o binário (Goloboff, 1993; Lopes, 2005). Por esse motivo, considerando-se o conjunto de dados apresentados neste trabalho, que inclui muitos caracteres com número de estados que varia de 2 a 8, optou-se pela aplicação do índice de adaptabilidade. Como o valor de k é arbitrário, realizou-se várias ponderações, alterando o valor de $\mathrm{K}(3,5,7,21$ e 43), para testar a sensibilidade dos dados a esses diferentes valores. 


\section{RESULTADOS E DISCUSSÃO}

\subsection{Lista de caracteres e e distribuição dos estados}

Foram obtidos 61 caracteres (0-60), 32 deles a partir da morfologia geral externa de machos e fêmeas (0-31), 16 da genitália masculina (32-47) e 13 da genitália feminina (4860). Quatro caracteres são informativos apenas para grupos externos $(15,25,57$ e 60). Quando necessário, certas decisões sobre a codificação e descrição dos caracteres são comentadas e justificadas. Todas as distribuições e transições de cada estado são baseadas no cladograma de consenso estrito dos oito cladogramas mais parcimoniosos (Fig. 1) resultantes da análise filogenética, mas as seis resoluções alternativas também são discutidas (Fig. 2). Os grupos monofiléticos são referidos pelo número do nó ancestral ou, quando possível, pelo nome do táxon mais basal seguido do sinal + ou * sobrescritos, como sugerido por Amorim (2002). Os táxons com variações interespecíficas são citados como "polimórficos". A ordem em que os caracteres são discutidos é aproximadamente a ordem da série de transformação obtida após a análise e o estado plesiomórfico é dado com referência ao grupo interno (clado 71). As ilustrações neste item são versões reduzidas e sem escalas das figuras anexas.

\section{Caracteres da morfologia externa de machos e fêmeas: 0-31.}

0. Tamanho do olho no macho (I. C. 0,20; I. R. 0,62):

0. pequeno (I.O. $<0,35)$.

1. médio (I.O. 0,40-0,60).

2. grande (I.O. 0,70-0,90).

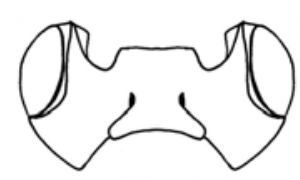

0

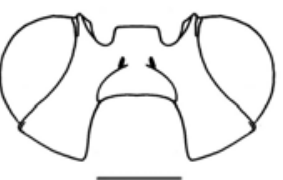

1

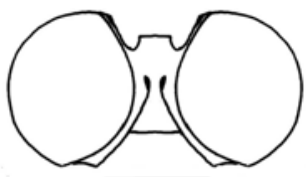

2

Os machos de muitas espécies de Pyrophorini possuem olhos levemente maiores ou muito maiores do que os das fêmeas. A princípio, com o exame superficial dos exemplares, foi possível distinguir três estados para o tamanho do olho nos machos: pequeno, médio e grande. Após obterem-se os índices oculares essa distribuição em 3 estados discretos 
se confirmou, embora a descontinuidade na distribuição dessas medidas tenha resultado muito mais sutil do que o exame superficial faria supor.

Distribuição:

Estado plesiomórfico: 1

Polimorfismos: grupo lampyris (0/1), grupo melanurus $(0 / 1)$

(1) Condição homóloga para os táxons Noxlumenes, Gênero A, Pyrophorus, Fulgeochlizus + grupo noctivagus, Ptesimopsia ${ }^{+}$, grupo cinnameus, Phanophorus adquirida paralelamente no clado $\mathrm{Hifo}^{+}$.

(0) A mudança do estado plesiomórfico para o estado 0 (olhos pequenos no macho) ocorre três vezes independentemente: no grupo Nyctophyxis + Cryptolampros; como autapomorfia de Meroplinthus e como evento único nos seis táxons basais do clado 65: Pyrearinus basalis, grupo lampyris, Coctilelater, Agnostelater, Paraphileus e Compsoplinthus.

(2) Condição adquirida três vezes paralelamente: como autapomorfia em Hypsiophthalmus e Ptesimopsia parallela e como sinapomorfia para o clado Pyrearinus pumilus $^{+}$.

\section{Margem ocular (I. C. 0,30; I. R. 0,63):}

0. não emarginada

1. com uma faixa preta por quase toda a borda ocular

2. levemente emarginada posteriormente

3. fortemente emarginada posteriormente
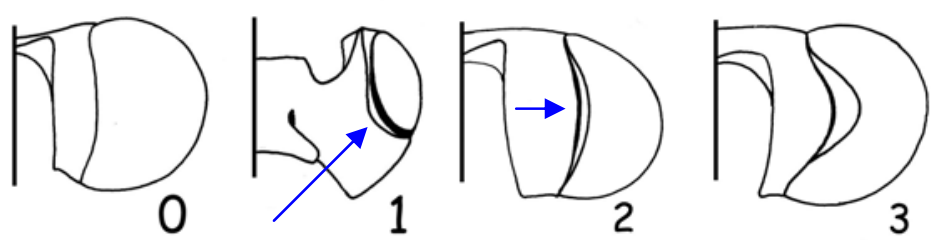

Em todos os espécimes, exceto de Hemirhipus lineatus, a margem da cabeça, 
junto à borda ocular é carenada. A margem dos olhos de espécimes de vários gêneros possui um faixa preta lisa e brilhante estendendo-se por quase toda a volta do olho, sendo mais estreita na região dorsal (estado 1), em outros essa faixa preta está ausente. Em muitos espécimes a carena na região posterior da cabeça é submarginal e a margem posterior dos olhos pode ser levemente ou fortemente emarginada pela borda da cabeça externa à carena submarginal (estados 2 e 3). Tanto machos como fêmeas apresentam as modificações da margem ocular.

Distribuição:

Estado plesiomórfico: 2

(?) Hifo. Os espécimes-tipo não puderam ser dissecados para verificar o estado do caráter.

(2) O estado plesiomórfico surge no nó 54 e permanece no grupo interno com transições para o estado 1 nos nós 89 e 62 e em Meroplinthus, para o estado 0 em Pyrophorus e Phanophorus ${ }^{+}$e com uma reversão em Opselater ${ }^{*}$.

(1) Três ocorrências homoplásticas são assinaladas para o estado 1: sinapomorfia para Nyctophyxis + Cryptolampros, autapomorfia para Meroplinthus e ocorre uma vez nos táxons basais do clado 62: Agnostelater, Paraphileus, Euplinthus e Compsoplinthus

(0) Margem ocular sem faixa preta e não emarginada é autapomorfia de Pyrophorus e sinapomorfia para grupo cinnameus ${ }^{*}$ (modificada para a condição 3 em $P$. pumilus ${ }^{+}$.

(3) Sinapomorfia de Pyrearinus pumilus ${ }^{+}$.

2. Margem interna das mandíbulas (I. C. 0,25; I. R. 0,40):

0. lisa

1. denteada

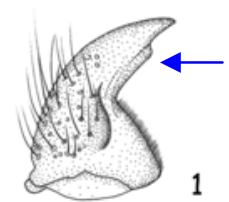

Distribuição: 
Estado plesiomórfico: 1

Polimórfico: Hypsiophthalmus (0/1)

(0) A mandíbula com margem interna lisa ocorre independentemente três vezes: como autapomorfia de Hypsiophthalmus e do grupo pumilus e como sinapomorfia do clado 64 (com duas reversões independentes, em Paraphileus e em $\mathrm{Hifo}^{+}$).

\section{Forma da fronte no macho (I. C. 0,47; I. R. 0,71):}

$\mathrm{r}=$ razão entre o comprimento e a largura da cabeça

0. trapezoidal mais larga que longa
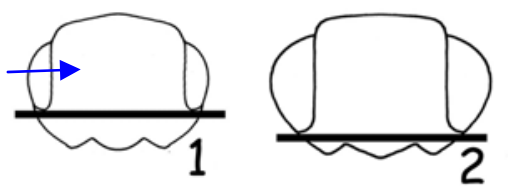

1. retangular $(\mathrm{r}=0,65-0,80)$ de lados retos ou curvos

2. subquadrada $(r=0,90-1,00)$ de lados retos
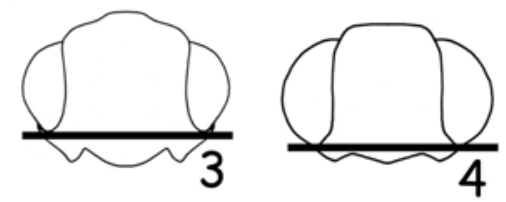

3. subquadrada $(\mathrm{r}=1,00-1,10)$ de lados curvos para dentro

4. retangular $(\mathrm{r}=1,20-1,30)$ mais longa que larga
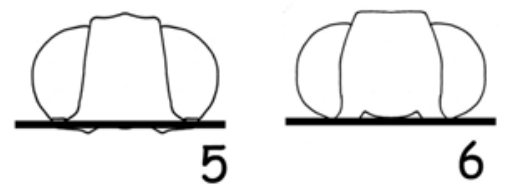

5. subtrapezoidal a trapezoidal alongada de lados retos

6. trapezoidal alongada de lados curvos para fora

7. trapezoidal com frente proeminente ocultando o labro

A variação de forma da fronte foi observada na região entre os olhos e anterior aos olhos, sem considerar a forma da margem anterior da fronte, pois ela pode variar de reta a sinuosa em exemplares de uma mesma espécie. A extensão da região posterior aos olhos é inversamente proporcional ao tamanho dos olhos (caráter 0), portanto, também foi desconsiderada.

Distribuição:

Estado plesiomórfico: 1.

(?) Hifo: não foi possível verificar o estado do caráter porque os espécimes-tipo não puderam ter a cabeça removida.

Polimórfico: grupo melanurus $(1 / 3)$ 
(0), (6) e (7) Autapomorfias, respectivamente de Hemirhipus lineatus, Hypsiophthalmus e Tibionema abdominalis.

(1) Ocorre como evento único no clado 90, no Gênero A, em Meroplinthus e nos sete táxons basais do clado 65. Derivado, independentemente, a partir da condição 3 no grupo melanurus.

(2) Sinapomorfia de Fulgeochlizus + grupo noctivagus, ocorre independentemente em Heligmus obscurus.

(3) Sinapomorfia compartilhada pelos táxons do clado Opselater $^{*}$, com dois surgimentos independentes nos táxons do grupo externo Alampoides tesselatus e Conoderus fuscofasciatus.

(4) Autapomorfia de Pyrophorus, convergente em grupo cinnameus.

(5) Ocorrem duas transições homoplásticas para o estado 5, uma como sinapomorfia para os táxons do clado Ptesimopsia parallela ${ }^{+}$(com uma reversão para o estado 1 em Pyroptesis) e outra no clado 82 (exceto em grupo cinnameus e em Hypsiophthalmus)

\section{Antena (I. C. 0,25; I. R. 0,25):}

0. serreada ou pectinada a partir do $4^{\circ}$ antenômero

1. serreada a partir do $3^{\circ}$ antenômero

Distribuição:

Estado plesiomórfico: 0.

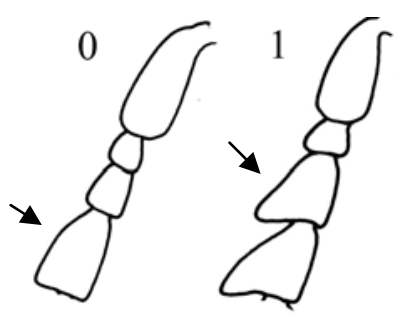

(1) A antena serreada a partir do $3^{\circ}$ antenômero é sinapomorfia para os táxons do clado Meroplinthus ${ }^{+}$com uma reversão para o estado plesiomórfico no componente distal Hapsodrilus $^{+}$. Ocorre mais duas vezes independentemente nos táxons externos Heligmus obscurus e Lacon ruber. 


\section{Comprimento da antena no macho (I. C. 0,25; I. R. 0,67): \\ 0. com o mesmo comprimento da antena da fêmea \\ 1. mais longa que a da fêmea}

Distribuição:

Estado plesiomórfico: 1

(?) Cryptolampros, Agnostelater, Hifo, grupo atlanticus e Lygelater bifossulatus. Não são conhecidas as fêmeas para esses táxons.

(0) Quatro transições homoplásticas são assinaladas para esse estado: como autapomorfias em Pyrophorus, Fulgeochlizus e Hypsiophthalmus e como sinapomorfia para os grupos de Pyrearinus do clado 86.

\section{Margem anterior do pronoto no macho (I. C. 0,75; I. R. 0,86):}

0. sinuosa a reta com ângulos anteriores agudos

1. sinuosa a arredondada pouco proeminente com ângulos anteriores retos
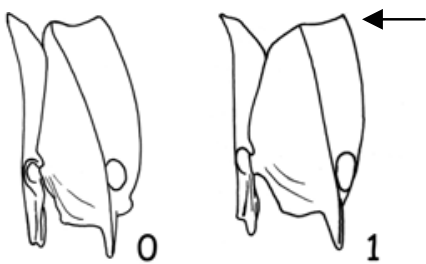

2. arredondada proeminente com ângulos anteriores retos

3. arredondada fortemente proeminente com ângulos anteriores
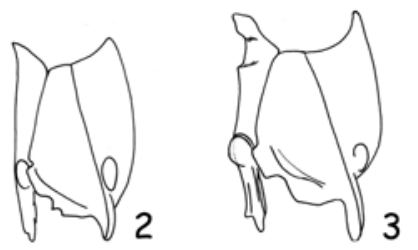
retos

Inicialmente tentou-se codificar a forma geral do pronoto, tomando-se como medida o índice pronotal (relação entre o comprimento e a maior largura do pronoto). No entanto, não foi encontrado nenhum padrão que justificasse a codificação da forma do pronoto. Os pronotos possuem formas muito variáveis e a maior parte das medidas não é comparável, uma vez que a maior largura do pronoto pode estar na região anterior (espécimes com ângulos anteriores grandes), na metade (tanto para espécimes com lados retos como para espécimes com lados arredondados), e na região posterior (forma mais ou menos trapezoidal). Essa tentativa de codificação resultou num número muito grande de estados, a maioria deles 
não informativa. No entanto, pelo menos na região anterior do pronoto do macho, incluindo os ângulos anteriores, foi possível encontrar 4 padrões de forma invariáveis e esses foram codificados nos 4 estados desse caráter. As fêmeas de todos os táxons terminais apresentam a forma da margem anterior do pronoto mais ou menos sinuosa com ângulos anteriores agudos.

Distribuição:

Estado plesiomórfico: 0.

(0) Ocorre na maioria dos táxons de Pyrophorini e em todos os táxons do grupo externo.

(1) Constitui uma sinapomorfia para os grupos de Pyrearinus do clado 86, com um surgimento homoplástico em Ptesimopsia parallela.

(2) e (3) Respectivamente, autapomorfias de Phanophorus e de Hypsiophthalmus.

\section{Região mediana posterior do pronoto (I. C. 0,25; I. R. 0,75):}

0. lisa

1. com um tubérculo

Distribuição:

Estado plesiomórfico: 0.

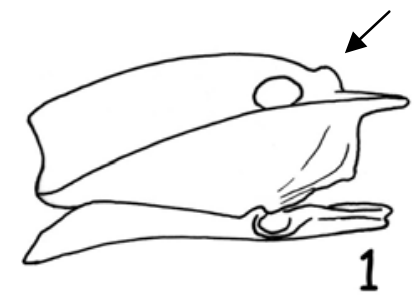

Polimórfico: Pyrophorus (0/1), Lygelater (0/1), Photophorus (0/1).

(1) Sinapomorfia de Paraphileus ${ }^{+}$(com reversões em Hifo e no grupo atlanticus). Também é sinapomorfia para o grupo externo Lanelater sp. + Lacon ruber.
8. Forma do protórax na fêmea em relação ao do macho (I. C. 0,36; I. R. 0,65):
0. igual
1. similar, com lados mais arredondados
2. levemente diferente, levemente mais convexo, com lados mais arredondados
3. diferente, fortemente mais convexo e com lados arredondados 
4. muito diferente, fortemente mais convexo de lados fortemente arredondados (Fig. 237).

A delimitação entre os estados desse caráter é bastante sutil, principalmente entre os estados 3 e 4, mas é possível obter alguma objetividade na identificação dos estados observando também a forma dos élitros, pois o aumento da convexidade e da largura dos élitros nas fêmeas de alguns táxons é diretamente proporcional à mudança da forma do pronoto. Assim, fêmeas com o estado 4 podem ser separadas das fêmeas com o estado 3 pela forma dos élitros (fortemente convexos e arredondados). Codificar a forma do élitro num caráter separadamente dobraria o peso do estado 4 em relação aos demais. Inicialmente a forma do élitro também foi incluída na definição dos estados, mas esse procedimento resultou em descrições muito longas para cada estado.

Distribuição:

Estado plesiomórfico: 0

(?) Cryptolampros, Agnostelater, Hifo, grupo atlanticus e Lygelater bifossulatus: táxons sem fêmeas para comparação.

Ambíguo: Como otimização desse caráter nos nós 68 e 81 é ambígua, a forma do protórax igual nos machos e fêmeas de Fulgeochlizus tanto pode ser interpretada como homóloga a do Gênero A e Pyrophorus (com o surgimento homoplástico da condição 1 no grupo noctivagus em relação à transição do estado 0 para 1 no nó 67) como uma reversão (sendo a condição 1 do grupo noctivagus homóloga àquela do clado 67).

(0) Condição homóloga para Gênero $A$ e Pyrophorus, que se originou independentemente pelo menos mais duas vezes, em Sooporanga e em Photophorus.

(1) É sinapomorfia para o clado 67 (exceto Ptesimopsia parallela, Sooporanga, Photophorus e clado 82). Ocorre no mínimo duas vezes independentemente nos táxons estudados, uma vez que ele também é sinapomorfia para o clado 59 do grupo externo.

(2) Autapomorfia de Ptesimopsia parallela e do grupo candelarius. 


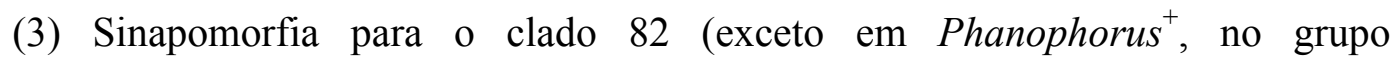
ferrugineus $^{+}$e no grupo candelarius).

(4) Três surgimentos homoplásticos são observados para esse estado, cada um deles constitui uma sinapomorfia para os clados: Noxlumenes ${ }^{+}$(exceto Cryptolampros), Phanophorus $^{+}$e grupo ferrugineus ${ }^{+}$.

\section{9. Órgão bioluminescente na região posterior do pronoto (I. C. 0,25; I. R. 0,79):}

0 . ausente

1. presente

O órgão bioluminescente sobre o pronoto na maioria dos exemplares examinados tem a forma de vesículas amareladas e transparentes, sob as quais é possível visualizar o tecido diferenciado de coloração amarela ou alaranjada. Em geral, a superfície das vesículas é mais delicadamente pontuada quando comparada ao tegumento adjacente. Nas espécies de Pyrearinus do grupo lampyris e em Coctilelater corymbitoides não ocorrem tais vesículas, mas sim uma mancha mais ou menos triangular junto aos ângulos posteriores do pronoto. Embora não haja nenhum registro de que esses insetos emitam luz por meio dessas manchas, a similaridade na transparência e na forma do tecido subjacente à cutícula levou a proposição de homologia primária para a função dessas estruturas como órgãos bioluminescentes.

Nesse caráter é inferida a homologia dessas estruturas baseando-se na sua suposta capacidade de emitir luminescência, desconsiderando, portanto, suas variações de forma e posição. Os padrões observados com relação à forma e à posição desses órgãos estão codificados nos caracteres 10 e 11 .

Distribuição:

Estado plesiomórfico: 0.

Polimórficos: Cryptolampros (0/1), Euplinthus (0/1). 
(1) A presença de uma par de órgãos bioluminescentes na região posterior do pronoto tem sido tradicionalmente considerada sinapomorfia para os gêneros de Pyrophorini, fato que é corroborado nesse estudo. No entanto, como a tribo Pyrophorini (sensu Costa, 1975b) resultou parafilética, a inclusão de alguns gêneros de Heligmini, que não apresentam órgãos bioluminescentes no pronoto, evidencia que esse caráter pode ter sido perdido em três grupos distintos: em Cryptolampros, gênero monotípico cuja perda dos órgãos bioluminescentes no pronoto parece não ter se fixado totalmente, em Meroplinthus e na base do clado 62 (Agnostelater, Paraphileus, Euplinthus, Compsoplinthus e Hifo). A transição para o estado presente no ramo distal 77 do clado 62 constitui um sinapomorfia para esse grupo e evidencia que o par de órgãos bioluminescentes no pronoto foi adquirido duas vezes independentemente.

Apesar da similaridade entre as pequenas vesículas de Euplinthus ophthalmicus e das espécies do grupo melanurus a hipótese de homologia primária para essas estruturas não se confirmou após a análise, indicando que o par de vesículas amareladas no pronoto de Euplinthus ophthalmicus, tendo ou não a função bioluminescente, constitui uma autapomorfia, adquirida paralelamente ao dos demais grupos de vaga-lumes.

10. Forma do órgão bioluminescente na região posterior do pronoto (I. C. 0,78; I. R. 0,86):

0. mancha circular grande
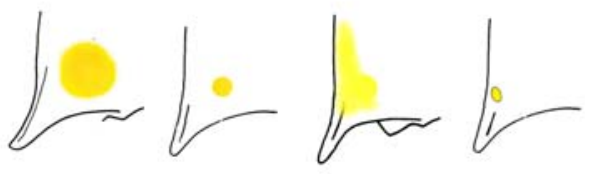

1. mancha circular pequena

2. mancha triangular curta ou alongada até o angulo
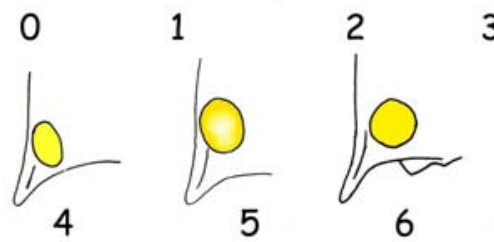
anterior

5

6

3. vesícula arredondada a oval muito pequena

4. vesícula oval, média a grande achatada a fracamente convexa

5. vesícula subcircular, grande e fortemente convexa 
6. vesícula circular, média à grande, levemente convexa

7. vesícula pequena, circular e fortemente convexa (Fig. 225)

Há grande variação de forma e tamanho nos órgãos bioluminescente dentro dos gêneros, dificultando a codificação desse caráter. No entanto, foi possível identificar certas descontinuidades na distribuição dessas formas que, embora sejam sutis, são suficientes para propor os 8 estados aqui apresentados. Parece haver uma dependência entre forma e tamanho por isso foram empregadas essas duas variáveis para descrever os estados. São chamados de manchas os órgãos luminescentes achatados com tegumento pouco diferenciado, ou seja, possui pontuação e pilosidade similar ao do tegumento adjacente. Um par de manchas similar ao de Fulgeochlizus bruchi, cuja luminescência foi observada em espécimes criados em laboratório, foi considerado como par de órgãos luminescentes.

Distribuição:

Plesiomórfico: 0

Polimorfismo: Lygelater (3/4), Nyctophyxis (0/1)

(-) Esse caráter não se aplica a todos os táxons do grupo externo e aos táxons Meroplinthus, Agnostelater, Paraphileus, Compsoplinthus e Hifo, que perderam os órgãos bioluminescentes na região posterior do pronoto.

Ambíguo. Tanto as manchas circulares grandes como as manchas circulares pequenas podem ser atribuídas no nó 89 , resultando no mesmo número de passos.

(0) Órgãos bioluminescentes em forma de um par de manchas circulares grandes é condição homóloga para Noxlumenes e Fulgeochlizus ${ }^{+}$. Pode ser interpretada como homóloga ou como homoplástica em relação às manchas grandes de Nyctophyxis, devido à ambigüidade no nó 89.

(1) Devido a ambiguidade na distribuição desse estado, o par de manchas circulares pequenas pode ser interpretado como homólogo ou como homoplástico entre Cryptolampros e Nyctophyxis. 
(7) e (5) Autapomorfias, respectivamente do Gênero A e de Pyrophorus

(6) Sinapomorfia para o clado 67 (exceto Meroplinthus) alterada para o estado 2 no nó 64.

(2) Condição homóloga nas espécies do grupo lampyris e em Coctilelater.

(3) No cladograma de consenso ocorre 4 vezes independentemente: no grupo melanurus, em alguns espécimes de Euplinthus, em Lygelater e em L. bifossulatus. Duas das quatro possíveis resoluções para o clado 77 (Fig. 2) apontam essa condição como sinapomorfia para o grupo melanurus e L. bifossulatus

(4) Sinapomorfia para os táxons do clado 77 (exceto Lygelater bifossulatus e grupo melanurus).

\section{Posição dos órgãos bioluminescentes do pronoto (I. C. 0,50; I. R. 0,84)}

0. laterais, encostando ou muito próximas da carena lateral do protórax

1. sublaterais, próximas das carenas dos ângulos posteriores

2. sublaterais, quase eqüidistantes à margem lateral e à linha mediana

3. laterais, estendendo-se até próximo da linha mediana do pronoto (Fig. 230)

Distribuição:

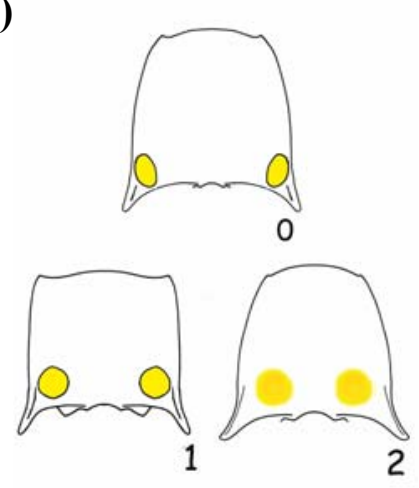

Plesiomórfico: 2

(-) Esse caráter não se aplica aos táxons do grupo externo e a Meroplinthus, Agnostelater, Paraphileus, Compsoplinthus e Hifo, que não possuem órgãos bioluminescentes na região posterior do pronoto

(2) Condição homóloga para os grupos basais do grupo interno: Noxlumenes ${ }^{+}$, Gênero A e Fulgeochlizus ${ }^{+}$, com transição para o estado 0 em Pyrophorus e para o estado 1 no nó 67. 
(0) Cinco surgimentos independentes são observados para esse estado: como autapomorfia para Pyrophorus, Pyroptesis, Phanophorus e Euplinthus e como sinapomorfia para os táxons de Opselater*

(1) Sinapomorfia para o clado 67 (exceto Meroplinthus, Pyroptesis, Phanophorus e ramo 64)

(3) Estado homólogo para grupo lampyris e Coctilelater.

12. Ângulos posteriores (I. C. 0,50; I. R. 0,00):

0. subparalelos a divergentes com margem externa reta

1. fortemente divergentes com margem externa curva

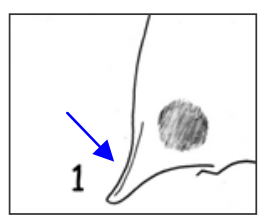

Distribuição:

Estado plesiomórfico: 0

Caráter de otimização ambígua no nó 90. A otimização “Acctran” favorece a hipótese de homologia primária para essa condição em Noxlumenes e Nyctophyxis, mas a otimização "Deltran” é igualmente provável.

13. Hipômeros (I. C. 0,40; I. R. 0,62):

0. inteiramente pilosos

1. com ângulo posterior e pequena área glabros

2. com $1 / 4-1 / 3$ posteriores glabros

3. com $1 / 2$ posterior glabra

4. com pilosidade apenas no $1 / 3$ anterior

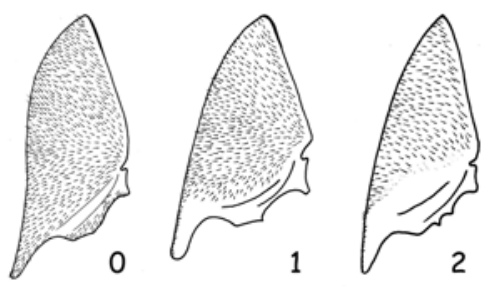

Distribuição:

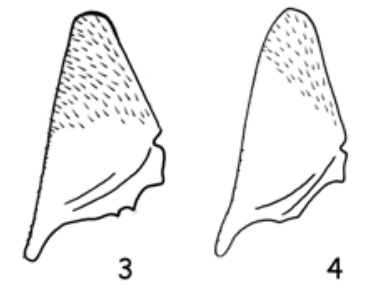

Estado plesiomórfico: 0

(?) Hifo: caráter não verificado.

Polimórfico: Ptesimopsia (1/2), Hapsodrilus (2/3), Pyroptesis (2/3), 
Hypsiophthalmus (2/3), grupo pumilus (0/1), grupo ferrugineus (0/1), grupo nyctolampis $(2 / 3)$, grupo lucernula (1/2), grupo lineatus (0/1/2), grupo lampyris $(1 / 2)$, Paraphileus $(0 / 1)$.

Ambíguo: Devido a ambigüidade no nó 93 não é possível inferir a condição ancestral para o clado Ptesimopsia ${ }^{+}$. A otimização do estado 1 ou do estado 2 neste nó resulta no mesmo número de passos, mas ambas permitem inferir que a condição 2, pelo menos em Hapsodrilus e Pyroptesis, é homóloga, sendo que a condição 3 nesses táxons corresponde a transições apomórficas independentes. A hipótese de homologia para o estado 3 em Hapsodrilus e Pyroptesis resulta menos parcimoniosa, um passo a mais, portanto ela pode ser descartada.

(0) O hipômero inteiramente coberto por cerdas ocorre como evento único na maioria dos grupos externos e se mantém sem alterações na base do grupo interno (Noxlumenes ${ }^{+}$, Gênero A e Pyrophorus). Essa condição em algumas espécies do grupo lineatus de Pyrearinus pode ser explicada como uma reversão.

(1) Sinapomorfia para o clado 68 com uma transição para o estado 2 em Pyrearinus basalis e duas transições homoplásticas para o estado 3, em Meroplinthus e em Phanophorus ${ }^{+}$. Para os táxons "polimórficos" do clado grupo pumilus ${ }^{+}$e do grupo lampyris é possível inferir que o estado plesiomórfico é o 1 , sendo as outras condições resultantes de transições apomórficas independentes. Verifica-se que a semelhança desta condição entre os táxons do grupo interno e do grupo externo (Hemirhipus lineatus, Anaissus tarsalis e Aeolus octoguttatus) não é devida à homologia, mas a 4 surgimentos paralelos independentes.

(2) Ocorre em Pyrearinus basalis, Ptesimopsia, Hapsodrilus, Pyroptesis, Hypsiophthalmus, grupo nyctolampis, grupo lucernula e grupo lineatus, mas somente para Hapsodrilus e Pyroptesis a hipótese de homologia primária para essa condição se confirmou após a análise.

(3) Sinapomorfia para Phanophorus e Hypsiophthalmus, sendo que a condição 2 neste último táxon é apomórfica em relação à condição 3. Hipômero com metade posterior 
glabra também ocorre independentemente em Hapsodrilus e Pyroptesis.

(4) Autapomorfia de Sooporanga.

14. Margem posterior do hipômero (I. C. 0,17; I. R. 0,58):

0. truncada com ângulo interno pouco a fortemente saliente

1. com dois espinhos

Distribuição:

Plesiomórfico: 0

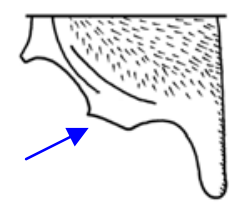

0

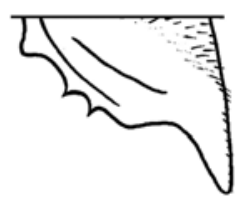

1

Polimórfico: Hapsodrilus, Pyroptesis, grupo lampyris, Opselater, grupo melanurus, grupo atlanticus, Vesperelater e Ignelater.

Ambíguo: Devido ao "polimorfismo" de Ignelater para esse caráter não é possível apontar o estado ancestral no nó 76; a similaridade entre as regiões posteriores dos hipômeros de Ignelater e de Photophorus pode ser interpretada como homóloga ou como homoplástica, com o mesmo número de passos.

(1) Dois espinhos na região posterior do hipômero é sinapomorfia para o clado Pyrearinus basalis $^{+}$com pelo menos 3 reversões independentes para o estado plesiomórfico em Paraphileus, Hifo e Photophorus. Outras quatro reversões independentes podem ser inferidas dentro dos táxons "polimórficos" (Opselater, grupo melanurus, grupo atlanticus e Vesperelater). Esses dois espinhos também ocorrem independentemente em Phanophorus e no clado 61 do grupo externo.
15. Sutura notosternal (I. C. 1,00; I. R. 1,00):
0 . fechada
1. aberta

Distribuição:

(1) Sinapomorfia do grupo externo Lanelater sp. + Lacon ruber. 
16. Prosterno no macho (I. C. 0,33; I. R. 0,78):

0. moderadamente alongado a longo de lados quase retos

1. curto de lados curvos para dentro

Distribuição:

Plesiomórfico: 0

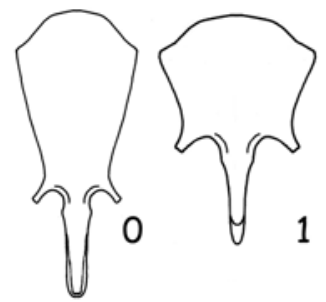

Polimórfico: Hapsodrilus e grupo lampyris

Ambíguo: Devido a ambigüidade no nó 82, não é possível definir se a semelhança na forma do prosterno observada entre Phanophorus $^{+}$e grupo pumilus ${ }^{+}$é devida à ancestralidade comum desses grupos ou à dois surgimentos paralelos independentes. Pelo mesmo motivo, a condição plesiomórfica desse caráter em Pyrearinus cinnameus tanto pode ser interpretada como homóloga àquela do clado 66 como poder ser devida a uma reversão, se for considerada a hipótese da aquisição apomórfica no nó 82.

(0) Todos os gêneros do grupo externo e a maioria dos táxons do grupo interno possuem prosterno moderadamente alongado ou longo com lados quase retos.

(1) Observam-se efetivamente três transições para o estado apomórfico nesse caráter, mas a condição prosterno curto com lados curvos deve ter surgido até cinco vezes independentemente se se levar em conta, além das aquisições independentes em Ptesimopsia parallela, Phanophorus ${ }^{+}$e grupo pumilus ${ }^{+}$, os "polimorfismos" de Hapsodrilus e de grupo lampyris.

17. Região posterior do processo prosternal (I. C. 0,25; I. R. 0,50):

0 . lisa

1. denteada

Distribuição:

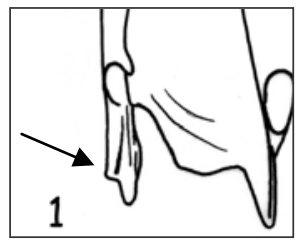

Plesiomórfico: 1

Polimórfico: Photophorus. 
(1) Quase todos os táxons do grupo interno possuem o processo prosternal denteado, exceto Compsoplinthus e em uma das espécies de Photophorus, nos quais a condição apomórfica surgiu independentemente.

(0) A condição apomórfica também ocorre duas vezes independentemente nos 3 ramos mais basais de Hemirhipus lineatus ${ }^{+}$(com reversão no nó 55) e em Alampes vestitus $^{+}$.

18. Comprimento da região posterior ao dente no processo prosternal (I. C. 0,29; I. R. 0,71):

0. pequena (até $5 \%$ )

1. médio $(7 \%-13 \%)$

2. longo (14\%-23\%)

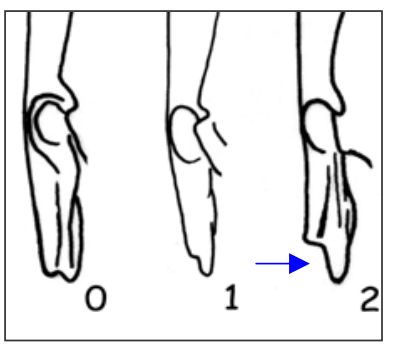

Esse caráter refere-se a uma variação linear do comprimento da região posterior ao dente do processo prosternal em relação ao comprimento total dessa estrutura.

Distribuição:

Plesiomórfico: 2

(-) Esse caráter não se aplica aos táxons que não possuem dente no processo prosternal: Hemirhipus lineatus, Heligmus obscurus, Lanelater sp.., Lacon ruber, Alampes vestitus, Alampoides tesselatus, Compsoplinthus e Photophorus.

Polimórfico: Pyrophorus (1/2), Ptesimopsia (1/2), Hapsodrilus (1/2), grupo pumilus (1/2), grupo cinnameus (1/2).

(2) A condição plesiomórfica desse caráter para o grupo interno surge no nó 55, com oito alterações independentes para a condição apomórfica 1 (das quais quatro ocorrem nos táxons terminais "polimórficos”) e duas transições paralelas para o estado 0 .

(0) Sinapomorfia para o clado Euplinthus ${ }^{+}$(ausente em Compsoplinthus e Photophorus), adquirida paralelamente no grupo externo Conoderus fuscofasciatus ${ }^{+}$.

(1) Autapomorfia de Phanophorus, Pyrearinus basalis, Coctilelater e 
Photophorus.

19. Margens látero-anteriores do mesoventrito (I. C. 0,60; I. R. 0,33):

0 . truncada reta

1. truncada obliquamente, face ventral mais alongada anteriormente que a dor

2. sulcada, dividida em duas partes pelo sulco: uma dorsal e outra ventral

3. fortemente emarginada

Distribuição:

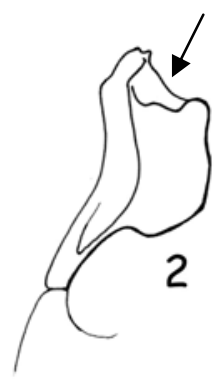

Plesiomórfico: 2

(2) Todos os táxons do grupo interno possuem as margens látero-anteriores do mesoventrito sulcada e essa condição é homóloga àquela encontrada nos grupos externos Tibionema abdominalis, Heligmus obscurus e Alampes vestitus ${ }^{+}$.

(0) Autapomorfia de Lanelater sp. e sinapomorfia de Conoderus fuscofasciatus ${ }^{+}$, ambos grupos externos.

(1) Autapomorfia para os grupos externos Hemirhipus lineatus e Lacon ruber.

(3) Autapomorfia do grupo externo Anaissus tarsalis.

20. Margem lateral anterior sulcada do mesoventrito (I. C. 0,50; I. R. 0,80):

0. quase reta oblíqua a curva próxima da base com ângulo externo não proeminente, parte dorsal visível

1. reta oblíqua a sinuosa desde a base com ângulo externo não proeminente, parte dorsal não visível

2. sinuosa desde um ponto próximo da base com ângulo externo proeminente, parte dorsal não visível a pouco visível

3. fracamente sinuosa a curva desde um ponto próximo da base, ângulo externo proeminente, parte dorsal visível 
4. quase reta a partir de um ponto posterior à base, ângulo externo proeminente, parte dorsal visível

5. quase reta a partir de um ponto posterior à base, ângulo externo não proeminente, parte dorsal largamente visível

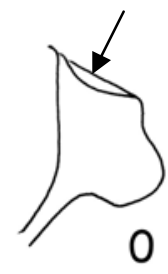

0

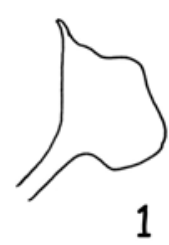

1

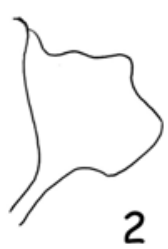

2

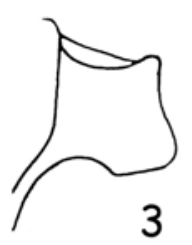

3

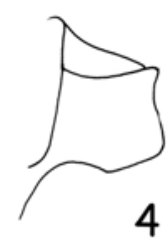

4

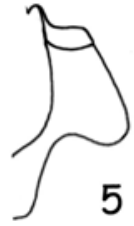

Devido a complexidade das formas da margem lateral anterior do mesoventrito nos táxons estudados, foram empregadas três variáveis para descrever cada estado (posição em relação à base, ângulo externo e parte dorsal), gerando certa dificuldade no reconhecimento de cada estado, mas, espera-se, que as ilustrações representem adequadamente cada um eles.

Distribuição:

Plesiomórfico: 4.

Polimórfico: Cryptolampros (2/4), grupo lineatus (2/3), grupo lampyris (0/3).

(-) Esse caráter não é aplicável aos táxons do grupo externo que não possuem a margem lateral anterior do mesoventrito sulcada.

(4) O estado plesiomórfico presente no táxon externo Alampoides tesselatus é

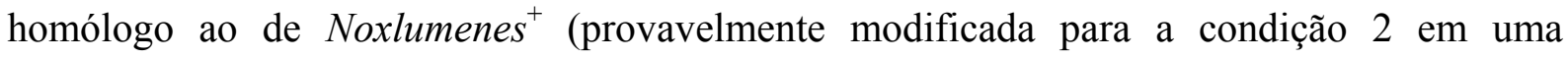
linhagem interna de Cryptolampros). Convergentemente, é sinapomorfia para Phanophorus + Hypsiophthalmus.

(2) Sinapomorfia para Gênero $A^{+}$alterada para a condição 0 no nó 66 e com duas reversões, uma no nó 73 compartilhada por Paraphileus, Euplinthus e Compsoplinthus e outra autapomórfica no grupo candelarius.

(0) Sinapomorfia para o clado 66, revertida para a condição 4 no nó 88 e para a condição 2 duas vezes, uma no nó 66 e outra no grupo candelarius. Alterada para o estado 3 no nó 88 e para a condição 1, independentemente, em Pyrearinus basalis e em Hifo ${ }^{+}$ 
(3) Sinapomorfia para os táxons do grupo 88 (exceto grupo candelarius), possivelmente com uma reversão para o estado 2 dentro da linhagem do grupo lineatus e adquirida independentemente a partir da condição 0 dentro do grupo lampyris.

(1) Sinapomorfia para o grupo $\mathrm{Hifo}^{+}$, adquirida mais duas vezes independentemente pelo grupo externo Alampes vestitus e por Pyrearinus basalis.

(5) Autapomorfia de Tibionema abdominalis e de Heligmus obscurus.

\section{Bordas da cavidade mesoventral (I. C. 0,60; I. R. 0,75):}

0 . metade posterior elevada e horizontal

1. metade posterior perpendicular ao eixo do corpo

2. fortemente inclinadas, visíveis lateralmente sobre as mesocoxas

3. pouco inclinadas, não saliente

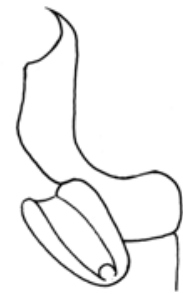
1

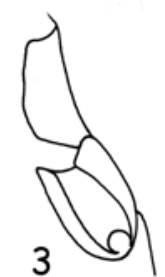

Distribuição:

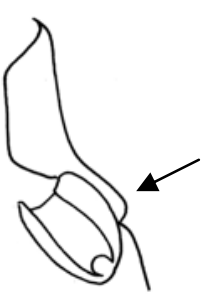

2

4. horizontal

5. quase horizontal com ápice achatado lateralmente

Plesiomórfico: 3 .

(4) Estado homólogo para Heligmus obscurus e Hemirhipus lineatus.

(3) Estado plesiomórfico para o grupo interno, adquirido no nó 60, alterado para o estado 2 em Euplinthus ${ }^{+}$.

(2) Sinapomorfia para o grupo Euplinthus ${ }^{+}$(exceto Compsoplinthus e Photophorus), convergente em Lanelater sp.

(1) Ocorre três vezes independentemente, de forma convergente no grupo externo Alampes vestitus e paralelamente entre os gêneros do grupo interno Compsoplinthus e Photophorus.

(5) Autapomorfia de Tibionema abdominalis.

(0) Presente em Lacon sp. e homóloga a de Anaissus tarsalis. 


\section{Margem anterior do mesepisterno (I. C. 0,80; I. R. 0,50):}

0 . arredondada

1. bissinuosa

2. com ângulo interno arredondado a agudo pouco proeminente

3. com ângulo interno agudo fortemente proeminente

4. com ângulo interno truncado proeminente

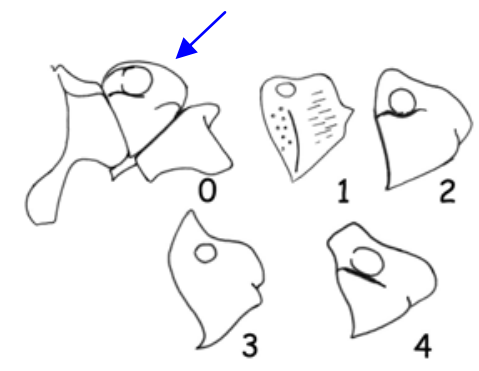

Distribuição:

Plesiomórfico: 2

(?) Hifo, não examinado com relação a esse caráter.

(0) Autapomorfia de Tibionema abdominalis e de Heligmus obscurus.

(2) Condição plesiomórfica para o grupo interno, é homoplástica em relação aquela apresentada por Hemirhipus lineatus. Quase todos os táxons do grupo interno possuem margem anterior do mesepisterno com ângulo interno arredondado a agudo pouco proeminente, exceto Photophorus, no qual o ângulo interno truncado e proeminente constitui uma autapomorfia.

(1) Autapomorfia de Lacon ruber.

(3) Sinapomorfia de Conoderus fuscofasciatus e Aeolus octoguttatus.

23. Região posterior da cavidade circular do mesepisterno (I. C. 0,67; I. R. 0,75):

0. não carenada

1. com carena longitudinal

2. com carena transversal

Distribuição:

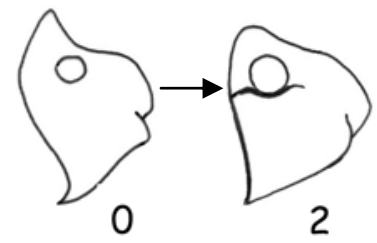

Plesiomórfico: 2

(-) Anaissus tarsalis não possui cavidade circular no mesepisterno.

(?) Hifo, estrutura não examinada. 
(2) Todas os táxons do grupo interno examinado possuem a borda anterior da cavidade circular do mesoventrito mais ou menos carenada.

(0) Sinapomorfia para o clado 59, adquirida paralelamente por Hemirhipus lineatus.

(1) Autapomorfia de Lacon ruber.

\section{Região posterior do metanoto (I. C. 0,40; I. R. 0,50):}

0 . lisa

1. com uma carena longitudinal fracamente saliente

2. com uma carena longitudinal fortemente saliente

Distribuição:

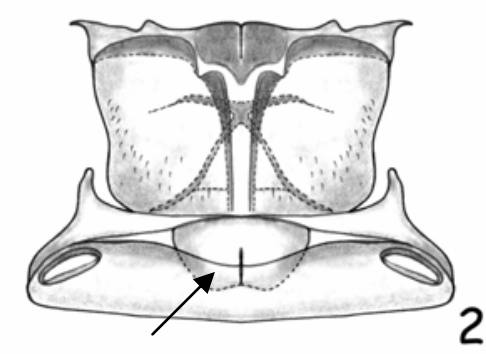

Plesiomórfico: 0

(?) Hifo e Alampes vestitus não puderam ser dissecados para averiguar a condição desse caráter.

(0) A região posterior do metanoto lisa ocorre como evento único nos grupos externos Tibionema abdominalis, Heligmus obscurus, Lanelater sp., Anaissus tarsalis e Conoderus fuscofasciatus ${ }^{+}$.

(1) Autapomorfia de Alampoides tesselatus, convergente em Agnostelater.

(2) Sinapomorfia do grupo interno, presente em quase todos os táxons examinados, exceto em Agnostelater. Ocorre mais duas vezes independentemente, em Hemirhipus lineatus e em Lacon ruber.

25. Número de esclerotizações do ápice da asa (I. C. 1,00; I. R. 1,00):

0. três

1. duas (Fig. 93)

2. uma 
Distribuição:

Plesiomórfico: 0

(0) a condição plesiomórfica presente em Hemirhipus lineatus é homóloga àquela de Tibionema abdominalis.

(1) A redução para 2 esclerotizações no ápice da asa ocorre no nó 54 e se mantém na maioria dos táxons do grupo externo e em todos os táxons do grupo interno. Essa condição encontra-se modificada apenas em Anaissus tarsalis, no qual ocorreu a perda de uma das duas esclerotizações.

\section{Comprimento da asa feminina (I. C. 0,67; I. R. 0,80):}

0. do mesmo comprimento do élitro a levemente mais curta

1. aprox. $1 / 8$ mais curta que o élitro

2. $1 / 3$ a $1 / 5$ mais curta que o élitro

Distribuição:

Plesiomórfico: 0.

(?) Cryptolampros, Agnostelater, Hifo, grupo atlanticus e Lygelater bifossulatus. Não são conhecidas as fêmeas para esses táxons.

(0) Todos os táxons do grupo externo e a maioria dos táxons do grupo interno apresentam o estado plesiomórfico para o comprimento da asa na fêmea.

(1) Sinapomorfia para o grupo Pyrearinus sp. $n .1^{+}$, adquirido independentemente no clado Noxlumenes ${ }^{+}$.

(2) Sinapomorfia para Phanophorus + Hypsiophthalmus.

27. Tarsos (I. C. 0,80; I. R. 0,50):

0. com lamela nos tarsômeros 1-4

1. com lamela no tarsômero 4 
2. com almofada setosa esponjosa desenvolvida nos tarsômeros 1-4

3. com almofada setosa esponjosa pouco desenvolvida nos tarsômeros 2-4

4. densamente pilosos

Distribuição:

Plesiomórfico: 4

(0) e (3) Autapomorfias, respectivamente de Tibionema abdominalis e Anaissus tarsalis.

(4) Estado plesiomórfico para o grupo interno.

(1) Sinapomorfia de Conoderus fuscofasciatus ${ }^{+}$.

(2) Autapomorfia de Hifo e de Photophorus.

\section{Primeiro esternito abdominal (I. C. 0,50; I. R. 0,85):}

0. membranoso a fracamente esclerotizado em todas a sua extensão

1. fortemente esclerotizado nas laterais e membranoso próximo da linha mediana

2. com lamelas laterais fortemente esclerotizadas

As lamelas laterais fortemente ou parcialmente esclerotizadas estão associadas aos órgãos bioluminescentes abdominais mais desenvolvidos, ou seja, que possuem um tecido diferenciado, amarelo a alaranjado, de contorno distinto. As lamelas laterais membranosas ocorrem tanto nos táxons que possuem órgão luminescente fracamente desenvolvido quanto naqueles que não possuem essa estrutura.

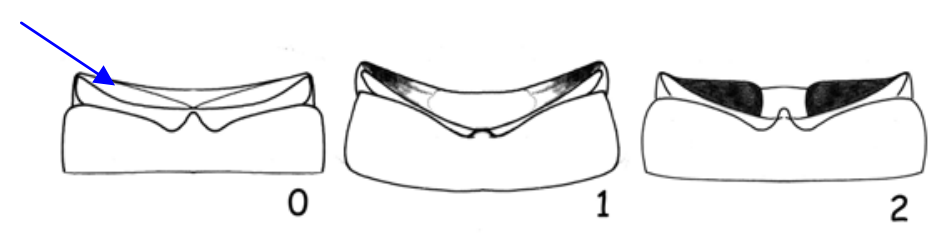

Distribuição:

Plesiomórfico: 0

Polimórfico: Hypsiophthalmus (0/2) 
(0) A condição plesiomórfica ocorre em todos os táxons do grupo externo e em na maioria dos táxons do grupo interno.

(2) É autapomorfia para Pyrophorus e Pyrearinus cinnameus e sinapomorfia para $\mathrm{Hifo}^{+}$, adquirida paralelamente também em algumas espécies de Hypsiophthalmus.

(1) Sinapomorfia de Ptesimopsia ${ }^{+}$, com uma reversão para o estado $0 \mathrm{em}$ Sooporanga.

29. Órgão bioluminescente abdominal (I. C. 0,25; I. R. 0,83):

0 . ausente

1. presente

Distribuição:

Plesiomórfico: 0

(1) A presença de um órgão bioluminescente no primeiro segmento abdominal é sinapomorfia para o clado Gênero $A^{+}$com duas reversões para o estado plesiomórfico: em Meroplinthus e no grupo Coctilelater ${ }^{+}$, ocorrendo neste último uma segunda transição para a condição apomórfica no nó 75. Portanto, o órgão bioluminescente abdominal dentro do grupo interno surgiu duas vezes independentemente, sendo a segunda aquisição uma sinapomorfia para o grupo $\mathrm{Hifo}^{+}$.

30. Forma do órgão bioluminescente abdominal no macho (I. C. 0,50; I. R. 0,80):

0. pouco desenvolvido mais ou menos triangular

1. desenvolvido, subquadrado ou retangular, ocupando no máximo 1/5 do esternito I

2. trapezoidal ou retangular ocupando $1 / 3$ à metade do esternito I

3. trapezoidal ocupando quase ou completamente o esternito I.
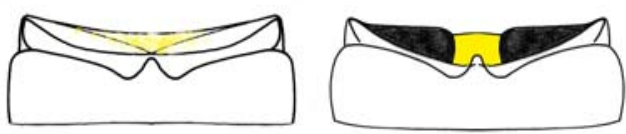

0

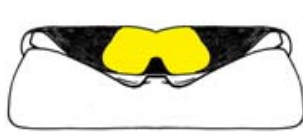

1

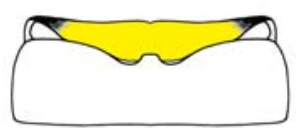


Distribuição:

Plesiomórfico: 2

Polimórfico: Pyrophorus (2/3), Fulgeochlizus (0/3), Hypsiophthalmus (0/2), Ptesimopsia (1/2), Hapsodrilus (2/3).

(-) Caráter não aplicável aos táxons que não possuem órgão bioluminescente abdominal: todos os terminais do grupo externo e os gêneros do grupo interno Noxlumenes, Nyctophyxis, Cryptolampros, Meroplinthus, Coctilelater, Agnostelater, Paraphileus, Euplinthus e Compsoplinthus.

Ambíguo. Devido às variações nos táxons do clado Ptesimopsia ${ }^{+}$não é possível apontar o estado ancestral para o nó 92.

(2) Condição homóloga compartilhada por Gênero A e Pyrophorus, adquirida independentemente mais quatro vezes em Sooporanga, grupo cinnameus, em Hapsodrilus e Hypsiophthalmus.

(0) Sinapomorfia para o clado 68, com duas transições independentes para o estado 3 (Fulgeochlizus e Phanophorus).

(3) Autapomorfia de Phanophorus, adquirida independentemente por subgrupos dos táxons terminais “polimórficos” Pyrophorus, Fulgeochlizus Hapsodrilus e Pyroptesis.

(1) Sinapomorfia para o grupo $\mathrm{Hifo}^{+}$, compartilhada por todos os táxons terminais deste clado.

\section{1. Órgão bioluminescente abdominal da fêmea (I. C. 0,50; I. R. 0,50):}

0. igual ao do macho

1. menos desenvolvido que o do macho

Distribuição:

Plesiomórfico: 0

Ambíguo: Devido a tritomia no clado 82 é possível inferir tanto a hipótese de 
homologia quanto a de homoplasia da condição 1 de Pyrearinus cinnameus em relação àquela de Phanophorus ${ }^{+}$, pois ambas são igualmente parcimoniosas.

(1) A hipótese de homologia primária para essa condição se confirmou apenas para Hypsiophthalmus e Phanophorus.

\section{Caracteres da genitália masculina: 32-47.}

\section{Base do ventrito IX (I. C. 0,25; I. R. 0,25):}

0. uniformemente esclerotizada a levemente mais clara na região mediana

1. margens laterais fortemente esclerotizadas e região mediana

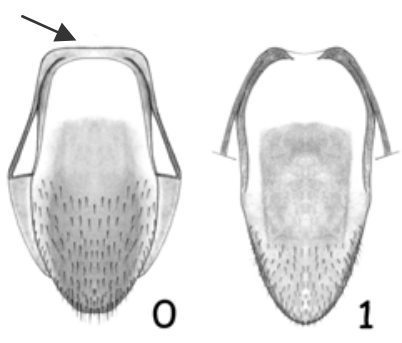
anterior membranosa

Distribuição:

Plesiomórfico: 0

Ambíguo: A ambigüidade no ramo ancestral de Hapsodrilus ${ }^{+}$permite inferir tanto a homologia da condição 1 de Sooporanga em relação àquela dos táxons basais de Meroplinthus $^{+}$(com duas reversões independentes em Hapsodrilus e Pyroptesis), quanto uma homoplasia a partir de uma reversão no nó 92.

(1) Para Meroplinthus, Ptesimopsia e P. parallela a hipótese de homologia para a base do ventrito IX foi corroborada após a análise, com no mínimo um surgimento independente dessa condição no grupo externo Alampoides tesselatus.

\section{Margens ventrais anteriores dos parâmeros (I. C. 0,67; I. R. 0,86):}

0 . livres

1. fusionadas ao esclerito ventral do pênis

2. fusionadas entre si

\section{Distribuição:}

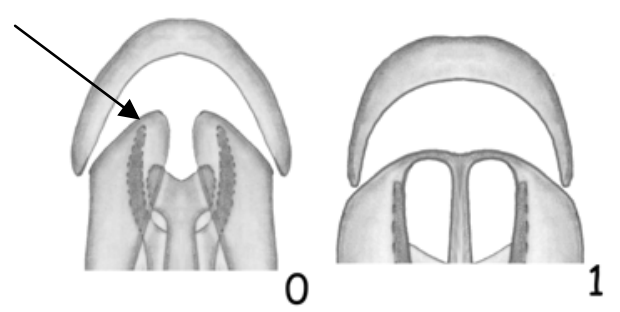


Plesiomórfico: 0

(1) As margens ventrais anteriores dos parâmeros fusionadas entre si está presente em Hemirhipus lineatus e, paralelamente, em Conoderus fuscofasciatus + Aeolus octoguttatus.

(2) Sinapomorfia do clado Meroplinthus ${ }^{+}$.

34. Forma do ápice dos parâmeros (I. C. 0,47; I. R. 0,33):

0 . arredondado, convergentes

1. em forma de ganchos fortemente recurvados, divergentes

2. truncado com ângulo externo agudo e proeminente

3. securiforme

4. gradualmente estreitado com ponta curva para fora

5. truncado a arredondado com carena ou espinho látero-dorsal

6. truncado ou afilado com espinho lateral pequeno

7. truncado com ângulo externo em forma de pequeno gancho

Distribuição:

Plesiomórfico: 5

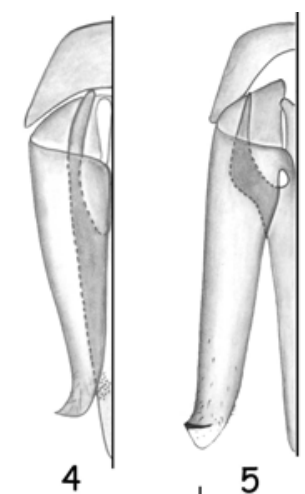

Polimórfico: Fulgeochlizus (5/6), Hypsiophthalmus (4/5)

(?) Hifo: não foi possível discriminar se o ápice dos parâmeros neste táxon era truncado, com espinho látero-apical pequeno ou com carena látero-apical, pois essas duas condições podem ser confundidas quando o edeago é examinado apenas dorsal ou ventralmente, não tendo sido possível, devido a montagem dessa estrutura em lâmina permanente, a observação em vista lateral.

Ambíguo: O "polimorfismo" de Hypsiophthalmus causa a ambigüidade no nó 88, no qual tanto a condição 4 como a 5 podem ser otimizadas, resultando no mesmo número de passos. 
(3) Condição homóloga para Tibionema abdominalis e Hemirhipus lineatus .

(1) e (7) Autapomorfias, respectivamente de Lacon ruber e Anaissus tarsalis.

(2) Sinapomorfia para o grupo externo 59, com uma mudança para o estado $0 \mathrm{em}$ Aeolus octoguttatus e para a condição 4 em Alampes vestitus.

(5) Estado plesiomórfico para os táxons do grupo interno com no mínimo quatro transições homoplásticas para o estado 4 (em Noxlumenes, Hapsodrilus ${ }^{+}$, Phanophorus e Lygelater bifossulatus) e quatro transições para a condição 6 (dentro de Fulgeochlizus e como autapomorfia para Meroplinthus, Pyrearinus basalis e Agnostelater).

35. Ápice dos parâmeros com carena ou espinho látero-dorsal (I. C. 0,57; I. R. 0,57):

0. carena lateral pequena

1. com carena látero-dorsal fraca a saliente

2. com uma carena látero-dorsal fortemente saliente

3. com um espinho látero-dorsal médio

4. com um espinho látero-dorsal grande e um posterior pequeno

5. com um espinho látero-dorsal pequeno e um posterior menor ou igual

Distribuição:

Plesiomórfico: 1

(-) Este caráter não é aplicável aos táxons que não possuem carena ou espinho látero-dorsal no ápice dos parâmeros: todos os grupos externos (exceto Lanelater sp.) e os táxons do grupo interno: Noxlumenes, Meroplinthus, Pyroptesis, Sooporanga, Phanophorus, Pyrearinus basalis, Agnostelater e Lygelater bifossulatus.

(?) Hifo, estrutura não examinada nesse táxon.

Polimórfico: Ptesimopsia (1/3/5), Lygelater (3/4), Ignelater (2/3).

Ambíguo: Não é possível inferir a condição ancestral no nó 93, devido ao “polimorfismo" de Ptesimopsia. 
(0) Autapomorfia de Lanelater sp.

(1) Uma carena látero-dorsal fraca ou saliente está presente na maioria dos táxons do grupo interno. Em Opselater e no grupo melanurus essa condição é homóloga a dos gêneros basais do clado 65 em todas as 8 hipóteses filogenéticas resultantes da análise.

(3) Todas as diferentes hipóteses filogenéticas apontam como homólogos os espinhos látero-dorsais de Deilelater, D. sirius, Photophorus, Ignelater e Lygelater, com a aquisição independente de uma estrutura semelhante em Hapsodrilus e dentro da linhagem de Ptesimopsia.

(2) A carena látero-dorsal fortemente saliente é autapomorfia do grupo atlanticus, adquirida independentemente por algumas espécies de Ignelater.

(4) Sinapomorfia de Vesperelater $+V$. gemmiferus, adquirida independentemente por algumas espécies de Lygelater.

\section{Articulação entre os parâmeros e o esclerito dorsal do pênis (I. C. 0,33; I. R. 0,43):}

0 . com um processo

1. sem processo

2. com uma área membranosa subcircular, transparente

Distribuição:

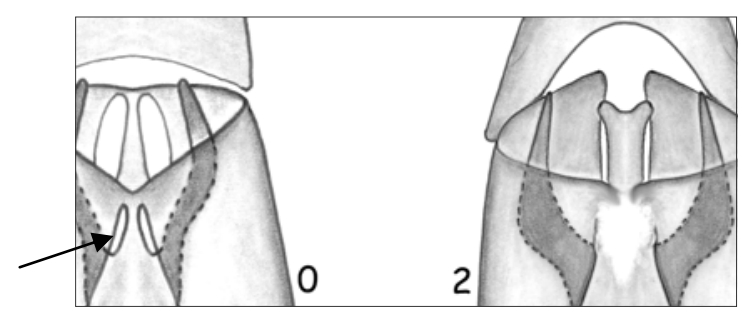

Plesiomórfico: 0

(0) A maioria dos táxons do grupo externo possui articulação entre os parâmeros e o esclerito dorsal do pênis com um processo, estado que permanece pouco alterado no grupo interno, com apenas três transições independentes para o estado 2 .

(1) Dois eventos homoplásticos convergentes ocorrem para esse estado: como autapomorfia em Anaissus tarsalis e em Conoderus fuscofasciatus.

(2) Quatro surgimentos homoplásticos paralelos podem ser observados para essa condição: duas sinapomorfias, para o grupo externo 59 e para Nyctophyxis + Cryptolampros, 
e duas autapomorfias, para Paraphileus e Compsoplinthus.

\section{Processo da articulação dorsal dos parâmeros (I. C. 0,50; I. R. 0,86):}

0 . inteira a levemente marginada

1. com recorte curto

2. com recorte alongado

Distribuição:

Plesiomórfico: 0

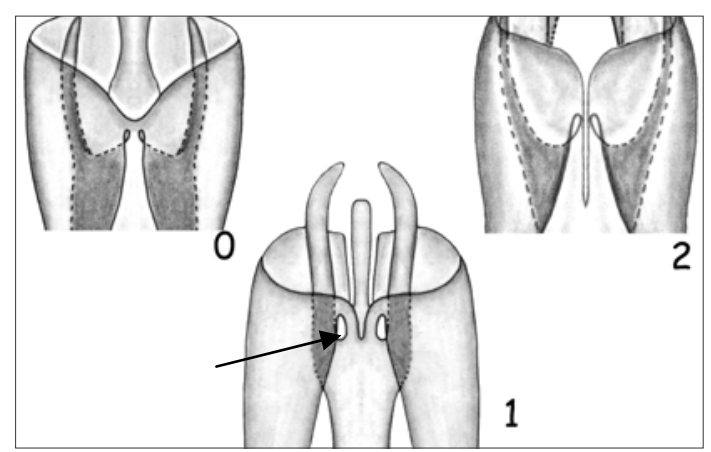

(-) Não se aplica aos táxons que não possuem processo na articulação dorsal dos parâmeros: Anaissus tarsalis, táxons do clado 59, Nyctophyxis, Noxlumenes, Paraphileus e Compsoplinthus.

Polimórfico: Fulgeochlizus (0/1) Ptesimopsia (0/1).

(0) Processo da articulação dorsal do edeago inteiro é a condição plesiomórfica presente nos grupos externos e nos táxons basais do grupo interno (Noxlumenes e Gênero A), com uma transição para o estado 1 no nó 69. Ocorre independentemente mais três vezes, sendo uma delas em uma das espécies de Fulgeochlizus, a partir da condição apomórfica 1, e outra sinapomorfia para Meroplinthus ${ }^{+}$.

(1) Sinapomorfia para o grupo Pyrophorus ${ }^{+}$com duas reversões independentes para o estado 0 (em Meroplinthus ${ }^{+}$e Euplinthus ${ }^{+}$) e uma transição sinapomórfica para o estado 2 no grupo pumilus $^{+}$. Ocorre independentemente dentro da linhagem de Ptesimopsia.

\section{Margens laterais do esclerito dorsal do pênis posteriores aos prolongamentos} basais

(I. C. 0,40; I. R. 0,25):

0. reta a levemente curva (Figs. 114-175)

1. com um abaulamento curto 
2. com um abaulamento alongado $(177,180,186)$

3. com um tubérculo (Fig. 188)

Distribuição:

Plesiomórfico: 0

Polimórfico: Ignelater (2/3).

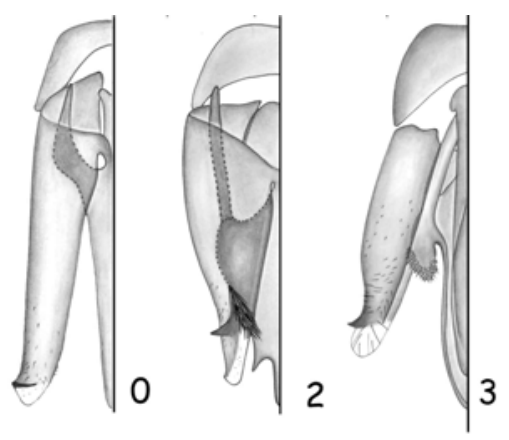

(0) O estado plesiomórfico está presente nos grupos externos e na maioria dos táxons do grupo interno com quatro transições para a condição 2, sendo três autapomórficas (Euplinthus, grupo melanurus e Lygelater) e uma como sinapomorfia para Photophorus + Ignelater.

(1) e (3) Autapomorfias, respectivamente de Opselater e de Ignelater.

39. Esclerito dorsal do pênis (I. C. 0,29; I. R. 0,17):

0 . lisa

1. com escamas minúsculas (Figs. 182)

2. com escamas curtas a alongadas (Figs. 183-187)

Distribuição:

Plesiomórfico: 0

Polimórfico: Pyrophorus (0/1), Hapsodrilus (0/1), Opselater (0/1), grupo atlanticus $(0 / 1)$.

(0) A condição lisa do esclerito dorsal do pênis está presente nos grupos externos e na maioria dos táxons do grupo interno.

(1) Quatro das oito hipóteses filogenéticas resultantes para o grupo em estudo apontam que as escamas minúsculas do esclerito dorsal do pênis é homóloga apenas entre grupo melanurus e Lygelater bifossulatus, ocorrendo independentemente em Pyrophorus, Sooporanga, Euplinthus nos demais táxons “polimórficos para esse caráter”. No entanto, as outras quatro hipóteses demonstram que essa condição deve ter surgido independentemente 
em todos os táxons que a possuem.

(2) Em todas as oito hipóteses filogenéticas obtidas as escamas curtas ou alongadas de Deilelater, Lygelater, Photophorus e Ignelater resultaram homólogas.

40. Ápice do esclerito dorsal do pênis (I. C. 0,67; I. R. 0,67):

0. arredondado a gradualmente afilado desde a base dos prolongamentos basais (Figs. 114175)

1. abruptamente afilado desde o quinto posterior (Figs. 176-180, 183)

2. abruptamente afilado desde uma região entre o terço e o quarto posterior do esclerito dorsal Figs. 191-194)

Distribuição:

Plesiomórfico: 0

(1) A hipótese de homologia primária para a forma do ápice do esclerito dorsal entre Lygelater e Deilelater é confirmada por duas das resoluções alternativas (Fig. 2, resoluçoes 1 e 3) para o nó 77. No entanto, a resolução 2 não sustenta essa hipótese e na 4 a otimização desse estado é ambígua.

(2) Sinapomorfia para o clado Deilelater sirius ${ }^{+}$.

41. Ápice do esclerito dorsal (I. C. 1,00; I. R. 1,00):

0. liso (Fig. 182, 184, 186)

1. com uma par de carenas (Figs. 190, 192, 194)

Distribuição:

Plesiomórfico: 0

(1) Ápice do esclerito dorsal com um par de carenas é sinapomorfia para o clado grupo atlanticus ${ }^{+}$. 


\section{Margens látero-ventrais posteriores do esclerito dorsal (I. C. 1,0; I. R. 1,00):}

0. não expandidas (Fig. 131)

1. com expansões membranosas curtas

2 com expansões membranosas alongadas

Distribuição:

Plesiomórfico: 0

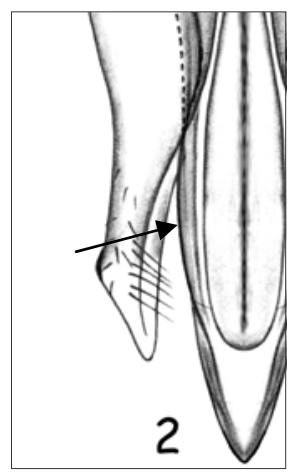

Polimórfico: Fulgeochlizus (0/2)

Ambíguo: No clado Fulgeochlizus ${ }^{+}$o estado 2 pode ser interpretado como uma apomorfia compartilhada pelos gêneros do grupo (com reversão para o estado 0 em Fulgeochlizus bruchi) ou como uma autapomorfia do grupo noctivagus (com um surgimento homoplástico dessa condição em uma das espécies de Fulgeochlizus).

(1) Autapomorfia de Opselater.

43. Esclerito ventral (I. C. 0,60; I. R. 0,64):

0. alongado com menos de 1/5 da largura do esclerito dorsal, côncavo

1. alongado com menos de $1 / 5$ da largura do esclerito dorsal, plano

2. curto, com metade do comprimento e quase da mesma largura do dorsal, plano

3. alongado com menos de $1 / 5$ da largura do esclerito dorsal e com corte transversal em $\mathrm{V}$ (Figs. 150, 152)

4. alongado com no mínimo $1 / 3$ da largura do esclerito dorsal fortemente saliente na linha mediana (corte transversal em V) (Figs. 116, 118)

5. alongado ocupando no mínimo $1 / 3$ da largura do esclerito dorsal, plano a levemente côncavo (Figs. 114, 120)

6. alongado, ocupando aprox 1/3, plano, triangular (Figs. 164, 166)

7. alongado, ocupando aprox. 1/3, com base abruptamente mais estreita (Fig. 168)

Distribuição: 
Plesiomórfico: 1

(0) Um esclerito muito estreito e plano está presente nos táxons do grupo externo, com duas transições homoplásticas para os estado 2 (Heligmus obscurus, Conoderus fuscofasciatus), uma para o estado 0 (Lanelater sp. ${ }^{+}$) e duas alterações paralelas para a condição 5 (Alampes vestitus e grupo interno).

(5) Sinapomorfia para o grupo interno, alterada paralelamente para a condição 4 em Nyctophyxis + Noxlumenes e em Pyrearinus cinnameus, para o estado 3 em Phanophorus + Hypsiophthalmus e para 6 nos táxons basais de Pyrearinus basalis $^{+}$, com uma reversão para o estado 5 em Paraphileus $^{+}$. Adquirida independentemente por Alampes vestitus.

(7) Autapomorfia de Agnostelater.

\section{Região anterior do esclerito ventral (I. C. 1,00; I. R. 1,00):}

0. plana

1. fortemente convexa e estreita

2. fortemente convexa e bilobada

Distribuição:

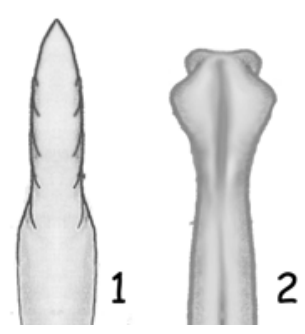

Plesiomórfico: 0

(?) Hifo, espécimes não examinados com relação a esse caráter.

(1) Autapomorfia de Paraphileus.

(2) Sinapomorfia de Fulgeochlizus ${ }^{+}$.

45. Margens laterais do esclerito ventral do pênis (I. C. 0,20; I. R. 0,64):

0. liso (Fig. 170, 172, 174)

1. com um par de pregas

Distribuição:

Plesiomórfico: 0

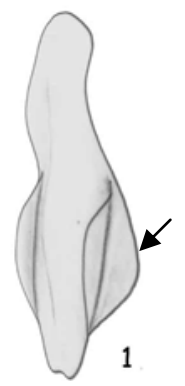


(1) Um par de pregas no esclerito ventral é, independentemente, sinapomorfia para o clado Ptesimopsia ${ }^{+}$(com reversão em Sooporanga) e para o ramo 77 (com reversão para o estado plesiomórfico em Opselater e grupo melanurus).

46. Região mediana posterior do esclerito ventral do pênis (I. C. 0,25; I. R. 0,33):

0. lisa (Fig. 114, 172)

1. com uma carena interna (Fig. 128, 131, 174)

2. com uma carena externa (Fig. 124)

Distribuição:

Plesiomórfico: 0

Polimórfico: Lygelater (0/2).

(0) Todas os táxons do grupo externo e a maioria dos táxons do grupo interno possuem a região mediana do esclerito ventral lisa.

(1) Autapomorfia para Gênero A, Fulgeochlizus e Compsoplinthus.

(2) Condição derivada do estado 0 em cinco eventos paralelos: como autapomorfia para Pyrophorus, Pyrearinus basalis e Hifo, dentro da linhagem de Lygelater e como sinapomorfia para o clado 85 .

47. Superfície do esclerito ventral do pênis (I. C. 0,50; I. R. 0,33):

0. lisa (Fig. 120, 122)

1. com escamas minúsculas dirigidas anteriormente (Fig. 137)

2. com escamas minúsculas dirigidas posteriormente (Fig. 127)

Distribuição:

Plesiomórfico: 0

Polimórfico: Pyrophorus (0/2) Ptesimopsia (0/1), Hapsodrilus (0/1), Pyroptesis (0/1), Hypsiophthalmus (0/2), Lygelater(0/2), Ignelater(0/2). 
(1) Sinapomorfia para o clado Ptesimopsia parallela ${ }^{+}$, com três reversões independentes para o estado plesiomórfico nos táxons "polimórficos" Ptesimopsia, Hapsodrilus e Pyroptesis.

(2) Na maioria das hipóteses alternativas resultantes da análise esse estado surgiu independentemente em todos os táxons que a possuem, somente dois dos oito cladogramas confirmam a hipótese de homologia primária para essa estrutura em Lygelater, L. bifossulatus e Deilelater.

Caracteres da genitália e do trato reprodutivo da fêmea: 48-60.

Em todos os caracteres a seguir os táxons Cryptolampros, Agnostelater, Hifo, grupo atlanticus e Lygelater bifossulatus foram codificados como dado ausente (?), porque suas fêmeas não são conhecidas.

48. Ângulos anteriores do tergito VIII (I. C. 1,00; I. R. 1,00):

0 . arredondados ou retos

1. agudos e projetados anteriormente

Distribuição:

Plesiomórfico: 0 .

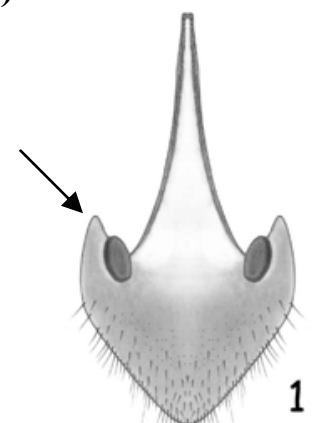

(1) Sinapomorfia para o clado 56, presente em todos os táxons terminais cujas fêmeas são conhecidas.

49. Par de escleritos na membrana interconectiva do segmento VIII (I. C. 0,20; I. R. 0,64):

0 . ausente

1. presente (Figs. 204, 218)

Distribuição:

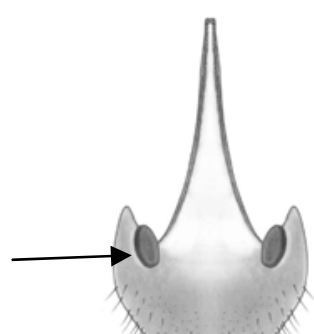


Plesiomórfico: (0)

(1) A presença de um par de escleritos na membrana interconectiva do segmento VIII é sinapomorfia para o grupo Meroplinthus ${ }^{+}$. Embora o cladograma de consenso estrito aponte quatro passos adicionais para esse estado no clado 77, todas as oito hipóteses resultantes da análise da matriz de caracteres apontam como homólogos entre si os escleritos de Lygelater, Deilelater, Ignelater e de D. sirius ${ }^{+}$.

50. Forma dos escleritos da membrana interconectiva do segmento VIIII (I. C. 0,67; I.

R. 0,50):

0. mais ou menos ovais e côncavos, grandes

1. irregular

2. oval muito pequeno

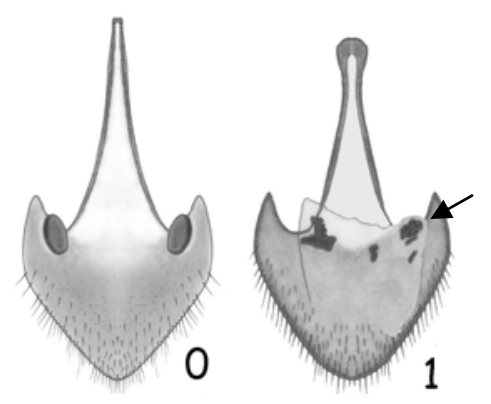

Distribuição:

Plesiomórfico: (0)

(-) Caráter não aplicável aos táxons cujas fêmeas estudadas não possuem escleritos na membrana interconectiva no segmento VIII: todos os grupos externos e os táxons do grupo interno, (exceto aqueles do clado 91, e parte do clado 78).

Ambíguo: a otimização do estado 2 no nó do grupo atlanticus ${ }^{+}$é ambígua, portanto a forma reduzida dos escleritos em Deilelater sirius e Vesperelater gemmiferus pode ser homo homóloga ou homoplástica, sendo essas duas hipóteses igualmente parcimoniosas.

(1) O estado 0 ocorre no grupo Meroplinthus ${ }^{+}$, com uma transição para o estado 1 em Pyroptesis + Sooporanga e, independentemente, como evento único para Lygelater, Deilelater e Ignelater. Devido a ambigüidade no nó 78 a forma grande e oval em Vesperelater pode tanto ser homóloga a dos demais táxons do ramo 77 como ser derivada, independentemente, da forma reduzida. 


\section{Vulva (I. C. 1,00; I. R. 1,00):}

0. membranosa

1. com uma estreita faixa mediana esclerotizada

2. metade anterior esclerotizada (Fig. 202)

3. margens esclerotizadas, linha mediana membranosa

Distribuição:

Plesiomórfico: 1

(1) Estado homólogo entre Tibionema abdominalis, Hemirhipus lineatus Heligmus obscurus

(2) A base da vulva é inteiramente esclerotizada em todos os táxons do grupo interno, condição homóloga àquelas dos grupos externos Lanelater sp. e clado 59.

(0) e (3) Autapomorfias, respectivamente de Lacon ruber e Anaissus tarsalis.

52. Baculi (I. C. 0,50; I. R. 0,50):

0. 4,5-6,0 X o comprimento dos coxitos

1. $0,5-2,5 \mathrm{X}$ o comprimento dos coxitos (Fig. 202)

Distribuição:

Plesiomórfico: (0)

(1) Condição adquirida no clado 54, com uma reversão em Lacon ruber. No grupo interno, todos os táxons possuem ovipositor com baculi no máximo duas vezes e meia mais longo que os coxitos.

\section{Glândulas coleteriais (I. C. 0,43; I. R. 0,43):}

0 . em forma de balão, com base estreita

1. saculiforme muito estreita e alongada

2. saculiforme, tão longa quanto larga a mais longa que larga (Fig. 202, 206) 
3. muito curta ou ausente (Fig. 200)

Distribuição:

Plesiomórfico: (2)

(?) A genitália do único exemplar fêmea de Noxlumenes estava em péssimo estado, não sendo possível averiguar a condição do caráter nesse gênero.

(3) Condição homóloga compartilhada por Tibionema abdominalis e Hemirhipus lineatus

(2) É a condição plesiomórfica no grupo interno, a partir da qual ocorrem duas alterações paralelas para o estado 3, uma em Meroplinthus ${ }^{+}$(com uma reversão em Hapsodrilus $^{+}$) e outra em Hypsiophthalmus.

(0) Autapomorfia de Lanelater sp., adquirida independentemente por Conoderus fuscofasciatus ${ }^{+}$.

(1) Autapomorfia de Lacon ruber.

54. Parede da vagina posteriormente às glândulas coleteriais (I. C. 0,86; I. R. 0,92):

0. completamente membranosa (Fig. 196, 198, 200, )

1. com um esclerito espinhoso fortemente esclerotizado

2. com uma área muito estreita e alongada irregularmente esclerotizada

3. com duas placas ventrais, pequenas e semicirculares

4. com duas áreas laterais triangulares formadas por microescleritos (Figs. 215, 216)

5. com um esclerito côncavo alongado formado por microescleritos (Fig. 212b)

6. com duas placas retangulares largas formadas por microescleritos

Distribuição:

Plesiomórfico: $(0)$

Polimórfico: grupo lineatus (0/5).

(5) Condição homóloga, compartilhada pelos táxons do clado 87, com reversão 
para o estado 0 dentro da linhagem do grupo lineatus.

(4) Sinapomorfia para Euplinthus ${ }^{+}$, adquirida paralelamente por Pyrearinus basalis .

(2) (1) (6) e (3) Autapomorfias, respectivamente de Heligmus obscurus, Lanelater sp., Anaissus tarsalis e Aeolus octoguttatus, todas derivadas do estado 0.

\section{5. Áreas laterais triangulares formadas por microescleritos (I. C. 0,40; I. R. 0,67):}

0. uniformemente fracamente esclerotizada (Fig. 213)

1. mais fortemente esclerotizada na base das glândulas coleteriais (Figs. 215, 216)

2. uniformemente fortemente esclerotizada (Figs. 220, 221)

Distribuição:

Plesiomórfico: 0 .

(-) Não aplicável aos táxons do grupo externo e àqueles do grupo interno que não possuem áreas laterais triangulares formadas por microescleritos na parede da vagina.

Polimórfico: Lygelater (0/1); Deilelater (0/1).

(0) Estado homólogo para os táxons do clado Euplinthus ${ }^{+}$em todas as hipóteses filogenéticas alternativas, ocorrendo independentemente em Pyrearinus basalis.

(1) e (2) Sinapomorfias, respectivamente para Vesperelater $+V$. gemmiferus e Photophorus + Ignelater, ambas derivadas da condição plesiomórfica. O estado 1 também ocorre mais três vezes paralelamente, em Compsoplinthus e nos táxons "polimórficos" Lygelater e Deilelater.

\section{Região anterior de cada glândula coleterial (I. C. 0,57; I. R. 0,81):}

0. membranosa (Fig. 206)

1. com um esclerito alongado côncavo formado por microescleritos (Fig. 216, 217)

2. com um esclerito fracamente esclerotizado (fig. 214) 
3. com um esclerito espinhoso fortemente esclerotizado (Figs. 210, 211, 212a)

4. com uma placa retangular formada por microescleritos

Distribuição:

Plesiomórfico: 0

Polimórfico: grupo lineatus (0/3)

(0) A condição plesiomórfica desse caráter ocorre na maioria dos grupos externos e nos táxons do grupo interno como evento único, com apenas uma reversão a partir do estado 3 dentro da linhagem do grupo lineatus.

(4) Autapomorfia de Anaissus tarsalis.

(2) Autapomorfia de Nyctophyxis, com um surgimento independente nos táxons Coctilelater, Paraphileus e Euplinthus.

(3) Ocorrem três transições paralelas do estado 0 para o 3: uma como autapomorfia em Gênero A e outras duas como sinapomorfias para os grupos Pyroptesis ${ }^{+}$e grupo lucernula*.

(1) Sinapomorfia de Compsoplinthus ${ }^{+}$, adquirida a partir da condição 2.

\section{Espermatecas (I. C. 0,50; I. R. 0,00):}

0 . ausente

1. presente (Figs. 202, 206, 211)

Distribuição:

Plesiomórfico: (0)

Todas os táxons do grupo interno e a maioria dos grupos externos possuem espermatecas. A perda dessas estruturas ocorre, paralelamente, em Lacon ruber e Anaissus tarsalis. 


\section{Forma das espermatecas (I. C. 0,62; I. R. 0,72):}

0. curtas com ápice dilatado e esclerotizado

1. muito alongada com ápice espiralado

2. curta, espiralada com mais de seis voltas, cada espiral diminuindo acentuadamente de diâmetro em direção ao ápice

3. moderadamente alongada, ápice espiralado com duas a cinco voltas, espirais diminuindo pouco de diâmetro em direção ao ápice (Figs. 196, 197)

4. divertículos capitados no ápice (Fig. 206)

5. divertículos moderadamente alongados, delgados (Figs. 200, 202)

Distribuição:

Plesiomórfico: 3

(-) Caráter não aplicável a Lacon ruber e Anaissus tarsalis, devido a ausência de espermatecas nesses táxons.

(0) Condição homóloga entre Tibionema abdominalis e Hemirhipus lineatus

(1) Sinapomorfia de Conoderus fuscofasciatus ${ }^{+}$.

(2) Autapomorfia de Lanelater sp.

(3) É a condição plesiomórfica no grupo interno, com três transições para o estado 5 e uma para o estado 4.

(5) Autapomorfia do grupo noctivagus e de Paraphileus e sinapomorfia de Meroplinthus ${ }^{+}$.

(4) Sinapomorfia do grupo ferrugineus e do grupo nyctolampis.

\section{Forma da região anterior da bursa copulatrix (I. C. 0,45; I. R. 0,70):}

0 . arredondada grande.

1. em espiral, com aprox. 7 voltas, cada espiral estreita

2. em espiral com 2 ou 3 voltas com fileira de espinhos alongados fortemente esclerotizados 
(Fig. 198, 211, 213)

3. uma espiral ou saculiforme pouco desenvolvida sem espinhos ou com poucos espinhos (Figs. 196, 202)

4. circular, pequena, ventral à região posterior

5. saculiforme bem desenvolvida, mais longa que larga.

Distribuição:

Plesiomórfico: 2

Polimórfico: grupo lineatus (2/3)

(4) e (5) Autapomorfias de Tibionema abdominalis e Hemirhipus lineatus .

(0) Ocorre independentemente em Lacon ruber e em Anaissus tarsalis.

(2) Estado plesiomórfico no grupo interno, homólogo nos táxons Gênero $A$ e Pyrophorus com uma transição para o estado 3 no nó 68 e três reversões independentes: no grupo lineatus, em Pyrearinus basalis e no clado Paraphileus ${ }^{+}$.

(3) Sinapomorfia para Noxlumenes ${ }^{+}$e do clado 68 (exceto táxons com reversões para o estado 2, citados anteriormente). Condição adquirida independentemente pelo táxon externo Heligmus obscurus.

\section{Glândula ventromediana na bursa copulatrix (I. C. 1,00; I. R. 1,00):}

0. ausente (Fig. 196, 197)

1. presente

Distribuição:

Plesiomórfico: (0)

A presença de glândula na região ventromediana da bursa copulatrix é sinapomorfia de Lanelater sp. e Lacon ruber. 


\subsection{Hipóteses filogenéticas}

A análise filogenética dos 61 caracteres não ordenados e com pesos iguais resultou em 8 árvores mais parcimoniosas com 318 passos. Os índices de consistência $(0,49)$ e de retenção $(0,70)$ indicam que apesar do número elevado de homoplasias a maior parte delas é informativa e constituem sinapomorfias. O cladograma de consenso estrito (Fig. 1, 3) apresenta 330 passos, índice de consistência 0,48 e de retenção 0,68 . As politomias nos nós 82 e 77 do consenso correspondem a duas resoluções alternativas para grupo cinnameus $^{*}$ e quatro para Opselater $^{*}$ (Fig. 2). Na discussão seguinte o número normal e o número subscrito (e.g. $0_{1}$ ) indicam, respectivamente, número e estado do caráter.

\subsubsection{Monofilia de Pyrophorini}

As 8 hipóteses filogenéticas obtidas demonstram que a tribo "Pyrophorini” (sensu Costa, 1975b) é parafilética, pois não inclui os gêneros Meroplinthus, Coctilelater, Agnostelater, Paraphileus, Euplinthus e Compsoplinthus (Fig. 1), todos eles anteriormente considerados Heligmini. São três as sinapomorfias que sustentam Pyrophorini, como definida no presente estudo, incluindo todos os descendentes do ancestral comum e exclusivo das espécies da tribo: a presença de um par de órgãos bioluminescentes na região posterior do pronoto $\left(9_{1}\right)$, a região posterior do metanoto com uma carena longitudinal fortemente saliente $\left(24_{2}\right)$ e o esclerito ventral do pênis alongado ocupando no mínimo $1 / 3$ da largura do esclerito dorsal, plano a levemente côncavo $\left(43_{5}\right)$.

A presença de órgãos bioluminescentes do pronoto já era tradicionalmente considerada uma sinapomorfia para "Pyrophorini” (Costa, 1975b). A conclusão inédita desse estudo, considerando-se a presente hipótese de monofilia para a tribo, é que esses órgãos foram perdidos dentro do grupo em duas ocasiões: uma em Meroplinthus e outra na linhagem ancestral do clado 62 que inclui Agnostelater, Paraphileus, Euplinthus, Compsoplinthus e 
Hifo, com um segundo surgimento paralelo desses órgãos no grupo distal a Hifo (clado Opselater $^{*}$ ).

A carena longitudinal fortemente saliente da região posterior do metanoto não é sinapomorfia exclusiva do grupo interno, ela também está presente em outros dois táxons do grupo externo, como autapomorfias para Hemirhipus lineatus e para Lacon ruber. Dentro de Pyrophorini ela ocorre em quase todos os táxons, exceto em Agnostelater no qual essa carena apresenta-se como uma fraca impressão, estado que ocorre independentemente no grupo externo Alampoides tesselatus. Vale ressaltar que Hifo e Alampes vestitus não puderam ser dissecados para observar a condição desse caráter.

O esclerito ventral do pênis com no mínimo $1 / 3$ da largura do esclerito dorsal, plano a levemente côncavo, também não é uma característica exclusiva de Pyrophorini, pois se originou paralelamente em Alampes vestitus. Dentro do grupo o esclerito ventral sofreu várias modificações apomórficas: para fortemente saliente na linha mediana $\left(43_{4}\right)$, em Nyctophyxis + Noxlumenes e, paralelamente, em grupo cinnameus; para uma forma menos desenvolvida, muito estreita $\left(43_{3}\right)$ em Phanophorus + Hypsiophthalmus e para um esclerito triangular nos táxons basais de Pyrearinus basalis ${ }^{+}$. Esta característica já era presumida como sinapomorfia, se não para a tribo, ao menos para subgrupos dentro desta, pois escleritos ventrais tão desenvolvidos são raros em Elateridae. A maioria dos elaterídeos parece não possuir esclerito ventral ou possui um esclerito pouco desenvolvido tendo, provavelmente, pouco valor taxonômico, motivo pelo qual vários autores não a consideram em suas descrições (e.g. Johnson, 1995; Calder, 1996; Aranda, 2001; Casari, 2004). Em Pyrophorini, ao contrário, o esclerito ventral é uma estrutura bastante complexa e fornece outros caracteres (44-47) que sustentam clados dentro do grupo interno.

Os resultados da análise filogenética confirmam a hipótese de monofilia entre os gêneros da Oceania, Photophorus e Hifo, e os Neotropicais (Costa, 1975b, 1984), a despeito da significativa disjunção geográfica entre esses táxons. 


\subsubsection{Relações filogenéticas entre Pyrophorini e outros Agrypninae}

No presente trabalho é possível apenas especular a resp eito da posição filogenética de Pyrophorini dentro da subfamília Agrypninae, uma vez que a pequena amostragem dos grupos externos não é adequada para inferir a monofilia das tribos de Agrypninae e suas relações filogenéticas, embora, no momento, tenha sido satisfatória para testar a monofilia da tribo e propor uma hipótese de relacionamento interno. Ainda assim, vale apontar alguns resultados que podem contribuir para estudos futuros nesse nível mais abrangente.

Pyrophorini compartilha com as demais espécies representantes de Agrypninae a presença de cerdas na face lateral das garras tarsais, a perda da célula anal na asa e a perda do stylus no ápice dos coxitos do ovipositor. Essas características já haviam sido mencionadas por outros autores como sinapomorfias para a subfamília (Crowson, 1961; Costa, 1984b; Calder et al., 1993). O que se observou nesse estudo pela primeira vez e que merece atenção em investigações futuras foi a forma da região anterior do metanoto, que nos Agrypninae examinados é separada da região mediana posterior por uma área membranosa transparente (Fig. 94), enquanto que em Tibionema abdominalis (Pityobiinae) essas áreas são contíguas, fusionadas entre si. Nos espécimes examinados de Ludius erithrocephalus (Denticollinae), inicialmente elegido como grupo externo, além da região anterior do metanoto similar a de Tibionema, está ausente a carena longitudinal, tanto da região anterior como da região posterior do metanoto.

As hipóteses filogenéticas obtidas demonstram que o grupo mais proximamente relacionado à Pyrophorini é aquele que inclui as duas espécies representantes de Conoderini (Conoderus fuscofasciatus + Aeolus octoguttatus) como grupo-irmão de duas espécies de Heligmini (Alampes vestitus + Alampoides tesselatus). Esta relação é sustentada por duas sinapomorfias: fronte no macho retangular de lados retos ou curvos $\left(3_{1}\right)$ e bordas da cavidade mesoventral inclinadas no máximo $45^{\circ}$, não salientes $\left(21_{3}\right)$. A proximidade filogenética entre 
Conoderini e Pyrophorini também foi demonstrada por Sagegami-Oba et al. (2007), em uma análise filogenética baseada em dados moleculares para Elateridae.

O resultado mais significativo com relação aos grupos externos na presente análise cladística foi a divisão da tribo "Heligmini", que resultou polifilética, com a maior parte de seus gêneros incluídos no grupo interno. Dentre esses últimos estão Coctilelater e Agnostelater, incluídos na subtribo "Alampina" por Costa (1975b), juntamente com Alampes e Alampoides que, como discutido anteriormente, parecem ser filogeneticamente mais próximos de Conoderini. Heligmus obscurus, aparece mais basal e compartilha com Hemirhipus lineatus dois caracteres aparentemente plesiomórficos das fêmeas de Agrypninae: os ângulos anteriores do tergito VIII arredondados $\left(48_{0}\right)$ e a vulva com uma estreita faixa mediana esclerotizada $\left(51_{1}\right)$.

Anaissus tarsalis é indicado, pelos resultados aqui obtidos, como o táxon irmão da linhagem ancestral que deu origem aos grupos Pyrophorini e Conoderus fuscofasciatus ${ }^{+}+$ Alampes vestitus $^{+}$, compartilhando com esses a sinapomorfia região posterior do processo prosternal denteada $\left(17_{1}\right)$.

\subsubsection{Monofilia dos gêneros}

Devido a grande variabilidade entre as espécies de Fulgeochlizus, Ptesimopsia, Pyrearinus, Opselater, Lygelater, Deilelater, e Vesperelater, esses gêneros foram divididos em grupos de espécies (Anexo 1) e estes foram incluídos como táxons terminais na análise. As hipóteses resultantes confirmaram apenas a monofilia de Vesperelater, corroborada pela sinapomorfias $35_{4}$ (ápice dos parâmeros com um espinho látero-dorsal grande e um posterior pequeno) e 551 (áreas laterais triangulares formadas por microescleritos mais fortemente esclerotizada na base das glândulas coleteriais) e de Fulgeochlizus com base nas 
sinapomorfias $3_{2}$ (fronte no macho subquadrada de lados retos) e $44_{2}$ (região anterior do esclerito ventral fortemente convexa e alargada).

"Ptesimopsia" mostrou-se merofilético porque inclui Ptesimopsia parallela, espécie que, segundo a hipótese filogenética apresentada aqui, é basal ao clado (Ptesimopsia (Hapsodrilus (Pyroptesis + Sooporanga))), compartilhando com esse grupo a forma da fronte no macho subtrapezoidal a trapezoidal alongada de lados retos $\left(3_{5}\right)$ e a superfície do esclerito ventral do pênis com escamas minúsculas dirigidas anteriormente $\left(47_{1}\right)$. P. parallela apresenta várias autapomorfias que a distingue das demais espécies de Ptesimopsia e que são homoplásticas em relação àquelas dos grupos de espécies de Pyrearinus do clado 85: machos com olhos grandes $\left(0_{2}\right)$, margem anterior do pronoto sinuosa a arredondada pouco proeminente com ângulos anteriores retos $\left(6_{1}\right)$ e prosterno curto de lados curvos $\left(16_{1}\right)$ e fêmeas com protórax levemente diferente em relação ao do macho $\left(8_{2}\right)$.

"Pyrearinus" foi o grupo mais heterogêneo, por isso foi dividido em dez subgrupos, dos quais seis (grupo pumilus, Pyrearinus sp. 1, grupo ferrugineus, grupo lucernula, grupo candelarius e grupo lineatus) formam um grupo monofilético (P. pumilus ${ }^{+}$) que inclui a espécie tipo do gênero, $P$. nyctolampis. Cinco sinapomorfias sustentam esse grupo: machos com olhos grandes $\left(0_{2}\right)$, com antenas com o mesmo comprimento da antena da fêmea $\left(5_{0}\right)$ e margem anterior do pronoto sinuosa a arredondada pouco proeminente com ângulos anteriores retos $\left(6_{1}\right)$, margem ocular fortemente emarginada posteriormente $\left(1_{3}\right)$ e processo da articulação dorsal dos parâmeros com um recorte alongado $\left(37_{2}\right)$. Por outro lado, as hipóteses filogenéticas obtidas demonstram que $P$. basalis e $o$ grupo lampyris não fazem parte da linhagem monofilética que inclui a espécie-tipo do gênero e aparecem mais proximamente relacionados aos táxons do clado 65. grupo cinnameus ocorre numa tritomia para a qual nenhuma das resoluções aponta a hipótese de monofilia desta espécie com o clado P. pumilus ${ }^{+}$. 
Opselater resultou merofilético nas hipóteses consideradas neste estudo. $\mathrm{Na}$ revisão recente do gênero (Rosa, 2004) já haviam sido reconhecidos os dois grupos distintos de espécies aqui inseridos como táxons terminais. Segundo os resultados da análise cladística o grupo melanurus pode ser basal aos demais táxons do clado 77 (Fig. 2, resoluções 1 e 2), seguido das demais espécies Opselater ou, como demonstrado por outras resoluções (Fig. 2, resoluções 3 e 4), pode ser grupo irmão de Lygelater bifossulatus, sendo ambos também basais aos demais táxons. A única sinapomorfia compartilhada pelas espécies de Opselater com os demais táxons do clado 77, ausente no grupo melanurus, é a forma dos órgãos bioluminescentes na região posterior do pronoto: vesículas ovais, médias a grandes e levemente convexas $\left(10_{4}\right)$, interpretada como uma reversão em Lygelater bifossulatus em duas resoluções alternativas (Fig. 2, resoluções 3 e 4).

Lygelater bifossulatus foi a única espécie do gênero incluída na análise como táxon terminal porque, apesar da semelhança na aparência externa com os demais espécies de Lygelater, não possuía as características do edeago tão conspícuas no grupo: abaulamentos laterais do esclerito dorsal bem desenvolvidos com escamas espiniformes alongadas e ápice do esclerito dorsal fortemente afunilado ou trilobado. Os resultados da análise confirmam que L. bifossulatus não está entre os descentes da linhagem ancestral comum exclusiva da espécietipo e das demais espécies do gênero no qual está atualmente alocado. No entanto a posição de Lygelater bifossulatus dentro do grupo permanece incerta, as resoluções possíveis (Fig. 2) apontam para três hipóteses possíveis de relacionamento filogenético entre esta espécie e os demais táxons do clado 77.

Deilelater neste estudo foi dividido em três grupos: o conjunto de espécies que inclui a espécie-tipo e espécies similares a esta, o par D. ustulatus e D. atlanticus (grupo atlanticus), e a espécie $D$. sirius. Para estes últimos, as características do edeago também justificam sua inclusão como táxons terminais na análise: D. ustulatus e D. atlanticus possuem edeago mais simples, sem escamas espiniformes alongadas, com esclerito dorsal 
com ápice gradualmente afilado e com uma par de carenas que não é encontrado no grupo da espécie-tipo do gênero, mas que é similar àquele das espécies de Vesperelater. Este par de carenas do ápice do esclerito ventral também é encontrado em D. sirius e constitui uma sinapomorfia $\left(41_{1}\right)$ para o clado (D. ustulatus (D. sirius (Vesperelater + Vesperelater gemmiferus))) presente em todas as oito hipóteses resultantes da análise filogenética. $D$. sirius compartilha com Vesperelater + Vesperelater gemmiferus a sinapomorfia ápice do esclerito dorsal abruptamente afilado desde uma região entre o terço e o quarto posterior $\left(40_{2}\right)$.

\subsubsection{Relacionamentos filogenéticos dentro de Pyrophorini}

Segundo o cladograma de consenso parcialmente colapsado das oito hipóteses mais parcimoniosas (Fig. 3) obtidas neste estudo, a primeira divergência cladogenética ocorrida na linhagem ancestral de Pyrophorini levou à formação das espécies ancestrais do grupo Noxlumenes ${ }^{+}$, representado por apenas três gêneros, e do clado Gênero $A^{+}$, no qual parece ter ocorrido uma maior radiação adaptativa, dando origem aos demais táxons atuais.

As sinapomorfias que sustentam Noxlumenes $^{+}$são todas das fêmeas, que não puderam ser verificadas em Cryptolampros, para o qual apenas machos são conhecidos: o protórax fortemente mais convexo e mais arredondado que o do macho $(84)$, o comprimento da asa que é cerca de 1/8 mais curta que o élitro $\left(26_{1}\right)$ e a região anterior da bursa copulatrix saculiforme, sem espinhos $\left(59_{3}\right)$, sendo esta última também uma condição sinapomórfica homoplástica para Fulgeochlizus ${ }^{+}$. A inclusão de Cryptolampros no clado provavelmente se justifica pela sua proximidade filogenética com Nyctophyxis, com o qual compartilha quatro caracteres sinapomórficos presentes no macho: olhos pequenos $\left(0_{0}\right)$ com margem ocular com uma faixa preta em quase toda a sua extensão $\left(1_{1}\right)$, esclerito dorsal do pênis com uma área membranosa transparente na articulação com os parâmeros $\left(36_{2}\right)$ e esclerito ventral com $1 / 3$ da largura do dorsal e fortemente saliente na linha mediana (434). Esses resultados reafirmam 
a hipótese de monofiletismo para o clado Noxlumenes ${ }^{+}$, o qual já fora reconhecido por Costa (1975b) ao erigir a subtribo Nyctophyxina para agrupar esses três gêneros com base no tamanho dos olhos, na forma e localização dos órgãos bioluminescentes do pronoto, na ausência de órgãos bioluminescentes abdominais e na forma geral do edeago.

O clado Gênero $A^{+}$sofreu a maior diversificação e é suportado por duas sinapomorfias: forma da margem lateral anterior do mesoventrito $\left(20_{2}\right.$, Figs. 80,81$)$, e o surgimento de um órgão bioluminescente no primeiro esternito abdominal, perdido duas vezes independentemente dentro do clado, em Meroplinthus e em Coctilelater ${ }^{+}$. Os três táxons mais basais são Gênero A seguido de Pyrophorus e Fulgeochlizus. O clado Pyrophorus ${ }^{+}$é sustentado pela sinapomorfia 37, (processo da articulação dorsal dos parâmeros com recorte curto) e o ramo Fulgeochlizus ${ }^{+}$(nó 68) pelas sinapomorfias $13_{1}$ (hipômero com ângulo posterior e pequena área glabra) $30_{0}$ (órgão bioluminescente abdominal pouco desenvolvido mais ou menos triangular) e $59_{3}$ (região anterior da bursa copulatrix saculiforme, sem espinhos).

O grupo irmão de Fulgeochlizus é o clado 67, definido pelas sinapomorfias $10_{6}$ (órgãos bioluminescentes em forma de vesículas circulares, médias a grandes) e $11_{1}$ (vesículas sublaterais, próximas das carenas dos ângulos posteriores). O clado 67 encontra-se dividido em três grupos monofiléticos maiores: (Meroplinthus $^{+}$(grupo cinnameus ${ }^{*}+$ Pyrearinus basalis $\left.^{+}\right)$.

Os táxons do clado Meroplinthus ${ }^{+}$correspondem àqueles anteriormente incluídos na subtribo Hapsodrilina mais o gênero Meroplinthus, alocado até o presente estudo na tribo Heligmini (Costa, 1975b). Os resultados da análise cladística realizada corroboram a monofilia dos táxons de Hapsodrilina, como apontada no nó 91, (Ptesimopsia paralella (Ptesimopsia (Hapsodrilus (Pyroptesis + Sooporanga)))), sendo este sustentado por duas sinapomorfias: forma da fronte no macho subtrapezoidal a trapezoidal alongada de lados retos (35) e superfície do esclerito ventral do pênis com escamas minúsculas dirigidas 
anteriormente. No entanto, as hipóteses resultantes contradizem a validade de Hapsodrilina, devido à inclusão de Meroplinthus como táxon basal do clado, sustentado por seis sinapomorfias: antena serreada a partir do $3^{\circ}$ antenômero $\left(4_{1}\right)$, base do ventrito IX do macho com margens laterais fortemente esclerotizadas e região mediana anterior membranosa $\left(32_{1}\right)$, edeago com margens ventrais anteriores dos parâmeros fusionadas ao esclerito ventral do pênis (33 $)$, processo da articulação dorsal dos parâmeros inteiro a levemente marginado(370), um par de escleritos na membrana interconectiva do segmento VIII (49.) e espermatecas em forma de divertículos moderadamente alongados e delgados (585). Por sua vez, a subtribo Pyrophorina (sensu Costa, 1975b) também se torna inválida, uma vez que incluiu a tribo Hapsodrilina, além de vários gêneros de Heligmini.

O clado grupo cinnameus ${ }^{*}+$ Pyrearinus basalis $^{+}$foi definido com base em uma sinapomorfia, a forma da margem lateral anterior do mesoventrito $\left(20_{0}\right.$, Fig. 86$)$, caráter que sofreu várias modificações dentro do clado, como discutidas anteriormente (item 4.1.2 - lista de caracteres).

Há duas resoluções possíveis para a tritomia do clado grupo cinnameus $^{*}$ : a hipótese que prevê grupo cinnameus como táxon basal ao ramo Phanophorus ${ }^{+}+$Pyrearinus (clado 86) é confirmada pela condição sinapomórfica da forma do protórax na fêmea, mais convexo, com lados mais arredondados que o do macho $\left(8_{3}\right)$, sendo o ramo Phanophorus $^{+}+$ Pyrearinus (clado 86) reunido pela forma do prosterno que, em todos as espécies do clado, é curto de lados curvos $\left(16_{1}\right)$. A sinapomorfia $8_{3}$ somada à forma da fronte no macho, subtrapezoidal a trapezoidal alongada de lados retos $\left(3_{5}\right)$, corrobora também a hipótese alternativa que propõe Pyrearinus (clado 86) como táxon basal a grupo cinnameus + Phanophorus $^{+}$, este último, por sua vez, apoiado na sinapomorfia órgão bioluminescente abdominal da fêmea menos desenvolvido que o do machos $\left(31_{1}\right)$. As sinapomorfias que validam a relação filogenética entre Phanophorus e Hypsiophthalmus, nas duas hipóteses alternativas, são a forma do protórax na fêmea muito diferente da do macho $(84)$, hipômeros 
com a metade posterior glabra $\left(13_{3}\right)$, a forma da margem lateral anterior do mesoventrito $\left(20_{4}\right.$, Fig. 78) e comprimento da asa da fêmea, 1/3 a 1/5 mais curta que o élitro $\left(26_{2}\right)$.

O clado Pyrearinus basalis ${ }^{+}$é legitimado pelas sinapomorfias olho pequeno no macho) $\left(0_{0}\right)$ e margem posterior do hipômero com dois espinhos $\left(14_{1}\right)$. Pyrearinus basalis e grupo lampyris são, respectivamente, o primeiro e o segundo táxons mais basais do ramo e ambos, até o presente trabalho, estavam incluídos no gênero "Pyrearinus". Três sinapomorfias sustentam a posição basal do grupo lampyris em relação aos demais táxons do clado: a perda do dente na margem interna das mandíbulas $\left(2_{0}\right)$, os órgãos bioluminescentes do pronoto na forma de manchas triangulares pouco desenvolvidos $\left(10_{2}\right)$, e o esclerito ventral triangular $\left(43_{6}\right)$.

O clado distal ao grupo lampyris tem como gêneros mais basais Coctilelater, Agnostelater, Paraphileus, Euplinthus e Compsoplinthus, todos, compreendidos até o presente momento, como gêneros de "Heligmini". As posições destes táxons dentro de Pyrophorini, entre os descendentes da linhagem ancestral exclusiva de Pyrearinus basalis*, são mantidas pelas seguintes sinapomorfias: a perda do órgão bioluminescente abdominal $\left(29_{0}\right)$ e a região anterior de cada glândula coleterial com um esclerito espinhoso fracamente esclerotizado $\left(56_{2}\right)$ em Coctilelater $^{+}$; a margem ocular com uma faixa preta em quase toda a sua extensão $\left(1_{1}\right)$ e a perda dos órgãos bioluminescentes do pronoto $\left(9_{0}\right)$ em Agnostelater $^{+}$; a presença de um tubérculo na região mediana posterior do pronoto $\left(7_{1}\right)$, a forma da margem lateral anterior do mesoventrito $\left(20_{2}\right.$, Fig. 80,81$)$ e a reversão para o esclerito ventral bem desenvolvido, plano a levemente côncavo $\left(43_{5}\right)$ em Paraphileus ${ }^{+}$; a região posterior ao dente no processo prosternal curta $\left(18_{0}\right)$, as bordas da cavidade mesoventral fortemente inclinadas e salientes $\left(21_{2}\right)$ e as áreas laterais triangulares formadas por microescleritos na parede da vagina $\left(54_{4}\right)$ em Euplinthus ${ }^{+}$e a região anterior de cada glândula coleterial com um esclerito alongado côncavo formado por microescleritos (561) em Compsoplinthus ${ }^{+}$. 
Os táxons do ramo distal $\mathrm{Hifo}^{+}$compartilham cinco sinapomorfias: olho no macho de tamanho mediano $\left(0_{1}\right)$, a reversão para a margem interna das mandíbulas denteada $\left(2_{1}\right)$, a forma da margem lateral anterior do mesoventrito $\left(20_{1}\right.$, Fig. 85$)$, as lamelas laterais fortemente esclerotizadas no primeiro esternito abdominal $\left(28_{2}\right)$, e a aquisição secundária do órgão bioluminescente abdominal (291).

O segundo surgimento paralelo dos órgãos bioluminescentes do pronoto $\left(9_{1}\right)$ e as margens laterais do esclerito ventral do pênis com um par de dobras $\left(45_{1}\right)$ são as evidências que corroboram a monofilia dos demais táxons de Pyrearinus basalis ${ }^{+}$, distais a Hifo, inseridos em uma politomia $\left(\right.$ Opselater $\left.^{*}\right)$, que corresponde a quatro hipóteses filogenéticas igualmente parcimoniosas (Fig. 2) entre os táxons desse ramo, sendo dois clados comuns a todas elas: o par Photophorus + Ignelater, validado pelas sinapomorfias margens laterais do esclerito dorsal do pênis com um abaulamento alongado $\left(38_{2}\right)$ e parede da vagina com áreas triangulares formadas por microescleritos fortemente esclerotizada $\left(55_{2}\right)$, e o clado (grupo atlanticus (D. sirius + Vesperelater)), cujas espécies compartilham um par de carenas no ápice do esclerito dorsal do pênis $\left(41_{1}\right)$.

\subsubsection{Suporte de Bremer}

Os suportes (Bremer, 1994) resultaram relativamente baixos. O mais alto deles foi 3, para Phanophorus + Hypsiophthalmus. Para Hifo $^{+}$e para Meroplinthus ${ }^{+}$apenas dois passos a mais seriam suficientes para serem colapsados no cladograma de consenso das árvores ótimas e subótimas. Todos os demais agrupamentos monofiléticos do grupo interno e o próprio grupo interno tiveram suporte 1, o que significa que esses grupos encontram-se colapsados numa grande politomia na segunda árvore mais parcimoniosa, com 319 passos. 


\subsubsection{Ponderação sucessiva a posteriori}

As cinco análises cladísticas com pesagem sucessiva dos caracteres, variando-se o valor da constante $(\mathrm{k})$ para o cálculo do índice de adaptabilidade, apresentaram os mesmos resultados, uma árvore mais parcimoniosa (Fig. 4) igual a uma das 8 árvores alternativas produzidas na análise inicial dos caracteres com pesos iguais As politomias aparecem completamente resolvidas: no clado 82 a hipótese resultante corresponde à resolução 2 e no clado 77 à resolução 3 (Fig. 2).

\subsubsection{Conclusões sobre as hipóteses de filogenia de Pyrophorini e suas implicações para a taxonomia da tribo.}

Da análise dos caracteres obtidos a partir do conjunto de táxons amostrados é possível concluir que, não só para a definição dos limites de Pyrophorini, mas também para as relações de parentesco entre seus gêneros, é fundamental tentar elucidar as relações entre e dentre os seus grupos mais filogeneticamente relacionados, principalmente de "Heligmini". É importante ressaltar que Arcanelater e Pyrischius de "Heligmini" não foram incluídos na presente análise, porque apenas as fêmeas são conhecidas para esses gêneros e que também para Alampes e Alampoides apenas as espécies-tipo foram incluídas, devido à grande variabilidade entre as espécies desses gêneros à ausência de exemplares para dissecção do metanoto e da genitália masculina. Também, dentro do grupo interno, para os táxons Cryptolampros, Agnostelater, Hifo, grupo atlanticus e Lygelater bifossulatus não foram incluídos os estados para os caracteres das fêmeas, porque essas não são conhecidas, além de vários outros estados não verificados em Hifo, cujos espécimes-tipos não puderam ser dissecados.

Apesar dessas ressalvas e dos baixos suportes para os ramos, acredita-se que a significativa amostragem de táxons do grupo interno no presente estudo, que abrange todos os 
gêneros de "Pyrophorini" (com cerca de 96\% das espécies estudadas) e quase todos os gêneros de Heligmini, além dos caracteres morfológicos inéditos para o grupo (e.g. caracteres do metanoto, do edeago, do mesoventrito) sejam suficientes para justificar, pelo menos, uma nova composição genérica para a tribo Pyrophorini, de acordo com as hipóteses filogenéticas obtidas. Além disso, o resultado da ponderação sucessiva, com a redução do número de cladogramas para uma das hipóteses alternativas iniciais, indica que os dados empregados são cladisticamente consistentes (Kitching et al. 2000; Goloboff, 1993) e mesmo aqueles com muitos eventos homoplásticos são filogeneticamente informativos.

Resumindo, os principais resultados alcançados com a análise filogenética foram:

1) A tribo Pyrophorini (sensu Costa, 1975) não é monofilética, pois inclui os gêneros Meroplinthus, Coctilelater, Agnostelater, Paraphileus, Euplinthus e Compsoplinthus, anteriormente alocados na tribo Heligmini.

2) Heligmini, no momento, fica reduzidida ao gênero Heligmus e aos gêneros não examinados, Arcanelater e Pyrischius. Os gêneros Alampes e Alampoides não estão entre os descendentes do ancestral exclusivo de Heligmus, no entanto seria precipitado propor-lhes uma nova classificação, uma vez que apenas as espécies-tipos desses gêneros foram incluídas na análise.

3) Os gêneros Pyrearinus, Deilelater, Lygelater e Ptesimopsia resultaram merofiléticos. Três grupos de espécies de Pyrearinus são erigidos a gêneros novos. Dois grupos de espécies de Deilelater ficam excluídos deste gênero: para o grupo atlanticus é erigido um novo gênero e $D$. sirius é transferido para Vesperelater. Há várias hipóteses de relacionamento entre Lygelater bifossulatus e outros gêneros, mas não proponho, neste momento, sua exclusão de Lygelater. Ptesimopsia parallela não está entre os descendentes da espécie ancestral exclusiva de Ptesimopsia, no entanto, como nem todas as espécies 
deste gênero foram incluídas na análise, parece ser prematuro excluir esta espécie do gênero.

4) Os gêneros da Oceania formam um grupo monofilético com os demais gêneros da América.

5) A tribo Pyrophorini, resultante da presente análise cladística, passa a ser composta por 159 espécies e 30 gêneros, divididos em duas subtribos. A subtribo Nyctophyxina é corroborada e a subtribo Pyrophorina é alterada para incluir os gêneros anteriormente alocados em Hapsodrilina em em Heligmini.

\subsection{Revisão Taxonômica}

\section{Pyrophorini Candèze, 1863}

Pyrophorites Candèze, 1863:3; Candèze, 1891: 5, 157.

Pyrophorina; Hyslop, 1917: 252; Blackwelder, 1944: 285.

Pyrophorinae; Schenkling, 1927: 345.

Pyrophorini; Champion, 1895: 463; Schwarz, 1906: 5, 209; Costa, 1975:81;

Golbach, 1984: 42; Johnson, 2002: 169.

Redescrição. Macho. Coloração do corpo uniforme (castanho-clara a castanhoescura ou castanho-amarelada a castanho-avermelhada) ou com antenas, pernas, hipômeros e epipleuras parcial ou inteiramente mais claros que o restante do corpo ou bicoloridos (preto e castanho avermelhado, preto e castanho amarelado a alaranjado). Heterogeneamente pontuados, pontuação muito fina (invisível a olho nu) a forte. Pilosidade muito curta (invisível a olho nu) a alongada, decumbente a eriçada, cinza, amarela, dourada, castanha ou preta. Tegumento brilhante ou opaco e micropontuado.

Cabeça levemente declinada, região occipital sem endocarina mediana; com um par de escleritos cervicais bem desenvolvidos, margem posterior junto à borda dos olhos leve 
a fortemente carenada, carena marginal (Fig. 19) ou submarginal (Figs. 20, 21). Fronte (Figs. 9-14) trapezoidal, quadrangular, retangular mais longa que larga ou retangular mais larga que longa, quase plana a côncava, com margem anterior não carenada a fracamente carenada, região frontoclipeal no máximo 0,2 vez mais longa que larga; pontuação muito fina a forte, densa e umbilicada. Antenas (Figs. 22-51) fracamente a fortemente serreadas a partir do terceiro ou do quarto antenômero, com 11 artículos, raramente subpectinadas com 12 artículos (Fulgeochlizus noctivagus); muito curta (atingindo a margem anterior do pronoto) a longa (ultrapassando o ângulo posterior a partir do $8^{\circ}$ antenômero). Olhos (Figs.15-18) pequenos a grandes (índice ocular 0,29-0,90), finamente facetados; margem posterior não emarginada (Fig. 19) ou emarginada (Figs. 20, 21), ou com uma faixa preta lisa estendendo-se por quase toda a volta do olho (Fig. 15). Peças bucais orientadas antero-ventralmente. Labro fortemente esclerotizado, semicircular, fortemente pontuado e piloso. Mandíbulas (Figs. 5, 6) simétricas, cada uma com ápice gradualmente curvo, margem látero-dorsal grosseiramente pontuada, com cerdas longas; margem interna lisa ou unidenteada próximo ao ápice, com prosteca. Maxila (Fig. 8) com gálea e lacínia membranosas, densamente pilosas; cardo e mediestipe com cerdas curtas e finas; basiestipe com cerdas longas e fortes; palpos maxilares 4-segmentados, último segmento securiforme. Lábio (Fig. 7) com pré-mento membranoso, com cerdas curtas; mento com cerdas longas e palpos com 3 segmentos. Nos espécimes com olhos muito grandes (índice ocular $0,70-0,90$ ) a base das maxilas e do lábio geralmente é comprimida lateralmente (Fig. 18).

Protórax (Figs.52-62) subtrapezoidal, quadrangular ou retangular, com lados paralelos ou levemente arredondados a arredondados; carenas laterais completas. Pronoto quase achatado a fortemente convexo; pontuação geralmente heterogênea, muito fina a forte, espaçada a densa, simples ou umbilicada na região discal e relativamente mais densa e umbilicada nas margens laterais. Com ou sem um par de vesículas ou manchas luminescentes na região posterior, de forma, tamanho e posição variáveis. Órgãos luminescentes geralmente 
visíveis nos hipômeros em extensão variável, completamente invisíveis em algumas espécies de Pyrophorus e no Gênero A gen. n.. Região mediana posterior com ou sem um pequeno tubérculo. Ângulos anteriores pequenos a grandes, agudos ou retos; ângulos posteriores bem projetados, delgados a fortes, subparalelos a fortemente divergentes. Prosterno (Figs. 63-67) moderadamente longo a longo de lados quase retos ou curto de lados curvos, levemente convexo, com pontuação heterogênea: fina a forte, espaçada a densa da região anterior ao processo prosternal até a mentoneira, relativamente mais densa nas margens laterais e mais fina e espaçada no prosterno. Comprimento do processo prosternal aproximadamente 2,5 vezes a largura da procoxa, região apical lisa ou denteada; comprimento da região posterior ao dente variável (2-21\% do comprimento total do processo). Sutura notosternal fechada. Hipômeros (Figs. 63, 68-72) inteiramente ou parcialmente pontuados e pilosos; pontuação fina a média, espaçada a densa, geralmente umbilicada, pilosidade mais curta que a do prosterno, margem posterior truncada com ângulo interno pouco a fortemente saliente ou com dois espinhos pequenos; impressões femorais posteriores oblíquas, fortemente sulcadas.

Mesoventrito (Figs. 73-86) com as margens laterais anteriores (Figs. 79-86) sulcadas dividindo-as em duas partes, uma dorsal e uma ventral; parte ventral de forma variável com ângulo externo não proeminente, localizada próxima ou junto à base do mesoventrito, ocultando ou não a parte dorsal em vista ventral (Fig. 85, 86) ou com ângulo externo proeminente localizada próxima ou posteriormente à base e expondo a parte dorsal em extensão variável (Figs. 79-84). Cavidade mesoventral (Fig. 73) profunda, de lados subparalelos na região anterior e convergente entre as mesocoxas, aproximadamente 2,4 vezes mais longa que a largura da mesocoxa; superfície interna com uma fileira de cerdas douradas minúsculas, bordas com a região posterior inclinada no máximo $45^{\circ}$ e não saliente (Figs. 75 , 76) ou gradualmente inclinada $c a \cdot 45-90^{\circ}$ salientes e visíveis lateralmente por trás das procoxas (Figs. 77, 78); poucos gêneros com a metade posterior perpendicular ao eixo do corpo (Fig. 74). Mesepisterno (Figs. 87, 88) com uma cavidade circular levemente carenada 
na região posterior e com ângulo interno geralmente arredondado a agudo pouco proeminente. Sutura meso-metaventral presente (quase indistinta em Compsoplinthus). Cavidades mesocoxais fechadas pelo mesepímero e mesepisterno, levemente transversal, oblíqua; mesotrocantin exposto. Escutelo (Figs. 91, 92) pentagonal a subtriangular abruptamente elevado acima do mesoscutum.

Metaventrito (Fig. 89) heterogeneamente pontuado, pontuação fina a média, espaçada a moderadamente densa, simples ou umbilicada, discrimen moderadamente longo. Metacoxas horizontais, contíguas, estendendo-se lateralmente até o élitro. Placas metacoxais bem desenvolvidas, estreitando-se gradualmente em direção as margens laterais. Metepisterno alongado, aproximadamente 6,7 vezes mais longo que largo. Metendosternito (Fig. 90) com processo anterior longo, tendões anteriores muito próximos; braços laterais curtos; processos látero-ventrais presentes; lâmina ausente. Metanoto (Fig. 94) com região anterior mediana carenada longitudinalmente e separada da região mediana posterior por uma área membranosa transparente (Fig. 94a); região posterior com uma carena longitudinal (Fig. 94b)

Élitros com estrias fraca a fortemente marcadas, interestrias achatadas com pontuação muito fina ou fina, espaçada a moderadamente densa; lados subparalelos até o terço apical ou gradualmente afilados do úmero ao ápice; ápices conjuntamente arredondados ou afilados e levemente divergentes com ou sem pequeno espinho.

Asa posterior (Fig. 93). Célula radial alongada ( $c a$. 5,7 vezes mais longa que larga), com ângulo interno posterior basal reto; RP alongada, quase atingindo a base da asa; $\mathrm{CuA}_{1}$ transversal, localizada entre $\mathrm{MP}_{3+4}$ e $\mathrm{CuA}_{2}$; campo mediano com 5 veias livres; área apical com duas esclerotizações e comprimento aproximadamente igual a 1/7 do comprimento total da asa; célula anal ausente.

Pernas (Figs. 95-100) delgadas e pilosas. Tíbias comprimidas lateralmente, com dois esporões apicais látero-ventrais; margens interna, externa e bordas do ápice com uma 
série de cerdas espiniformes. Tarsômeros simples, vertical ou obliquamente truncados na extremidade distal, face ventral densamente pilosa; apenas dois gêneros (Hifo e Photophorus) com uma pequena almofada esponjosa nos tarsômeros 2-4; tarsômeros 1 e 2 com cerdas espiniformes apicais nas margens externa e interna. Garras tarsais (Fig. 101) simples, com uma ou duas cerdas fortes (quatro em Photophorus) alongadas na superfície da base ventral externa e várias cerdas finas na superfície dorsal; empódio com duas cerdas fortes.

Abdômen gradualmente arredondado a afilado posteriormente, ventritos com pontuação muito fina e espaçada na região mediana, relativamente maior e mais densa nas margens laterais (ventritos I-IV) e posterior (ventrito V). Primeiro esternito abdominal membranoso ou parcialmente esclerotizado (Fig. 102-107), com ou sem um órgão luminescente de forma e tamanho variáveis. Tergito VIII (Fig. 110) uniformemente esclerotizado, sub triangular, com base quase reta e ápice arredondado; margens látero-distais e posterior com cerdas longas. Esternito VIII (Fig. 111) transverso parcialmente membranoso, de lados subparalelos, com base quase reta a sinuosa e ápice emarginado; margens látero-distais com cerdas longas. Esternito IX e tergito IX (Figs. 108, 109, 112) fusionados basalmente; base geralmente uniformemente esclerotizada, alguns gêneros com região mediana basal membranosa e transparente (Figs. 112, 113). Esternito IX parcialmente membranoso, com base quase reta ou sinuosa e ápice arredondado a afilado; região posterior esclerotizada com cerdas curtas a alongadas. Tergito IX com base quase reta e ápice bilobado; margem posterior com cerdas curtas e longas. Tergito X (Fig. 109) com base conata no ápice do tergito IX, membranoso, arredondado.

Genitália masculina. Edeago (Figs. 114-194). Falobase mais larga que longa, localizada ventralmente sobre os parâmeros, geralmente com margem anterior mais esclerotizada. Parâmeros mais curtos que o lobo médio, com ápice afilado ou mais ou menos truncado, com cerdas simples de comprimento variável, com carena látero-dorsal ou com 1 espinho lateral ou 1-2 espinhos látero-dorsais; base mediana dorsal de cada parâmero 
articulada ao esclerito dorsal do pênis por meio de um processo de comprimento variável (em alguns gêneros a área de articulação é membranosa, transparente), bases medianas ventrais livres ou fusionadas ao esclerito ventral do pênis; processo da articulação dorsal inteiro ou com um recorte curto a alongado. Pênis geralmente bem desenvolvido, muito delgado a largo, formado por dois escleritos, um dorsal e outro ventral. Esclerito dorsal do pênis com prolongamentos basais $0,2-1,1$ vez o comprimento da região posterior, liso ou com escamas minúsculas a alongadas, com margens laterais posteriores aos prolongamentos basais reta a levemente curva, abaulada ou com tubérculos proeminentes, gradualmente afilado para o ápice ou com ápice abruptamente afilado, algumas espécies com ápice trilobado. Esclerito ventral do pênis liso, com um par de pregas laterais ou com uma carena longitudinal mediana, forma variável, geralmente bem desenvolvido com no mínimo $1 / 3$ da largura do terço apical do esclerito dorsal, alguns gêneros com esclerito ventral mais largo que o dorsal na sua maior largura e outros com esclerito ventral muito mais estreito que o dorsal; superfície lisa, sem escamas, ou com minúsculas escamas, dirigidas posteriormente (Fig. 127) ou anteriormente (Fig. 137).

Fêmea: Geralmente maior, igual aos machos no aspecto geral ou diferente, com variáveis tipos de dimorfismo sexual. O dimorfismo pode estar relacionado predominantemente ao comprimento das antenas, sendo este menor nas fêmeas, neste caso geralmente com nenhuma ou pequena diferença na forma do pronoto, pouco mais convexo e arredondado que o do macho; em algumas espécies as fêmeas possuem antenas sutilmente menos serreadas. Em muitos gêneros o dimorfismo sexual relacionado às formas do pronoto e dos élitros é mais acentuado, sendo esses mais convexos e arredondados nas fêmeas. O tamanho dos olhos das fêmeas pode ser pouco menor ou muito menor que o do macho. As asas femininas podem ser mais curtas que a dos élitros, enquanto que nos machos são sempre quase do mesmo comprimento que o dos élitros. Em algumas espécies os órgãos luminescentes do pronoto são maiores nas fêmeas e em alguns gêneros os órgãos abdominais 
das fêmeas são muito menos desenvolvidos que os do macho. Fêmeas pertencentes a diferentes gêneros podem apresentar apenas um ou uma combinação variável desses tipos de dimorfismos.

Segmento VIII. Membrana interconectiva do segmento VIII (Figs. 200, 204, 218) com ou sem um par de escleritos laterais ovais ou de formato irregular. Tergito VIII (Fig. 219) subtriangular a semicircular, uniformemente esclerotizado; margens laterais e posterior com cerdas longas. Esternito VIII (Fig. 204, 218) com espículo moderadamente alongado (1,1-2,7 vezes o comprimento do esternito); ápice arredondado, ângulos látero-anteriores projetados anteriormente; margens látero-distais e posterior com cerdas longas. Ovipositor (Figs. 195-203, 206-209, 211, 213, 215, 216, 220, 221) sem styli; coxitos parcialmente membranosos com ápices arredondados ou afilados (mais esclerotizados em Noxlumes); parte membranosa interna revestida por pilosidade fina, curta e densa, região esclerotizada com cerdas um pouco mais alongadas, mais fortes e espaçadas; vulva com metade anterior completamente esclerotizada, metade posterior membranosa; baculi com comprimento $0,8-2,5$ vezes o comprimento dos coxitos, fortemente esclerotizados.

Trato genital feminino (Figs. 196, 197, 198, 200, 202, 206, 208, 211, 213, 215, 216, 220, 221). Região anterior da vagina estreita a alargada, geralmente com um par de glândulas coleteriais saculiformes membranosas laterais, localizadas anteriormente ao oviduto comum, geralmente bem desenvolvidas, quase tão longa quanto larga a mais larga que longa; em alguns gêneros são muito curtas ou indistintas. Região posterior de cada glândula coleterial membranosa, com áreas alongadas microesclerotizadas ou com escleritos pequenos (Fig. 212b); região anterior membranosa ou com escleritos pequenos (Figs. 205, 210, 212a, 214, 217). Bursa copulatrix aparentemente não dividida em duas regiões, espiralada, com duas ou três espirais e uma série de espinhos alongados, com apenas uma espiral ou saculiforme pequena, com espinhos reduzidos ou ausentes. Duas espermatecas 
moderadamente alongadas com ápice espiralado (duas a cinco espirais quase do mesmo diâmetro), não espiraladas ou em forma de divertículos com ápice capitado.

Dimensões. Comprimento total 7,4-41,0 mm. Comprimento do élitro 2,4-4,5 vezes o comprimento do protórax. Largura do úmero 0,9-1,2 vezes a largura do protórax.

Distribuição. Do sul dos Estados Unidos (Arizona, Texas, Flórida e Alabama) à Argentina (Patagônia), Antilhas e Oceania (Tonga, Fidji, Vanuatu)

Comentários. Os gêneros com um par de órgãos luminescentes na região posterior do pronoto podem ser prontamente associados à Pyrophorini, mas outros elaterídeos também possuem órgãos luminescentes. Dentro de Elateridae a bioluminescência sobre o protórax surgiu pelo menos quatro vezes paralelamente, em Throscinae, em Campyloxeninae e duas vezes dentro de Pyrophorini (sensu novo). Órgãos luminescentes em forma de vesículas no protórax também ocorrem em Balgus schnusei (Throscidae), mas essa espécie possui um aspecto muito peculiar, que a difere dos demais vaga-lumes elaterídeos (corpo inteiramente recoberto por tubérculos, antenas muito curtas e subpectinadas). Campyloxenus pyrothorax (Campyloxeninae) também possui um par de órgãos luminescentes no protórax, mas esses são em forma de duas manchas medianas difusas, ocupando quase inteiramente o pronoto. Seu facies é mais similar a dos piroforíneos, mas, assim como Balgus schnusei, esta espécie não possui as cerdas na face externa das garras tarsais, presentes nos vaga-lumes elaterídeos. Certas espécies de Conoderini podem ser confundidas tanto com os vaga-lumes Pyrophorini, pela presença de uma mancha amarelada junto aos ângulos posteriores, quanto com as espécies sem órgãos bioluminescentes (anteriormente em Heligmini). Ainda assim, é possível separar facilmente as espécies de Pyrophorini daquelas de Conoderini, pois esses últimos possuem fronte geralmente mais convexa com carena mais marcada. As espécies de Conoderini examinadas no presente trabalho apresentam mesepisterno com uma cavidade circular pequena, não carenada posteriormente (carenada nos piroforíneos) e com ângulo interno agudo mais proeminente. Também foi observado que as bordas da cavidade 
mesoventral dos Conoderini são paralelas em toda a sua extensão, enquanto que nos gêneros de Pyrophorini elas geralmente convergem gradualmente entre as mesocoxas. Anaissus pode ser separado dos demais gêneros de Pyrophorini pela sutura notosternal sulcada, pela ausência da cavidade circular no mesepímero e pelas almofadas esponjosas grandes nos tarsômeros 14. 


\section{Lista de gêneros}

Subtribo Nyctophyxina Costa, 1975

Cryptolampros Costa, 1975

Noxlumenes Costa, 1975

Nyctophyxis Costa, 1975

Subtribo Pyrophorina Candèze, 1863

Agnostelater Costa, 1975

Coctilelater Costa, 1975

Compsoplinthus Costa, 1975

Deilelater Costa, 1975

Euplinthus Costa, 1975

Fulgeochlizus Costa, 1975

Hapsodrilus Costa, 1975

Hifo Candèze, 1881

Hypsiophthalmus Latreille, 1834

Ignelater Costa, 1975

Lygelater Costa, 1975

Meroplinthus Candèze, 1891

Opselater Costa, 1975

Paraphileus Candèze, 1891
Phanophorus Solier, 1851

Photophorus Candèze, 1863

Ptesimopsia Costa, 1975

Pyrearinus Costa, 1975

Pyrophorus Billberg, 1820

Pyroptesis Costa, 1975

Sooporanga Costa, 1975

Vesperaleter Costa, 1975

Gênero $A$ gen. n.

Gênero B gen. n.

Gênero $C$ gen. $\mathbf{n}$.

Gênero D gen. n.

Gênero E gen. n. 


\section{Noxlumenes Costa, 1975}

(Figs. 22, 52, 79, 114, 115, 222)

Pyrophorus Billberg, 1820: 20 (pars).

Noxlumenes Costa, 1975: 86, 87; Golbach, 1994: 28, 43.

Espécie- tipo: Noxlumenes bardus Costa, 1975: 87 (localidade-tipo: Argentina).

Redescrição. Macho (Fig. 222). Coloração geral do corpo uniformemente castanho-avermelhada. Pilosidade castanha, semidecumbente, espaçada e muito curta. Tegumento brilhante, não micropontuado.

Fronte retangular (1,3 vezes mais larga que longa) cônvaca, com margem anterior carenada; pontuação forte, densa e umbilicada. Antenas (Fig. 22) serreadas a partir do quarto antenômero, ultrapassando o ângulo posterior a partir do $8^{\circ}$ ou do $9^{\circ}$ antenômero; $3^{\circ}$ antenômero subigual ao $2^{\circ}, 4^{\circ}$ antenômero $c a$. 1,7 vezes o comprimento do $3^{\circ}$. Olhos de tamanho médio (índice ocular 0,45), margem ocular levemente emarginada na região posterior. Mandíbula denteada.

Protórax (Fig. 52) subtrapezoidal, com lados levemente arredondados convergentes anteriormente. Pronoto levemente convexo, com pontuação homogênea, forte, densa e umbilicada, com um par de órgãos luminescentes em forma de manchas grandes, circulares e localizadas quase eqüidistantes à linha mediana e à margem lateral, visíveis do hipômero. Região mediana posterior sem tubérculo. Ângulos anteriores agudos, pequenos; ângulos posteriores delgados, com margem externa curva, fortemente divergentes e carenados. Prosterno moderadamente alongado de lados quase retos, com pontuação forte, densa e umbilicada. Processo prosternal com região apical denteada, dente saliente, região posterior ao dente longa (ca. $23 \%$ do comprimento total do processo). Hipômeros inteiramente pilosos, com pontuação média, densa e umbilicada; margem posterior truncada, sem espinhos. 
Mesoventrito. Margem lateral anterior (Fig. 79) com ângulo externo proeminente, parte ventral quase reta, localizada posteriormente à base, parte dorsal visível. Cavidade mesoventral com bordas posteriores levemente inclinadas em relação à região anterior. Metaventrito com pontuação fina, densa, simples e umbilicada. Élitros com estrias marcadas, interestrias achatadas com pontuação fina, densa; lados gradualmente afilados até os ápices; ápices conjuntamente arredondados. Abdômen gradualmente afilado posteriormente, ventritos com pontuação fina, simples. Primeiro esternito abdominal membranoso sem órgão luminescente.

Edeago (Figs. 114, 115). Parâmeros delgados a partir do terço anterior, com ápices afilados com cerdas longas; articulação dorsal com um processo levemente emarginado; bases medianas ventrais livres. Esclerito dorsal do pênis com prolongamentos basais 0,2 vez o comprimento da região posterior, liso, gradualmente afilado para o ápice. Esclerito ventral do pênis plano com aproximadamente $1 / 3$ da largura do esclerito dorsal, base bilobada.

Fêmea: Com antenas mais curtas, olhos levemente menores; protórax e élitros fortemente mais convexos e arredondados. Asas aproximadamente 1/8 mais curtas que os élitros.

Membrana interconectiva do segmento VIII sem escleritos laterais. Genitália Feminina. Coxitos moderadamente esclerotizados, com ápices afilados, achatados dorsoventralmente. Baculi 2,3 vezes mais longo que os coxitos. Trato genital. Vagina membranosa, sem escleritos. Bursa copulatrix saculiforme pequena, sem espinhos. Espermatecas com ápice espiralado.

Dimensões. Comprimento total $\widehat{\partial} 17,7-23,0 \mathrm{~mm}$, $q 22,2 \mathrm{~mm}$. Comprimento dos élitros em relação ao do protórax: $\overbrace{}^{\Uparrow} 3,1-3,7$; † 2,8. Largura do úmero em relação à do protórax: $\curvearrowright 1,2 ; \uparrow 0,9$

Espécies. Noxlumenes bardus Costa, 1975. 
Distribuição. Argentina.

Material examinado. ARGENTINA. Neuquén: Las Hajas, 16.i.1967, S. Martin \& Monné col., $\widehat{O}$ (Holótipo) (MZSP); Zapala, 23.iii.1964, A. Mesa \& R. Sanduleki col., 2 đ (Parátipos) (MZSP); idem, 1 đ̊ (Parátipo) (MZSP). Chubut: Patagônia, 27.xi.1989, G. Hangay col., 1m, 1 f(MUSA).

Comentários. Apenas uma fêmea desse gênero estava disponível para estudo. $\mathrm{O}$ trato reprodutivo estava em mau estado e não foi possível concluir se as glândulas coleteriais não existiam ou se haviam sido perdidas durante o processo de dissecção. Noxlumenes é similar à Nyctophyxis na formà do protórax e dos élitros e no dimorfismo sexual das fêmeas, mas difere por suas antenas mais longas, olhos maiores, pela coloração do corpo, que em Nyctophyxis é castanho-escura ou preta, e pela pilosidade curta.

\section{Nyctophyxis Costa, 1975}

(Figs. 23, 116, 117, 195, 196, 223)

Pyrophorus Billberg, 1820: 20 (pars).

Nyctophyxis Costa, 1975: 86; Golbach, 1994: 28, 43.

Espécie- tipo: Pyrophorus ocellatus Germar, 1841 (localidade-tipo: Chile).

Redescrição. Macho (Fig. 223). Coloração geral do corpo uniformemente castanho-escura (alguns espécimes com ângulo posterior amarelado ou avermelhado). Pilosidade preta, castanho-escura ou acizentada, longa e eriçada, mais curta nos élitros e no abdômen. Tegumento brilhante, não micropontuado.

Fronte retangular (aprox. 1,5 vezes mais larga que longa) quase plana a levemente cônvaca, com margem anterior fracamente carenada; pontuação forte, densa e umbilicada. Antenas (Fig. 23) serreadas a partir do quarto antenômero, ultrapassando o ângulo posterior a partir do $10^{\circ}$ ou $11^{\circ}$ antenômero; $3^{\circ} \mathrm{ca}$. 1,5 vezes mais longo que o $2^{\circ}, 4^{\circ}$ antenômero $c a$. 1,4 vezes o comprimento do $3^{\circ}$. Olhos pequenos (índice ocular 0,30-0,35), margem ocular com uma faixa preta em quase toda a sua extensão. Mandíbula denteada. 
Protórax subtrapezoidal, com lados levemente arredondados, convergentes anteriormente. Pronoto levemente convexo com a linha longitudinal mediana geralmente saliente; pontuação homogênea, forte, densa e umbilicada, com um par de órgãos luminescentes em forma de manchas pequenas a grandes, circulares e localizadas quase eqüidistantes à linha mediana e à margem lateral, visíveis do hipômero. Região mediana posterior sem tubérculo. Ângulos anteriores agudos, pequenos; ângulos posteriores delgados, com margem externa curva, fortemente divergentes e carenados. Prosterno moderadamente alongado de lados quase retos, com pontuação forte, densa e umbilicada. Processo prosternal com região apical denteada, dente fraca a fortemente saliente, região posterior ao dente longa (ca. $20 \%$ do comprimento total do processo). Hipômeros inteiramente pilosos, com pontuação média, densa e umbilicada; margem posterior truncada, sem espinhos.

Mesoventrito. Margem lateral anterior com ângulo externo proeminente, parte ventral quase reta, localizada posteriormente à base, parte dorsal visível. Cavidade mesoventral com bordas posteriores levemente inclinadas em relação à região anterior. Metaventrito com pontuação fina, densa e umbilicada. Élitros com estrias marcadas, interestrias achatadas com pontuação fina, densa; lados subparalelos até o terço apical ou gradulamente arredondados; ápices conjuntamente arredondados. Abdômen gradualmente afilado posteriormente, ventritos com pontuação fina, simples. Primeiro esternito abdominal membranoso sem órgão luminescente.

Edeago (Figs. 116, 117). Parâmeros com ápice truncado com carena láterodorsal; articulação dorsal com uma área membranosa transparente; bases medianas ventrais livres. Esclerito dorsal do pênis com prolongamentos basais $0,4-0,6$ vez o comprimento da região posterior, afilado para o ápice. Esclerito ventral do pênis com aproximadamente 1/3 da largura do terço posterior do esclerito dorsal, com linha longitudinal mediana saliente, ou seja, em forma de "V" invertido em corte transversal. 
Fêmea: Maior, com antenas mais curtas, olhos levemente menores; protórax e élitros fortemente mais convexos e arredondados. Asas aproximadamente 1/8 mais curtas que os élitros.

Membrana interconectiva do segmento VIII sem escleritos laterais Genitália Feminina (Figs. 195, 196). Baculi ca. 2,5 vezes mais longo que os coxitos. Trato genital. Vagina com um par de glândulas coleteriais quase tão longa quanto larga. Região posterior de cada glândula coleterial membranosa, região anterior com um esclerito espinhoso fracamente esclerotizado. Bursa copulatrix com uma espiral, com poucos espinhos curtos. Espermatecas com ápice espiralado.

Dimensões. Comprimento total $\widehat{\jmath} 14,0-21,7 \mathrm{~mm}$, $q$ 21-22,5 mm. Comprimento dos élitros em relação ao do protórax: $\widehat{\jmath}$ 1,6-2,6; $\uparrow$ 2,0-2,5. Largura do úmero em relação à do protórax: ㅅ 1,0-1,2; 우 0,9-1,0.

Espécies. Nyctophyxis ocellatus (Germar, 1841); N. leporinus (Candèze, 1863).

Distribuição. Chile e Argentina. (Costa, 1977).

Material examinado. $N$. ocellatus. CHILE. Sem localidade, sem data, sem coletor, $9 \hat{\sigma}$

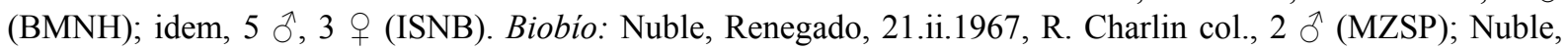
Cobquecura, 12-14.ii.1959, L. E. Pena col., 2 §ิ (MZSP); Recinto, ii.1953, L. E. Pena col., 1 क (MZSP); idem,

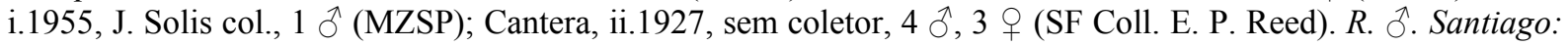
Baños Colina, Los Valdes, 04-07.vi.1947, L. E. Pena col., 1 ㅇ (MZSP); Santiago, sem data, sem coletor, 1 ઈ (ISNB); El Peumo, Rio Maipo, xi.1951, sem coletor, 1 ô (MZSP). Coquimbo: Nague, Los Vilos, 27.ii.1963, L.

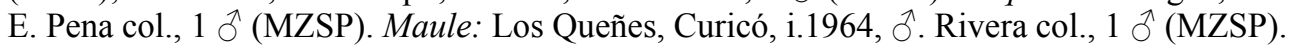

Comentários. Espécimes de $N$. leporinus não foram examinados. Segundo Costa (1977) esta espécie é muito similar a $N$. ocellatus, diferindo apenas por sua pilosidade acizentada. Os espécimes de Nyctophyxis são semelhantes àqueles de Noxlumenes, dos quais podem ser prontamente separados pela sua coloração, preta ou castanha escura, e por sua pilosidade longa e eriçada. 


\section{Cryptolampros Costa, 1975}

(Figs. 9, 15, 24, 118, 119, 224)

Pyrophorus Billberg, 1820: 20 (pars).

Cryptolampros Costa, 1975: 86, 88; Golbach, 1994: 28.

Espécie- tipo: Pyrophorus coecus, Germar, 1841 (localidade-tipo: Brasil, RS)

Redescrição. Macho (Fig. 224). Coloração do corpo uniformemente preta com élitros castanho-claros ou inteiramente castanho-clara amarelada. Pilosidade acinzentada ou amarelada, densa, decumbente, curta, mais curta nos élitros. Tegumento do pronoto opaco, micropontuado, élitros relativamente mais brilhantes.

Fronte (Fig. 9) retangular (aprox. 1,4 vezes mais larga que longa) quase plana a levemente cônvaca, com margem anterior fracamente carenada; pontuação média, densa e umbilicada. Antenas (Fig. 24) serreadas a partir do quarto antenômero, atingindo o ângulo posterior no $11^{\circ}$ antenômero; $3^{\circ}$ antenômero $c a$. 1,5 vezes mais longo que o $2^{\circ}, 4^{\circ}$ antenômero 1,4-1,5 vezes o comprimento do $3^{\circ}$. Olhos (Fig. 9, 15) pequenos (índice ocular 0,30-0,35), margem ocular com uma faixa preta em quase toda a sua extensão. Mandíbula denteada.

Protórax subquadrado (1,0-1,1 vez mais longo que largo), de lados subparalelos. Pronoto levemente convexo; pontuação heterogênea, média, densa e umbilicada na região discal, menor mas margens, sem órgãos luminescentes ou com um par de órgãos luminescentes em forma de manchas pequenas, circulares e localizadas quase eqüidistantes à linha mediana e à margem lateral, visíveis do hipômero. Região mediana posterior sem tubérculo. Ângulos anteriores agudos, pequenos; ângulos posteriores delgados ou fortes, divergentes e carenados. Prosterno moderadamente alongado de lados quase retos, com pontuação forte, densa e umbilicada. Processo prosternal com região apical denteada, dente saliente, região posterior ao dente longa (ca. $22 \%$ do comprimento total do processo). 
Hipômeros inteiramente pilosos, com pontuação média, densa e umbilicada; margem posterior truncada, sem espinhos.

Mesoventrito. Margem lateral anterior com ângulo externo proeminente, parte ventral quase reta ou sinuosa, localizada posteriormente à base, parte dorsal visível. Cavidade mesoventral com bordas posteriores levemente inclinadas em relação à região anterior. Metaventrito com pontuação fina, densa e umbilicada. Élitros com estrias fracamente marcadas, interestrias achatadas com pontuação fina, muito densa; lados gradualmente afilados até os ápices; ápices conjuntamente arredondados ou levemente divergentes. Abdômen gradualmente afilado posteriormente, ventritos com pontuação fina, simples. Primeiro esternito abdominal membranoso sem órgão luminescente.

Edeago (Figs. 118, 119). Parâmeros com ápice truncado com carena láterodorsal; articulação dorsal com uma área membranosa transparente; bases medianas ventrais livres. Esclerito dorsal do pênis com prolongamentos basais 0,4 vez o comprimento da região posterior, liso, afilado para o ápice. Esclerito ventral do pênis com aproximadamente 1/3 da largura do esclerito dorsal, com linha longitudinal mediana saliente, ou seja, em forma de "V" invertido em corte transversal.

Fêmea: desconhecida.

Dimensões. Comprimento total 12,7-21,0 $\mathrm{mm}$. Comprimento dos élitros em relação ao do protórax: 2,8-2,9. Largura do úmero em relação à do protórax: 1,1-1,2

Espécie. Cryptolampros coecus (Germar, 1841).

Distribuição. Colômbia, Guiana Francesa, Brasil (SP, PR, RS), Paraguai. (Costa, 1975b).

Material examinado. C. coecus. BRASIL. Sem localidade, sem data, sem coletor, $1 \hat{\delta}$ (DEIC). Paraná: Ponta Grossa, iii.1939, Camargo col., 1 đ (MZSP). Rio Grande do Sul: Pelotas, 24.xi.1953, Jezanki col., 2 ô (AMNH). PARAGUAI. Eng. Bley, 08.ii.1940, R. B. Lange col., 4 ô (MZSP); sem localidade, sem data, sem coletor, 2 ô (BMNH). 
Comentários. Cryptolampros coecus assemelha-se às espécies de Nyctophyxis pela forma do esclerito ventral do edeago, pelos olhos pequenos com uma faixa preta em quase toda a sua borda e pela forma da área de articulação do esclerito dorsal com os parâmeros. Todas essas similaridades foram confirmadas como homólogas entre esses gêneros após a análise cladística e são sinapomorfias que sustentam a relação de gruposirmãos entre eles. Na aparência externa, no entanto, Cryptolampros é mais similar à Opselater hebes (grupo melanurus), do qual pode ser separado pela pontuação do pronoto, menor, mais densa e mais umbilicada, pela pilosidade mais curta e mais densa e pela posição dos órgãos luminescentes do pronoto, que em $O$. hebes são laterais.

\section{Gênero A gen. n.}

(Figs. 25, 68, 120, 121, 197, 225)

Espécie- tipo: Gênero $A$ sp. 1 sp. $\boldsymbol{n}$.

Redescrição. Macho (Fig. 225). Coloração geral do corpo castanha-avermelhada com terço mediano longitudinal do pronoto mais escuro. Pilosidade amarelada, decumbente, curta, mais curta nos élitros. Tegumento brilhante, não micropontuado.

Fronte retangular (aprox. 1,2 vezes mais larga que longa) cônvaca, com região dorsal às inserções antenais carenadas e salientes; margem anterior entre as inserções antenais não carenada; pontuação fina, densa e umbilicada. Antenas (Fig. 25) serreadas a partir do quarto antenômero, atingindo o ângulo posterior no $11^{\circ}$ antenômero; $3^{\circ} \mathrm{ca}$. 1,4 vezes mais longo que o $2^{\circ}, 4^{\circ}$ antenômero 1,9 vezes o comprimento do $3^{\circ}$. Olhos de tamanho médio (índice ocular 0,47), margem ocular levemente emarginada posteriormente. Mandíbula denteada.

Protórax retangular (aprox. 1,2 vezes mais largo que longo), de lados subparalelos. Pronoto levemente convexo, com a linha longitudinal mediana levemente 
sulcada; pontuação heterogênea, média, moderadamente densa e umbilicada no terço longitudinal mediano, fina, densa e umbilicada nas laterais; com um par de órgãos luminescentes em forma de vesículas pequenas, subovais a circulares, fortemente convexas, dirigidas para fora e localizadas quase eqüidistantes à linha mediana e à margem lateral, não visíveis do hipômero. Região mediana posterior sem tubérculo. Ângulos anteriores agudos, grandes; ângulos posteriores delgados e divergentes, carenados. Prosterno moderadamente alongado de lados quase retos, com pontuação forte, espaçada ou densa e umbilicada. Processo prosternal com região apical denteada, dente saliente, região posterior ao dente longa (ca. 24-25,5\% do comprimento total do processo). Hipômeros (Fig. 68) inteiramente pilosos, com pontuação fina, densa e umbilicada; margem posterior truncada, sem espinhos.

Mesoventrito. Margem lateral anterior com ângulo externo proeminente, parte ventral sinuosa, próxima da base, parte dorsal não visível ou parcialmente visível. Cavidade mesoventral com bordas posteriores pouco inclinadas em relação à região anterior. Metaventrito com pontuação fina, densa e umbilicada. Élitros com estrias fracamente marcadas, interestrias achatadas com pontuação fina, densa; lados gradualmente afilados até os ápices; ápices fracamente divergentes. Abdômen gradualmente afilado posteriormente, ventritos com pontuação fina, simples e umbilicada. Primeiro esternito abdominal fracamente esclerotizado, com órgão luminescente subtrapezoidal ocupando aprox. 1/3 da largura do esternito I.

Edeago (Figs. 120, 121). Parâmeros com ápice truncado com carena láterodorsal; articulação dorsal com um processo inteiro; bases medianas ventrais livres. Esclerito dorsal do pênis com prolongamentos basais 0,6 vez o comprimento da região posterior, liso, afilado para o ápice. Esclerito ventral do pênis com aproximadamente $1 / 2$ da largura do esclerito dorsal, plano, com uma carena dorsal pouco saliente,

Fêmea. Iguais aos machos, exceto pelo comprimento das antenas, mais curtas. 
Membrana interconectiva do segmento VIII sem escleritos laterais. Genitália Feminina (Fig. 197). Baculi com comprimento subigual ao dos coxitos. Trato genital. Vagina com um par de glândulas coleteriais mais longa que larga. Região posterior de cada glândula coleterial membranosa, região anterior com um esclerito espinhoso alongado, fortemente esclerotizado. Bursa copulatrix com 2-3 espirais, com muitos espinhos alongados. Espermatecas com ápice espiralado.

Dimensões. Comprimento total $\widehat{\overbrace{}} 22,0 \mathrm{~mm}, q 23,0-35,0 \mathrm{~mm}$. Comprimento dos élitros em relação ao do protórax: $\widehat{\jmath} 3,1$; + 3,0-3,3. Largura do úmero em relação à do protórax: $\widehat{\jmath}$ e $q 1,1$.

Espécies. Gênero $A$ sp. 1 sp. n.

Distribuição. Trinidad \& Tobago, Venezuela.

Material examinado. TRINIDAD \& TOBAGO. Caparo, sem data, A. Heyne, Berlin-Wllm, 2 đ̊, 1 † (MNHN); St. Ann's, 28.vi.1957, M. Nieves col., 1 ㅇ (AMNH). VENEZUELA. Falcón: Morrocoy, 31.iii.1958, T. F. A. col., 1 ex. (MLS). Monagas: Jasepin, 05.vi.1967, sem coletor, 1 \& (MIZA). Bolivar: S. Nuria, 3 Chorros, 26.v.1975, B. Bechyne col., 1 ô, (MIZA).

Comentários. Este gênero é um pouco similar a algumas espécies de Pyrophorus que possuem o corpo um pouco menos convexo e a região mediana do pronoto mais escura, mas Gênero A sp. 1 é muito mais achatado dorso-ventralmente. A forma e a posição de seus órgãos luminescentes do pronoto o distinguem de qualquer outro Pyrophorini.

\section{Pyrophorus Billberg, 1820}

(Figs. 10, 26, 53, 103, 122-127, 226)

Elater Linnaeus, 1758: 404 (pars).

Pyrophorus Billberg, 1820:20 (pars); Eschoschltz, 1829: 32; Castelnau, 1840:

235; Germar, 1841: 1; Candéze, 1863: 3; Champion, 1895: 463; Schenkling, 1927: 345; Blackwelder, 1944: 285; Navajas, 1952:52-56; Costa 1975b: 95, 110; Golbach, 1994:29. 
Espécie- tipo: Elater noctilucus Linnaeus, 1758 (designado por Hyslop, 1921: 668) (Localidade-tipo: “América”)

Redescrição. Macho (Fig. 226). Coloração do corpo geralmente uniformemente castanho-escura ou castanho-avermelhada ou com terço mediano longitudinal do pronoto mais escuro, ou com élitros pouco mais claros. Pilosidade amarelada, decumbente, curta, muito densa, às vezes conferindo um tom esverdeado ao tegumento, geralmente mais longa na face ventral do pterotórax. Tegumento brilhante ou opaco, micropontuado.

Fronte (Fig. 10) retangular (1,20-1,30 vezes mais longa que larga), quase plana a levemente côncava, carenada ou fracamente carenada; pontuação fina a média, densa e umbilicada. Antenas (Fig. 26) serreadas a partir do quarto antenômero, curtas, geralmente atingindo a metade do comprimento do protórax ou pouco mais da metade; $3^{\circ}$ antenômero $c a$. 1,2-1,5 vezes mais longo que o $2^{\circ}, 4^{\circ}$ antenômero $1,0-1,3$ vezes o comprimento do $3^{\circ}$. Olhos de tamanho médio (índice ocular 0,50-60), margem ocular junto à margem da cabeça sem faixa preta e não emarginada. Mandíbula denteada.

Protórax (Fig. 53) retangular (aprox. 1,2 vezes mais largo que longo), de lados subparalelos. Pronoto convexo; pontuação heterogênea, média a forte, densa a muito densa e simples ou umbilicada na região discal, menor, mais densa e umbilicada nas margens laterais e posterior, com um par de órgãos luminescentes em forma de vesículas grandes, subovais a circulares, fortemente convexas, localizadas próximas da margem lateral e afastadas da margem posterior (em algumas espécies dirigidas para fora), visíveis ou não do hipômero. Região mediana posterior sem tubérculo ou com pequeno tubérculo. Ângulos anteriores agudos, grandes; ângulos posteriores delgados ou fortes, geralmente divergentes, fortemente carenados. Prosterno moderadamente alongado de lados quase retos, com pontuação forte, espaçada ou densa e simples e umbilicada. Processo prosternal com região apical denteada, dente saliente, região posterior ao dente com comprimento médio a longo (7,5-19\% do 
comprimento total do processo). Hipômeros inteiramente pilosos, com pontuação fina, densa e umbilicada; margem posterior truncada, sem espinhos.

Mesoventrito. Margem lateral anterior (Fig. 80) com ângulo externo proeminente, parte ventral sinuosa, próxima da base, parte dorsal parcialmente visível. Cavidade mesoventral com bordas posteriores inclinadas no máximo 45 graus em relação à região anterior, não saliente. Metaventrito com pontuação fina, densa e umbilicada. Élitros com estrias fracamente marcadas, interestrias achatadas com pontuação fina, muito densa; lados gradualmente afilados até os ápices; ápices conjuntamente arredondados ou levemente divergentes, geralmente com pequeno espinho sutural. Abdômen gradualmente afilado posteriormente, ventritos com pontuação fina, simples e umbilicada. Primeiro esternito abdominal com lamelas laterais fortemente esclerotizadas, com órgão luminescente subtrapezoidal ou retangular ocupando 1/3 a completamente o esternito I (Fig.103).

Edeago (Figs.122-127). Parâmeros com ápice truncado ou arredondado com carena látero-dorsal; processo da articulação dorsal com um recorte curto; bases medianas ventrais livres. Esclerito dorsal do pênis com prolongamentos basais 0,4-0,5 vez o comprimento da região posterior, de lados arredondados ou retos, gradualmente afilados para o ápice, com minúsculas escamas dorsais nas regiões laterais subapicais em extensão variável ou recobrindo completamente a região apical. Esclerito ventral do pênis com aproximadamente $1 / 3$ da largura do esclerito dorsal, com minúsculas escamas dirigidas posteriormente (Fig. 127), cobrindo parcialmente o ápice em extensão variável ou completamente recoberto por escamas; base de forma variável, geralmente bilobada; gradualmente afilado para o ápice ou com terço apical abruptamente afilado; linha mediana com uma carena ventral fortemente saliente (Fig. 124).

Fêmea. Iguais aos machos.

Membrana interconectiva do segmento VIII sem escleritos laterais. Genitália feminina. Baculi 1,1-1,3 vezes mais longo que os coxitos. Trato genital. Vagina com um 
par de glândulas coleteriais tão longa quanto larga ou mais longa que larga. Regiões posterior e anterior de cada glândula coleterial membranosas. Bursa copulatrix com 2-3 espirais, com muitos espinhos alongados. Espermatecas com ápice espiralado.

Dimensões. Comprimento total 19,0-38,0 mm. Comprimento dos élitros em relação ao do protórax: 2,6-3,8. Largura do úmero em relação à do protórax: 1,0-1,2.

Espécies. $P$. angustus Blanchard, 1843; P. avunculus Costa, 1972; P. clarus Germar, 1841; P. divergens Eschscholtz, 1829; P. dulcifer Costa, 1972; P. evexus Costa, 1972; P. expeditus Costa, 1972; P. hayekae Costa, 1968; P. indisdinctus Germar, 1841; P. indulcatus Costa, 1972; P. ingens Costa, 1972; P. jocundus Costa, 1972; P. luscus Candèze, 1889; P. magnus Costa, 1972; P. mellifluus Costa, 1972; P. mellitus Costa, 1972; P. noctilucus (Linnaeus, 1758); P. pisticus Costa, 1972; P. plagiophthalmus Germar, 1841; P. phosphorescens Castelnau, 1840; P. punctatissimus Blanchard, 1843; P. strabus Germar, 1841; P. stupendus Costa, 1972; P. tuberculifer Eschscholtz, 1829; P. validus Costa, 1972; P. veriloquus Costa, 1972.

Distribuição. México, Guatemala, Belize, Honduras, Nicarágua, Costa Rica, Panamá, Cuba, Jamaica, Haiti, República Dominicana, Guadaloupe, Dominica, Martinica, Santa Lúcia, St. Vincent, Trinidad \& Tobago, Colômbia, Venezuela, Guiana, Suriname, Guiana Francesa, Equador, Peru, Brasil (AP, AM, PA, AC, RO, CE, AL, BA, MT, MS, GO, MG, ES, RJ, SP, PR, SC, RS), Bolívia, Paraguai, Uruguai, Argentina. (Costa, 1969; 1975).

Material examinado. P. angustus. EQUADOR. Zamora: 1928, C. Carrión col., 1 ex. (BMNH). PERU. Ica: Chanchamayo, 18.ix.1948, J. M. Schunke col., 2 exs. (CASC); idem, sem data, sem coletor, 2 ex. (ISBN); idem, 01.x.1939, Weyrauch col., 1 ex. (FIOC); (?): Marcapata, 1902, J. Kalinowski col., 1 ex. (BMNH). BOLÍVIA. (?): Reyes, 1921-1922, W. M. Mann col., 2 exs. (USNM). Beni: Rurrenaque, 19211922, W. M. Mann col., 3 exs. (USNM). Cochabamba: Cristal Mayu, 30.ix.1949, L. Pena col., 2 exs. (CMNH). P. avunculus. PANAMÁ. (?): Potrerillos, 28.iv-08.v.1933, sem coletor, 5 exs. (Parátipos) (CASC). idem, i.1934, sem coletor, 1 (Parátipo) (CASC Coll. Van Dyke); P. clarus. COLÔMBIA. (?): Bogotá, sem data, Lewy, 1 ex. (MNHN); idem, Fr. Apollinaire-Marie, 1 ex. (MNHN). Santander: Prima (Primavera), 28.v.1965, sem coletor, 1 ex. (MIZA); sem localidade, sem data, Felipe Ovalle, 1 ex., (AMNH). P. divergens. COLÔMBIA. Bogotá, sem data, sem coletor, 1 ex. (ISBN).VENEZUELA. Bolivar: Guayaraca, 20.iv.1956, E. Fernades \& C. J. Rosales col., 1 ex. (MIZA); Aragua: El Limon, 11.v.1955, E. Fernades \& C. J. Rosales col., 1 ex. (MIZA); Caracas (Valley), 20.vii.1921, R. L. Reynold col., 1 ex. (CNHM). SURINAME. Sem localidade, sem data, sem coletor, 1 ex. (SF Coll. Van Dyke). BRASIL. Amazonas: Benjamin Constant (R. Javari), sem data, Dirings col., 2 exs. (MZSP); Manaus (Uypiranga), xi.1941, Dirings col., 1 ex. (MZSP); São Paulo de Olivença, sem data, Dirings col., 2 exs. (MZSP). Pará: Óbidos, xi.1962, Dirings col., 5 exs. (MZSP); Itaituba (Santarenzinho, Rio Tapojós), v.1962, Dirings col., 2 ex. (MZSP). Ceará: Cerquejo, ii.1960, Dirings col., 1 ex. (MZSP). Alagoas: São Miguel, x.1951, E. Dante col., 1 ex. (MZSP). Bahia: Ilhéus (Faz. São Caetano), xii.1967, Dirings col., 1 ex. (MZSP). Mato Grosso: Chapada, sem data, sem coletor, 17 exs. (CMNH); Barra do Tapirapé, xi.1964, B. Malkin col., 3 exs. (MZSP); Mato Grosso do Sul: Caarapó (Santa Luzia), 28.ix.1969, G. R. Kloss col., 1 ex. (MZSP). Goiás: Anápolis, sem data, sem coletor, 1 ex. (MCZC); Niquelândia, x.1979, C. Coibra Jr. Col., 1 ex. (MZSP); Jataí (Faz. Aceiro), x.1962, Exp. Dep. Zool. Col., 3 ex. (MZSP). Minas Gerais: Buritis (Ribeirão Confins), 29-31.x.1964, Exp. Dep. Zool. Col., 3 ex. (MZSP); Monte Verde, 28.xi.1969, J. Halik col., 28.xi.1969, (MZSP); Santa Bárbara, Serra do Caraça, 23-25.ix.1960, Araújo \& Martins, 1 ex. (MZSP). Espírito Santo: Córrego Itá, xi.1956, W. Zikan, 8 ex. (MZSP); Linhares (Pq. Sooretana), xi.1960, D. Zajclw col., 1 ex. (MZSP).Rio de Janeiro: Itatiaia, i.1970, Dirings col., 1 ex. (MZSP); Nova Friburgo, 01-15.i.1978, Gred \& Guimarães col., 7 exs. (MZSP). São Paulo: Ilha de São Sebastião, sem data, sem coletor, 1 ex. (MZSP); Itatiba, xii.1927, J. Lima col., 6 ex. (MZSP); Rio Claro, xii.1942, P. Pereira col., 2 ex. (MZSP); Presidente Epitácio, xi.1926, J. Lima col., 11 ex. (MZSP); Salesópolis (E. B. B.), 14.i.1964, Rabello col., 1 ex. (MZSP); Capão Bonito (Sítio Cambará), 4-22.i.1988, A. Campanha col., 33 exs. (MZSP). Paraná: Guaíra, 09.xii.1969, G. B. 
Kloss col., 1 ex. (MZSP); Ponta Grossa, xii.1939, Camargo col., 22 exs. (MZSP). Santa Catarina: Anita Garibaldi, xii.1936, Dirings col., 1 ex. (MZSP); Blumenau, 02-05.xii.1975, Exp. DZUSP col., 2 ex. (MZSP); Nova Teotônia, xii.1966, P. Plaumann col., 12 exs. (MZSP). Rio Grande do Sul: Salvador do Sul, xi.1968, Pe. S. Schimitt col., 3 ex. (MZSP). P. dulcifer. EQUADOR. Quito, 1922, Cap. D'Espinay, 2 ex. (Parátipos) (MNHN); Rio Blanco, Oriente, 28.viii.1937, sem coletor, 1 ex. (AMNH); Balzapanba, sem data, sem coletor, 1 ex. (Parátipo) (MNHN). PERU. Huancabamba, sem data, sem coletor, 1 ex. (MCZC). COLÔMBIA. Sem localidade, sem data, sem coletor, 1 ex. (Parátipo) (AMNH); Cali, sem data, sem coletor, 1 ex. (Parátipo) (MCZC). P. expeditus. VENEZUELA. Merida: sem data, sem coletor, 1 ex. (Parátipo) (USNM). P. hayekae. SURINAME. Kayserberg, 1960-1962, H. Beatty col., 2 ex. (Parátipo) (CNHM).GUIANA. Kaieteur, 13.viii.1911, sem coletor, 1 ex. (Parátipo) (AMNH); Rio Mazzaruni (Upper), ix-x.1938, sem coletor, 1 ex. (Parátipo) (AMNH); Rio Essequibo (Moraballi Creek), 28-29.ix.1929, Oxf. Univ. Exp. Col., 1 ex. (BMNH).GUIANA FRANCESA. Cayenne, sem data, sem coletor, 1 ex. (BMNH). BRASIL. Pará: Mocajuba, Mangabeira, viii.195, Orlando Rego col., 1 ex. (Parátipo) (MZSP); Santarém, sem data, sem coletor, 1 ex. (Parátipo) (CMNH). Amapá: Serra Lombarda (Limão), 30.viii.1961, J. \& B. Bechyné, 1 ex. (Parátipo) (MPEG). P. indistinctus. COSTA RICA. Turrialba, 03.ii-11.iii.1944, T. Grant col., 1 ex. (USNM); sem localidade, sem data, P. Biolley, 1 ex. (BMNH).GUIANA FRANCESA. St. Laurent, sem data, sem coletor, 1 ex. (MCZC). BRASIL. Amazonas: Benjamin Constant (Colônia), vii.1942, A. Parko col., 1 ex. (MNRJ).Pará: Mocajuba, Mangabeira, iv.1952, Orlando Rego col., 1 ex. (MNRJ); Rodovia Belém-Brasília (Km 86) vii.1960, E. Dente col., 13 exs. (MZSP); Óbidos, viii-xi.1956-1970, Dirings col., 8 exs. (MZSP); Santarém (Faz Taperinha), 23.vii.1968, Exp. Perm. Amaz., 3 exs. (MZSP). Amapá: Rio Jari (Cachoeira do Itapacará) 1961, W. Egler col, 1 ex. (MPEG); Rio Felício, 06.viii.1959, J. Lane col., 1 ex. (IBSP). P. indulcatus. SÃO VICENTE E GRANADINAS. S. Vincent, sem data, H. H. Smith col., 4 exs. (Parátipos) (BMNH). P. ingens. COSTA RICA. Carrilo, 1920, Paul Serre, 1 ex. (Parátipo) MNHN). PANAMÁ. 0 sem localidade, sem data, sem coletor, 1 ex. (Parátipo) (CISC Coll. J. J. DuBois). P. jocundus. PANAMÁ. Sem localidade, sem data, sem coletor, 3 exs. (Parátipos) (CISC Coll. J. J. DuBois); Potrerillos, 28.iv-08.v.1933, sem coletor, 2 exs (Parátipos) (SF Coll. Van Dyke); idem, 27.iv.1934, R. F. Sternitzky col., 1 ex. (Parátipo) (SF); idem, i.1934, D. V. Brown col., 1 ex. (Parátipo) (SF). P. luscus. MÉXICO. Oaxaca: Palomares (Finca San Carlos), 26.v.1959, G. \& V. Halfter col., 3 ex. (IBSP). GUATEMALA. 25.vi.1894, sem coletor, 1 ex (Paralectótipo). (MNHN). BELIZE. Stann Creek: Middlesex, iv.1965, sem coletor, 21 exs. (CNHM); idem, 28.iii.1965, sem coletor, 2 exs. (MZSP). Toledo: Temash ("Rio Temas"), iv.1937, J. J. White col., 1 ex. (BMNH). COSTA RICA. Sem localidade, sem data, sem coletor, 1 ex. (MCZC). COLÔMBIA. Cauca: Fazenda García, 29.i.1935, J. O. Cordoba col., 1 ex. (AMNH). Holguin: Mayari (Baia de Nipe), 1883, Chaper, 1 ex. (Parátipo) (MNHN). P. magnus. EQUADOR. Cascho Crespejo (Tmabo à Starosa), sem data, Y. Mexia col., 1 ex. (Holótipo) (CASC). P. mellifluus. MÉXICO. Sem localidade, sem data, sem coletor, 1 ex. (Parátipo) (MCZC Coll. F. C. Bowditch). CUBA. Guantanamo: sem data, sem coletor, 1 ex. (Parátipo) (NHRS). Isla de la Juventud: Isle de Pines, Nueva Gerona, 27.iii.1913, G. Link col., 2 ex. (Parátipos) (CMNH Coll. Schwarz). HAITI. Sem data, sem coletor, 2 ex. (Parátipo) (DEIC); Diquini, sem data, W. M. Mann col., 1 ex. (Parátipo) (MCZC). REPÚBLICA DOMINICANA. Puerto Plata, 05.vii.1915, sem coletor, 1 ex. (Parátipo) (AMNH).MARTINICA. Sem data, sem coletor, 1 ex. (MNHN). SANTA LÚCIA. 1851, Bonnecour, 1 ex. (Parátipo) (MNHN). P. mellitus. SANTA LÚCIA. iv.1889, G. A. Ramage col., 4 exs. (Parátipos) (BMNH 97-67). P. noctilucus. TRINIDAD \& TOBAGO. 1903, sem coletor, 1 ex. (BMNH). GUIANA. Katabo, sem data, sem coletor, 1 ex. (CASC Coll. Van Dyke). SURINAME. Marowijni: Anapaike (Rio Lawa), xi.1963, B. Malkin col., 2 ex. (MZSP). VENEZUELA. Bolivar: Rio Caura, 25.iv.1957, S. Martin col., 3 ex. (MZSP); Cecilia Magdalena, 01.i.1957, S. Martin col., 1 ex. (MZSP). Yaracuy: Yumaré, 01-05.vi.1970, sem coletor, 10 exs. (MIZA). Barinas: Reserva Florestal Ticoporo, 02-10.vi.1966, sem coletor, 3 exs. (MIZA). COLÔMBIA. Cacagualito, sem data, sem coletor, 1 ex. (CMNH). BRASIL. Amazonas: São Gabriel, xi.1936, Camargo col., 2 ex. (MZSP); Borba, ix-x.1943, A. Parko col., 3 exs. (MNRJ); Benjamin Costant, ix.1963, Dirings col., 7 exs. (MZSP); Itacoatiara, xi.1960, Dirings col., 2 exs. (MZSP). Amapá: Serra do Navio, ix.1957, K. Lenko col., 1 ex. (MZSP). Pará: Óbidos, i.1961, Dirings col., 31 exs. (MZSP); Mocajuba, Mangabeira, vii.1943, A. Parko col., 3 ex. (MZSP). Acre: Selva alto Purus, xi.1950, Dirings col., 1 ex. (MZSP); Alto Purús, ix.1950, Dirings col., 12 exs. (MZSP).Bahia: Jequié, sem data, Camargo col., 1 ex. (MZSP);Ilhéus (Faz. São Caetano), xii.1967, Dirings col., 8 exs. (MZSP). Espírito Santo: Córrego Itá, ii.1955, W. Grossmann col., 2 ex. (Kmec). PERU. Loreto: vii.1939, W. F. Walsh Jr. col., 1 ex. (MCZC). P. pisticus. EQUADOR. Morona Santiago: $2^{\circ}-4^{\circ}$ S; $78^{\circ}$ W (600900 §̊), 10.xii.1934, W, von Hagen col., 1 ex. (Parátipo), (AMNH). Pacto (4500 pés), 1927, Dolby-Tyler col., 1 ex. (Parátipo) (BMNH). P. plagiophthalmus. Saint Thomas: Bath, 22.vii.1967, W. Klopp col., 5 ex. (CNHM). Saint Elisabeth: Balaclava, 12.ii, Chapin \& Blackwelder col., 1 ex. (MZSP). P. phosphorescens. PANAMÁ. Sem localidade, sem data, sem coletor, 2 exs. (MCZC). GUIANA FRANCESA. Cayenne, sem data, sem coletor, 1 ex. (ISNB). GUADALOUPE. Sem data, sem coletor, 1 ex. (BMNH Coll. Jansen); idem, 4 ex. (MNHN); "Vitrac" sem data, sem coletor, 2 exs. (ISNB); "Delauney", sem data, sem coletor, 1 ex. (MNHN). DOMINICA. "La Belle", sem data, Y. Utowana col., 1 ex. (MCZC); vi-vii.1930, Yale Exp., H. W. Foote col., 1 ex. (USNM).P. punctatissimus. BRASIL. Goiás: Cabeceiras (Lagoa Formosa), 24-27.x.1964, Exp. Dep. Zool. Col., 1 ex. (MZSP); Caldas Novas, x.1982, C. Coibra Jr. col., 1 ex. (MZSP); Aruanã (Rio Araguaia), ii.1962, Dirings col., 1 ex. (MZSP). Mato Grosso: Barra do Tapirapé, xi.1964, B. Malkin col., 1 ex. (MZSP). Mato Grosso do 
Sul: Corumbá (Serra do Urucum), 27.xi.1960, K. Lenko col., 5 exs. (MZSP); Camapuã, x.1967, sem coletor, 21 ex. (MZSP); Caarapó (Santa Luzia), 28.ix.1969, G. R. Kloss col., 19 ex. (MZSP); Fátima do Sul (Sítio Alpha), 02.x.1993, T. F. N. col., 1 ex. (MZSP). Minas Gerais: Monte Alegre, 23.x.1962, K. Lenko col., 1 ex. (MZSP); Rosário D' Oeste, ix.1973, Dirings col., 1 ex. (MZSP); Barra do Paraopeba, sem data, Vital R. de Souza col., 1 ex. (MNRJ). São Paulo: Taquaritinga, 06.xii.1969, J. C. Carvalho col., 1 ex. (MZSP); Ribeirão Preto, 22.x.1970, W. Kerr col., 2 exs. (MZSP); Botucatu, 12.ix.1979, J. Paulo col., 1 ex. (MZSP); Batatais, x.1946, Pe. Pereira col., 1 ex. (MZSP). BOLÍVIA. Sara: Nueva Maka, ii.1950, A. Martinez col., 2 ex. (MZSP). PARAGUAI. Caaguazu: Paso Yobai, xii1950, Förster col., 3 exs. (MZSP); Estancia Carumbé, 01.ii-08.iii.1966, Golbach col., 2 exs. (MZSP). ARGENTINA: Jujuy: Yavi, sem data, sem coletor, 1 ex. (MCZC). Missiones: Puerto Libertad ("Pto. Bemberg"), 12-29.iii.1945, Hayward, Willink \& Golbach col., 4 exs. (MZSP). Buenos Aires: San Isidro, xii.1961, A. Martinez col., 15 exs. (MZSP). Santiago del Stero: xii.1964, Golbach col., 4 exs. (MZSP). Tucuman: V. Padre Monti, 17.i-07.ii.1948, Golbach col., 4 exs. (MZSP). Salta: Aquaray, xii.1959, A. Martinez col., 2 exs. (MZSP). Santa Fé: Vila Ana, 02-26.ii.1927, K. J. Hayward col., 1 ex. (BMNH).URUGUAI. Paysandu: Puerto Pepe - Azí, 18.i.1962, Morey \& Monné col., 3 exs. (MZSP). JAMAICA. Sem localidade, sem data, sem coletor, 3 exs. (CMNH Coll Holland). P. strabus. MÉXICO. (?): Jalapa, sem data, W. Schaus col., 1ex. (AMNH). Chiapas: Santa Rosa, 22.iv.1962, G. Halfter col., 1 ex. (MZSP). Oaxaca: 30 km L Palomares (Finca San Carlos), v.1959, G. \& V. Halfter col., 1 ex. (MZSP). BELIZE. Mana-Tee, viii.1905, sem coletor, 2 ex. (MCZC); Punta Gorda, iii.1924, B. W. I. col., 1 ex. (AMNH); Benque Viejo, sem data, Pe. Stanton, 1 ex. (MCZC). P. stupendus. VENEZUELA. Distrito Federal: Faz. El Limon, Guacatal, 19.xi.1966, L. J. Joly \& J. L. Garcia col., 1 ex. (Parátipo) (MZSP). Aragua: Rancho Grande (1.100 đ̂), 02.vii.1964, A. Fernadez col., 1 ex. (MIZA); idem, 17.v.1973, J. Salcedo \& J. Clavijo col., 1 ex. (MIZA). Rancho Grande (1.100 §̊), 28.ii.1957, F. Fernandez \& C. J. Rosales col., 1 ex. (MIZA); Carabobo: Borburata, 15.iii.1940, G. Vivas col., 1 (Parátipo) (USNM); Miranda: Los Guayabitos, 10.i.19633, Y. Ramirez col., 1 (Parátipo) (MLS); BRASIL. Pará: Canindé (Rio Gurupi), xii.1964, B. Malkin col., 1 ex. (MZSP); Santarém, 1921, Garbo col., 2 exs. (MNHN). P. tuberculifer. Bahia: Jequié, sem data, Camargo col., 2 exs. (Cótipos) (MZSP). Mato Grosso do Sul: Salobra (Zona da N. O. C), 18-29.1938, Instituto Oswaldo Cruz, 4 exs. (MZSP); Três Lagoas (Faz. Canaã), i.1968, F. Lane col., 2 ex. (MZSP). Goiás: sem localidade, sem data, sem coletor, 1 ex. (MNHN). Minas Gerais: Mariana, 1918, sem coletor, 3 ex. (MZSP). Espírito Santo: Córrego Itá, xi.1956, W. Zikan, 4 exs. (Kmec). Rio de Janeiro: Angra dos Reis, 27-29.xii, L. T. F. E. R. col., 1 x. (MZSP); Ilha Comprida, 29.xii.2001, R. P. Rosa col., 1 ex. (MZSP). São Paulo: Franca, xi.1902, O. Dreher col., 1 ex. (MZSP). Rio Grande do Sul: Porto Alegre, 10.ii.1964, Pe. Buck col., 1 ex. (MZSP). Paraná: Londrina, xii.1935, Dirings col., 2 exs. (MZSP); Rolândia, x.1946, Dirings col., 2 exs. (MZSP). Santa Catarina: Blumenau, iii.1957, Dirings col., 1 ex. (MZSP). PARAGUAI. Assuncion, ix.1922-iv.1923, E. G. Kent col., 1 ex. (BMNH). ARGENTINA. (?): San Ignacio, sem data, sem coletor, 1 ex. (MNHN). P. validus. COLÔMBIA. Antioquia: Medelin, sem data, sem coletor, 1 ex. (Parátipo) (MNHN Coll. Oberthur). Cauca: Distrito de Pereira, 1886, Roman M. Valencia, 1 ex. (Parátipo) (MNHN). EQUADOR. Santiago: Macas, sem data, Beckley, 1 ex. (Parátipo) (BMNH). Napo: Zatzayacu 30.vii.1934, W. Macintyre col., 1 (Parátipo) (AMNH); Tungurahua: Ambato, sem data, R. P. I. Blanc col, 1 ex. (Parátipo) (MNHN). P. veriloquus. GUATEMALA. Sem localidade, sem data, Conradt, 3 exs. (Parátipos) $(\mathrm{MNHN})$; idem, sem coletor, 1 ex. (Parátipo) (DEIE Coll. Kraatz).

Comentários. Pyrophorus é um dos maiores gêneros de Pyrophorini, com 26 espécies descritas, das quais apenas $P$. evexus não foi examinada no presente estudo. Os resultados da análise cladística sugerem várias autapomorfias para o gênero: margem ocular não emarginada posteriormente e sem faixa preta; fronte retangular mais longa que larga no macho; ausência de dimorfismo sexual no comprimento da antena, no tamanho dos olhos, na formà do protórax e no comprimento das asas; as vesículas luminescentes do pronoto grandes e fortemente convexas; as lamelas laterais do esternito I fortemente esclerotizadas e pela carena mediana do esclerito ventral do pênis. 
$\mathrm{O}$ conjunto dessas autapomorfias, associado ao corpo robusto e convexo e às antenas muito curtas distingue Pyrophorus de quaisquer outros gêneros de Pyrophorini. Dentro do gênero é possível distinguir dois grupos de espécies que diferem quanto à presença da mancha luminescente nos hipômeros, que correspondem às vesículas do pronoto. Em $P$. divergens e espécies similares (grupos A e B segundo Costa, 1976) as vesículas luminescentes não são visíveis nos hipômeros, enquanto que em $P$. noctilucus e espécies similares (Grupos C, D e E segundo Costa, 1976) as vesículas são visíveis no hipômero. Nessas últimas a forma da margem ventral basal dos parâmeros é dobrada, uma autapomorfia em relação aos demais Pyrophorini.

\section{Fulgeochlizus Costa, 1975}

(Figs. 12, 27, 28, 69, 102, 128-132, 198, 199, 227)

Pyrophorus Billberg, 1820:20 (pars).

Fulgeochlizus Costa, 1975: 103; Golbach, 1994: 29, 42.

Espécie- tipo: Pyrophorus bruchi Candèze, 1896 (Localidade tipo: Córdoba, Argentina).

Redescrição. Macho (Fig. 227). Coloração geral do corpo castanho-escura, castanho-avermelhada ou castanho-amarelada, com pronoto uniformemente colorido ou com o terço mediano longitudinal mais escuro, geralmente com a margem lateral dos hipômeros alaranjada e F. bruchi também com margens laterais do abdômen alaranjada. Pilosidade geralmente amarelada, decumbente, curta, muito densa, às vezes conferindo um tom esverdeado ao tegumento ou alternada com regiões recobertas por pilosidade castanha originando manchas irregulares por toda a face dorsal (F. bruchi). Tegumento brilhante ou opaco, micropontuado.

Fronte (Fig. 12) subquadrada (1,0-1,10 vezes mais longa que larga), levemente côncava, fracamente carenada; pontuação média, densa e umbilicada. Antenas (Figs. 27, 28) 
serreadas ou subpectinadas a partir do quarto antenômero, com 11 ou 12 artículos, atingindo no mínimo a metade do comprimento do protórax, no máximo ultrapassando os ângulos posteriores no $11^{\circ}$ antenômero; $3^{\circ}$ antenômero ca. 1,0-1,2 vezes mais longo que o $2^{\circ}, 4^{\circ}$ antenômero 1,5-3,0 vezes o comprimento do $3^{\circ}$. Olhos de tamanho médio (índice ocular 0,4055), margem ocular levemente emarginada na região posterior. Mandíbula denteada.

Protórax quadrado ou retangular (1,0-1,2 vezes mais largo que longo), de lados subparalelos ou convergentes anteriormente. Pronoto levemente convexo; pontuação heterogênea, média, densa e umbilicada na região discal, menor, mais densa e umbilicada nas margens laterais e posterior, com um par de órgãos luminescentes em forma de manchas arredondadas grandes, localizadas quase eqüidistantes à linha mediana e à margem lateral, visíveis do hipômero. Região mediana posterior sem tubérculo. Ângulos anteriores agudos, pequenos a grandes; ângulos posteriores fortes, geralmente divergentes, carenados a fortemente carenados. Prosterno moderadamente alongado de lados quase retos, com pontuação forte, espaçada a densa, simples e umbilicada. Processo prosternal com região apical denteada, dente saliente, região posterior ao dente com comprimento longo $(17,6-$ 21,4\% do comprimento total do processo). Hipômeros (Fig. 69) com ângulos posteriores e pequena área posterior glabros, com pontuação média, densa e umbilicada; margem posterior truncada, sem espinhos ou com ângulo interno projetado, em forma de espinho.

Mesoventrito. Margem lateral anterior com ângulo externo proeminente, parte ventral levemente sinuosa a curva, próxima ou posterior à base, parte dorsal não visível ou parcialmente visível. Cavidade mesoventral com bordas posteriores fracamente inclinadas em relação à região anterior. Metaventrito com pontuação fina, densa e umbilicada. Élitros com estrias fracamente marcadas, interestrias achatadas com pontuação fina, muito densa; lados gradualmente afilados até os ápices; ápices conjuntamente arredondados, com ou sem um pequeno espinho sutural. Abdômen gradualmente afilado posteriormente, ventritos com pontuação fina, simples e umbilicada. Primeiro esternito abdominal com lamelas laterais 
fracamente esclerotizadas, com órgão luminescente subtrapezoidal ocupando completamente o esternito I (F. bruchi, Fig. 102) ou subtriangular, pouco desenvolvido ocupando aproximadamente $1 / 3$ do esternito $\mathrm{I}$.

Edeago (Figs. 128-132). Parâmeros com ápice truncado ou arredondado com um espinho pequeno lateral ( $F$. bruchi) ou com carena látero-dorsal; processo da articulação dorsal inteira com um recorte curto; bases medianas ventrais livres. Esclerito dorsal do pênis com prolongamentos basais $0,3-0,5$ vez o comprimento da região posterior, de lados subparalelos ou gradualmente afilados até o ápice, liso, com ou sem as margens láteroventrais expandidas em forma de lamelas alongadas. Esclerito ventral do pênis com aproximadamente $1 / 3-1 / 2$ da largura do esclerito dorsal, base bilobada, dividida longitudinalmente por um sulco raso ou profundo; linha mediana com ou sem uma carena dorsal saliente.

Fêmea. Geralmente iguais aos machos ou levemente mais convexa, com antena mais curta que a do macho (F. noctivagus).

Membrana interconectiva do segmento VIII sem escleritos laterais. Genitália Feminina (Fig. 198,199). Baculi 1,5-1,80 vezes mais longo que os coxitos. Trato genital. Vagina com um par de glândulas coleteriais tão longa quanto larga ou mais longa que larga. Regiões posterior e anterior de cada glândula coleterial membranosas. Bursa copulatrix com 2-3 espirais, com muitos espinhos alongados (F. bruchi) ou saculiforme pequena com poucos espinhos curtos. Espermatecas com ápice espiralado ou não espiralado.

Dimensões. Comprimento total 13,0-40,0 $\mathrm{mm}$. Comprimento dos élitros em relação ao do protórax: 2,4-3,1. Largura do úmero em relação à do protórax: 1,1.

Espécies. F. bruchi (Candèze, 1896); F. germari (Candèze, 1863); F. noctivagus Costa, 1991; F. pullatus Costa, 1991

Distribuição. Brasil (PA, MS), Bolívia, Paraguai e Argentina. 
Material examinado. F. bruchi. BRASIL. Pará: Caruru (?) aprox.56 W, 8 S, xi.1958, José Hidan col., 1 ex. (MZSP). Mato Grosso do Sul: Três Lagoas (Faz. Canaã), i.1968, F. Lane col., 27 exs. (MZSP); idem, 26.x--4.xi.1970, F. Lane col., 13 exs. (MZSP); Costa Rica (Faz. Santa Cruz), 16.x.1989, Exp. MZ-IQUSP col., 17 exs. (MZSP). PARAGUAI. Sem localidade, sem data, sem coletor, 1 ex. (CNHM). ARGENTINA. Buenos Aires: La Plata, 1868 , sem coletor, 2 exs. (MZSP). Tucuman: sem localidade, sem data, sem coletor, 2 ex. (CNHM). F. germari. BRASIL. Organ Mt. (Serra dos Órgãos?), sem data, sem coletor, 1 ex. (BMNH). BOLÍVIA. Sara: Nueva Maka, ii.1950, A. Martinez col., 2 ex (MZSP). PARAGUAI. Boqueron: Chaco, iii.1947, J. Hunger col., 2 exs. (IBSP). ARGENTINA. Santiago del Stero: Rio Selado, sem data, Wagner col., 1 ex. (IBSP); Chaco, margem do R. Selado, 1909 , E. R. Wagner col., 21 exs. (MNHN). Missiones: sem localidade, sem data, sem coletor, 6 exs. (MZSP). F. pullatus. PARAGUAI. Chaco: Filadelfia, 15.xi.1955, J. L.

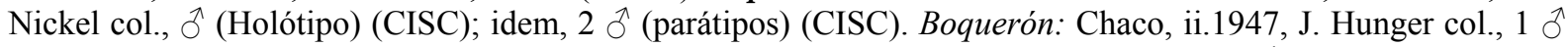
(IBSP). F. noctivagus. ARGENTINA. San Juan: Marayes, 13.xii.1964, A Martinez col., ồ (Holótipo) (MZSP); idem, 7 ô (Parátipos) (MZSP). La Rioja: Mascasin, I. 1959, sem coletor, 1 ô (Parátipo) (MZSP); idem, ii.1958, sem coletor, 1 † (MZSP); La Rioja, ii.1957, sem coletor, 1 ô (Parátipo) (CNC); idem, 06.iii.1970, Porter Stange col., 1 đ (Parátipo) (BMNH); Patquia, 1933, K. J. Hayward col., 1 ô (Parátipo) (BMNH). Catamarca: El Rodeo, 08-28.i.1959, Golbach col., 1 ô (Parátipo) (IMLA). Formosa: Guaycolec, ii.1949, A. Martinez col., 1 đ (Parátipo) (MZSP).

Comentários. Espécimes de $F$. bruchi e $F$. germari são tão robustos quanto aqueles de Pyrophorus, mas podem ser facilmente separados destes pela forma dos órgãos luminescentes e pelos protórax e élitros menos convexos. F. noctivagus é a única espécie de Pyrophorini que possui antenas pectinadas. F. pullatus é muito similar a $F$. noctivagus, mas possui antena fortemente serreada, ambas são levemente similares à Noxlumenes bardus, do qual podem ser prontamente separados pela formà do protórax, com lados menos convergentes anteriormente, e pelos ângulos posteriores mais curtos e menos divergentes.

\section{Meroplinthus Candèze, 1891}

(Figs. 29, 133, 134, 200, 201, 228)

Adelocera Latreille, 1829: 451 (pars)

Meroplinthus Candèze, 1891: 163; Schwarz, 1906: 210, 217; Schenkling, 1927:

356; Blackwelder, 144: 286; Costa, 1975b: 72, 75; Golbach, 1994: 28, 42.

Espécie-tipo: Adelocera trilineata Lucas, 1859 (designado por Hyslop, 1921: 657)

(Localidade-tipo: Brasil) 
Redescrição. Macho (Fig. 228). Bicoloridos, laranja e preto em padrões de manchas variáveis. Pilosidade muito curta e muito fina, dourada, geralmente invisíveis a olho nu. Tegumento brilhante.

Fronte retangular ( $c$ a. 1,4 vezes mais larga que longa) quase plana a côncava, com margem anterior não carenada a fracamente carenada, pontuação fina a média, muito densa e umbilicada. Antenas (Fig. 29) serreadas a partir do terceiro antenômero, atingindo o ângulo posterior no $11^{\circ}$; comprimento do $3^{\circ}$ antenômero 2,3 vezes o comprimento do $2^{\circ} ; 4^{\circ}$ subigual ao $3^{\circ}$. Olhos pequenos (índice ocular $0,30-0,35$ ), margem ocular com uma faixa preta em quase toda a sua extensão. Mandíbula denteada.

Protórax subquadrado (1,0-1,1 mais longo que largo), lados levemente arredondados. Pronoto convexo, com pontuação heterogênea, fina ou média, espaçada ou moderadamente densa e simples na região discal, maior, densa e umbilicada nas margens laterais; sem órgãos luminescentes. Região mediana posterior sem tubérculo. Ângulos anteriores agudos, pequenos ou grandes; ângulos posteriores delgados, levemente divergentes e fracamente carenados. Prosterno alongado de lados quase retos, com pontuação média a forte, densa, simples e umbilicada. Processo prosternal com região apical denteada, dente saliente, região posterior ao dente longa (aproximadamente $15,0 \%$ do comprimento total do processo). Hipômeros com a metade posterior glabra, metade anterior com pontuação fina ou média, espaçada a densa e umbilicada, margem posterior truncada, sem espinho.

Mesoventrito. Margem lateral anterior com ângulo externo proeminente, parte ventral sinuosa, posterior à base, parte dorsal visível. Cavidade mesoventral com bordas quase horizontais. Metaventrito com pontuação fina, densa, umbilicada. Élitros com estrias marcadas a fortemente marcadas, interestrias achatadas a levemente convexas, com pontuação fina, espaçada ou densa; lados subparalelos até o terço apical; ápices conjuntamente arredondados. Abdômen gradualmente arredondado posteriormente, ventritos com pontuação fina, densa, simples ou umbilicada. Primeiro esternito abdominal membranoso, sem órgão 
luminescente. Base fusionada do esternito IX e tergito IX com região mediana anterior menos esclerotizada que as laterais

Edeago (Figs. 133, 134). Parâmeros, com ápice truncado, com um espinho lateral pequeno, processo da articulação dorsal inteiro, bases medianas ventrais fusionadas ao esclerito ventral do pênis. Esclerito dorsal do pênis com prolongamentos basais $0,3-0,4$ vezes o comprimento da região posterior, de lados subparalelos até o ápice afilado, liso. Esclerito ventral do pênis com aproximadamente 1/2 da largura do esclerito dorsal.

Fêmea: Similares aos machos, levemente mais convexas, com lados do protórax mais arredondados (protórax 1,1-1,2 mais largo que longo), com antenas mais curtas.

Membrana interconectiva do segmento VIII (Fig. 200) com um par de escleritos laterais grandes, ovais e côncavos Genitália feminina (Figs 200, 201). Baculi 1,1-1,2 vezes mais longo que os coxitos. Trato genital. Vagina com um par de glândulas coleteriais muito curtas ou indistintas. Regiões posterior e anterior de cada glândula coleterial membranosas. Bursa copulatrix saculiforme pequena, sem espinhos ou com poucos espinhos reduzidos. Espermatecas não espiraladas.

Dimensões. Comprimento total $\lesssim$ 17,0-22,0 mm, ㅇ 19,0-31,0 mm. Comprimento dos élitros em relação ao do protórax: $\widehat{\jmath}$ 2,5-2,6; $\uparrow$ 2,5-2,9. Largura do úmero em relação à do protórax: $\widehat{\jmath}$ e $q 1,0-1,1$.

Espécies. M. ambrosius Costa, 1975; M. costae Golbach, 1984; M. decorus Costa, 1975; M. schneideri (Schwarz, 1906); M. trilineatus (Lucas, 1859).

Distribuição. Brasil (MT, GO, RJ, SP, SC, RS) e Uruguai.

Material examinado. M. ambrosius. BRASIL. Mato Grosso: sem localidade, 1886 P. Germain, 1 ô (Parátipo) (MNHN). Goiás: Jataí, 1895-1896, Ch. Pujol col., 1 \& (Parátipo) (MNHN). São Paulo: Piracicaba sem data, Escola de Agronomia, 1 ô (Holótipo) (MNHN). M. decorus. BRASIL. Rio Grande do Sul: Pelotas, ii.1934, I. Figueiredo col., 1 ㅇ (Parátipo) (IBSP). URUGUAI. Montevideo: Sayago, 25.i.1948, A. Silveira col., 1 q (Holótipo) (IBSP). M. schneideri. BRASIL. São Paulo: Pariquera-Açu, 08.ii.1977, Rabello col., 1 ㅇ (MZSP); Peruíbe, 10.i.1951, H. Zellibor col., 1 ㅇ (MZSP); São Paulo, xii.1960, Dirings col., 1 우 (MZSP). Santa Catarina: Timbó, i.1958, Dirings col., 1 q (MZSP); Pinhal, xii.1952, A. Maller col., 1 우 (MZSP); M. trilineatus. BRASIL. Rio de Janeiro: Rio de Janeiro, Corcovado, 28.x.1954, Zajclk col., 1 ㅇ (MZSP); idem, i.1955, Zajclk col., 1 ô (MZSP); idem, 15.xi.1976, M. A. Monné col., 1 ô (MZSP); idem, 13.i.1977 , C. A. C. Seabra col., 1 ô (MZSP); idem, ix-x.1958, Alvarenga \& Seabra col., 2 ๆ (MZSP). 
Comentários. M. costae não foi examinada. As espécies de Meroplinthus estudadas são caracterizadas principalmente por sua coloração, preta e laranja brilhante. $M$. schneideri e M. trilineatus possuem um padrão de manchas levemente similar ao de Sooporanga formosa, mas diferem desta espécie pelo corpo bem mais convexo, antena serreada a partir do $3^{\circ}$ artículo e pela ausência de órgãos luminescentes no pronoto. $M$. ambrosius tem pronoto laranja com região discal preta, similar ao de algumas espécies de Pyroptesis, do qual pode ser separado pela forma das antenas e pela ausência de órgãos luminescentes. A ausência de órgãos luminescentes em Meroplinthus é sugerida pelas hipóteses filogenéticas como uma autapomorfia para o gênero, homoplástica àquela do clado 62 (Agnostelater, Paraphileus, Euplinthus, Compsoplinthus e Hifo).

\section{Ptesimopsia Costa, 1975}

(Figs. 16, 30, 112, 113, 135-139, 229)

Pyrophorus Billberg, 1820: 20 (pars).

Ptesimopsia Costa, 1975: 89, 91; Golbach, 1994: 28, 43.

Espécie-tipo: Pyrophorus candezei Fauvel, 1861 (Localidade-tipo:Cayenne).

Redescrição. Macho (Fig. 229). Uniformemente castanho-escuros. Pilosidade muito curta ou curta, fina, dourada, semidecumbente ou eriçada. Tegumento brilhante.

Fronte subtrapezoidal, geralmente côncava, com margem anterior entre as inserções antenais não carenada, fracamente carenada sobre as inserções antenais; pontuação fina a média, densa, simples. Antenas (Fig. 30) subserreadas ou serreadas a partir do terceiro antenômero, atingindo a base do ângulo posterior no $11^{\circ}$ a ultrapassando o ângulo posterior no $9^{\circ}$; comprimento do $3^{\circ}$ antenômero $1,5-2,5$ vezes o comprimento do $2^{\circ}$; $4^{\circ} 1,1-1,3$ vezes o comprimento do $3^{\circ}$. Olhos (Fig. 16) de tamanho médio (índice ocular 0,49-0,57), margem ocular levemente emarginada. Mandíbula denteada. 
Protórax subquadrado (0,90-1,1 mais largo que longo), de lados paralelos a arredondados Pronoto achatado dorso-ventralmente a convexo, com a linha longitudinal fracamente a fortemente sulcada com pontuação heterogênea, fina ou média, espaçada a densa e simples na região discal, mais densa e umbilicada nas margens laterais; com órgãos luminescentes em forma de vesículas ovais a circulares, levemente convexas, sublaterais ou laterais, visíveis do hipômero. Região mediana posterior sem tubérculo. Ângulos anteriores agudos, pequenos ou grandes; ângulos posteriores geralmente delgados, levemente divergentes e fracamente carenados. Prosterno alongado de lados quase retos, com pontuação média, densa, simples. Processo prosternal com região apical denteada, dente saliente, região posterior ao dente com comprimento médio a longo (12,0-20,7\% do comprimento total do processo). Hipômeros com no mínimo a região do ângulo posterior glabra, no máximo com o terço posterior glabro, com pontuação média, espaçada a densa e umbilicada, margem posterior truncada, sem espinho.

Mesoventrito. Margem lateral anterior com ângulo externo proeminente, parte ventral fracamente sinuosa a sinuosa, próxima da base, parte dorsal geralmente não visível. Cavidade mesoventral com bordas posteriores pouco inclinadas em relação à região anterior. Metaventrito com pontuação fina, densa, umbilicada. Élitros com estrias fracamente a fortemente marcadas, interestrias achatadas ou levemente convexas, com pontuação muito fina e espaçada ou fina e densa; lados subparalelos até o terço apical, ápices conjuntamente arredondados. Abdômen gradualmente arredondado posteriormente, ventritos com pontuação fina, densa, simples ou umbilicada. Primeiro esternito abdominal com lamelas laterais parcialmente esclerotizadas (mais esclerotizada nas laterais, membranosas na região mediana), com órgão luminescente retangular ou subtrapezoidal ocupando de 1/5 a 1/3 a do esternito I. Base fusionada do esternito IX e tergito IX (Figs 112, 113) com região mediana anterior menos esclerotizada que as laterais. 
Edeago (Figs.138-139). Parâmeros, com ápice truncado ou arredondado com carena látero-dorsal, com um espinho látero-dorsal de tamanho médio ou com dois espinhos látero-dorsais, um posterior, geralmente maior, e outro anterior. Processo da articulação dorsal inteiro ou com recorte curto, bases medianas ventrais fusionadas ao esclerito ventral do pênis. Esclerito dorsal do pênis delgado, fortemente afilado para o ápice, com prolongamentos basais 0,5-0,6 vezes o comprimento da região posterior, liso. Esclerito ventral do pênis com um par de pregas laterais, com largura aproximadamente $0,3-0,7$ vezes a largura do esclerito dorsal, geralmente liso, sem escamas.

Fêmea: Similares aos machos, levemente mais convexas, com antenas mais curtas, menos serreadas.

Membrana interconectiva do segmento VIII com um par de escleritos laterais grandes, ovais e côncavos. Genitália feminina. Baculi 1,2-1,3 vezes mais longo que os coxitos. Trato genital. Vagina com um par de glândulas coleteriais muito curtas ou indistintas. Regiões posterior e anterior de cada glândula coleterial membranosas. Bursa copulatrix saculiforme pequena, sem espinhos. Espermatecas não espiraladas.

Dimensões. Comprimento total $\overparen{1} 17,0-22,0 \mathrm{~mm}$, + 19,0-31,0 mm. Comprimento dos élitros em relação ao do protórax: $\widehat{\jmath}$ 2,5-2,6; $\uparrow$ 2,5-2,9. Largura do úmero em relação à do protórax: $\widehat{\jmath}$ e $q 1,0-1,1$.

Espécies. P. brunnea Costa, 1975; P. candezei (Fauvel, 1861); P. elongata Costa, 1975; P. gracilis Rosa, 2004; P. lucifuga (Curtis, 1839); P. luculentus (Germar, 1841); P. luscinia Costa, 1975b; P. parallela (Germar, 1841); P. pyraustes (Germar, 1841)

Distribuição. México, Brasil (AM, AC, SE, BA, MS, MG, ES, RJ, SP, PR, SC, RS), Paraguai, Uruguai e Argentina. É provável que o único exemplar assinalado para o México tenha sido erradamente rotulado.

Material examinado. P. brunea. BRASIL. São Paulo: Salesópolis, (E. B. Boracéia), I.1950,

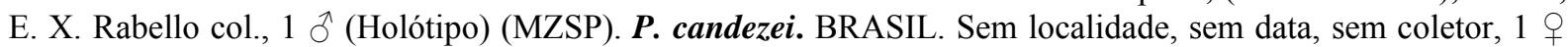
(ISBN); idem, 1 ㅇ (MZSP). Amazonas: Benjamin Constant, R. Javary, 1942, B. Pohl, 1 ô (IBSP); idem, x.1960, Dirings col., $1 \overbrace{}^{\top}$ (MZSP); São Paulo de Olivença, ix.1959, Dirings col., 1 ô (MZSP). Acre: Feijó, xi.1956, sem 


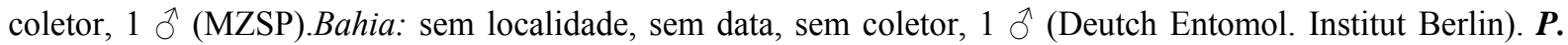
elongata. BRASIL. São Paulo: Pindamonhangaba, Eug. Lefevre 1.200m, 21.xii.1962, Exp. Dep. Zool. Col., $\hat{0}$ (Holótipo); (MZSP); Porto Flor, i.1922, J. Halik col., 1 ô, (MZSP). Santa Catarina: Pinhal, xii.1952, A. Maller col., 2 đ̄ (MZSP). P. gracilis. BRASIL. Sergipe: Canindé do São Francisco (Faz. Jaburu), 17.ix.2000, L. Ianuzzi col., $\widehat{\jmath}$ (Holótipo); (MZSP); idem, 1 ○े (Parátipo) (MZSP). P. lucifuga. URUGUAI. Treita y Tres: Quebrada de los Cuervos, 17.ii.1952, C. S. Carbonell col., 2 ○ (MZSP); Montevideo, sem data, sem coletor, 1 ઈ (BMNH); Piedra de los Indios, 24-31.iii.1969, G. J. Wibmer \& Z. Assandri col., 1 §ै (FHCM). Rivera: Berruti, 24.xi.1959, P R. San Martin col., 1 (MZSP). ARGENTINA. Santiago del Stero: sem data, sem coletor, 1 (ISNB). P. luculenta. MÉXICO. Chiapas: Huixtla, 09.iii.1962, M. A. Vulcano col., 1 ơ (MZSP). BRASIL. Minas Gerais: Viçosa, sem data, sem coletor, 1 ô (IBSP). Espírito Santo: Santa Teresa, 07-15.xii.1964, Claudionor Elias col., 1 $\delta$ (DZUP); Linhares (Pq. Sooretana), 17-27.x.1962, F. S. Pereira col., 1 ơ (MZSP). Rio de Janeiro: sem localidade, sem data, sem coletor, 2 ô (CMNH). São Paulo: Barueri, 17.xii.1962, K. Lenko col., 1 ઈิ (MZSP); idem, xii.1966, K. Lenko col., 1 đิ (MZSP); Boracéia, ii.1942, Araújo col., 1 đ̊ (MZSP). Paraná: Ponta Grossa,

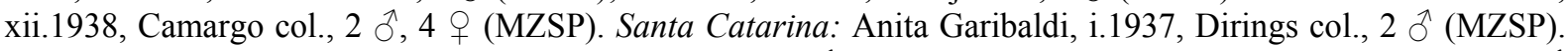
Rio Grande do Sul: Porto Alegre, i.1938, Pe. Buck col., 1 ô (MAPA); São Leopoldo, sem data, sem coletor, $2 \hat{\sigma}$ (NHRS). P. Iuscinia. BRASIL. Rio Grande do Sul: Porto Alegre, 1962, sem coletor, 1 ð (Parátipo) (MZSP); idem, 1921, sem coletor, 1 + (Parátipo) (MZSP). PARAGUAI. Alto paraná: Hohenau, 1954, H. Jacob col., 10 (BMNH). ARGENTINA. Cordoba: sem localidade, sem data, sem coletor, 1 ô (Parátipo) (MCZC). URUGUAI. Soriano: Arroyo Cololó, 20.i.1964, C. S. Morey col., 1 ○ (Parátipo) (MZSP). Salto: Salto Grande, 18.xii.1956, F. Azambuya col., 4 q (Parátipos) (MZSP). P. parallela. BRASIL. São Paulo: Ribeirão Preto, x.1954, Barreto col., 1 ô (MZSP). Rio Grande do Sul: Quaraí, Cerro do Jarão, 27.i.1963, Carbonell col., 1 † (MZSP). PARAGUAI. Carumbé, ii-iii.1959, Golbach col., $1 \hat{\jmath}$ (IMLA); Rio Grande, sem data, sem coletor, $6 \hat{\jmath}, 1 \mathrm{f}$ (MCZC). ARGENTINA. Buenos Aires: Dpto. Puan, S. Solá, i.1959, A. Matinez col., 3 ô, 1 q (MZSP). Tucuman: sem localidade, xii.1960, Golbach col., 2 đ (IMLA). URUGUAI. Tacuarembó: Arroyo Laureles, 1315.xii.1965, Monné col., 1 đ̄ (MZSP). Rivera: Sierra de la Aurora, Arroyo de la Aurora, 12-26.i.1971, Monné, Moratorio, Morey e Wibmer col., 5 o (FHCM). Maldonado: Sierra de las Animas, 06.i.1965, Ximenes \& Zolessi col., 1 † (MZSP). Canelones: Salinas, i.1961, E. Terga col., 1 đ̊ (FHCM). La Floresta, 10.i.1959, Moné col., 1 đ̋ (FHCM). Paysandu: Puerto Pepe - Ají, 13-18.i.1972, Mnné \& Casini col., 1 đ̄ (FHCM). P. pyrausta.

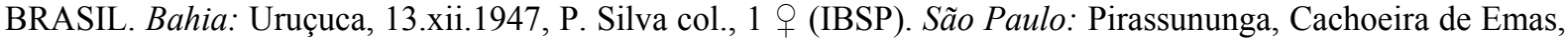
01-08.xi.1962, Reichardt col., 1 q (MZSP).

Comentários. Embora relativamente pequeno, este gênero compreende espécies bastante diversas, principalmente com relação à forma dos ápices dos parâmeros e na forma do pronoto. Duas delas, $P$. parallela e P. brunea são ainda mais distintas das demais e não foram consideradas na redescrição acima. $P$. parallela difere das demais espécies pela forma da margem anterior do pronoto, com ângulos anteriores retos, pelo tamanho dos olhos, maiores (índice ocular 0,70), pelo acentuado dimorfismo sexual, com fêmeas com protórax de ângulos anteriores agudos, mais convexo e mais arredondado, pelo prosterno curto de lados curvos, pela forma do esternito I, fracamente esclerotizado e do órgão abdominal luminescente, subtriangular e pequeno. Todas esses caracteres são muito similares àqueles das espécies de Pyrearinus, mas segundo as hipóteses resultantes da análise filogenética essa semelhança é devida a surgimentos homoplásticos nos dois táxons. A forma do edeago de $P$. parallela também é bastante peculiar, os ápices de seus parâmeros são similares aos de 
Meroplinthus, mas com uma carena látero-dorsal fracamente saliente e região apical membranosa mais alongada (Fig. 135, 136); o esclerito ventral possui escamas minúsculas dirigidas anteriormente (Fig. 137).

P. brunea compartilha com $P$. parallela a forma do prosterno, do esternito I e do órgão abdominal luminescente, mas seus olhos, são um pouco menores (índice 0,60) e o protórax é diferente, mais similar ao de Phanophorus. O pênis possui características autapomórficas e apenas um exemplar macho é conhecido, por esses motivos esta espécie não foi incluída como táxon terminal na análise filogenética. No momento não proponho a exclusão dessas duas espécies do gênero, embora as hipóteses filogenéticas sugiram que pelo menos $P$. parallela não faça parte da linhagem monofilética que inclui $P$. candezei, porque os caracteres levantados não foram suficientes para definir uma sinapomorfia para as espécies de Ptesimopsia, não compartilhada por $P$. parallela e $P$. brunea. Uma análise filogenética para um nível menos inclusivo, incluindo como terminais todas as espécies de Ptesimopsia e de outros táxons filogeneticamente mais próximos poderá definir melhor o gênero e a relações entre as suas espécies.

\section{Hapsodrilus Costa, 1975}

(Figs. 20, 31, 81, 104, 140-143, 230)

Pyrophorus Billberg, 1820: 20 (pars).

Hapsodrilus Costa, 1975: 89, 90; Golbach, 1994: 28, 42.

Espécie-tipo: Pyrophorus ignifer Germar, 1841 (Localidade-tipo:Brasil).

Redescrição. Macho (Fig. 230). Castanho-escuros com uma mancha lateral amarelada no pronoto restrita aos ângulos posteriores ou atingindo a metade do comprimento do pronoto, ocultando parcialmente as vesículas luminescentes. Pilosidade moderadamente alongada, fina, dourada e eriçada. Tegumento brilhante. 
Fronte subtrapezoidal, geralmente côncava, com margem anterior entre as inserções antenais não carenada, fracamente carenada sobre as inserções antenais; pontuação média, densa ou muito densa, umbilicada. Antenas (Fig. 31) subserreadas a serreadas a partir do quarto antenômero, atingindo a base do ângulo posterior no $11^{\circ}$ antenômero ou ultrapassando o ângulo posterior no $9^{\circ}$ antenômero; comprimento do $3^{\circ}$ antenômero $1,3-2,0$ vezes o comprimento do $2^{\circ} ; 4^{\mathrm{o}} 1,5-1,7$ vezes o comprimento do $3^{\circ}$. Olhos de tamanho médio (índice ocular 0,50-0,55), margem ocular levemente emarginada na região posterior (Fig. 20). Mandíbula denteada.

Protórax subquadrado (0,90-1,1 mais largo que longo), de lados paralelos. Pronoto levemente convexo, com pontuação heterogênea, média a forte, densa e levemente umbilicada a umbilicada na região discal, mais densa e umbilicada nas margens laterais; com órgãos luminescentes em forma de vesículas mais ou menos circulares, geralmente com contorno pouco marcado, levemente convexas, sublaterais. Região mediana posterior sem tubérculo. Ângulos anteriores agudos, pequenos; ângulos posteriores geralmente delgados, levemente divergentes e fracamente carenados. Prosterno moderadamente alongado de lados quase retos ou curto de lados curvos, com pontuação média, densa, umbilicada. Processo prosternal com região apical denteada, dente saliente, região posterior ao dente com comprimento médio a longo (12,0-21,4\% do comprimento total do processo). Hipômeros com 1/4-1/2 posterior glabra, com pontuação média, espaçada a densa e umbilicada, margem posterior truncada, sem espinho ou com dois espinhos pequenos.

Mesoventrito. Margem lateral anterior (Fig. 81) com ângulo externo proeminente, parte ventral sinuosa, próxima da base, parte dorsal geralmente não visível. Cavidade mesoventral com bordas posteriores pouco inclinadas em relação à região anterior. Metaventrito com pontuação fina, densa, umbilicada. Élitros com estrias fraca a fortemente marcadas, interestrias achatadas a levemente convexas, com pontuação muito fina e espaçada; lados subparalelos até o terço apical; ápices conjuntamente arredondados. Abdômen 
gradualmente arredondado posteriormente, ventritos com pontuação fina, densa, simples ou umbilicada. Primeiro esternito abdominal (Fig. 104) com lamelas laterais parcialmente esclerotizadas (mais esclerotizada nas laterais, membranosas na região mediana), com órgão luminescente retangular ou subtrapezoidal ocupando de $1 / 3$ a quase inteiramente o esternito I.

Edeago (Figs.140-143). Parâmeros, com ápice arredondado e com um espinho látero-dorsal de tamanho médio ou com ápice afilado e carenado (H. pyrotis); processo da articulação dorsal inteiro, bases medianas ventrais fusionadas ao esclerito ventral do pênis. Esclerito dorsal do pênis delgado, afilado para o ápice, com prolongamentos basais 0,6-0,7 vez o comprimento da região posterior, linha mediana da região subapical com ou sem um saliência curta, com ou sem escamas minúsculas nas margens laterais; com ou sem espinhos cônicos minúsculos látero-dorsais (Fig. 143). Esclerito ventral do pênis com um par de pregas laterais, quase da mesma largura ou mais largo que o dorsal, geralmente com escamas minúsculas dirigidas anteriormente.

Fêmea: Similares aos machos, levemente mais convexas, com antenas mais curtas.

Membrana interconectiva do segmento VIII com um par de escleritos laterais grandes, ovais e côncavos. Genitália feminina. Baculi 1,1 vez mais longo que os coxitos. Trato genital. Vagina com um par de glândulas coleteriais tão longas quanto largas. Regiões posterior e anterior de cada glândula coleterial membranosas. Bursa copulatrix saculiforme pequena, sem espinhos. Espermatecas não espiraladas.

Dimensões. Comprimento total $\lesssim$ 13,0-22,5 mm, ㅇ 13,0-25,0 mm. Comprimento dos élitros em relação ao do protórax: $\widehat{\jmath}$ 3,1-3,6 † 3,0-3,3. Largura do úmero em relação à do protórax: $\widehat{\jmath}$ e $q 1,1$.

Espécies. H. amydrus Casari-Chen, 1986; H. funale (Candèze, 1863); H. ignifer (Germar, 1841); H. pyrotis (Germar, 1841). 
Distribuição. Brasil (MS, GO, MG, RJ, SP, PR, SC, RS), Uruguai e Argentina.

(Costa, 1975b).

Material examinado. Hapsodrilus ignifer. BRASIL. Rio de Janeiro: Petrópolis, sem data, sem coletor, 1 ㅇ (MZHF). São Paulo: S. Paulo, Interlagos, 10.i.1970, C. Costa col., 1 đิ (MZSP); Ipiranga, i.1921, Luedw. col., 1 q (MZSP). Paraná: Ponta Grossa, xi-xii.1938, Camargo col., 2 ô, 6 o (MZSP); idem, iiii.1939, Camargo col., 1 กิ, 18 † (MZSP). Santa Catarina: Anita Garibaldi, xi.1936, Dirings col., 2 ô (MZSP); idem, i.1960, 1 (MZSP); idem, i.1945, 1 đ (MZSP); xii.1950, 1 ô (MZSP); Mafra, xii, Anton Maller col., 1 q, (MNRJ). Rio Grande do Sul: Itapiranga, ii.1934, Pe. Buck col., 1 ô (MAPA); São Francisco de Paula, 23.i.1938, Pe. Buck col., 1 đ̊ (MAPA). H. amydrus. BRASIL. Mato Grosso do Sul: Costa Rica, 21-25.x.1984, Exp. MZIQUSP col., ô (Holótipo) (MZSP); idem, i + (Parátipo) (MZSP).H. pyrotis BRASIL. Rio de Janeiro: Teresópolis, i.1957, D. Zajclw col., 4 ○ (MZSP); Teresópolis, Serra dos Órgãos, 23.xi.1966, San Martin \& Monné col., 3 đ̃, 4 q (MZSP). São Paulo: Casa Grande, i.1935, sem coletor, 1 ô (IBSP Coll. J. Guerin);

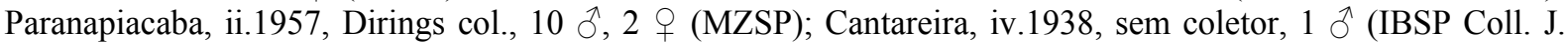
Guerin). Paraná: Ponta Grossa, iii.1939, Camargo col., 1 ô, 1f (MZSP). Santa Catarina: Rio Vermelho, i.1950,

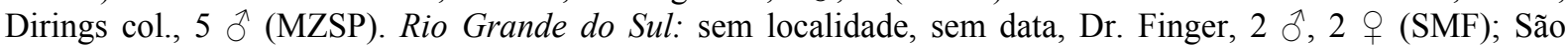
Francisco de Paula, 23.i.1938, Pe. Buck col., 5 ô, (MAPA). URUGUAI. Rivera: Sierra de la Aurora, 15.i.1961, Carbonell \& Zolessi col., 1 đ (MZSP) idem, Arroyo de la Aurora, 12-26.i.1971, Monné, Moratorio, Morey \& Wibmer col., 1 ô (MZSP).

Comentários. H. funale, única espécie não examinada, é conhecida apenas pela fêmea (Casari-Chen, 1986). As espécies estudadas do gênero Hapsodrilus são bem caracterizadas pela formà do protórax subquadrado, com tegumento mais claro próximo dos ângulos posteriores, geralmente ocultando parcialmente as vesículas luminescentes e por sua pilosidade, muito fina e eriçada.

\section{Pyroptesis Costa, 1975}

(Figs. 32, 144, 145, 231)

Pyrophorus Billberg, 1820: 20 (pars).

Pyroptesis Costa, 1975: 89, 90; Golbach, 1994: 28.

Espécie-tipo: Pyrophorus cincticollis Germar, 1841 (Localidade-tipo:Salto

Grande).

Redescrição. Macho (Fig. 231). Bicoloridos, predominantemente castanhoescuros ou pretos com pronoto e hipômeros parcialmente ou completamente amarelados ou 
alaranjados, epipleuras geralmente alaranjadas. Pilosidade curta, fina, dourada, semidecumbente ou eriçada. Tegumento brilhante.

Fronte subretangular (aprox.1,3 vezes mais larga que longa), levemente côncava, com margem anterior entre as inserções antenais não carenada, fracamente carenada sobre as inserções antenais; pontuação média, densa ou muito densa, umbilicada. Antenas (Fig. 32) serreadas a partir do quarto antenômero, ultrapassando o ângulo posterior no $9^{\circ}, 10^{\circ}$ ou $11^{\circ}$ antenômero; comprimento do $3^{\circ}$ antenômero 1,5-1,9 vezes o comprimento do $2^{\circ}$; $4^{\circ} 1,5-1,6$ vezes o comprimento do $3^{\circ}$. Olhos de tamanho médio (índice ocular 0,40-0,47), margem ocular levemente emarginada posteriormente. Mandíbula denteada.

Protórax subquadrado ou subretangular (1,0-1,2 mais largo que longo), de lados arredondados. Pronoto levemente convexo a convexo, com pontuação heterogênea, média, densa e simples na região discal, mais densa e umbilicada nas margens laterais; com órgãos luminescentes em forma de vesículas subcirculares, geralmente com contorno quase indistinto, achatadas a pouco convexas, sublaterais. Região mediana posterior sem tubérculo. Ângulos anteriores agudos, pequenos; ângulos posteriores geralmente delgados, levemente divergentes e fracamente carenados. Prosterno moderadamente alongado de lados quase retos, com pontuação média, densa, umbilicada. Processo prosternal com região apical denteada, dente saliente, região posterior ao dente longa $(15,4-21,9 \%$ do comprimento total do processo). Hipômeros com 1/4-1/2 posterior glabra, com pontuação média, espaçada a densa e umbilicada, margem posterior truncada, sem espinho ou com dois espinhos pequenos.

Mesoventrito. Margem lateral anterior com ângulo externo proeminente, parte ventral sinuosa, próxima da base, parte dorsal pouco visível a não visível. Cavidade mesoventral com bordas posteriores pouco inclinadas em relação à região anterior. Metaventrito com pontuação fina, densa, umbilicada. Élitros com estrias marcadas, interestrias achatadas a levemente convexas, com pontuação fina, espaçada ou densa; lados subparalelos até o terço apical; ápices conjuntamente arredondados. Abdômen gradualmente 
arredondado posteriormente, ventritos com pontuação fina, densa, simples ou umbilicada. Primeiro esternito abdominal inteiramente membranoso ou com lamelas laterais parcialmente esclerotizadas (mais esclerotizada nas laterais, membranosas na região mediana), com órgão luminescente ocupando metade a quase inteiramente o esternito I.

Edeago (Figs. 144, 145). Parâmeros, gradualmente afilados para o ápice ou abruptamente mais afilados no terço posterior, sem carena ou espinho látero-dorsal; processo da articulação dorsal inteiro, bases medianas ventrais fusionadas ao esclerito ventral do pênis. Esclerito dorsal do pênis delgado, afilado para o ápice, com prolongamentos basais 0,3-0,6 vez o comprimento da região posterior, liso. Esclerito ventral do pênis com um par de pregas laterais, quase tão largo quanto o dorsal, com ou sem escamas minúsculas dirigidas anteriormente.

Fêmea: Similares aos machos, levemente mais convexas, com antenas mais curtas.

Membrana interconectiva do segmento VIII com um par de escleritos laterais de formato irregular. Genitália feminina. Baculi tão longo quanto os coxitos. Trato genital. Vagina com um par de glândulas coleteriais tão longas quanto largas. Região posterior de cada glândula coleterial membranosa e anterior com um esclerito espinhoso. Bursa copulatrix saculiforme pequena, sem espinhos. Espermatecas não espiraladas.

Dimensões. Comprimento total $\widehat{\partial} 11,0-17 \mathrm{~mm}$, $q$ 17,0-23,0 mm. Comprimento dos élitros em relação ao do protórax: $\widehat{~}$ 2,9-3,4 $\uparrow$ 2,8-3,6. Largura do úmero em relação à do protórax: đ̂ e $\uparrow$ 1,0-1,1.

Espécies. P. cincticollis (Germar, 1841); P. gilvus Costa, 1975; P. maculicollis (Candèze, 1863)

Distribuição. Brasil (BA, MG, ES, RJ, SP, PR, SC, RS). (Costa, 1975a; 1975b).

Material examinado. P. cincticollis. BRASIL. Rio de Janeiro: Itatiaia, i.1967, Dirings col., 2

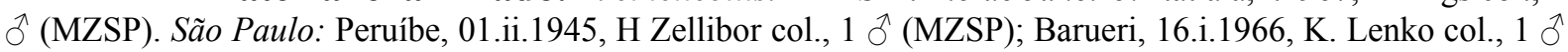

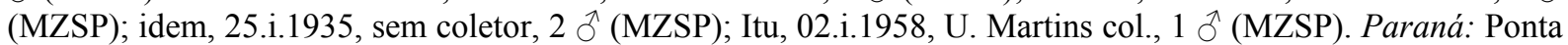

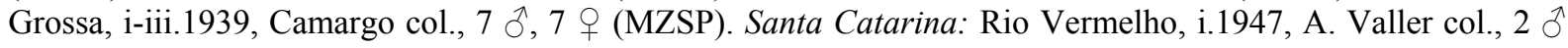


(AMNH). Rio Grande do Sul: Aratinga, 25.ii.1964, Carbonell, Mesa \& Monné col., 2 q (MZSP); P. gilvus. Sem localidade, sem data, sem coletor, 1 đ̄ (IBSP). BRASIL. São Paulo: Salesópolis (Boracéia), 12-14.xi.1969, C. Costa col., ô (Holótipo) (MZSP); idem, 1 (Parátipo) (MZSP); idem, 16-18.i.1980, Exp. MZUSP col., 1 우 (MZSP); Casa Grande, 27.ii.1986, Exp. MZUSP col., 1 q (MZSP). P. maculicollis. BRASIL. Rio de Janeiro: Itatiaia, i.1967, Dirings col., 3 $\widehat{~}$ (MZSP). São Paulo: São Paulo, Cantareira, i.1941, Dirings col., 1 đ̊ (MZSP); idem, 24.i.1938, Zellibor-Hauff col., 1 đ̄ (MNRJ); Ipiranga, 21.xii.1965, U. R. Martins col., 1 q (MZSP). Santa Catarina: Anita Garibaldi, xii.1936, i.1941, Dirings col., 1 Jे, 1 ○ (MZSP).

Comentários. Pyroptesis pode ser facilmente separado dos demais gêneros da tribo pela coloração do pronoto, amarelado ou alaranjado com uma mancha preta ou castanha, grande e subcircular na região discal ( $P$. cincticollis) ou com uma mancha mais ou menos trapezoidal cobrindo o terço mediano do pronoto (P. maculicollis). P. gilvus possui o pronoto inteiramente amarelado ou castanho alaranjado. P. cincticollis é similar a Meroplinthus ambrosius, mas pode ser diferenciada desta pela coloração alaranjada mais clara e mais brilhante e pela forma do terceiro antenômero. A forma dos ápices dos parâmeros nas espécies de Pyroptesis parece ser uma sinapomorfia para o gênero.

\section{Sooporanga Costa, 1975}

(Figs. 33, 72, 146, 147, 202-205, 232 )

Pyrophorus Billberg, 1820: 20 (pars).

Sooporanga Costa, 1975: 89; Golbach, 1994: 28.

Espécie-tipo: Pyrophorus formosus Germar, 1841 (Localidade-tipo:Brasil).

Redescrição. Macho (Fig. 232). Bicolorido, predominantemente alaranjado com uma estreita e alongada mancha preta mediana na região discal do pronoto, margens laterais e suturais dos élitros pretas, antenômeros 4-11 geralmente castanhos ou pretos. Pilosidade curta, fina, dourada, semidecumbente a eriçada. Tegumento brilhante.

Fronte subtrapezoidal, levemente côncava, com margem anterior entre as inserções antenais não carenada, fracamente carenada sobre as inserções antenais; pontuação fina, espaçada e simples. Antenas (Fig. 33) serreadas a partir do quarto antenômero, 
ultrapassando o ângulo posterior no $10^{\circ}$ antenômero; comprimento do $3^{\circ}$ antenômero 2,1 vezes o comprimento do $2^{\circ} ; 4^{\circ} 1,4$ vezes o comprimento do $3^{\circ}$. Olhos de tamanho médio (índice ocular 0,48-0,50), margem ocular levemente emarginada posteriormente. Mandíbula denteada.

Protórax subquadrado (1,1 vez mais largo que longo), de lados arredondados. Pronoto pouco convexo, com pontuação homogênea, fina, espaçada e simples; com órgãos luminescentes em forma de vesículas ovais a subcirculares, convexas, sublaterais. Região mediana posterior sem tubérculo. Ângulos anteriores agudos, grandes; ângulos posteriores delgados, divergentes e fracamente carenados. Prosterno moderadamente alongado de lados quase retos, com pontuação fina, moderadamente densa, simples. Processo prosternal com região apical denteada, dente saliente, região posterior ao dente longa $(14-17,5 \%$ do comprimento total do processo). Hipômeros (Fig. 72) com aproximadamente 3/4 posterior glabros, com pontuação fina, espaçada a densa e umbilicada, margem posterior truncada, sem espinho.

Mesoventrito. Margem lateral anterior com ângulo externo proeminente, parte ventral sinuosa, próxima da base, parte dorsal não visível. Cavidade mesoventral com bordas posteriores pouco inclinadas em relação à região anterior. Metaventrito com pontuação fina, espaçada a moderadamente densa, simples. Élitros com estrias fracamente marcadas, interestrias achatadas, com pontuação muito fina e muito espaçada, quase imperceptível.; lados gradulamente afilados até os ápices; ápices arredondados. Abdômen gradualmente afilado posteriormente, ventritos com pontuação fina, espaçada, simples. Primeiro esternito abdominal com lamelas laterais fracamente esclerotizadas, com órgão luminescente ocupando $1 / 3$ do esternito I. Base fusionada do esternito IX e tergito IX com região mediana anterior menos esclerotizada que as laterais.

Edeago (Figs.146, 147). Parâmeros gradualmente afilados para o ápice, sem carena ou espinho látero-dorsal; processo da articulação dorsal inteiro, bases medianas 
ventrais fusionadas ao esclerito ventral do pênis. Esclerito dorsal do pênis delgado, afilado para o ápice, com prolongamentos basais 0,6 vez o comprimento da região posterior, com escamas minúsculas nas margens látero-anteriores e espinhos cônicos minúsculos nas margens látero-posteriores. Esclerito ventral do pênis com aproximadamente 3/4 da largura do esclerito dorsal, com minúsculas escamas dirigidas anteriormente nas margens láteroposteriores

Fêmea: Similares aos machos, levemente mais convexas, com antenas mais curtas.

Membrana interconectiva do segmento VIII (Fig. 204) com um par de escleritos laterais de formato irregular. Genitália feminina (Fig. 202, 203). Baculi quase tão longos quanto os coxitos. Trato genital. Vagina com um par de glândulas coleteriais tão longas quanto largas. Região posterior de cada glândula coleterial membranosa e anterior com um esclerito espinhoso fortemente esclerotizado (Fig. 205). Bursa copulatrix saculiforme pequena, com poucos espinhos. Espermatecas não espiraladas.

Dimensões. Comprimento total $\widehat{\overbrace{}} 19,0-25,0 \mathrm{~mm}$, $, 25,0-26,0 \mathrm{~mm}$. Comprimento dos élitros em relação ao do protórax: $\widehat{o}$ e $\rho$ $3,5-3,8$. Largura do úmero em relação à do protórax: $\widehat{o}$ e $q$ 1,0-1,2.

Espécie. S. formosa (Germar, 1841).

Distribuição. Brasil (MG, RJ, SP, PR, SC).

Material examinado. BRASIL. Minas Gerais: Serra do Caraça, 27.xi.1972, Exp. MZUSP col., 1 ○ (MZSP); idem, xi.1961, Kloss, Lenko, Martins \& Silva col., 1 q (MZSP); idem, 25.xii.1974, M. A. Monné col., 1 đ (MZSP).Rio de Janeiro: Teresópolis, Soberbo (1000 đ), 22.i.1939, Travassos \& Oiticica col., 1 ô (MZSP). São Paulo: Campos do Jordão, sem data, sem coletor, 1 \& (MZSP); Botucatu, i.1974, Mantovani col., 1 ô (MZSP); Pindamonhangaba, Eug. Lefevre 1.200m, 21.xii.1962, Exp. Dep. Zool. Col., 1 ô, 2 우 (MZSP); Salesópolis (Boracéia), 12-17.i.1948, L. Trav. RF. \& D. Braz col., 1 đ̂ (IBSP). Paraná: Curitiba, ii.1942, sem coletor, 1 đ (IBSP Coll. J. Guerin). Santa Catarina: Rio Vermelho, i.1956, Dirings col., 1 ๙ (MZSP). 
Comentários. Sooporanga formosa é inconfundível entre os elaterídeos por sua coloração, pelo formato geral do corpo, delgado e alongado, e pelas vesículas luminescentes salientes.

\section{Gênero B gen. n.}

(Figs. 34, 148, 149, 233)

Pyrearinus Costa, 1975: 20 (pars).

Espécie-tipo: Pyrearinus cinnameus Costa, 1978 (localidade-tipo: Brasil, MT).

Descrição. Macho (Fig. 233). Coloração do corpo uniformemente castanhoescura ou com pernas e antenas mais claros. Pilosidade amarelada, fina, decumbente, curta, moderadamente densa. Tegumento brilhante.

Fronte retangular (1,20 mais longa que larga), quase plana, de lados paralelos, fracamente carenada; com pontuação média, densa e umbilicada. Antenas (Fig. 34) subserreadas a partir do quarto antenômero, atingindo no mínimo a base e no máximo o ápice dos ângulos posteriores; $3^{\circ}$ antenômero $1,5-2,0$ vezes mais longo que o $2^{\circ}, 4^{\circ} 1,2$ vezes o comprimento do $3^{\circ}$. Olhos de tamanho médio (índice ocular 0,50-52), margem ocular sem faixa preta e não emarginada. Mandíbula denteada.

Protórax subquadrado (quase tão largo quanto longo, de lados subparalelos) ou trapezoidal (lados fortemente convergentes anteriormente). Pronoto convexo; pontuação heterogênea, média a forte, densa e umbilicada por quase todo o pronoto, menor e mais densa junto às carenas laterais, com um par de órgãos luminescentes em forma de vesículas médias a grandes, subcirculares, levemente convexas ou achatadas, sublaterais, visíveis do hipômero. Região mediana posterior sem tubérculo. Ângulos anteriores agudos, grandes e fortemente projetados anteriormente; ângulos posteriores delgados fortemente carenados, pouco divergentes ou divergentes. Prosterno moderadamente alongado de lados quase retos, com 
pontuação forte, densa e umbilicada. Processo prosternal com região apical denteada, dente saliente, região posterior ao dente com comprimento médio a longo $(13 \%$ ou $19 \%$ do comprimento total do processo). Hipômeros com ângulos posterior e pequena área glabros; margem posterior truncada, sem espinhos.

Mesoventrito. Margem lateral anterior com ângulo externo não proeminente, parte ventral quase reta, próxima da base, parte dorsal pouco visível. Cavidade mesoventral com bordas posteriores pouco inclinadas em relação à região anterior. Metaventrito com pontuação fina, moderadamente densa a densa e umbilicada. Élitros com estrias marcadas, interestrias achatadas ou levemente convexas, com pontuação fina, moderadamente densa ou densa, umbilicada; lados subparalelos na metade anterior, gradualmente afilados para os ápices na metade posterior. Abdômen gradualmente arredondado posteriormente, ventritos com pontuação fina, espaçada a moderadamente densa, simples. Primeiro esternito abdominal com lamelas laterais fortemente esclerotizadas, com órgão luminescente subtrapezoidal ocupando $1 / 3$ a quase metade do esternito I.

Edeago (Figs. 148, 149). Parâmeros com ápice truncado carena látero-dorsal pouco saliente; processo da articulação dorsal com um recorte curto; bases medianas ventrais livres. Esclerito dorsal do pênis com prolongamentos basais 0,4 vez o comprimento da região posterior, de lados gradualmente afilados para o ápice. Esclerito ventral do pênis com aproximadamente $1 / 3$ da largura do terço posterior do esclerito dorsal, com linha longitudinal mediana saliente, ou seja, em forma de "V" invertido em corte transversal.

Fêmea. Com protórax de formato diferente, fortemente mais convexo e mais arredondado, antenas mais curtas, órgão luminescente abdominal menos desenvolvido.

Genitália Feminina. Membrana interconectiva do segmento VIII sem escleritos laterais. Baculi 1,4 vezes mais longo que os coxitos. Trato genital. Vagina com um par de glândulas coleteriais tão longa quanto larga. Regiões posterior e anterior de cada glândula 
coleterial membranosas. Bursa copulatrix com 1 espiral, sem espinhos. Espermatecas com ápice espiralado.

Dimensões. Comprimento total $\widehat{\partial} 17,0-20,0 \mathrm{~mm}$, $q$ 21,0 mm. Comprimento dos élitros em relação ao do protórax: $\overbrace{}^{\Uparrow} 2,6-3,4$; + 3,0. Largura do úmero em relação à do protórax: đ̊ 1,0-1,1; 9 0,9.

Espécies. Gênero B cinnameus (Costa, 1978) comb. n.; Gênero B sp. 2 sp. n.

Distribuição. Brasil (MS, ES, RS)

Material examinado. Gênero B cinnameus. BRASIL. Mato Grosso do sul: Camapuã, x.1967, sem coletor, 1 đิ (Holótipo) (MZSP); idem, 2 ô, 1 q (Parátipos) (MZSP). Rio Grande do Sul: sem localidade, sem data, sem coletor, $4 \delta$ (Parátipos) (NHRS); idem, 1 O (Parátipo) (MZSP); Porto Alegre, sem data, sem coletor, 1 (Parátipo) (MZSP). Gênero B sp. 2 sp. n. BRASIL. Espírito Santo: Linhares (Pq. Sooretana), xi.1960, D. Zajclw col., 7 ठै (MZSP).

Comentários. Este novo gênero é proposto para Pyrearinus cinnameus e para uma espécie nova similar que em nenhuma das hipóteses filogenéticas foram sugeridas como descendentes da linhagem ancestral exclusiva que inclui a espécie-tipo do gênero Pyrearinus. As autapomorfias desse gênero são: a fronte no macho retangular, mais longa que larga, que ocorre, independentemente também em Pyrophorus, e a forma do esclerito ventral do pênis, similar, mas homoplástica àquela de Nyctophyxis e Cryptolampros.

Gênero n. B se dintingue das demais espécies do gênero Pyrearinus pelas antenas mais alongadas, com artículos 4-11 foscos (em Pyrearinus são parcialmente brilhantes), pelos olhos menores não marginados posteriormente, pela forma da margem anterior do pronoto, com ângulos anteriores fortemente projetados, pelo prosterno mais alongado e pelo órgão luminescente abdominal, grande e bem desenvolvido. A fêmea de Genero n. B é muito similar a fêmea de várias espécies de Pyrearinus, mas pode ser separada destas pelas antenas relativamente mais longas e com artículos 4-11 foscos pelos élitros mais afilados na metade posterior. Gênero B cinnameus se diferencia da espécie nova principalmente pela forma de seu protórax, trapezoidal com ângulos posteriores divergentes. Os edeagos das duas espécies são muito similares. Fêmeas da espécie nova ainda não são conhecidas. 


\section{Phanophorus Solier, 1851}

(Figs. 35, 54, 71, 150, 151, 234)

Phanophorus Solier, 1851: 26; Lacordaire, 1857: 205; Candèze, 1863: 3, 67-66; Schenkling, 1927: 345; Blackwelder, 1944: 285; Costa, 1975b: 95, 96; Golbach, 28.

Espécie-tipo: Phanophorus parallelus Solier, 1851 (designado por Hyslop, 1921: 663) (Localidade-tipo: Chile).

Redescrição. Macho (Fig. 234). Coloração geralmente uniformemente castanhoclara a castanho-escura, raramente uniformente preta ou com protórax parcial a completamente mais claro, castanho amarelado. Pilosidade dourada, fina, curta na face dorsal, mais alongada na face ventral, semidecumbente, moderadamente densa a espaçada. Tegumento brilhante.

Fronte subtrapezoidal, levemente cônvaca, fracamente carenada; pontuação fina, densa e umbilicada. Antenas (Fig. 35) subserreadas a partir do quarto antenômero, ultrapassando os ângulos posteriores no $10^{\circ}$ antenômero; $3^{\circ}$ antenômero 1,3 vezes mais longo que o $2^{\circ}, 4^{\circ} 1,3$ vezes o comprimento do $3^{\circ}$. Olhos de tamanho médio (índice ocular 0,51-54), borda posterior do olho não emarginada. Mandíbula denteada.

Protórax (Fig. 54) subtrapezoidal, com lados levemente arredondados e convergentes anteriormente. Pronoto pouco convexo, com margem anterior arredondada e proeminente; pontuação heterogênea, fina, espaçada e simples na região discal e posterior, mais densa e umbilicada nas margens laterais e anterior, com um par de órgãos luminescentes em forma de vesículas médias a grandes, subcirculares, levemente convexas ou achatadas, laterais, visíveis do hipômero. Região mediana posterior sem tubérculo. Ângulos anteriores retos não projetados além da margem mediana anterior do pronoto; ângulos posteriores delgados, carenados e divergentes. Prosterno curto de lados curvos, com pontuação média, densa e umbilicada. Processo prosternal com região apical denteada, dente pouco saliente, região posterior ao dente com comprimento médio $(8,5-10,9 \%$ do comprimento total do 
processo). Hipômeros (Fig. 71) com 1/2 posterior glabra; margem posterior com dois espinhos.

Mesoventrito. Margem lateral anterior com ângulo externo proeminente, parte ventral curva, posterior à base, parte dorsal visível. Cavidade mesoventral com bordas posteriores pouco inclinadas em relação à região anterior. Metaventrito com pontuação fina, moderadamente densa a densa, simples. Élitros com estrias pouco marcadas, interestrias achatadas, com pontuação fina, densa; lados subparalelos até o terço apical; ápices conjuntamente arredondados. Abdômen gradualmente arredondado posteriormente, ventritos com pontuação fina, espaçada a moderadamente densa, simples. Primeiro esternito abdominal com lamelas laterais fracamente esclerotizadas, com órgão luminescente subtrapezoidal ocupando quase completamente o esternito I.

Edeago (Figs. 150, 151). Parâmeros abruptamente estreitados no terço apical, ápice afilado com ponta, dirigido látero-ventralmente, sem carena ou espinho; processo da articulação dorsal com um recorte curto; bases medianas ventrais livres. Esclerito dorsal do pênis com prolongamentos basais 0,2 vez o comprimento da região posterior, de lados gradualmente arredondados para o ápice. Esclerito ventral do pênis com aproximadamente 1/5 da largura do terço posterior do esclerito dorsal, com linha longitudinal mediana saliente, ou seja, em forma de "V" invertido em corte transversal.

Fêmea. Com olhos menores, protórax de formato diferente, fortemente mais convexo e mais arredondado; élitros mais arredondados e convexos; antenas mais curtas; órgão luminescente abdominal menos desenvolvido; asas 1/3 mais curtas que os élitros.

Membrana interconectiva do segmento VIII sem escleritos laterais. Genitália Feminina. Baculi 0,9 vezes mais longo que os coxitos. Trato genital. Vagina com um par de glândulas coleteriais tão longa quanto larga. Regiões posterior e anterior de cada glândula coleterial membranosas. Bursa copulatrix saculiforme pequena, sem espinhos. Espermatecas com ápice espiralado. 
Dimensões. Comprimento total $\widehat{\overbrace{}} 10,0-14,0 \mathrm{~mm}$, $q$ 12,0-15,0 mm. Comprimento dos élitros em relação ao do protórax: $\widehat{\jmath}$ 3,7-4,5; ㅇ 3,1-4,2. Largura do úmero em relação à do protórax: đึ 1,2; ㅇ 0,9-1,0.

Espécie. Phanophorus perspicax (Guérin-Méneville, 1830).

Distribuição. Chile.

Material examinado. CHILE. Concepción: Fundo Pinares, 27.ii.1967, T. Cekalovic col., 19 ô (MZSP); idem, 23.ii.1968, T. Cekalovic col., 23 o (MZSP); idem, 12.i.1969, T. Cekalovic col., 14 ๙ 1 ㅇ

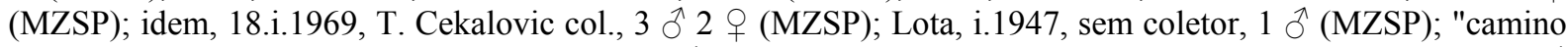
a Santa Juana", 23.i.1968, T. Cekalovic col., 9 ô (MZSP). Malleco: Angol, 30.i.1964, A. J. Sanchez col., 1 ठे (Mich. St. Univ.); idem, 25.i.1964, A. J. Sanchez col., 1 đิ (Mich. St. Univ.). Cautin: Temuco, 15.xii.1967, sem coletor, 5 § (MZSP); $20 \mathrm{Km}$ de Temuco, 08.i.1951, Ross \& Michelbacher col., 1 우 (S. F.); Zahuelhue, 05.i.1958, sem coletor, 1 ð (Mich. St. Univ.); Gorbea, 18.ii.1965 sem coletor, 1 † (Mich. St. Univ.); Vilcún, 02.i.1960, G. Caba col, 1 ○े (Mich. St. Univ.). Osorno: 1905, P. Herbst, 1 ㅇ (S. F.). Arauco: sem data, sem coletor, 1 ô (MZSP). Colchagua: sem data, sem coletor, $1 \hat{\jmath}$ (S. F.).

Comentários. Phanophorus pode ser facilmente identificado pelo aspecto geral do corpo, com protórax subtrapezoidal e élitros muito mais alongados que o pronoto. Assemelha-se levemente a Hypsiophthalmus, do qual pode ser prontamente separado pelos olhos menores, pela fronte menos côncava e pela forma do pronoto, com lados menos convergentes anteriormente e margem mediana anterior menos projetada. As fêmeas de Phanophorus também são similares as de Hypsiophthtalmus e podem ser separadas pelo corpo menos convexo, geramente mais brilhante e pelas antenas mais alongadas.

\section{Hypsiophthalmus Latreille, 1834}

(Figs. 11, 19, 36, 55, 59, 105, 152, 153, 236, 237)

Pyrophorus Billberg, 1820: 20 (pars).

Hypsiophthalmus Latreille, 1834: 145; Germar, 1841: 11; Candèze, 1863: 3, 68;

Schenkling, 1927: 345; Blackwelder, 1944: 285; Costa, 1975b: 95, 97; Golbach, 1994: 28, 42.

Belania Castelnau, 1840: 236; Candèze, 1863: 3, 67; Schenkling, 1927: 345;

Blackwelder, 1944: 285; Costa, 1975b: 97 
Espécie-tipo: Pyrophorus boophthalmus Eschscholtz, 1829 (designado por Costa, 1975b: 98) (Localidade-tipo: La Plata).

Redescrição. Macho (Fig. 236). Coloração uniformemente castanho-escura. Face dorsal glabra ou com pilosidade curta a alongada, dourada, muito fina, espaçada, semidecumbente a eriçada; face ventral sempre pilosa, cerdas mais alongadas que a da face dorsal. Tegumento brilhante ou opaco e micropontuado

Fronte (Fig. 11) trapezoidal com lados curvos para fora, cônvaca, fracamente carenada ou não carenada entre as inserções anternais, pontuação fina, densa e umbilicada. Antenas (Fig. 36) subserreadas a partir do quarto antenômero, curtas, atingindo no mínimo as vesículas luminescentes e no máximo a base dos ângulos posteriores; $3^{\circ}$ antenômero $1,5-1,7$ vez mais longo que o $2^{\circ}, 4^{\circ} 0,8-1,1$ vez o comprimento do $3^{\circ}$; em algumas espécies os antenômeros 4-11 são recobertos por cerdas alongadas e eriçadas. Olhos grandes (índice ocular 0,76-0,88), borda posterior do olho não emarginada (Fig. 19). Mandíbula com ou sem dente subapical, base do lábio e das maxilas comprimidas lateralmente.

Protórax (Fig. 55, 59) trapezoidal, com lados levemente arredondados e fortemente convergentes anteriormente. Pronoto pouco convexo, com margem anterior arredondada e fortemente proeminente; pontuação geralmente homogênea, fina a média, espaçada a moderadamente densa simples ou umbilicada, com um par de órgãos luminescentes em forma de vesículas grandes, subcirculares, levemente convexas, sublaterais, visíveis do hipômero. Região mediana posterior sem tubérculo. Ângulos anteriores retos não projetados além da margem mediana anterior do pronoto; ângulos posteriores delgados e alongados ou fortes e curtos, carenados, divergentes. Prosterno curto de lados curvos, com pontuação média, densa e umbilicada. Processo prosternal com região apical denteada, dente saliente, região posterior ao dente longa (19\% do comprimento total do processo). Hipômeros com 1/4-1/3 posterior glabro; margem posterior truncada, sem espinhos. 
Mesoventrito. Margem lateral anterior (Fig. 82) com ângulo proeminente, parte ventral curva, posterior à base, parte dorsal visível. Cavidade mesoventral com bordas posteriores pouco inclinadas em relação à região anterior. Metaventrito com pontuação fina, moderadamente densa a densa, simples. Élitros com estrias pouco ou fortemente marcadas, interestrias achatadas a levemente convexas, com pontuação fina, densa; lados gradualmente arredondados até o ápice; ápices conjuntamente arredondados. Abdômen gradualmente arredondado posteriormente, ventritos com pontuação fina, espaçada a moderadamente densa, simples. Primeiro esternito abdominal (Fig. 105) com lamelas laterais membranosas ou fortemente esclerotizadas, em algumas espécies as lamelas são contínuas, estendendo-se na frente do órgão, formando uma projeção mediana; com órgão luminescente retangular ou subtrapezoidal ocupando 1/3-1/2 do esternito I.

Edeago (Figs. 152, 153). Parâmeros gradualmente estreitados para o ápice; ápice afilado em ponta com ou sem uma carena látero-dorsal ou truncado e com carena-láterodorsal; processo da articulação dorsal com um recorte curto; bases medianas ventrais livres. Esclerito dorsal do pênis com prolongamentos basais $0,2-0,6$ vez o comprimento da região posterior, delgado de lados afilados para o ápice. Esclerito ventral do pênis com aproximadamente 1/5 da largura do esclerito dorsal, com linha longitudinal mediana saliente, ou seja, em forma de "V" invertido em corte transversal, com ou sem escamas minúsculas dirigidas posteriormente.

Fêmea (Fig. 237). Com olhos menores; protórax de formato diferente, fortemente mais convexo e mais arredondado; élitros mais arredondados e convexos; órgão luminescente abdominal menos desenvolvido; asas 1/3 mais curtas que os élitros.

Membrana interconectiva do segmento VIII sem escleritos laterais. Genitália Feminina. Baculi 1,6 vezes mais longo que os coxitos. Trato genital. Vagina com glândulas coleteriais muito curtas ou indistintas. Regiões posterior e anterior de cada glândula coleterial 
membranosas. Bursa copulatrix saculiforme pequena, sem espinhos ou com poucos espinhos reduzidos. Espermatecas com ápice espiralado.

Dimensões. Comprimento total $\overparen{\jmath} 13,0-20,0 \mathrm{~mm}$, $\uparrow$ 15,0-22,0 mm. Comprimento dos élitros em relação ao do protórax: $\widehat{\jmath}$ 3,3-4,3; $\uparrow$ 2,7-3,6. Largura do úmero em relação à do protórax: đ̂ 1,2-1,3; q 0,9-1,0.

Espécies. H. ardens (Candèze, 1863); H. boops (Germar, 1841); H. buphthalmus (Eschscholtz, 1829); H. charops Costa, 1979; H. grossicollis (Blanchard, 1843); H. longipennis (Germar, 1841); H. luscius Costa, 1979; H. microspilus (Germar, 1841); H. punctatum Costa, 1979; H. raninus (Eschscholtz, 1829)

Distribuição. Brasil (MG, RJ, SP, PR, SC, RS), Paraguai, Uruguai e Argentina. Costa (1979).

Material examinado. H. ardens. BRASIL. Minas Gerais: Manhuaçu, 15.x.1936, sem

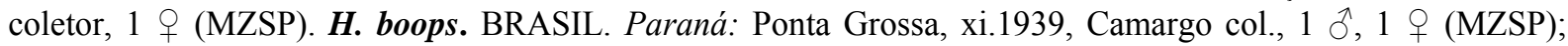
Curitiba, xii.1934, Morretes col., $3 \widehat{\diamond}$ (MZSP); idem, sem data, Szabo, $3 \widehat{\diamond}$ (S. F. Coll. A. Fenyes). H. boophthalmus. BRASIL. Paraná: Ponta Grossa, xi.1939, Camargo col., 1 đิ (MZSP). Rio Grande do Sul: i.1962, sem coletor, 1 ô (MZSP). Sem localidade, sem data, sem coletor, 2 ô (BMNH Coll. Janson ex Schaum). URUGUAI. Montevideo: Montevideo, sem data, sem coletor, $1 \hat{\jmath}$ (ISNB Coll. Candèze). H. charops. BRASIL. Sem localidade, sem data, sem coletor, $2 \hat{\jmath}$ (MZHF); idem, $2 \hat{~}$ (CNHM); idem, $1 \hat{\jmath}$ (ISNB Coll. Candèze). Rio de janeiro: Petrópolis, sem data, sem coletor, $1 \widehat{\jmath}$ (MZHF); Petrópolis, ii.1857, H. Clark col., 1 § (BMNH); sem localidade, sem data, sem coletor, 1 § (BMNH). H. grossicollis. BRASIL. Rio Grande do Sul: sem data, Pe. Buck col., 1 ô (MZSP); Pelotas, sem data, sem coletor, 1 o (MNHN). URUGUAI. Sem localidade, sem data, sem coletor, 4 ô, 3 ㅇ (ISNB Coll. Candèze). Artigas: Arroyo de la Invernada, 18.xi.1954, C. S. Carbonell col., 2 ㅇ (MAPA); Arroyo Catalém Chico, 23.i.1960, C. Fuques col., 1 ㅇ (MAPA); Rio Cuareim Picada del Negro Muerto, 15.i.1952, C. S. Carbonell col., 1 क (MAPA). Durazno: Paso de la Cruz (Arroyo Cordobez), 29.i.1968, P. R. San Martin col., 3 đ , 2 + (MAPA). Rivera: Subida de Peña Cuchila Negra, 21.xi.1961, Carbonel \& Zolossi col., 1 ๆ (MAPA); Arriera, 08.i.1934, C. S. Carbonell col., 1 ○ (MAPA). Tacuarembó: Arroyo Laurales, xi. 1965, Monné col., 1 † (MAPA); Puntas Arroyo Laurales, 12.xi.1954, C. S. Carbonell col., 1 q (MAPA). Teinta y Tres: Santa Clara de Olimar, 13.i.1960, Zolessi \& Spiritoso, 1 ㅇ (MZSP). Paysandú: Arroyo Guariyú, 06.i.1951, P. R. San Martin col., 1 (MAPA); Arroyo Guariyú Parada Ribas, 19.i.1951, P. R. San Martin col., 1

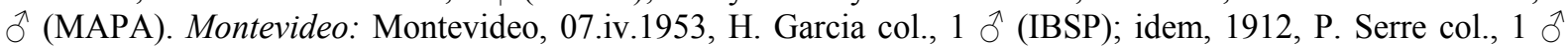
(MNHN). BRASIL. Rio de janeiro: Teresópolis, 01-08.xii.1977, F. Val col., 1 ô (MZSP). H. longipennis. BRASIL. Sem localidade, sem data, sem coletor, 5 q (ISNB Coll. Candèze). Rio de janeiro: 1907, sem coletor, 1 q (SMFTD Coll. C. Felsche). Santa Catarina: Corupá, xii.1953, A. Maller col., 1 Ô, 3 f (MNRJ Col. Campos Seabra). H. luscius. São Paulo: São Paulo, Parque Bristol, 10.x.1965, B. N. Dias col., ô (Holótipo) (MZSP); Ipiranga, sem data, sem coletor, 1 q (Parátipo) (MZSP); Capital, 1946, sem coletor, 1 ô (Parátipo) (MZSP); Jundiaí, sem data, sem coletor, 1 đิ (Parátipo) (MZSP); Casa rande, iii.1937, sem coletor, 1 đิ (Parátipo) (MZSP); Peruíbe, 15.x.1936, sem coletor, 1 ô (MZSP); Cidade Universitária USP, 17.x.1979, L. R. Fontes, 1 ภ (MZSP). H. microspilus. BRASIL. São Paulo: Rio Claro, i. 1925, sem coletor, 1 ô (MZSP). Paraná: Curutiba,

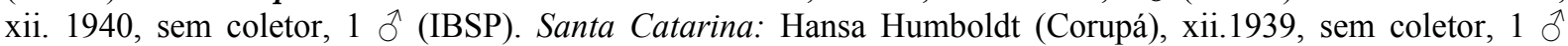
(AMNH). H. punctatum. PARAGUAI. Alto Paraná: Hohenau, 1954, H. Jacob col., 1 đo (Parátipo) (BMNH).H. raninus. BRASIL. Paraná: Parque Nacional Foz do Iguaçu, iii.2002, C. A. Rheims et al. col., 1 ô (MZSP). Santa Catarina: Corupá, xii.1953, A. Maller col., 3 ô (MNRJ Col. Campos Seabra); Rio vermelho, i.1956, Dirings col., 3 ô (MZSP); Anita Garibaldi, ii.1936, Dirings col., 1 ô (MZSP). 
Comentários. $H$. ardens não foi considerada na análise filogenética porque apenas a fêmea desta espécie é conhecida. Esta espécie difere das demais do gênero pelas asas tão longas quanto os élitros e pelo órgão luminescente abdominal bem desenvolvido. Esses caracteres parecem ser autapomórficos para esta espécie, mas as cerdas alongadas e eriçadas em todos os artículos das antenas parece ser uma sinapomorfia compartilhada com várias outras espécies de Hypsiophthalmus. Os machos de Hypsiophthalmus são bem caracterizados pelos olhos grandes, pela forma da fronte, trapezoidal de lados curvos para fora e fortemente convexa e pela forma do pronoto, trapezoidal com ângulos anteriores retos e margem mediana anterior fortemente projetada. As fêmeas são similares às de algumas espécies de Pyrearinus, mas possuem asas mais curtas.

\section{Pyrearinus Costa, 1975}

(Figs. 6, 14, 17, 18, 21, 37, 56, 57, 60, 61, 66, 67, 75, 76, $83,84,154-161,206-212,235)$

Pyrophorus Billberg, 1820: 20 (pars).

Pyrearinus Costa, 1975: 95, 99; Golbach, 1994: 29, 43.

Espécie-tipo: Pyrophorus nyctolampis Germar, 1841 (Localidade-tipo: porto Alegre).

Redescrição. Macho (Fig. 235). Coloração geralmente uniforme, castanha-clara a preta, ou com pronoto bicolorido, castanho e alaranjado ou amarelado com padrões de manchas variáveis. Aparentemente glabro a olho nu ou com pilosidade curta a alongada, dourada, amarelada ou acizentada, espaçada a densa, decumbente a semidecumbente; pilosidade da face ventral igual ou mais alongada que a da face dorsal. Tegumento brilhante ou opaco e micropontuado. Pontuação geral do corpo muito variável, muito fina a forte, espaçada a muito densa, simples ou umbilicada. 
Fronte (Fig. 14) trapezoidal com lados retos, levemente cônvaca a côncava, fracamente carenada ou não carenada entre as inserções antenais. Antenas (Fig. 37) subserreadas a partir do quarto antenômero, atingindo no mínimo a margem anterior do pronoto e no máximo a base dos ângulos posteriores; $3^{\circ}$ antenômero 1,3-2,1 vezes mais longo que o $2^{\circ}, 4^{\circ}$ 1,0-1,1 vez o comprimento do $3^{\circ}$; antenômeros 4-11 divididos longitunalmente em duas áreas: uma interna fosca e uma externa brilhante. Olhos (Figs. 17, 18) grandes (índice ocular 0,70-0,94), margem ocular fortemente emarginada posteriormente (Fig. 21). Mandíbula (Fig. 6) com ou sem dente subapical, base do lábio e das maxilas geralmente comprimidas lateralmente.

Protórax (Figs. 56, 57, 60, 61) subquadrado ou subretangular (1,1-1,4 vezes mais largo que longo), com lados paralelos ou levemente arredondados. Pronoto pouco convexo, com margem anterior sinuosa a levemente arredondada, pouco projetada; pontuação geralmente homogênea ou mais densa e umbilicada nas laterais; com um par de órgãos luminescentes em forma de vesículas médias a grandes, subcirculares, levemente convexas e sublaterais, visíveis do hipômero. Região mediana posterior sem tubérculo. Ângulos anteriores retos; ângulos posteriores delgados e alongados ou fortes e curtos, fracamente carenados a carenados, pouco divergentes a divergentes. Prosterno (Figs. 66, 67) curto de lados curvos. Processo prosternal de perfil curvo ou reto (Figs. 60, 61), com região apical denteada, dente saliente, região posterior ao dente com comprimento médio a longo $(11,6-$ $23,6 \%$ do comprimento total do processo). Hipômeros inteiramente pilosos a $1 / 3$ posterior glabro; margem posterior truncada, sem espinhos.

Mesoventrito. Margem lateral anterior (Figs. 83, 84) geralmente com ângulo externo proeminente, parte ventral levemente sinuosa a curva, próxima da base e parte dorsal visível ou parte ventral sinuosa, próxima da base e parte dorsal pouco visível. Cavidade mesoventral com bordas posteriores (Figs. 75, 76) pouco inclinadas em relação à região anterior, não salientes. Élitros com estrias fraca a fortemente marcadas, interestrias achatadas 
a levemente convexas, gradualmente afilado para os ápices; ápices conjuntamente arredondados. Abdômen gradualmente afilado posteriormente. Primeiro esternito abdominal com lamelas laterais membranosas, com órgão luminescente pouco desenvolvido, mais ou menos triangular, ocupando $1 / 5$ do esternito I.

Edeago (Figs.154-161). Parâmeros com ápice truncado ou arredondado, com carena látero-dorsal fracamente saliente ou saliente; processo da articulação dorsal com um recorte longo, quase atingindo a metade da região posterior; bases medianas ventrais livres. Esclerito dorsal do pênis com prolongamentos basais $0,3-0,7$ vez o comprimento da região posterior, geralmente delgado de lados afilados para o ápice. Esclerito ventral do pênis com aproximadamente $1 / 3$ da largura do esclerito dorsal, com ou sem uma carena alongada na linha longitudinal mediana, raramente com ápice alargado e espatulado ( $P$. ferrugineus, $P$. fulvus e P. fulvescens, Fig. 156)

Fêmea. Com olhos menores; protórax de formato diferente, com ângulos anteriores agudos, levemente a fortemente mais convexo e arredondado; élitros subiguais aos do macho ou mais arredondados e convexos. Fêmeas de algumas espécies possuem asas aproximadamente 1/8 mais curtas que os élitros, outras possuem vesículas luminescentes maiores.

Membrana interconectiva do segmento VIII sem escleritos laterais. Genitália Feminina (Figs. 206-212). Baculi 1,1-2,1 vezes mais longo que os coxitos. Trato genital. Vagina com glândulas coleteriais tão longas quanto largas a mais longas que largas. Região posterior de cada glândula coleterial com ou sem um esclerito côncavo formado por microscleritos (Fig. 212b), região anterior com ou sem um esclerito espinhoso fortemente esclerotizado (Figs. 212a, 210). Bursa copulatrix saculiforme pequena, sem espinhos ou com poucos espinhos reduzidos ou com 2-3 espirais com espinhos alongados. Espermatecas com ápice espiralado ou capitado (Fig. 206). 
Dimensões. Comprimento total $\widehat{\jmath} 7,4-19,2 \mathrm{~mm}$, $q$ 10,0-21,7 $\mathrm{mm}$. Comprimento

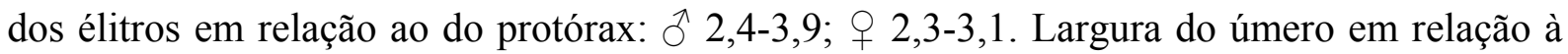
do protórax: ㅅ 1,0-1,2; ㅇ 0,9-1,0.

Espécies. P. sp. 1 sp.n.; P. acutus (Candèze, 1863); P. adustus Costa, 1978; P. alvarengai (Cobos, 1959); P. amplicollis (Candèze, 1863); P. baliolus Costa, 1978; P. brevicollis (Eschscholtz, 1829); P. brunneus Costa, 1978; P. candelarius (Germar, 1841); P. castaneus Costa, 1978; P. cinerarius (Germar, 1841); P. coctilis Costa, 1978; P. commissator (Germar, 1841); P. depressicollis (Blanchard, 1843); P. flatus Costa, 1978; P. ferrugineus Costa, 1978; P. fulgurans (Candèze, 1863); P. fulvescens Costa, 1978; P. fulvus Costa, 1978; P. fragilis Costa, 1978; P. janus (Herbst, 1806); P. lampadion (Illiger, 1807); P. latus Costa, 1978; P. lineatus (Candèze, 1863); P. lucernula (Illiger, 1807); P. lucidulus (Illiger, 1807); P. lucidus (Candèze, 1863); P. lucificus (Germar, 1841); P. luscinus Costa, 1978; P. micatus Costa, 1978; P. nictitans (Illiger, 1807); P. nyctolampis (Germar, 1841); P. nyctophilus (Germar, 1841); P. pumilus (Candèze, 1863); P. pusillus Costa, 1978; P. retrospiciens (Illiger, 1807); P. ruscus Costa, 1978; P. scintillula (Candèze, 1881); P. termitilluminans Costa, 1982; P. vitticollis (Germar,1841).

Distribuição. Trinidad \& Tobago, Colômbia, Venezuela, Guiana, Suriname, Guiana Francesa, Equador, Peru, Brasil (AM, PA, AP, RO, RN, CE, PE, AL, SE, BA, MT, MS, GO, MG, ES, RJ, SP, PR, SC, RS), Bolívia, Paraguai, Uruguai, Argentina. (Costa, 1978).

Material examinado. P. sp. 1. BRASIL. Minas Gerais: Monte Verde, 24.xii.1970, J. Halik col., 7 đ 4 , 9 (MZSP). P. acutus. VENEZUELA. Amazonas: San Juan de Manapiare, 24;iii.1958, sem coletor, 1 I (MLS); Caracas, sem data, sem coletor, 1 ( (MNHN). COLÔMBIA. Sem localidade, sem data, sem coletor, 2 ㅇ (ISNB Coll. Candèze). Cordoba: Cispata Bay, vi.1916, Bruce Martin col., 3 ${ }^{1}$ (SMFD). Magdalena: Minca, sem data, sem coletor, 1 † (CMNH). P. alvarengai. BRASIL. Pernambuco: Fernado de Noronha, v. 1954, M. Alvarenga col., $\widehat{o}$ (Holótipo) (MZSP). P. amplicollis. TRINIDAD \& TOBAGO. Arima Valley, 11.iii.1952, sem coletor, 1 ○े (AMNH); St. Augustine, iv.1929, Darlington, 1 ㅇ (MCZ); 24.iii.1922, L. R. Reybold col., 2 우 (CNHM); Arima Valley, 13.iv.1951, sem coletor, 1 ô (AMNH). VENEZUELA. Sem localidade, 19.iv.1899, sem coletor, 4 đ (CMNH). Bolivar: Rio Caura, Cecilia Magdalena, 01.i.1957, P. San Martin col., 1 ô (MAPA). GUIANA. Bartica, Kartabo, 1917, sem coletor, 1 ㅇ (SMFD); Bartica, Kartabo, 19.x.1920, sem coletor, 1 ㅇ (SMFD). BRASIL. Amazonas: Reserva Ducke AM 010 Km 26, 06.ix.1977, Jorge Arias col., 1 ○ (MZSP). Rondônia: Porto Velho, 24.viii.1979, J. Campbell, 1 + (MZSP). PERU. Rio Ucayali, 01.xii.1923, sem coletor, 1f (AMNH Coll. H. Bassler). P. baliolus. URUGUAI. Paysandú: Blanquillo, i. 1947, A. Mesa col., ồ (Holótipo) (IBSP). San José: Ruta 3 Km 123, 09.ii.1970, L. E. F. A col., 8 ô (FHCM). Rivera: Sierra de la Aurora, 1226.i.1971, M. A. Monné et al. col., 3 ô (FHCM). P. bruneus. URUGUAI. Artigas: 23.i.1958, C. Fuques, 2 đ (MAPA). Rivera: 19.ii.1961, Carbonell \& Zolessi col., 1 กे (MAPA). ARGENTINA. Santiago del Stero: 
xi.1956, El Pinto col., $\widehat{o}$ (Holótipo) (CNCI); idem, 4 đิ (Parátipos) (CNCI). Chaco: Rio Salado, sem data, sem coletor, 4 ô (MNHN). Missiones: Rio Parana, sem data, sem coletor, 1 o, 1 ( $(\mathrm{MNHN})$. P. adustus. BRASIL. Bahia: Bom Jesus dos Meiras, x.1923, O. Harrington col., § (Holótipo) (CNHM); idem, 13 đ (Parátipos) (CNHM). P. candelarius. BRASIL. Alagoas: sem localidade, xi.1952, S. Miguel col., 1 ô (MZSP). Espírito Santo: Linhares, Parque Sooretama, sem data, Dirings col., 1 ते (MZSP). Minas Gerais: Serra do Caraça, 27.xi.1972 Exp. MZSP col., 7 ô (MZSP); Serra do Caraça 1380 ô, xi.1961, Kloss, Lenko, Martins e Silva col., 3 $\widehat{\jmath}$ (MZSP). Rio de Janeiro: Itatiaia, i.1972, Dirings col., 1 đิ (MZSP); Parque Nacional Itatiaia, 20-28.ii.1968, H.

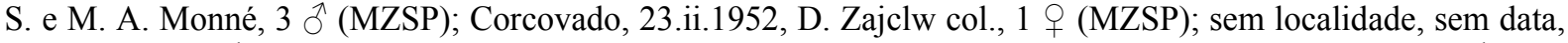
sem coletor, 5 ô (MZHF). São Paulo: Bragança Paulista, Faz. Santana, 19.ii.1987, J. da Silva col., 4 ô, 3 우 (MZSP); São Paulo, Ipiranga, sem data, sem coletor, 1 đ̃ (MZSP); Capão Bonito, Sítio Cambará, 4-22.i.1988, Aldo Campanha col., 22 ô, 1 q (MZSP); Anhembi, xi.1957, E. Dente col., 3 ô (MZSP); Itu, Faz. Pau d'Alho, 21.xii.1957, U. Martins col., 1 † (MZSP); Campinas, xi.1945, J. Guérin col., 1 đ̃ (MZSP). Paraná: Ponta Grossa, xii. 1938, Camargo col., 7 ô, 11 (MZSP); Ponta Grossa, xii.1988, C. A. Camargo col., 4m, 3 ㅇ (MZSP). Santa Catarina: Blumenau, 2-5.xii.1975, Exp. DZUSP, 1 đ̄ (MZSP); Joinville, xii.1950, Dirings col., 1 ô (MZSP); Rio Vermelho, iii.1960, Dirings col., 1m (MZSP). PARAGUAI. Rio He Houg (?), xii.1936, B. Podtiaguine col., $5 \pi$ (ISNB). P. brevicollis. BRASIL. Bahia: sem localidade, sem data, D. Davis col., $1 \hat{\sigma}$

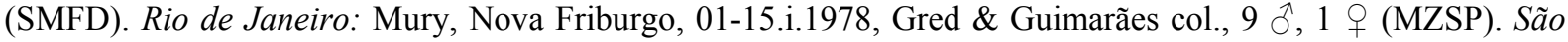

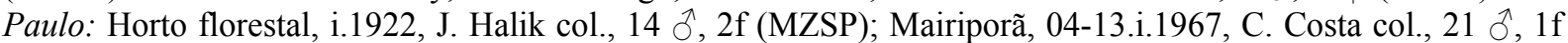
(MZSP). Paraná: Prudentópolis, 1955, J. Issak \& Zewlereje col., 2 đ̄ (CNHM). Santa Catarina: Nova Teutônia, ii.1966, F. Plaumann col., 1 đิ (MZSP). P. castaneus. Bahia: Água Preta, 07.xi.1946, J. Souza col., 2 ô, $1 \mathrm{f}$

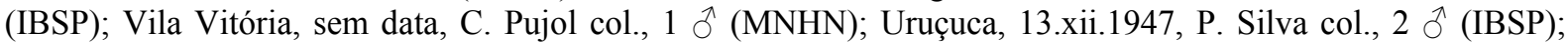

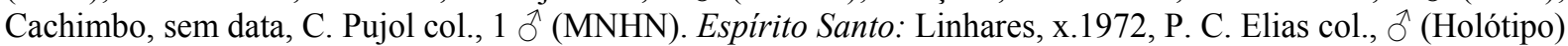
(MZSP); idem, 2 đ, 7 q (Parátipos) (MZSP). São Paulo: Ribeirão Preto, vii.1955, M. P. Barreto col., $1 \delta$ (MZSP). P. cinerarius. BRASIL. Santa Catarina: Nova Teutônia, i.1967, F. Plaumann col., 25 § (MZSP); idem, 10.i.1949, sem coletor, 5 ô (SMFD); Bom Retiro, i.1929, sem coletor, 2 q (MZSP); Florianópolis, i.1956, sem coletor, 5 (MZSP). P. coctilis. BRASIL. Mato Grosso: Diamantino, 14.xi.1966, Lenko \& Pereira col., 1 § (Parátipo) (MZSP); Porto Velho, Rio Tapirapé, 30.xii.1964, R. T. Lima col., 1m, 1 O (Parátipos) (MZSP). P. fulgurans. Mato Grosso do Sul: Murtinho, 22.xi.1928, Spitz col., 1 đ (Parátipo) (MZSP); Porto Esperança, Corumbá, 07.xii.1960, K. Lenko col., 1 (MZSP). Goiás: Jataí, Faz. Nova Orlandia, i.1964, Martins, Morgante \& Silva col., $\widehat{o}$ (Holótipo) (MZSP); idem, 3 ô (Parátipos) (MZSP). VENEZUELA. Bolivar: Rio Caura, Cecilia Magdalena, 01.i.1957, P. San Martin col., 2 ○ (MAPA).GUIANA. Kariabo, Bartica, 04.xi.1920, sem coletor, 2 q (SMFD Coll. Van Dyke). SURINAME. Anapaike (Rio Lawa), Marowijne, xi.1963, B. Malkin col., 2 우 (MZSP). GUIANA FRANCESA. Maroni, 1901, H. Lourtau col., 1 q (MNHN); Kaiserberg, 1960-1962, H. Beatty col., 1 F (CNHM); sem localidade, sem data, sem coletor, 3 ô, 4 q (ISNB).BRASIL. Amapá: Rio Amapari, 1959, J. Lane col., 1 ( (MZSP); Serra do navio, x.1964, E. Dente col., 1 ô (MZSP). Amazonas: Lago Acará, Borba, ix.1943, A. Parko col., 9 ○ (MNRJ); Itapiranga, xii. Xi.1968, Exp. Perm. Amaz., 2 q (MZSP). Pará: Mocajuba, Mangabeira, i.1953, Orlando Rego col., 13 đ, 15 q (MNRJ); Santarém, Faz. Taperinha, 01-

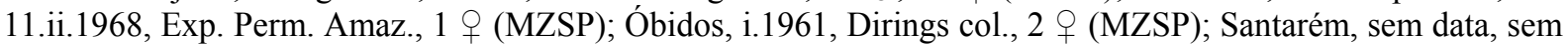
coletor, 2 đ̃, 1 q (CMNH). Rondônia: Forte Príncipe da Beira, 19.xi-03.xii.1967, G. R. Kloss col., 1 Q (MZSP). Mato Grosso: Utiariti, Rio Papagaio, 01-12.xi.19666, Lenko \& Pereira col., 1 q (MZSP); Porto Velho, Rio Tapirapé, xi-xii.1962, R. Pinheiros col., 3 ô, 1 q (SMFD). Goias: Trindade, sem data, C. Pujol. col., 1 ㅇ (MNHN). P. janus. BRASIL. Ceará: Cerqueiro, xii.1963, Dirings col., 2 ○ (MZSP). Pernabuco: Tapera, i.1932, sem coletor, 1 đ (MZSP). Bahia: Santo Antônio da Barra, 11.xii.1888, Gounelle, 1 ( (MNHN). Mato Grosso: Chapada dos Guimarães, x.1972, Kloss \& F. Val col., 1 q (MZSP); Chapada, sem data, sem coletor, 2 ô, $1 \mathrm{f}$ (Parátipos) (CMNH). Goiás: Jataí, Faz. Cachoeirinha, x.1962, Exp. Dep. Zool., 1 đે (MZSP); Niquelândia, xi.1940, P. Mota col., 2 (MZSP); Caldas Novas, x.1982, C. Coimbra col., 1 ô, 1 q (MZSP); Vianópolis, xi.1931, R. Spitz col., 1m, 1f (MZSP); Jataí, sem data, sem coletor, 2 ○े (MNHN); Campinas, x.1937, Dirings col., 2 ઈิ (MZSP). Minas Gerais: Pedra Azul, xi.1970, F. H. Oliveira col., 1m, 2f (MZSP); Pouso Alegre, xii.1965, F. Pereira col., 1 † (MZSP); Uberlândia, x.1962, Exp. Dep. Zool., 1 ô (MZSP); Águas Vermelhas, x. 1977, O. Roppa col., 2 đ̃, 4 O (MZSP). São Paulo: São José dos Campos, 04.xi.1969, Tiemann col., 4 ô. $1 f$ (MZSP). P. lampadion. BRASIL. Bahia: Ilhéus, Faz. São Caetano, xii.1967, Dirings col., 2 † (MZSP); Juazeiro, ix.1957, sem coletor, 1 ô (DZUP); sem localidade, sem data, sem coletor, 1 o (MNHN); sem localidade, sem data, sem coletor, 3 (ISNB). P. Iatus. BRASIL. Mato Grosso: Chapada, n. 2966, sem data,

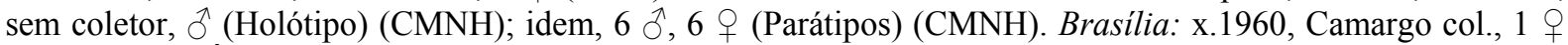
(MZSP). BOLÍVIA. Santa Cruz Provincia Sara, xi.1912, J. Steinbach col., 1 đ, 1 q (CMNH). P. lineatus. BRASIL. Bahia: sem localidade, sem data, sem coletor, 2 ô (MZSP). Mato Grosso: sem localidade, 1886, P. Germain col., 2 q (MNHN); Pimentel barbosa (Rio das Mortes), x.1949, Dente e Werner col. 1 (MZSP). Goiás: Lagoa Feia- Formosa, 19.xi.1961, J. C. M. C. col., 4 ô (MNRJ); Colinas do Sul, Serra da Mêsa, 0215.xii.1995, C. Campaner col., 2 ๙ (MZSP); Cabeceiras (Lagoa Formosa), 24-27.x.1964, Exp. Dep. Zool., 2 ๙ (MZSP). Minas Gerais: Arinos, 06-08.xi.1964, Exp. Dep. Zool., 4 ð (MZSP); Buritis (Ribeirão Confins), 2931.x.1964, Exp. Dep. Zool., 18 ふૈ, 1f (MZSP); Belo Horizonte, 14.xii.1956, R. L. Araújo col., 1 ઈิ (IBSP); Rosário Oeste, i.1971, Dirings col., 2 đ̃, 2 q (MZSP). São Paulo: São Paulo, Ipiranga, i.1929, Spitz col., 1 ㅇ 
(MZSP); Itu, xi.1958, U. Martins col., 2 đ (MZSP). BOLÍVIA. Santa Cruz: Sara, xii.1912, J. Steinbach col., 37 ô, 1 q (CMNH Acc 5043); Rio Japacani, sem data, J. Steinbach col., 3 ô (CMNH Acc 5572). PARAGUAI.

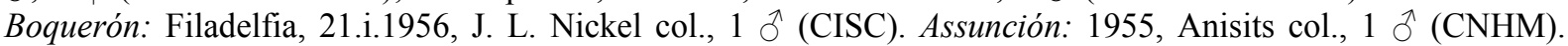
ARGENTINA. Salta: Senillosa, 1927, G. L. Harrington col., 1 q (USNM). P. lucernula. BRASIL. Piauí: Pq. Nacional das Sete Cidades, xi.1968, D. Zajclw col., 1 đ̄ (MZSP). Ceará: Russas, ii.1940, P. C. A. Antunes col., $1 \hat{\jmath}$ (IBSP); Quixadá, sem data, Juarez col., $3 \hat{\jmath}$ (IBSP); Fortaleza, sem data, sem coletor, $1 \hat{\jmath}$ (IBSP). Pernambuco: Recife, v.1949, M. A., 1 đ (MZSP). Alagoas: Olho d'Água do Casado (Faz. Vera Cruz), 18.v.2000, L. Ianuzzi col., 1 ô, 1 ○ (MZSP); Olho d'Água do Casado (Faz. Capelinha), 25.v.2000, L. Ianuzzi

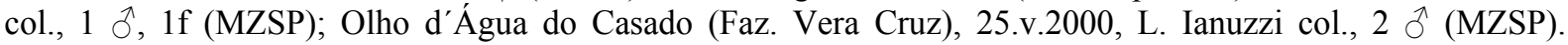
Sergipe: Canindé do são Fancisco (Faz. Brejo), 15.v.2000, L. Ianuzzi col., 3 đ̃ (MZSP); Canindé do são Fancisco (Reserva Chesf), 25.v.2000, L Ianuzzi col., 2 ○ (MZSP); Canindé do são Fancisco (Faz. Poço Verde), 18.iii-22.iv.2000, L. Ianuzzi col., 3 ô, 1 O (MZSP). Bahia: Morro de São Paulo, Cairu, 13.iii.1987, L. Gondim col., 9 đ̃, 1 \& (MZSP). P. lucidulus. PERU. Loreto: Ucayali, Yarina Cocha, 09.xi.1953, Peter Hocking col., 1

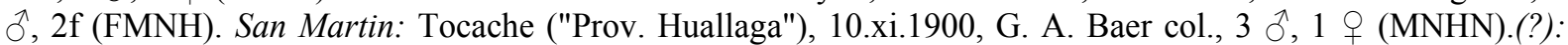
Tarapoto, v-viii.1886, M. de Mathan col., 1 Jै, 4 (MNHN). BOLÍVIA. El Beni: Reyes, Rio Beni, 1891, Balzan col., 2 ô (MNHN); Rurrenabaque, 1921-1922, Wm. M. Mann col., 1m, 7 q (USNM). Santa Cruz: Provicia Sara, 450 đ̃, xi.1910, J. Steinbach col., 3 ô (CMNH). BRASIL. Amazonas: Tarapoto, x-xii.1885, M. de Mathan col., 1 ô (MNHN). P. luscinus. BRASIL. Mato Grosso do Sul: Salobra (Aona da N. O. B.), 18-29.x.1938, sem coletor, సิ (Holótipo) (MZSP); idem, 4 đิ (Parátipos) (MZSP); Corumbá, sem data, sem coletor, $1 \mathrm{~m}$ (MNHN). Minas Gerais: Curvelo, xi.1977, O. Roppa col., 6 ô, 5 o (MZSP). São Paulo: Ribeirão Preto (Tamanduá), x.1954,

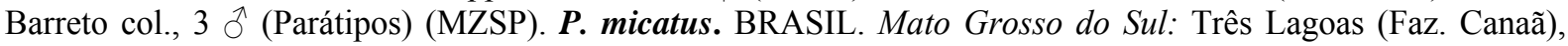

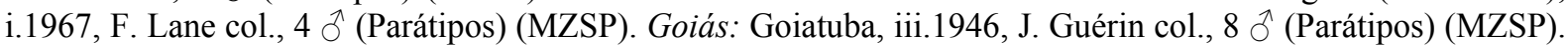
São Paulo: Mairiporã, 4-13.i.1967, C. Costa col., đิ (Holótipo) (MZSP); idem, 14 đ̃ (Parátipos) (MZSP); Itu, Faz. Pau d'Alho, 27.xii.1967, U. Martins col., 12 đ (Parátipos) (MZSP); Bragança Paulista, Faz. Santana,

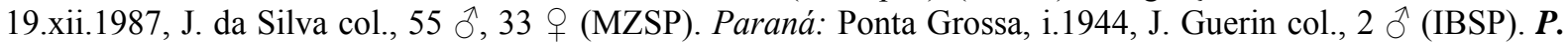

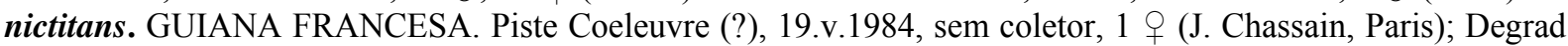
Saramaca, 15.iii.1983, M. Durenton col., 1 đ (J. Chassain, Paris); Recoucoua (?) Iracoubo PK 4 PL, 23.vii.1984 sem coletor, 1 đิ (J. Chassain, Paris). BRASIL. Amazonas: São Paulo de Olivença, 1952, M. de Mathan col., 3 ㅇ (MNHN); Tefé (Ega), ix-x.1879, M. de Mathan col., 1 ð̋ (MNHN). Pará: Bragança, 1952, M. de Mathan col.,

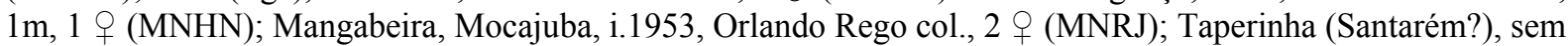
data, sem coletor, 1 đ̄ (CMNH). P. nyctophylus. BRASIL. Rio Grande do Sul: sem localidade, sem data, sem coletor, 4 đิ (MNHN); Quaraí, Cerro do Jarão, 27.i.1963, Carbonell col., 1 ô (MAPA). ARGENTINA. Buenos Aires, sem data, sem coletor, 1 đ̃, 3 (ISNB); idem, $2+$ (MNHN). URUGUAI. Artigas: Arroyo Tres Cruces Grandes, 18.ii.1955, C. S. Carbonell, 4 (FHCM); Arroyo de la Invernada, 18.ii.1954, C. S. Carbonell, 2 우 (FHCM); Arroyo Mandiyu, 18.ii.1960, M. A. Monné, 1 đ̃ (MAPA); Arroyo Cuaró, iii-iii.1960, B. L. de

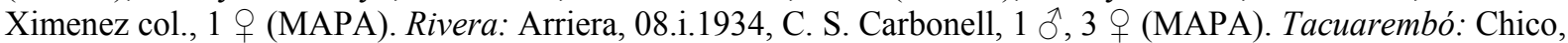
20.i.1960, C. S. Carbonell, 1 † (MAPA); Bañados de Zapucay, 15.i.1960, C, S. Morey col., 1 ઈ (MAPA). Paysandú: 12.i.1949, P. R. San Martin col., 3 (MAPA). Colonia: Piedra de los Indios, 14-31.xii.1972, Z.

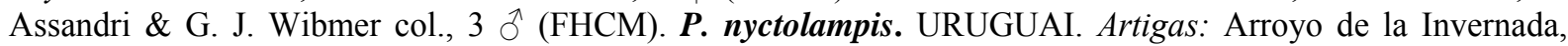
18.ii.1954, C. S. Carbonell, 1, 7 q (MAPA); Arroyo Tres Cruces Grandes, 10-16.ii.1967, C. S. Morey \& E. M. Casella, 1 đ (FHCM). Rivera: Carpinteria, 31.iii.1961, D. Antunes col., 1 ㅇ (MAPA); Sierra de la Aurora, 14.i.1961, C. S. Carbonell \& Zolessi col., 1 đ̊ (MZSP). Treinta y Tres: Santa Clara de Olimar, 12.i.1960, Zolessi $\&$ Spintoso col., 8 ○ (MAPA); idem, 23.ii.1958, L. Covelo \& Zolessi col., 1 ( (MAPA); Rio Olimar, 23.ii.1958, M. A. Vignoli col., 1 (MAPA). Durazno: Paso de la Cruz, 22.i.1968, M. Coelho col., 4 9 (MAPA); idem, 21.i.1968, R. S. M. \& C. S. C. col., 1 q (MAPA). Rocha: 20.ii.1953, C. Peduto col., 3 q (FHCM). P. pusillus. PARAGUAI. Boquerón: Filadelfia, 21.i.1956, J. L. Nickel col., ô (Holótipo) (CISC). P. depressicollis. ARGENTINA. Salta: Pq. Nacional Finca el Rey, viii.1958, A. Martinez, 2 đ (MZSP). Catamarca: Capayan, xii.1975, sem coletor, 1 ઈे (DZUP); sem localidade, xii.1943, sem coletor, 1 ઈิ (SMFD); Buenos Aires, sem data, sem coletor, 1 đ (MNHN).URUGUAI. Durazno: Arroyo del Cordobés, 29.i.1963, A. Dolber col., 1 ○े (MAPA). P. retrospiciens. GUIANA FRANCESA. Saul, viii.1979, G. Nazart col., 1 ô (J. Chassain, Paris); Degrad des Cannes, Cabassou, xi.1978, G. Nazart col., 1 $\widehat{\jmath}$ (J. Chassain, Paris); sem localidade, sem data, sem coletor, $5 \hat{\jmath}$, 5 o (MNHN). BRASIL. Amazonas: Tefé (Ega), xii-xiii.1879, M. de Mathan col., 1 đ̃ (MNHN). Pará:

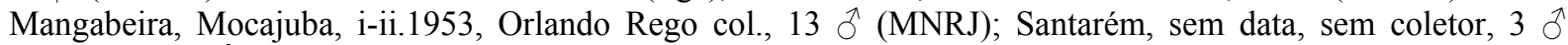
(CMNH). BOLÍVIA. Santa Cruz: Província Sara, xii.1912, J. Steinbach col., 1 ô (CMNH). P. ruscus. BRASIL. São Paulo: São Paulo (Santo Amaro), 05.i.1924, sem coletor, đo (Holótipo) (MZSP). Paraná: Ponta Grossa

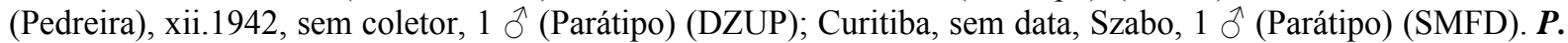
termitilluminans. BRASIL. Goiás: Parque Nacional das Emas, 02-4.x.1981, K. H. Redford col., ô (Holótipo) (MZSP); idem, $8 \lesssim$ (Parátipos) (MZSP); Mineiros (Faz. Santa Crus), 18.x.1989, Exp. MZ-IQUSP col., $1 \AA$ (MZSP); Aruanã, Rio Araguaia, ii.1963, Dirings col., 1 q (MZSP). Mato Grosso: Barra do Tapirapé, xi.1964, B. Malkin col., 1 đ (MZSP). Mato Grosso do Sul: Costa Rica, 21-25.x.1984, Exp. MZUSP, 3 ô, 1 (MZSP). Minas Gerais: Rosário Oeste, xii.1972, Dirings col., 1 ๙ (MZSP). P. pumilus. BRASIL. Sem localidade, sem

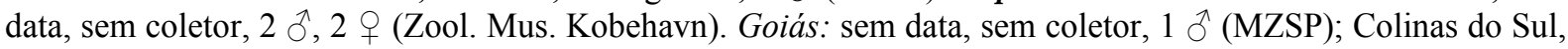


Serra da Mesa, 02-15.xii.1995, C. Campaner col., 2 đ (MZSP). Minas Gerais: Rosário Oeste, x.1973, Dirings col., 4 O (MZSP); Sertão de Diamantina (Faz. Das Melancias), x-xi.1902, E. Gounelle col., 1 ð̄ (MNHN). São Paulo: Mococa, i.1969, R. Carvalho col., 1 đิ (MZSP); Batatais, xi.1939, J. Guerin col., 1 q (IBSP). P. scintillula. BRASIL. Amazonas: Reserva Ducke AM 010 Km 26, 22.xi-27.xii.1977, Jorge Arias col., $1 \lambda$ (MZSP); idem, 21.xii.1978, 1 đ̄ (MZSP); Benjamin Constant, R. Javari, Alto Amazonas, ii.1961, Dirings col., 2

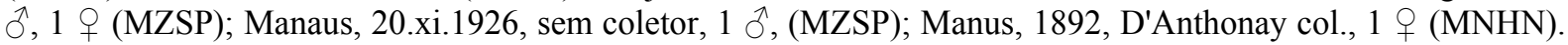
Pará: Santarém, sem data, sem coletor, 2 ô (MZSP); Santarém (Faz. Taperinha), 17-18.ii.1968, Exp. Perm. Amaz., 1 đ (MZSP); Mangabeira, Mocajuba, ii.1953, Orlando Rego col., 2 ㅇ (MNRJ). Mato Grosso: sem localidade, 1886, P. Germain col., 2 ㅇ (MNHN); Chapada, sem data, sem coletor, 1 ㅇ (CMNH). PERU. Rio Ucayali, 22.ix.1923, sem coletor, 1 đ̊ (AMNH Coll. H. Bassler). BOLIVIA. Santa Cruz: Província Sara, sem

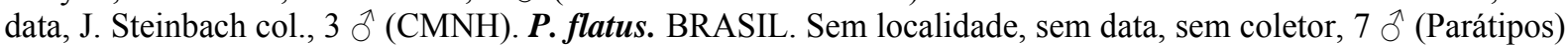
(DEIC).Mato Grosso: Chapada, sem data, sem coletor, 5 + (Parátipos) (CMNH).São Paulo: Castilho (marg. esq. Rio Paraná), x.1964, Exp. Dep. Zool., ô (Holótipo) (MZSP); Novo Horizonte, xi.1944, Araújo col., 2 ঠ (MZSP); Ibirá (Termas), x.1953, Dirings col., 1 đ (MZSP). PARAGUAI. Sem localidade, sem data, sem coletor, 1 o (MNHN). Cordillera: San Bernardino, 31.i.1913, A Fischer S. G. col., 1 ô (SMF). P. fragilis. BRASIL. Amazonas: Reserva Ducke, 01.iii.1980, F. Schaller col., 1 đ (MZSP). Pará: Mangabeira, Mocajuba, xii.1952, Orlando Rego col., $\widehat{\jmath}$ (Holótipo) (MZSP); idem, 6 đิ (Parátipos) (MZSP); Bragança, 1852, M. de Mathan col., 1 $\widehat{\sigma}(\mathrm{MNHN})$; Itaituba, Santarenzinho, xi.1963, Dirings col., 1 đิ (MZSP). P. viticollis. BRASIL. Espírito Santo: Linhares, xi.1972, P. C. Elias col., 1 đ̄ (MZSP). P. fulvus. BRASIL. São Paulo: Itu (Faz. Pau d'Álho), i.1958, U. R. Martins col., $\widehat{\jmath}$ (Holótipo) (MZSP). P. ferrugineus. ARGENTINA. Córdoba, 45 mi N Rio Cuarto, 07.ii.1951, Ross \& Michelbacher col., ô (Holótipo) (CASC). P. fulvescens. BRASIL. Santa Catarina: Mafra, sem data,

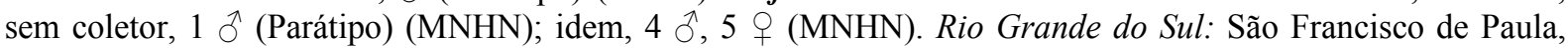
i.1937, Pe. Buck col., 2 ○ิ (MZSP).

Comentários. Além da exclusão de P. cinnameus do gênero Pyrearinus, proponho também a exclusão de P. basalis (Schwarz, 1902) e das espécies P. cereus Costa, 1978, P. lampyris (Candèze, 1863), P. vesculus Costa, 1978 e P. vescus Costa, 1978 que serão transferidas para dois novos gêneros. Essa exclusão é necessária porque, segundo as hipóteses filogenéticas obtidas na análise cladística, essas espécies não estão entre os descendentes da espécie ancestral exclusiva de Pyrearinus nyctolampis, espécie-tipo do gênero. Ainda assim, Pyrearinus permanece como o gênero mais numeroso da tribo, com 40 espécies, das quais apenas $P$. comissator, $P$. lucidus e $P$. lucificus não foram examinadas.

P. comissator é conhecida apenas pela fêmea, $P$. lucidus, segundo Candèze (1863), é similar a $P$. nictitans e $P$. lucificus possui formà do protórax e das vesículas luminescentes do pronoto similar ao da maioria das espécies de Pyrearinus (Costa, 1978). As espécies estudadas compartilham como sinapomorfias os olhos grandes nos machos, a ausência de dimorfismo sexual no comprimento das antenas, a forma da margem anterior do pronoto, a margem posterior dos olhos fortemente emarginada e o recorte alongado no processo da articulação dorsal do pênis. 
O gênero é morfologicamente bastante diverso, em geral pode ser reconhecido pelo tamanho dos olhos, grandes, e pelas formas do protórax e das antenas. $P$. termitilluminans, cujas larvas habitam cupinzeiros na Região Centro-Oeste do Brasil e espécies similares (P. vitticollis, $P$. scintillula, P. pumilus, $P$. flatus e $P$. fragilis) possuem como autapomorfias a superfície do corpo muito brilhante e glabra a olho nu, as margens laterais do protórax fortemente achatadas, os ângulos posteriores, também achatados, curtos, sem carena ou fracamente carenados e a margem interna da mandíbula lisa, sem dente.

\section{Gênero $C$ gen. n.}

(Figs. 38, 70, 106, 162, 163, 238)

Pyrophorus Billberg, 1820: 20 (pars).

Pyrearinus Costa, 1975: 99 (pars).

Espécie- tipo: Pyrophorus basalis Schwarz, 1902: 284 (localidade-tipo: Equador, Napo, Archidona).

Descrição. Macho (Fig. 238). Bicolorido, predominantemente castanho-escuro a preto, com hipômeros e pernas amarelos e pronoto inteiramente amarelo ou laranja ou com uma mancha discal alongada castanha ou preta, ocupado $1 / 3$ a $1 / 2$ da largura do pronoto, raramente com epipleuras e úmeros também amarelados. Pilosidade dourada, moderadamente densa, decumbente, muito curta, mais alongada no prosterno. Tegumento brilhante.

Fronte retangular (aprox. 1,3 vezes mais larga que longa), de lados curvos para dentro; quase plana a levemente cônvaca, com margem anterior fracamente carenada; pontuação forte, muito densa e umbilicada. Antenas (Fig. 38) serreadas a partir do quarto antenômero, atingindo o ápice do ângulo posterior no $11^{\circ}$ antenômero; $3^{\circ}$ antenômero $c a .1,3$ vezes mais longo que o $2^{\circ}, 4^{\circ}$ antenômero 1,3 vezes o comprimento do $3^{\circ}$. Olhos pequenos (índice ocular 0,30-0,38), margem posterior do olho levemente emarginada. Mandíbula denteada. 
Protórax subquadrado (1,0-1,1 vez mais largo que longo), de lados subparalelos a arredondados, levemente convergentes anteriormente. Pronoto convexo; pontuação heterogênea, forte, densa e umbilicada na região discal, mais densa e mais umbilicada mas laterais, com órgãos luminescentes em forma de vesículas de tamanho médio, circulares e sublaterais, visíveis do hipômero. Região mediana posterior sem tubérculo. Ângulos anteriores agudos, grandes; ângulos posteriores fortes, alongados não divergentes e fracamante carenados. Prosterno alongado de lados quase retos, com pontuação forte, moderadamente densa e levemente umbilicada. Processo prosternal com região apical denteada, dente saliente, região posterior ao dente de comprimento médio (ca. $9 \%$ do comprimento total do processo). Hipômeros (Fig. 70) com 1/4-1/3 posterior glabro, com pontuação média, densa e umbilicada; margem posterior geralmente com dois espinhos.

Mesoventrito. Margem lateral anterior com ângulo externo não proeminente, parte ventral quase reta, próxima da base, parte dorsal pouco visível. Cavidade mesoventral com bordas posteriores levemente inclinadas em relação à região anterior. Metaventrito com pontuação fina, espaçada a densa e umbilicada. Élitros com estrias marcadas, interestrias levemente convexas com pontuação fina, muito densa; lados gradualmente afilados até os ápices; ápices conjuntamente arredondados. Abdômen gradualmente afilado posteriormente, ventritos com pontuação fina, espaçada e levemente umbilicada. Primeiro esternito abdominal (Fig. 106) com lamelas laterais fracamente esclerotizadas com órgão luminescente pouco desenvolvido, subtriangular ocupando $1 / 5$ do esternito I.

Edeago (Figs. 162, 163). Parâmeros com ápice truncado com um espinho lateral pequeno; articulação dorsal com um recorte curto; bases medianas ventrais livres. Esclerito dorsal do pênis com prolongamentos basais 0,5 vez o comprimento da região posterior, gradualmente afilado para o ápice. Esclerito ventral do pênis com aproximadamente $1 / 3$ da largura do esclerito dorsal, com uma carena fracamente saliente na linha longitudinal mediana. 
Fêmea: Semelhante ao macho, com pronoto levemente mais convexo e pouco mais arredondado, com antenas mais curtas.

Membrana interconectiva do segmento VIII sem escleritos laterais. Baculi 1,20 vezes mais longo que os coxitos Genitália Feminina. Trato genital. Vagina com um par de glândulas coleteriais mais longa que larga. Região posterior de cada glândula coleterial com uma área triangular formada por microescleritos, fracamente esclerotizada, região anterior membranosa. Bursa copulatrix com 2-3 espirais, com muitos espinhos alongados. Espermatecas com ápice espiralado.

Dimensões. Comprimento total $\widehat{\delta}$ 9,0-10,0 mm, $q$ 9,0-11,0 mm. Comprimento dos élitros em relação ao do protórax: $\widehat{\jmath}$ e $\rho$ 2,4-2,5. Largura do úmero em relação à do protórax: ^ 1,$0 ; q 0,9-1,0$.

Espécie. Gênero C basalis (Schwarz, 1902) comb. n.

Distribuição. Brasil (AM), Equador.

Material examinado. Gênero $C$ basalis comb. n.. BRASIL. Sem localidade, sem data, sem

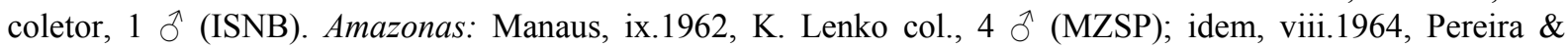
Machado col., 1 đ (MZSP); Reserva Ducke (20 km N Manaus), 29.viii.1978, J. Arias \& N. Penny col., 1 q (MZSP); idem (AM 010, Km 26), 08, 29.viii.1978, sem coletor, 2 ○ (MZSP); Benjamin Constant, 18-28.ix.1962 K. Lenko col., 1 ô (MZSP); Maturaca (Rio Cauaburi), 12-17.xii.1962, J. Bechyné col., 2 ô (MZSP); Tefé (Ega), sem data, Bates, 1 đ (MZSP); "Pehas" sem data, Hahnel, 1 + (MNHN). EQUADOR. Chimborazo: Pichincha,

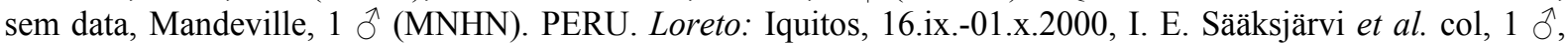
(MZSP); idem, 14.ix.2000, I. E. Sääksjärvi et al. col, 1 †, (MZSP); idem, 01-16.ix.1998, I.Eaudor E. Sääksjärvi et al. col, 1 đે, (MZSP); idem, 14.ix.2000, I. E. Sääksjärvi et al. col, 1 ô, (MZSP).

Comentários. Este gênero é erigido para Pyrearinus basalis, excluída de Pyrearinus pelos motivos discutidos anteriormente. Muito similar a Pyrearinus vesculus na coloração, tamanho e formato geral do corpo, diferindo pela forma da fronte, mais larga, pela pontuação geral do corpo, pouco maior e mais umbilicada, pelas vesículas luminescentes, pelas mandíbulas denteadas, pelos ângulos posteriores, mais fracamente carenados e pela forma do edeago, com ápices dos parâmeros com pequeno espinho lateral, esclerito dorsal do pênis menos delgado e esclerito ventral carenado. O trato reprodutivo da fêmea possui áreas 
microesclerotizadas na vagina e bursa copulatrix espiralada com muitos espinhos, caracteres ausentes na fêmea de $P$. vesculus.

\section{Gênero D gen. n.}

(Figs. 39, 164, 165, 239)

Pyrophorus Billberg, 1820: 20 (pars).

Pyrearinus Costa, 1975: 99 (pars).

Espécie- tipo: Pyrophorus lampyris Candèze, 1863: 49 (localidade-tipo: Brasil).

Descrição. Macho (Fig. 239). Bicolorido, predominantemente castanho a preto, hipômeros amarelos, pronoto amarelo com uma mancha discal alongada castanha ou preta, ocupado até $1 / 3$ da largura do pronoto ou predominantemente castanho ou preto com mancha triangular junto aos ângulos posteriores curta ou estendendo-se até os ângulos anteriores. Pilosidade dourada ou prateada, moderadamente densa, decumbente, muito curta, mais alongada no prosterno. Tegumento brilhante.

Fronte retangular (aprox. 1,3 vezes mais larga que longa), de lados curvos para dentro; quase plana a levemente cônvaca, com margem anterior fracamente carenada; pontuação fina a média, muito densa e umbilicada. Antenas (Fig. 39) subserreadas a partir do quarto antenômero, atingindo o ápice do ângulo posterior no $11^{\circ}$ antenômero; $3^{\circ}$ antenômero ca. 1,1-1,4 vezes mais longo que o $2^{\circ}, 4^{\circ}$ antenômero $1,3-1,5$ vezes o comprimento do $3^{\circ}$. Olhos pequenos ou médios (índice ocular 0,31-0,46), margem posterior do olho levemente emarginada. Mandíbula sem dente subapical.

Protórax subparalelo a subtrapezoidal (1,1 vez mais largo que longo), de lados levemente convergentes anteriormente. Pronoto pouco convexo; pontuação heterogênea, média, densa, simples ou umbilicada na região discal, mais densa e mais umbilicada mas laterais, com órgãos luminescentes em forma de manchas mais ou menos triangulares, de 
contorno indistinto, geralmente confundindo-se com a coloração amarelada do pronoto, com borda externa encostando na carena lateral do protórax e borda interna próxima da linha mediana; visíveis do hipômero. Região mediana posterior sem tubérculo. Ângulos anteriores agudos, fraca a fortemente projetados; ângulos posteriores divergentes e fortemente carenados. Prosterno moderadamente alongado de lados quase retos a curtos de lados curvos, com pontuação média, moderadamente densa e levemente umbilicada. Processo prosternal com região apical denteada, dente saliente, região posterior ao dente de alongada $(16,1-19,0 \%$ do comprimento total do processo). Hipômeros com ângulo posterior e pequena área glabra a $1 / 3$ posterior glabro, com pontuação muito fina a fina densa e umbilicada; margem posterior truncada sem espinho ou com dois espinhos pequenos.

Mesoventrito. Margem lateral anterior com ângulo externo não proeminente, parte ventral quase reta, próxima da base, parte dorsal pouco visível ou com com ângulo externo proeminente, parte ventral curva, próxima da base e parte dorsal visível. Cavidade mesoventral com bordas posteriores levemente inclinadas em relação à região anterior. Metaventrito com pontuação fina, espaçada a densa e umbilicada. Élitros com estrias marcadas, interestrias achatadas com pontuação fina, muito densa; lados gradualmente afilados até os ápices; ápices conjuntamente arredondados. Abdômen gradualmente afilado posteriormente, ventritos com pontuação fina, espaçada, simples. Primeiro esternito abdominal com lamelas laterais fracamente esclerotizadas com órgão luminescente pouco desenvolvido, subtriangular, ocupando no máximo $1 / 5$ do esternito I.

Edeago (Figs. 164, 165). Parâmeros com ápice truncado com uma carena-látero dorsal pouco saliente; articulação dorsal com um recorte curto; bases medianas ventrais livres. Esclerito dorsal do pênis com prolongamentos basais $0,2-0,3$ vez o comprimento da região posterior, fortemente afilado para o ápice. Esclerito ventral do pênis com aproximadamente 1/3 da largura do esclerito dorsal na base, triangular, fortemente afilado para o ápice. 
Fêmea: Semelhante ao macho, com pronoto levemente mais convexo e pouco mais arredondado, com antenas mais curtas.

Membrana interconectiva do segmento VIII sem escleritos laterais. Genitália Feminina. Baculi 1,3-1,4 vezes mais longo que os coxitos. Trato genital. Vagina com um par de glândulas coleteriais mais longa que larga. Regiões posterior e anterior de cada glândula coleterial membranosa. Bursa copulatrix com 1 espiral, com poucos espinhos ou sem espinhos. Espermatecas com ou sem ápice espiralado.

Dimensões. Comprimento total $\widehat{\overbrace{}}$ 9,0-15,0 mm, $q$ 11,0-17,0 mm. Comprimento dos élitros em relação ao do protórax: $\widehat{\jmath}$ e $q$ 3,0-3,6. Largura do úmero em relação à do protórax: ^ $1,0-1,1 ;$; $\subsetneq$ 0,9-1,0.

Espécies. Gênero D cereus (Costa, 1978) comb. n.; Gênero D lampyris (Candèze, 1863) comb. n.; Gênero D vesculus (Costa, 1978) comb. n.; Gênero D vescus (Costa, 1978) comb. $n$.

Distribuição. Guiana Francesa, Equador, Brasil (AM, BA, MS, GO, MG, RJ).

Material examinado. Gênero D cereus comb. n. BRASIL. Bahia: sem localidade, sem data, Reed, 2 ○ (Parátipos) (BMNH); Uruçuca, 13.xii.1947, P. Silva col., 1 ô (Parátipo) (IBSP). Mato Grosso do Sul: Corumbá, sem data, sem coletor, $1 \widehat{\partial}$ (MNHN). Rio de Janeiro: Muri, 20.i.1952, W. Wittmer col., $1 \widehat{\partial}$ (IBSP). Gênero D lampyris comb. n. Sem localidade, sem data, sem coletor, $1 \hat{\jmath}$ (MNHN); idem, $1 \hat{\jmath}$ (MNHN). BRASIL. Sem localidade, sem data, sem coletor, 1 ㅇ (ISNB). Rio de Janeiro: sem localidade, sem data, sem coletor, 2 đ (MZHF); Petrópolis, sem data, sem coletor, 1 đ (MZHF). Gênero D vesculus comb. n. GUIANA FRANCESA. Sem localidade, sem data, sem coletor, $1 \hat{\jmath}$ (MNHN). EQUADOR. Morona Santiago: Chiguinda, sem data, sem coletor, 1 ô (Parátipo) (BMNH). BRASIL. Amazonas: Tefé (Ega), sem data, sem coletor, 1 우 (Parátipo) (BMNH); idem, sem data, Bates, 1 đ (Parátipo) (MZSP); idem, sem data, Hahnel, 1 ô (Parátipo) (MNHN); Benjamin Constant, x.1958, L. G. Pereira col, 1 ô (MZSP). Gênero D vescus comb. n. BRASIL. Goiás: Fazenda Cachoeirinha, Jataí, x.1962, Exp. Dep. Zool. Col., 1 ơ (Holótipo) (MZSP). Minas Gerais: Pedra Azul, xi.1971, Seabra \& Alvarenga col., 27 $\widehat{\jmath}, 4$ † (DZUP).

Comentários. A inclusão deste grupo de espécies como um táxon terminal na análise filogenética foi baseada numa suposta autapomorfia, a forma de seus órgãos luminescentes do pronoto. Após a análise, essa condição resultou homóloga àquela encontrada em Coctilelater corymbitoides. Portanto, não foi encontrada neste estudo uma sinapomorfia para as espécies do Gênero D. Posteriormente, uma análise filogenética incluindo as espécies deste gênero e de outros mais filogeneticamente próximos, como táxons 
terminais, poderá corroborar ou não a monofilia do gênero e as sinapomorfias que o definem. Ainda assim, proponho esse novo gênero para as espécies do grupo lampyris, porque nenhuma das hipóteses filogenéticas obtidas sugerem uma ancestralidade comum e exclusiva para elas e Coctilelater.

\section{Coctilelater Costa, 1975}

(Figs 40, 86, 166, 167, 240)

Pyrophorus Billberg, 1820 (pars); Candèze, 1900: 85.

Alampes Champion, 1895 (pars); Schwarz, 1906: 214; Schenkling, 1927: 350, Blackwelder, 1944: 285; Costa, 1975b: 54.

Coctilelater Costa, 1975: 54, 64; Golbach, 1994: 28.

Espécie- tipo: Alampes corymbitoides Candèze, 1900: 85 (localidade-tipo: Brasil, Goiás).

Redescrição. Macho (Fig. 240). Uniformemente castanho-escuro ou bicolorido, com hipômeros amarelos ou alaranjado e pronoto amarelo ou alaranjado com uma mancha discal arredondada castanha ou preta. Pilosidade dourada ou prateada, moderadamente densa, decumbente, muito curta, mais alongada no prosterno. Tegumento brilhante.

Fronte retangular (aprox. 1,3 vezes mais larga que longa), de lados curvos para dentro ou quase retos; quase plana, com margem anterior fracamente carenada; pontuação média, muito densa e umbilicada. Antenas (Fig. 40) serreadas a partir do quarto antenômero, atingindo a base do ângulo posterior; $3^{\circ}$ antenômero $1,2-1,4$ vezes mais longo que o $2^{\circ}, 4^{\circ}$ antenômero 1,3-1,4 vezes o comprimento do $3^{\circ}$. Olhos pequenos (índice ocular $0,30-0,38$ ), margem posterior do olho levemente emarginada. Mandíbula sem dente subapical.

Protórax subquadrado (1,0-1,20 vez mais largo que longo), de lados subparalelos a levemente convergentes anteriormente. Pronoto convexo; pontuação heterogênea, forte, 
densa e umbilicada na região discal, mais densa e mais umbilicada mas laterais, com órgãos luminescentes em forma de manchas mais ou menos triangulares, com contorno indistinto, geralmente confundindo-se com a coloração amarelada do pronoto, com borda externa encostando na carena lateral do protórax e borda interna próxima da linha mediana; visíveis do hipômero. Região mediana posterior sem tubérculo. Ângulos anteriores agudos, grandes; ângulos posteriores divergentes ou paralelos e fortemente carenados. Prosterno moderadamente alongado de lados quase retos, com pontuação média, densa e umbilicada. Processo prosternal com região apical denteada, dente saliente ou fracamente saliente, região posterior ao dente de comprimento médio ( $14 \%$ do comprimento total do processo). Hipômeros com ângulo posterior e pequena área, com pontuação fina ou média, densa e umbilicada; margem posterior com dois espinhos pequenos.

Mesoventrito. Margem lateral anterior (Fig. 86) com ângulo externo não proeminente, parte ventral quase reta, próxima da base, parte dorsal visível Cavidade mesoventral com bordas posteriores levemente inclinadas em relação à região anterior. Metaventrito com pontuação fina, espaçada a densa e umbilicada. Élitros com estrias marcadas, interestrias, achatadas com pontuação fina, densa, simples; lados gradualmente afilados até os ápices; ápices conjuntamente arredondados. Abdômen gradualmente afilado posteriormente, ventritos com pontuação fina, espaçada ou densa, simples. Primeiro esternito abdominal membranoso, sem órgão luminescente.

Edeago (Figs.166, 167). Parâmeros com ápice truncado com uma carena-látero dorsal pouco saliente; articulação dorsal com um recorte curto; bases medianas ventrais livres. Esclerito dorsal do pênis com prolongamentos basais $0,3-0,4$ vez o comprimento da região posterior, fortemente afilado para o ápice. Esclerito ventral do pênis com aproximadamente 1/3 da largura do esclerito dorsal na base, triangular, fortemente afilado para o ápice.

Fêmea: Semelhante ao macho, com pronoto levemente mais convexo, com antenas mais curtas. 
Membrana interconectiva do segmento VIII sem escleritos laterais. Genitália Feminina. Baculi 1,4 vezes mais longo que os coxitos. Trato genital. Vagina com um par de glândulas coleteriais mais longa que larga. Região posterior de cada glândula coleterial membranosa, região anterior com um esclerito espinhosos fracamente esclerotizado. Bursa copulatrix com 1 espiral, com poucos espinhos. Espermatecas com ápice espiralado.

Dimensões. Comprimento total $\widehat{\jmath} 7,6-12,9 \mathrm{~mm}$, $+11,0 \mathrm{~mm}$. Comprimento dos élitros em relação ao do protórax: $\widehat{\jmath}$ e $q$ 2,5-2,8. Largura do úmero em relação à do protórax: ô e $91,0-1,2$.

Espécies. Coctilelater corymbitoides (Candèze, 1900); Coctilelater sanguinicollis (Candèze, 1878).

Distribuição. Guiana Francesa, Brasil (AM, PA, MA, GO, MG, SP).

Material examinado. C. corymbitoides. Goiás: Jataí, ix-xi.1897, sem coletor, 2 đิ (MZSP); idem, sem data, sem coletor, 1 (DEIC). Minas Gerais: sem localidade, sem data, sem coletor, 1 (BMNH). São Paulo: São Paulo, Ipiranga, i.1931, R. Spitz col., 2 đ (MZSP); Estrada alto da serra, i.1923, sem coletor, 1 $\widehat{\partial}$ (MZSP); Franca, 18.vii.1968, Garbo col., 1 ○ (MZSP); Itu, 13.xi.1960, U. Martins col., 1 ㅇ (MZSP). $\boldsymbol{C}$. sanguinicollis. GUIANA FRANCESA. Gourdonville, sem data, sem coletor, 1 + (MZSP); Cayenne, sem data, sem coletor, 1 ô (BMNH). BRASIL. Amazonas: sem localidade, sem data, sem coletor, 1 ô (ISNB). Pará: Tucuruí (Faz. Senador), o1.xii.2001, Rafael \& Vidal col., 1 §ิ (INPA). Maranhão: Vila Nova dos Martírios (F. Sta. Rosa), 06.xii.2001, F. J. Oliveira \& J. Vidal col., 2 ऽે (INPA); São Pedro da Água Branca (Faz. Esplanada), 07.xii.2001, Rafael, Oliveira \& Vidal col., 3 ${ }^{\lambda}$ (INPA).

Comentários. Esse gênero estava anteriormente incluído na tribo Heligmini, provavelmente porque as manchas amareladas próximas dos ângulos posteriores de $C$. corymbitoides não eram consideradas órgãos luminescentes. Devido à semelhança da mancha amarelada de $C$. corymbitoides com aquelas das espécies do grupo lampyris, foi postulada a hipótese de homologia primária entre elas, que se confirmou após a análise dos dados. No entanto, nem para o grupo lampyris há registros de que essas manchas tenham realmente a capacidade de emitir luminescência. Sejam órgãos luminescentes ou não, essas manchas parecem ser homólogas, de acordo com os resultados da análise cladística, e a ausência delas em C. sanguinicollis pode ser interpretada como uma autapomorfia. 


\section{Agnostelater Costa, 1975}

(Figs. 41, 168, 169, 241)

Pyrophorus Billberg, 1820: 20 (pars).

Agnostelater Costa, 1975: 54, 55; Golbach, 1994: 28.

Espécie- tipo: Pyrophorus mesochrous Germar, 1843: (localidade-tipo: Brasil,

Goiás).

Redescrição. Macho (Fig. 241). Protórax, cabeça e face ventral do pterotórax castanho-avermelhados, élitros e abdômen castanho-amerelados com úmeros, epipleuras e, às vezes, a base do pronoto amarelos; antena preta. Pilosidade dourada ou prateada, densa, decumbente, muito curta, pouco mais alongada no prosterno e muito mais alongada no ápice do último ventrito. Tegumento brilhante.

Fronte retangular (aprox. 1,3 vezes mais larga que longa), de lados quase retos; quase plana, com margem anterior não carenada; pontuação forte, muito densa e umbilicada. Antenas (Fig. 41) serreadas a partir do quarto antenômero, ultrapassando o ângulo posterior a partir do $10^{\circ}$ antenômero; $3^{\circ}$ antenômero 0,8 vez o comprimento do o $2^{\circ}, 4^{\circ} 2,5$ vezes o comprimento do $3^{\circ}$. Olhos pequenos (índice ocular 0,38), margem posterior do olho levemente emarginada. Mandíbula sem dente subapical.

Protórax subretangular (1,1-1,20 vez mais longo que largo), de lados subparalelos. Pronoto convexo; pontuação heterogênea, forte, muito densa e muito umbilicada na região discal, mais densa e mais umbilicada mas laterais, sem órgãos luminescentes. Região mediana posterior sem tubérculo. Ângulos anteriores agudos, grandes; ângulos posteriores não divergentes e carenados a fracamente carenados. Prosterno alongado de lados quase retos, com pontuação forte, densa e umbilicada. Processo prosternal com região apical denteada, dente saliente, região posterior ao dente de longa $(21,4 \%$ do 
comprimento total do processo). Hipômeros com ângulo posterior e pequena área, com pontuação média, densa e umbilicada; margem posterior com dois espinhos pequenos.

Mesoventrito. Margem lateral anterior sulcada do mesoventrito com ângulo externo não proeminente, parte ventral quase reta, próxima da base, parte dorsal visível Cavidade mesoventral com bordas posteriores levemente inclinadas em relação à região anterior. Metaventrito com pontuação média, densa e umbilicada. Élitros com estrias marcadas, interestrias, achatadas com pontuação fina, densa, simples; lados gradualmente afilados até os ápices; ápices afilados e levemente recurvados dorsalmente. Abdômen gradualmente afilado posteriormente, com pontuação fina, densa, simples e com ápice do último ventrito recurvado dorsalmente. Primeiro esternito abdominal membranoso, sem órgão luminescente.

Edeago (Figs.168, 169). Parâmeros com ápice truncado e com um espinho lateral pequeno; articulação dorsal com um recorte curto; bases medianas ventrais livres. Esclerito dorsal do pênis com prolongamentos basais 0,4 vez o comprimento da região posterior, fortemente afilado para o ápice. Esclerito ventral do pênis com aproximadamente 1/3 da largura do esclerito dorsal na região posterior, região anterior abruptamente mais estreita.

Fêmea: Desconhecida.

Dimensões. Comprimento total 12,0-14,0. Comprimento dos élitros em relação ao do protórax: 2,4-2,5. Largura do úmero em relação à do protórax: 1,0.

Espécie. Agnostelater mesochrous (Germar, 1843).

Distribuição. Brasil (TO, GO, SP).

Material examinado. Agnostelater mesochrous. BRASIL. Tocantins: Dianópolis 1622.i.1962, J. Bechyné col., 3 ठ (MZSP). Goiás: Leopoldo de Bulhões, xii.1933, R. Spitz col., 12 ○े (MZSP); Vianópolis, xi.1931, R. Spitz col., 2 ô (MZSP). São Paulo: Mogi Guaçu (Faz. Campininha), 17-19.xi.1967, H.

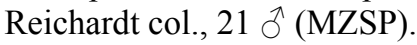

Comentários. A única espécie deste gênero, A. mesochrous, pode ser reconhecida entre os Pyrophorini pelo tamanho pequeno, corpo delgado com pontuação geral bem marca e 
muito densa e, principalmente, pela forma do ápice do último ventrito, recurvado dorsalmente e com muitas cerdas alongadas. A forma de seu edeago é muito similar ao das espécies de Coctilelater e do Gênero D., do qual difere pela forma do esclerito ventral e pelo espinho látero-apical dos parâmeros.

\section{Paraphileus Candèze, 1881}

(Figs. 42, 170, 171, 242)

Aphanobius Germar, 1844: 188 (pars).

Paraphileus Candèze, 1881: 92; 1891: 163; Schwarz, 1906: 210, 217; Schenkling, 1927: 356; Blackwelder, 1944: 286; Costa, 1975b: 66, 70; Golbach, 1994: 28, 43.

Espécie-tipo: Aphanobius thoreyi Germar, 1844. (designado por Hyslop, 1921: 662) (Localidade-tipo: Brasil).

Redescrição. Macho (Fig. 242). Face dorsal castanho-avermelhada (raramente alaranjada), com antenas, região discal do pronoto, ângulos posteriores, escutelo e pontos das estrias dos élitros pretos; face ventral preta com pernas, epipleuras e margem lateral dos hipômeros castanho-avermelhadas escuras. Pilosidade muito curta, castanho-clara, decumbente; mais longa e eriçadada no prosterno e pterotórax ventral. Tegumento brilhante.

Fronte retangular (1,3 vezes mais longa que larga), quase plana, fracamente carenada, pontuação forte, densa e umbilicada. Antenas (Fig. 42) fortemente serreadas a partir do quarto antenômero, atingindo o ápice dos ângulos posteriores; $3^{\circ}$ antenômero 1,0-1,1 vezes mais longo que o $2^{\circ}, 4^{\circ} 5$ vezes o comprimento do $3^{\circ}$. Olhos pequenos (índice ocular 0,30), margem ocular com uma faixa preta em quase toda a sua extensão. Mandíbula denteada.

Protórax 1,0-1,1 vezes mais largo que longo, com lados fortemente arredondados e convergentes anteriormente. Pronoto convexo, com pontuação forte, densa e umbilicada na 
região discal, menor em todas as margens e mais densa nas laterais. Região mediana posterior com tubérculo muito pequeno. Ângulos anteriores agudos e grandes; ângulos posteriores curtos e fortes, fortemente carenados, pouco divergentes. Prosterno alongado de lados quase retos, com pontuação forte, densa e umbilicada. Processo prosternal com região apical denteada, dente fortemente saliente, região posterior ao dente longa $(23,7 \%$ do comprimento total do processo). Hipômeros com pontuação média, densa e umbilicada, inteiramente pilosos ou com ângulo posterior e pequena área glabros, margem posterior truncada, sem espinhos.

Mesoventrito. Margem lateral anterior com ângulo externo proeminente, parte ventral curva, próxima da base, parte dorsal visível. Cavidade mesoventral com bordas posteriores pouco inclinadas em relação à região anterior. Metaventrito com pontuação fina, densa e umbilicada. Élitros com estrias fortemente marcadas, interestrias convexas com pontuação fina, espaçada e simples, gradualmente afilado para os ápices; ápices conjuntamente arredondados. Abdômen gradualmente arredondado posteriormente. Primeiro esternito abdominal fracamente esclerotizado, sem órgão luminescente.

Edeago (Figs. 170, 171). Parâmeros com ápice truncado, com carena láterodorsal fracamente saliente; articulação dorsal com uma área subcircular membranosa, transparente; bases medianas ventrais livres. Esclerito dorsal do pênis com prolongamentos basais 0,3 vez o comprimento da região posterior, lados afilados para o ápice. Esclerito ventral do pênis com aproximadamente $1 / 3$ da largura do esclerito dorsal, com terço basal mais estreitado e cônvaco.

Fêmea. Protórax mais convexo, ângulos anteriores do pronoto mais largos e antenas mais curtas.

Membrana interconectiva do segmento VIII sem escleritos laterais. Genitália Feminina. Baculi 1,9 vezes mais longo que os coxitos. Trato genital. Vagina com glândulas coleteriais mais longas que largas. Região posterior de cada glândula coleterial membranosa, 
região anterior com esclerito alongado, côncavo, fracamente esclerotizado. Bursa copulatrix com 2-3 espirais com espinhos alongados. Espermatecas com ápice não espiralado.

Dimensões. Comprimento total $\overparen{\partial} 21,0-29,0 \mathrm{~mm}$, $q$ 30,0-32,0 mm. Comprimento dos élitros em relação ao do protórax: $\widehat{O}$ e $q$ 2,5. Largura do úmero em relação à do protórax: ๙ิ $1,0-1,1 ;$ 1,0 .

Espécies. P. thoreyi (Germar, 1844); P. martinezi Golbach, 1984

Distribuição. Brasil (MT), Uruguai, Argentina. (Costa, 1975b)

Material examinado. P. thoreyi. Sem localidade, sem data, Inst. Entom. Agr. do RJ (1.177-

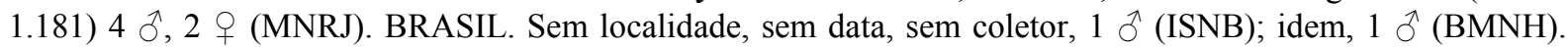
URUGUAI. Artigas: Arroyo Cuaró, 24.ii.1955, C. S. Carbonell col., 2 ○े (MZSP).

Comentários. P. martinezi não foi examinada. De acordo com Golbach (1984) esta espécie se diferencia de $P$. thoreyi principalmente pela coloração do corpo e pelos élitros, fortemente estriados, com interestrias mais convexas. $P$. thoreyi tem forma do pronoto e coloração do corpo muito conspícuas, que a separam de todos os demais Pyrophorini. A maioria dos espécimes examinados desta espécie possuem na região posterior do pronoto um par de saliências mais ou menos circulares, quase eqüidistantes à linha mediana e às margens laterais, que lembram vagamente órgãos luminescentes. No entanto, a completa ausência de um tecido amarelado, visível sob transparência no tegumento, não permitiu inferir uma hipótese de homologia primária entre essas estruturas.

\section{Euplinthus Costa, 1975}

(Figs. 43, 172, 173, 213, 214, 243)

Monocrepidius Eschscholtz, 1829 (pars).

Calais Castelnau, 1836: 9 (pars); Candèze, 1891: 163.

Meroplinthus Candèze, 1891: 163 (pars); Schenkling, 1927: 356; Blackwelder, 1944: 286; Costa; 1975: 66.

Euplinthus Costa, 1975: 66, 67; Golbach, 1994: 28. 
Espécie-tipo: Monocrepidius ophthalmicus Perty, 1830.

Redescrição. Macho (Fig. 243). Bicolorido, face dorsal laranja (raramente amarela), com antenas e cabeça pretos, pronoto com três manchas pretas (duas subcirculares a ovais, laterais e uma retangular posterior); escutelo preto e élitros com duas listras pretas anteriores que se fundem na região posterior; face ventral preta com epipleuras amareladas ou alaranjadas e hipômeros parcialmente amarelados. Pilosidade curta, dourada a castanho-clara, decumbente; levemente mais longa e eriçadada no prosterno e pterotórax ventral. Tegumento brilhante.

Fronte retangular (1,4 vezes mais longa que larga), quase plana, não carenada, com pountuação, com pontuação forte, densa e umbilicada. Antenas (Fig. 43) fortemente serreadas a partir do quarto antenômero, atingindo o ápice dos ângulos posteriores; $3^{\circ}$ antenômero 1,0-1,1 vez mais longo que o $2^{\circ}, 4^{\circ} 2$ vezes o comprimento do $3^{\circ}$. Olhos pequenos (índice ocular 0,30), margem ocular com uma faixa preta em quase toda a sua extensão. Mandíbula sem dente subapical.

Protórax subquadrado (1,0-1,1 vezes mais longo que largo), com lados subparalelos. Pronoto convexo, com pontuação forte, densa e umbilicada na região discal, menor em todas as margens e mais densa nas laterais. Região mediana posterior com tubérculo grande, alongado, achatado lateralmente. Ângulos anteriores agudos e pequenos; ângulos posteriores delgados ou fortes, fracamente carenados, pouco divergentes. Prosterno alongado de lados quase retos, com pontuação forte, densa e umbilicada. Processo prosternal com região apical denteada, dente saliente, região posterior ao dente com comprimento curto a médio (5-8\% do comprimento total do processo). Hipômeros com pontuação média, densa e fortemente umbilicada, com ângulo posterior e pequena área glabros, margem posterior com dois espinhos. 
Mesoventrito. Margem lateral anterior sulcada do mesoventrito com ângulo externo proeminente, parte ventral sinuosa, próxima da base, parte dorsal pouco ou parcialmente visível. Cavidade mesoventral com bordas posteriores inclinadas aproximadamente $45^{\circ}$ em relação à região anterior, visíveis lateralmente sobre as mesocoxas. Metaventrito com pontuação fina, densa. Élitros com estrias fortemente marcadas, interestrias convexas, com pontuação muito fina ou fina e espaçada, simples, gradualmente afilado para os ápices; ápices conjuntamente arredondados. Abdômen gradualmente arredondado posteriormente. Primeiro esternito abdominal fracamente esclerotizado, sem órgão luminescente.

Edeago (Figs. 172, 173). Parâmeros com ápice truncado, com carena láterodorsal saliente; processo da articulação dorsal inteiro; bases medianas ventrais livres. Esclerito dorsal do pênis com prolongamentos basais 0,3 vez o comprimento da região posterior; margem lateral posterior aos prolongamentos basais com um tubérculo pouco saliente, alongado, recoberto por minúsculas. Esclerito ventral do pênis com aproximadamente $1 / 3$ da largura do esclerito dorsal.

Fêmea. Protórax mais convexo, com lados levemente arredondados e antenas mais curtas.

Membrana interconectiva do segmento VIII sem escleritos laterais. Genitália Feminina (Fig. 213). Baculi 1,6 vezes mais longo que os coxitos. Trato genital. Vagina com glândulas coleteriais mais longas que largas. Região posterior de cada glândula coleterial com uma área triangular formada por microescleritos, fracamente esclerotizada, região anterior com um esclerito alongado, côncavo, fracamente esclerotizado (Fig. 214). Bursa copulatrix com 2-3 espirais com espinhos alongados. Espermatecas com ápice espiralado.

Dimensões. Comprimento total $\widehat{\overbrace{}} 15,0-20,0 \mathrm{~mm}$, $q$ 18,0-20,0 mm. Comprimento dos élitros em relação ao do protórax: $\widehat{\delta}$ e ${ }_{+}$2,2-2,5. Largura do úmero em relação à do protórax: $\widehat{\jmath}$ e $q 1,0$. 
Espécies. E. notatissimus (Candèze, 1881); E. ophthalmicus (Perty, 1830).

Distribuição. Suriname, Brasil (BA, MG). (Costa, 1975b).

Material examinado. E. notatissimus. BRASIL. Sem localidade, sem data, sem coletor, 1 ๙ , 1 ㅇ (USNM). Bahia: sem localidade, 1905 Fry $2 \widehat{\jmath}$ (BMNH). E. ophthalmicus. Sem localidade, sem data, sem coletor, 1 क (MNHN). BRASIL. Bahia: Nova Conquista, xii.1969, F. H. Oliveira col., 3 ô (MZSP); Estrada Rio-Bahia, Km 965 xi.1971, Seabra \& Roppa col., 3 ô, 3 + (MZSP). Minas Gerais: Pedra Azul, ii.1970, F. H. Oliveira col., 1 + , (MZSP).

Comentários. Euplinthus pode ser prontamente identificado pela coloração do corpo. Possui a forma e a pontuação do pronoto e o edeago similares aos das espécies do grupo melanurus (Opselater), mas pelo menos para os caracteres do edeago (carena látero dorsal dos parâmeros, abaulamento alongado e escamas minúsculas nas margens laterais do esclerito dorsal do pênis) essa semelhança é conseqüência de surgimentos independentes paralelos nos dois táxons. Alguns espécimes possuem também uma vesícula amarelada e translúcida similar aos órgãos luminescentes de O. melanurus, mas os cladogramas obtidos na análise filogenética não corroboram a hipótese de homologia primária entre essas estruturas.

\section{Compsoplinthus Costa, 1975}

(Figs. 44, 174, 175, 215, 244)

Pyrophorus Billberg, 1820: 20 (pars).

Meroplinthus Candèze, 1891: 163 (pars); Schenkling, 1927: 356; Blackwelder, 1944: 286; Costa; 1975: 71.

Compsoplinthus Costa, 1975: 71; Golbach, 1994: 28.

Espécie-tipo: Pyrophorus ruber Candèze, 1878 (Localidade-tipo: Brasil, Bahia).

Redescrição. Macho (Fig. 244). Bicolorido, face dorsal predominantemente castanho-alaranjada, com antenas, cabeça e escutelo pretos, margem apical dos élitros quase preta; face ventral e pernas pretas com epipleuras e margem lateral dos hipômeros castanhoalaranjados. Pilosidade muito curta, dourada, decumbente.. Tegumento brilhante. 
Fronte retangular (1,5 vezes mais larga que longa), convexa, não carenada, com pontuação média, densa e umbilicada. Antenas (Fig. 44) fortemente serreadas a partir do quarto antenômero, atingindo a base dos ângulos posteriores; $3^{\circ}$ antenômero 1,0 vez mais longo que o $2^{\circ}, 4^{\circ} 1,8$ vezes o comprimento do $3^{\circ}$. Olhos pequenos (índice ocular 0,24 ), margem ocular com uma faixa preta em quase toda a sua extensão. Mandíbula sem dente subapical.

Protórax subquadrado (tão largo quanto longo), com lados levemente arredondados. Pronoto pouco convexo, com pontuação fina, espaçada e simples, muito maior, mais densa e umbilicada nas laterais. Região mediana posterior com tubérculo pequeno. Ângulos anteriores agudos e grandes; ângulos posteriores fortes, fracamente carenados, pouco divergentes. Prosterno alongado de lados quase retos, com pontuação forte, densa e umbilicada. Processo prosternal não denteado. Hipômeros com pontuação forte, densa e fortemente umbilicada com ângulo posterior e pequena área glabros, margem posterior com dois espinhos.

Mesoventrito. Margem lateral anterior com ângulo externo proeminente, parte ventral sinuosa, próxima da base, parte dorsal pouco ou parcialmente visível. Cavidade mesoventral com bordas posteriores inclinadas $90^{\circ}$ em relação à região anterior. Metaventrito com região entre as mesocoxas tão saliente quanto as bordas posteriores do mesoventrito; com pontuação fina a média, densa e umbilicada. Sutura meso-metaventral pouco marcada. Élitros com estrias fortemente marcadas, interestrias convexas com pontuação fina, densa e simples, gradualmente afilado para os ápices; ápices conjuntamente arredondados. Epipleuras não carenadas junto à base dos élitros. Abdômen gradualmente arredondado posteriormente. Primeiro esternito abdominal fracamente esclerotizado, sem órgão luminescente.

Edeago (Figs. 174, 175). Parâmeros com ápice truncado, com carena láterodorsal saliente; articulação dorsal com uma área subcircular membranosa, transparente; bases 
medianas ventrais livres. Esclerito dorsal do pênis com prolongamentos basais 0,4 vez o comprimento da região posterior, lados gradualmente afilados para o ápice. Esclerito ventral do pênis com aproximadamente $1 / 3$ da largura do esclerito dorsal, com uma carena dorsal pouco saliente.

Fêmea. Protórax mais convexo com lados mais arredondados, antenas mais curtas.

Membrana interconectiva do segmento VIII sem escleritos laterais. Genitália Feminina (Fig. 215). Baculi 1,1 vez mais longo que os coxitos. Trato genital. Vagina com glândulas coleteriais mais longas que largas. Região posterior de cada glândula coleterial com uma área triangular formada por microescleritos, mais esclerotizada na base das glândulas; região anterior com esclerito alongado, côncavo, formado por microescleritos. Bursa copulatrix com 2-3 espirais com espinhos alongados. Espermatecas com ápice espiralado.

Dimensões. Comprimento total $\overparen{\partial} 16,0-18,0 \mathrm{~mm}$, + 22,0-27,0 mm. Comprimento dos élitros em relação ao do protórax: $\widehat{o}$ e $q$ 2,-2,6. Largura do úmero em relação à do protórax: ^ e $q 1,0-1,1$.

Espécies. C. ruber (Candèze, 1878).

Distribuição. Brasil (GO, MG).

Material examinado. C. ruber. BRASIL. Goiás: Sem localidade, sem data, sem coletor, 1 ㅇ (MZSP). Vianópolis, xi.1931, R. Spitz col., 2 Oૈ, 1f (MZSP). Goiânia, xi.1978, C. Coimbra col., 1 q (MZSP). Minas Gerais: Pirapora, 02.iii.1969, Garbo col., 1 $\widehat{\jmath}$ (MZSP); Barra do Paraopeba, sem data, Vital R. Souza, 1 ㅇ (MZSP).

Comentários. A região posterior do mesoventrito, perpendicular ao eixo do corpo, e a ausência de carena na margem externa das epipleuras são as autapomorfias que caracterizam C. ruber e a distingue entre os gêneros da tribo Pyrophorini. A coloração geral do corpo e a pontuação do pronoto também são bastante conspícuas. A forma da região posterior do mesoventrito é muito similar a de Photophorus, mas as hipóteses filogenéticas indicam que esta semelhança se deve a eventos paralelos independentes nos dois gêneros. No 
trato reprodutivo da fêmea, o esclerito anterior às glândulas coleteriais é homólogo ao de Euplinthus e dos táxons do clado Opselater $^{*}$, a presença de duas áreas triangulares formadas por microescleritos também é condição homóloga à dos táxons do clado Opselater $^{*}$, mas a modificação na região anterior desta estrutura para fortemente esclerotizada em Compsoplinthus é uma autapomorfia.

\section{Hifo Candèze, 1881}

Hifo Candèze, 1881: 94; Schwarz, 1906: 216; Schenkling, 1927: 355; Costa, 1975: 50; Stibick, 1979: 165; Costa, 1984: 399.

Espécie-tipo: Hifo pacificus Candèze, 1881 (localidade-tipo: Tonga-Tabu).

Comentários. Hifo é gênero monotípico, conhecido apenas por dois exemplares machos de Tonga (Oceania) que não foram examinados no presente estudo e que por esse motivo não serão redescritos. Os dados de Hifo pacificus para a análise filogenética foram obtidos na redescrição desta espécie realizada por Costa (1984b) e também pela comunicação pessoal desta autora que examinou recentemente, a meu pedido, os espécimes tipos depositados no Institut Royal des Sciences Naturelles de Belgique (Bruxelas) e verificou os estados dos caracteres levantados no presente estudo. A região posterior da cabeça e o metanoto não foram examinados porque os exemplares-tipos não puderam ser dissecados, portanto, os caracteres encontrados nessas estruturas foram codificados como ausentes. Também não foram codificados alguns caracteres relativos ao edeago que não puderam ser visualizados porque esta peça está montada em lâmina permanente. Hifo parece ter perdido os órgãos bioluminescentes do pronoto mas possui órgão bioluminescente abdominal homólogo ao dos táxons do clado Opselater ${ }^{*}$. Outras quatro sinapomorfias sustentam a hipótese de monofilia entre este gênero e Opselater ${ }^{*}$ : o tamanho do olho no macho, médio, a reversão para a margem interna das mandíbulas denteada, a forma da margem lateral anterior do 
mesoventrito (com ângulo externo não proeminente e parte dorsal não visível) e as lamelas laterais fortemente esclerotizadas no primeiro esternito abdominal.

\section{Opselater Costa, 1975}

(Figs. 63, 73, 78, 89-93, 95-101, 108-11)

Elater Linnaeus, 1758: 404 (pars).

Pyrophorus Billberg, 1820: 20 (pars); Candèze, 1863: 29; Schenkling, 1927: 353;

Blackwelder, 1944: 286; Costa, 1975b: 103

Opselater Costa, 1975: 103; Costa, 1980: 164; Golbach, 1994: 29; Rosa, 2004:

204.

Espécie-tipo: Elater pyrophanus Illiger, 1807 (localidade-tipo: Bahia).

O gênero e as espécies de Opselater foram revisados recentemente (Rosa, 2004).

Os dois grupos de espécies reconhecidos nesta revisão foram incluídos como táxons terminais na presente análise cladística e o gênero resultou polifilético. O grupo melanurus aparece como grupo irmão de Lygelater bifossulatus em duas das resoluções possíveis (Fig. 2) para a

politomia do clado Opselater $^{*}$ e como táxon basal a todos aos demais táxons nas outras duas resoluções. Devido a essa ambigüidade na posição filogenética do grupo melanurus não proponho, neste momento, um novo gênero para as espécies do grupo.

\section{Lygelater Costa, 1975}

(Figs. 45 ,46, 176-180, 216, 218, 219)

Pyrophorus Billberg, 1820: 20 (pars).

Lygelater Costa, 1975: 95, 106; Golbach, 1994: 29.

Espécie-tipo: Lygelater fulgidus Germar, 1841 (Localidade-tipo: Santa Fé de Bogotá) 
Redescrição. Macho. Predominantemente castanhos, pronoto com margens laterais amareladas, antenas, hipômeros e epipleuras geralmente amarelados. Pilosidade curta, densa, amarelada ou acizentada, decumbente. Tegumento brilhante ou levemente opaco.

Fronte subquadrangular (1,0-1,1 vez mais longa que larga) de lados curvos para dentro, côncava, levemente carenada, com pontuação média a forte, densa e umbilicada. Antenas (Fig. 45, 46) serreadas a partir do quarto antenômero, atingindo o ápice dos ângulos posteriores ou ultrapassando os ângulos posteriores a partir do $10^{\circ}$ ou $11^{\circ}$ antenômero; $3^{\circ}$ antenômero 1,0-1,3 vez mais longo que o $2^{\circ}, 4^{\circ} 1,8-3,1$ vezes o comprimento do $3^{\circ}$. Olhos de tamanho médio (índice ocular 0,42-0,53), margem ocular levemente emarginada na região posterior. Mandíbula denteada.

Protórax subquadrado (1,0-1,1 vezes mais longo que largo), com lados subparalelos. Pronoto levemente convexo, com pontuação média a forte, densa e umbilicada na região discal, mais densa e mais umbilicada nas laterais; com um par de órgãos luminescentes em forma de vesículas ovais, pequenas a médias, achatadas, localizadas lateralmente, visíveis dos hipômeros. Região mediana posterior com ou sem um tubérculo pequeno. Ângulos anteriores agudos e grandes; ângulos posteriores delgados, fracamente carenados, pouco divergentes. Prosterno alongado de lados quase retos, com pontuação forte, densa e umbilicada. Processo prosternal com região apical denteada, dente saliente, região posterior ao dente curta ( $\mathrm{ca}$. 3,0\% do comprimento total do processo). Hipômeros com pontuação média, densa e fortemente umbilicada, com ângulo posterior e pequena área glabros, margem posterior com dois espinhos pequenos.

Mesoventrito. Margem lateral anterior sulcada do mesoventrito com ângulo externo não proeminente, parte ventral sinuosa, junto à base, parte dorsal não visível. Cavidade mesoventral com bordas posteriores fortemente inclidadas em relação à região anterior, visíveis lateralmente sobre as mesocoxas. Metaventrito com pontuação fina, densa. Élitros com estrias marcadas, interestrias achatadas, com pontuação fina, espaçada a densa e 
simples, gradualmente afilado para os ápices; ápices conjuntamante arredondados ou levemente divergentes. Abdômen com pontuação fina, moderadamente densa e simples, gradualmente afilado posteriormente. Primeiro esternito abdominal com lamelas laterais fortemente esclerotizadas, com órgão luminescente subquadrado, ocupando mais ou menos 1/5 do esternito I, em algumas espécies parcial a completamente recoberto pelas lamelas laterais.

Edeago (Figs. 176-180). Parâmeros com ápices geralmente arredondados, com um espinho látero-dorsal médio subapical ou com dois espinhos (um anterior, dorsal, grande e um subapical, lateral, pequeno); processo da articulação dorsal inteiro; bases medianas ventrais livres. Esclerito dorsal do pênis com prolongamentos basais 0,5-0,8 vez o comprimento da região posterior; margem lateral posterior aos prolongamentos basais com um abaulamento alongado e saliente, recoberto por escamas alongadas; ápice abruptamente afilado a partir do $1 / 5$ posterior, trilobado em algumas espécies. Esclerito ventral do pênis com quase a mesma largura do esclerito dorsal, de formato variável, com duas pregas laterais (Fig. 178), raramente também com uma carena longitudinal mediana pouco saliente (Fig. 179); com ou sem minúsculas escamas dirigidas posteriormente.

Fêmea. Protórax mais convexo, com lados levemente arredondados e antenas mais curtas.

Membrana interconectiva do segmento VIII com escleritos laterais ovais, grandes (Fig. 218). Genitália Feminina (Fig. 216). Vulva com base estreita ou fortemente alargada. Baculi $0,7-0,8$ vez mais longo que os coxitos. Trato genital. Vagina com glândulas coleteriais mais longas que largas. Região posterior de cada glândula coleterial com uma área triangular formada por microescleritos, uniformemente fracamente esclerotizada ou mais esclerotizada na base das glândulas coleteriais; região anterior com um esclerito alongado, côncavo, formado por microescleritos. Bursa copulatrix com 2-3 espirais com espinhos alongados. Espermatecas com ápice espiralado. 
Dimensões. Comprimento total $\widehat{\overbrace{}} 14,0-29,0 \mathrm{~mm}$, $q$ 19,0-28,0 mm. Comprimento dos élitros em relação ao do protórax: $\sigma^{\lambda}$ e $q$ 2,3-2,9. Largura do úmero em relação à do protórax: đ̂ e $\uparrow$ 0,9-1,0.

Espécies. L. bifossulatus (Candèze, 1865); L. fulgidus (Germar, 1841); L. ignitus

(Fabricius, 1787); L. indicus (Herbst, 1783); L. piceus (Schwarz, 1902); L. succinum Costa,

1980; L. torridus Costa, 1980.

Distribuição. Guatemala, Costa, Rica, Panamá, Colômbia, Venezuela, Suriname,

Guiana Francesa, Equador, Peru, Brasil (AM, PA), Bolívia. Costa (1980b).

Material examinado. L. indicus. GUIANA FRANCESA. Cayenne, sem data, sem coletor, $1 \hat{\delta}$ (BMNH); Pariacabo, 1906 Pennel, $2 \hat{\jmath}, 1$ (MNHN); Gourdonville, sem data, sem coletor, 1 + (MNHN, Coll. Le Moult). BRASIL. Amazonas: Manaus, 10. Viii.1995, Projeto Shift (Embrapa), 1 đ (MZSP); Tefé (Ega), sem data, sem coletor, 2 đ̂, 2 + (BMNH); Borba, vii.1973, sem coletor, 1 † (IBSP). Pará: sem localidade, sem data, sem coletor, $1 \hat{\delta}(\mathrm{BMNH})$; EQUADOR. Sem localidade, sem data, sem coletor, $1 \hat{\sigma}$ (MNHN). PERU. Amazonas: "Cavallo Cocho", v-vii.1884, M. de Mathan col., 3 ठิ (MNHN). L. piceus. BRASIL. Mato Grosso: sem localidade, 1886, P. Germain, 1 ô (MNHN); Corumbá, Serra do Urucum, 25.vi.1960, K. Lenko col., 1 ઈ (MZSP). BOLÍVIA. Beni: Rurrenabaque, xi-xii.1921-1922 W. M. Mann col., 2 + (USNM). Cochabamba: 1889, P. Germain, 1 ô (MNHN); Cristal Mayu, 09.x.1949, L. Pena, 1 o (CNHM). L. torridus. GUIANA FRANCESA. Cayenne, sem data, sem coletor, 3 q (Parátipos) (ISBN); sem localidade, idem, 3 q (Parátipos) (ISBN). BRASIL. Amazonas: Parintins, i.1940, J. Guérin, 1 + (Parátipo) (IBSP). Pará: Canindé (Rio Gurupi), xii.1964, B. Malkin col., $\widehat{o}$ (Holótipo) (MZSP); idem, 10.vi.1963, B. Malkin col., 1 đ (Parátipo) (MZSP). L. succinum. PANAMÁ. Chiquiri: Bugaba (800-1500ft), sem data, Champion, ô (Holótipo) (BMNH); idem, 1 ㅇ (Parátipo) (BMNH). L. bifossulatus. GUIANA FRANCESA. Cayenne, sem data, sem coletor, 1 o (BMNH). BRASIL. Amazonas: Maturacá, alto Rio Cauaburi, 17-20.i.1963, J, Bechyné col., 1 ô (MZSP); Taracuá, R. Uaupés, viii.1964, Pereira \& Machado col., 1 o (MZSP). L. fulgidus. COSTA RICA. Sem localidade, sem data, sem coletor, 2 đ (BMNH). PANAMÁ. Herrera: Porto Bello, 18.xi, August Busck col., 5 ô (USNM). Chiquiri: Bugaba (800-1500 ft), sem data, Champion, 3 ô (BMNH). Darien: Barro Colorado, 08.v.1926, Van Tyne col., 1 ô (MCZC); idem, v.1929, Darlington col., 1 † (MCZC). COLÔMBIA. (?) Santa Marta, 1853, Fontanier, 3 đิ, 1 † (MNHN). Boyaca: Muzo 780 ô, 10.ii.1942, sem coletor, 1 ô (MZSP). Valle del Cauca: MT-416, viii.1987, L. C. Pardo Locarno col., 1 đ (MNHN). VENEZUELA. Sem localidade, sem data, sem coletor, 1 ð (BMNH). SURINAME. Sem localidade, sem data, sem coletor, $2 \widehat{\partial}$ (MNHN). GUIANA FRANCESA. Saint Laurent du Moroni, 1862, Audoit, 1 ๙ (MNHN). EQUADOR. Chimbo, i-vi.1892, M. de Mathan col., 4 o (MNHN). BRASIL. Sem localidade, sem data, sem coletor, 2 ô (DEIC). Amazonas: São Paulo de Olivença, vi-vii.1883,

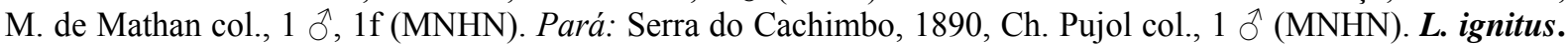
VENEZUELA. Sem localidade, sem data, sem coletor, 1 ô (BMNH). Aragua: El Limon, 17.x.1977, F. Fernandez col., 1 đ̃, 3 \& (MIZA). Zulia: Orope, 10.iii.1908, sem coletor, 1 + (CNHM). Miranda: Caucágua, 1923, Mayeul Grisol, 5 ô, 7 o (MNHN). Distrito Federal: Caracas, sem data, sem coletor, 1 ô (MNHN). GUIANA. Barima-Waini: Mission, x-xi.1969, Balachowski-Gruner col., 1 o (MNHN). Demerara-Mahaica: Georgetown, 1877, sem coletor, 1 \& (BMNH). GUIANA FRANCESA. Cayenne, sem data, sem coletor, 1 o (BMNH). TRINIDAD \& TOBAGO. Sem localidade, sem data, sem coletor, 1 ㅇ (BMNH). SANTA LÚCIA. Sem localidade, sem data, sem coletor, 6 o (MNHN). COLÔMBIA. Valle del Cauca: IT-396, sem data, L. C. Pardo Locarno col., 1 ô (MZSP). BRASIL. Amazonas: Tapuruquara (R. Negro), 14-16.ii.1963, J. Bechyné col., $1 \lesssim$ (MZSP).

Comentários. L. bifossulatus foi incluído como táxon terminal na análise porque possui edeago bastante diferente (Fig. 181, 182) do edeago das demais espécies do gênero, sem a suposta sinapomorfia compartilhada por elas: esclerito dorsal com margem lateral com 
abaulamento fortemente saliente. Após a análise a exclusão de Lygelater do grupo da espécietipo do gênero se confirmou, mas essas supostas sinapomorfias para o gênero não são apontadas em todas as hipóteses. Algumas das hipóteses demonstram que Lygelater bifossulatus deve ser filogeneticamente mais próximo das espécies do grupo melanurus (Opselater), com o qual compartilha as minúsculas escamas nas margens laterais do esclerito dorsal (Fig.181) e a as vesículas luminescentes arredondadas muito pequenas. No entanto a similaridade externa entre essas espécies e as demais do gênero Lygelater e a politomia do nó 77 sugerem que uma análise filogenética, incluindo como terminais as espécies e caracteres mais apropriados para esse nível, poderiam indicar mais precisamente as relações filogenéticas entre elas e mudanças taxonômicas, se necesssárias, mais estáveis. Algumas espécies de Lygelater, incluindo L. bifossulatus, são caracterizadas pela pontuação geral do pronoto, forte, densa e umbilicada, pelas vesículas luminescentes muito pequenas, pela forma dos antenômeros 2 e 3, pequenos e subiguais e pela margem lateral do protórax amareladas. Essas características também são encontradas nas espécies do grupo melanurus (Opselater). Lygelater (excl. L. bifossulatus) possui edeago bastante conspícuo, que o separa prontamente dos demais Pyrophorini. O ápice dos parâmeros em algumas espécies (com um espinho látero-dorsal grande, mais anterior e mais dorsal, e um posterior pequeno) é semelhante ao das espécies de Vesperelater, mas as hipóteses filogenéticas apontam essa semelhança como homoplástica entre esses táxons.

\section{Deilelater Costa, 1975}

(Figs. 5, 47, 183, 184, 245)

Pyrophorus Billberg, 1820: 20 (pars).

Deilelater Costa, 1975: 96, 108; Golbach, 1994: 29; Johnson, 2002:169

Espécie-tipo: Pyrophorus physoderus Germar, 1841 (Localidade-tipo: Alabama). 
Redescrição. Macho (Fig. 245). Uniformemente castanhos. Pilosidade curta, densa, amarelada ou acizentada, decumbente. Tegumento brilhante.

Fronte subquadrangular (1,0-1,1 vez mais longa que larga) de lados curvos para dentro, côncava, levemente carenada, com pontuação média a forte, densa e umbilicada. Antenas (Fig.47) fracamente serreadas a partir do quarto antenômero, ultrapassando os ângulos posteriores a partir do $10^{\circ}$ ou $11^{\circ}$ antenômero; $3^{\circ}$ antenômero $1,4-1,5$ vezes mais longo que o $2^{\circ}, 4^{\circ} 1,6-2,1$ vezes o comprimento do $3^{\circ}$. Olhos de tamanho médio (índice ocular 0,43-0,52), margem ocular levemente emarginada na região posterior. Mandíbula denteada (Fig. 5).

Protórax subquadrado (0,9-1,1 vezes mais longo que largo), com lados subparalelos, levemente arredondados ou convergentes anteriormente. Pronoto levemente convexo a convexo, com pontuação fina a forte, densa e simples ou umbilicada na região discal, mais densa e mais umbilicada nas laterais; com um par de órgãos luminescentes em forma de vesículas ovais, médias a grandes, achatadas, localizadas lateralmente. Região mediana posterior com um tubérculo pequeno. Ângulos anteriores agudos e grandes; ângulos posteriores delgados, fracamente carenados a carenados, divergentes. Prosterno alongado de lados quase retos, com pontuação média a forte, densa e umbilicada. Processo prosternal com região apical denteada, dente saliente, região posterior ao dente curta $(3,0-4,5 \%$ do comprimento total do processo). Hipômeros com pontuação média, densa e fortemente umbilicada, com ângulo posterior e pequena área glabros, margem posterior com dois espinhos pequenos.

Mesoventrito. Margem lateral anterior com ângulo externo não proeminente, parte ventral quase reta, junto à base, parte dorsal não visível. Cavidade mesoventral com bordas posteriores fortemente inclidadas em relação à região anterior, visíveis lateralmente sobre as mesocoxas. Metaventrito com pontuação fina, densa. Élitros com estrias pouco marcadas, interestrias achatadas, com pontuação fina, espaçada a densa e simples, 
gradualmente afilado para os ápices; ápices conjuntamante arredondados. Abdômen com pountuação fina, moderadamente densa e simples, gradualmente afilado posteriormente. Primeiro esternito abdominal com lamelas laterais fortemente esclerotizadas, com órgão luminescente subquadrado, ocupando mais ou menos $1 / 5$ do esternito I.

Edeago (Figs. 183, 184). Parâmeros com ápices geralmente arredondados, com um espinho látero-dorsal médio a grande; processo da articulação dorsal inteiro; bases medianas ventrais livres. Esclerito dorsal do pênis com prolongamentos basais 0,4-0,7 vez o comprimento da região posterior, de lados arredondados ou paralelos até o ápice abruptamente afilado a partir do $1 / 5$ posterior, com escamas alongadas nas margens látero dorsais posteriores. Esclerito ventral do pênis com 1/3 da largura ou quase da mesma largura do esclerito dorsal, com ápice truncado ou emarginado, com duas pregas laterais e minúsculas escamas dirgidas posteriormente.

Fêmea. Protórax levemente convexo, com lados levemente mais arredondados e antenas mais curtas.

Membrana interconectiva do segmento VIII com escleritos laterais ovais, grandes. Genitália Feminina. Baculi 0,9 vezes mais longo que os coxitos. Trato genital. Vagina com glândulas coleteriais mais longas que largas. Região posterior de cada glândula coleterial com uma área triangular formada por microescleritos, uniformemente fracamente esclerotizada ou mais esclerotizada na base das glândulas coleteriais; região anterior com um esclerito alongado, côncavo, formado por microescleritos. Bursa copulatrix com 2-3 espirais com espinhos alongados. Espermatecas com ápice espiralado.

Dimensões. Comprimento total $\widehat{\partial} 18,0-25,0 \mathrm{~mm}, q$ 19,0-28,0 mm. Comprimento dos élitros em relação ao do protórax: $\widehat{o}$ e $q$ 2,4-3,1. Largura do úmero em relação à do protórax: đ̂ e $\uparrow$ 1,0-1,1.

Espécies. D. bellamyi (Van Zwaluwenberg, 1936); D. mexicanus (Champion, 1895); D. physoderus (Germar, 1841); D. radians (Champion, 1895); D. stella (Candèze, 1863). 
Distribuição. Estados Unidos, México, Guatemala, Belize, San Salvador, Honduras, Nicarágua, Costa Rica, Panamá. (Costa, 1983).

Material examinado. D. mexicanus. COSTA RICA. (?): Bebidero sem data, sem coletor, 2 $\widehat{\jmath}$ (MNHN). San José: sem localidade, sem data, P. Biolley, 2 ô (CMNH); Miravalles, 1952 P. Biolley, 1m, 3 ㅇ (MNHN). Cartago: sem localidade, sem data, sem coletor, 1 o (BMNH). EL SALVADOR. San Salvador: 15.v.1956, E. Möhn col., 1 ○ (SMF). D. physoderus ESTADOS UNIDOS. Texas: Del Rio, Val Verde Co., 25.v.1952, W. Cazier, W. Gertsch \& R. Scrammel col., 2 ऊ (AMNH); sem localidade, sem data, sem coletor, 2 ô, 1 ㅇ (MCZ); idem, Davis Mt. State Park, 25.vii.1986, W. F. Chamberlain col., 6 ô (TAMU); Boquillas, Big Bend Nat. Park, 16.vii.1973, M. L. Allender, 1 q (TAMU). MÉXICO. Chihuahua: Cerro Campana (5 km N) Sierra del Nido, 28.vi-01.vii.1959 W. C. Russell col., 13 o (CISC); Canon Prieto nr. Primavera, 02.vii.1947, Exp. Cazier col., 10 đิ (AMNH); Primavera, 30.vi.1947, Exp. Cazier col., $5 \hat{\jmath}$ (AMNH); Cuauhtemoc (15 mi E), 11.vii.1959, J. A. Chemsak \& J. Powell col., 12 ơ (CISC). Nuevo León: Liñares (15 mi W), 27.vii.1978, Plitt \& Schaffner col., 5 ô (TAMU); idem, 1-3.vii.1973, Mastro e Schaffner col., 5 o (TAMU); idem, 23.vii.1973, Peigler, Gruetzmacher, \& Schaffner col., 8 ô, 2 q (TAMU). Tamaulipas: Villagran (14 Km S), 25.v.1948, P.

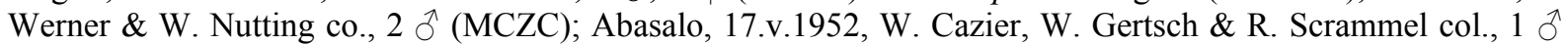
(AMNH). Veracruz-Llave: Puente nacional, 21.vi.1962 D. H. Janzen col., 1 ô (CISC); Cotaxtla, 03.iv.1958; Alejandro Ortega col., 1 ○े (MZSP). D. radians. MÉXICO. Veracruz-Llave: 1922 A. Gérin col., 1 ○े (MNHN); Córdoba, 06.vii.1966, Gardner col., 1 \& (CASC). Chiapas: Tuxtla Gutierrez, 27.iv.1926, sem coletor, 1m (AMNH); idem, 21.vi.1987, sem coletor, 1m, 2 q (TAMU); Cinco Cerros, 26.vi.1987, W. F. Chamberlain col., 3 ô, 1 o (TAMU). Querétaro de Arteaga: Landa de Matamoros, 22-23.vii.1970, Murray, Hart, Phelps \& Schaffner col., 1 ô (MZSP). BELIZE ("Brit. Honduras"). Rio Temas, 02.v.1937, J. J. White col., 3 ô, 1 ㅇ (BMNH);"M-Tee District", i-ii.1906, sem coletor, 4 ô (MCZC). GUATEMALA. Alta Verapaz: Senahu, sem data, Champion, 1m, 1f (BMNH). Baja Verapaz: Purulha, sem data, Champion, $2 \hat{\jmath}, 1 \mathrm{f}(\mathrm{BMNH})$. HONDURAS. Francisco Morazan: Tegucigalpa, 30.v.1982, R. W. Jones col., 2 ô (MZSP); idem (EAP), v.1985, sem coletor, 4

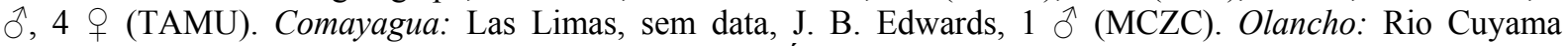

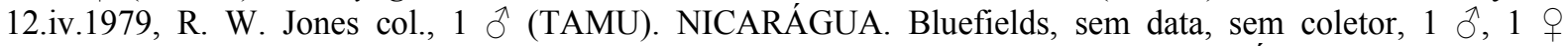
(MNHN). Manágua, 18.vi.1972, R. R. \& M. E. Murray col., 2 đ̊ (MZSP). PANAMÁ. Pearl Is. San Jose, 10.v.1944, Morrison, 2m, 1f (USNM). D. stella. MEXICO. Veracruz-Llave: Jalapa, v.1947, Wegenre col., 5 ô, 1 우 (AMNH); Misantla, sem data, sem coletor, 3 ô, 1 우 (BMNH); La Antigua, 10.v.1901, F. E. Lutz col., 1 우 (CMNH).

Comentários. Deilelater foi dividido em três subgrupos: o grupo da espécie-tipo do gênero, o grupo atlanticus e o grupo sirius (ver anexo I) que foram incluídos como táxons terminais na análise filogenética. Todas as hipóteses resultantes demonstram que esses três táxons não formam um grupo monofilético, e que os grupos atlanticus e sirius são mais filogeneticamente relacionados às espécies de Vesperelater.

$$
\text { Para o grupo atlanticus (Gênero E), cujas espécies compartilham como }
$$
sinapomorfias a carena látero-dorsal fortemente saliente nos ápices dos parâmeros e a ausência de tubérculo na base do pronoto proponho um gênero novo (Gênero E), porque essas sinapomorfias definem uma linhagem monofilética distinta daquela da espécie-tipo do gênero

\section{Deilelater.}


Por outro lado, a forma dos ápices dos parâmeros e o tubérculo na base do pronoto não são caracteres exclusivos das demais espécies de Deilelater e a similaridade entre essas estruturas e a de outros táxons do clado 77 (Figs. 1, 2) pode ser interpretada como autapomorfias ou como homoplasias, dependendo da hipótese considerada. As autapomorfias de Deilelater (ápice do esclerito dorsal abruptamente afilado a partir do $1 / 5$ posterior e minúsculas escamas no esclerito ventral) também podem ser interpretadas como sinapomorfias compartilhadas com Lygelater, devido à politomia no nó 77.

Proponho também a transferência de D. sirius (Candèze, 1878) para o gênero Vesperelater, com o qual compartilha a sinapomorfia ápice dos parâmeros abruptamente afilado entre $1 / 3$ e 1/4 posterior, embora, como discutido anteriormente, uma análise filogenética mais adequada para as espécies do táxon 77 seja necessária para esclarecer melhor as relações entre esses gêneros e definir suas sinapomorfias e gerar uma classificação mais estável. Na aparência externa, todos esses táxons (grupos atlanticus e sirius, Deilelater e Vesperelater) são muito semelhantes e, para muitos deles, apenas o exame da genitália masculina permite identificá-los.

\section{Photophorus Candèze, 1863}

(Figs. 13, 48, 74, 88, 185, 186, 220, 247)

Photophorus Candèze, 1863: 72.

Espécie-tipo: Photophorus jansonii Candèze, 1863 (designado por Hyslop, 1921: 664) (Localidade-tipo: Viti-Levu).

Redescrição. Macho (Fig. 247). Uniformemente castanhos a pretos ou com uma estreita faixa amarelada nas margens laterais. Pilosidade curta, moderadamente densa, amarelada, decumbente. Tegumento brilhante.

Fronte (Fig. 13) subquadrangular (1,0-1,1 vez mais longa que larga) de lados curvos para dentro, côncava, levemente carenada, com pontuação fina, densa e simples. 
Antenas (Fig. 48) serreadas a partir do quarto antenômero, ultrapassando os ângulos posteriores a partir do $9^{\circ}$ ou do $11^{\circ}$ antenômero; $3^{\circ}$ antenômero $1,0-1,3$ vezes mais longo que o $2^{\circ}, 4^{\circ} 2,1-2,7$ vezes o comprimento do $3^{\circ}$. Olhos de tamanho médio (índice ocular 0,47 ), margem ocular levemente emarginada na região posterior. Mandíbula denteada.

Protórax subquadrado (1,0-1,2 vezes mais longo que largo), com lados arredondados, convergentes anteriormente. Pronoto pouco convexo, com pontuação homogênea, muito fina e espaçada ou fina e moderadamente densa, simples; com um par de órgãos luminescentes em forma de vesículas ovais, médias, levemente convexas, localizadas lateralmente, visíveis dos hipômeros. Região mediana posterior com ou sem um tubérculo pequeno. Ângulos anteriores agudos e grandes; ângulos posteriores fortes, fortemente carenados, pouco divergentes. Prosterno alongado de lados quase retos, com pontuação fina e espaçada. Processo prosternal com região apical denteada, dente saliente, região posterior ao dente de comprimento médio ( $c a .7,6 \%$ do comprimento total do processo). Hipômeros com pontuação fina e espaçada e simples ou média, densa e fortemente umbilicada, com ângulo posterior e pequena área glabros, margem posterior truncada, sem espinhos.

Mesoventrito. Margem lateral anterior com ângulo externo não proeminente, parte ventral fracamente sinuosa, junto à base, parte dorsal não visível. Cavidade mesoventral com bordas posteriores (Fig. 74) perpendiculares ao eixo do corpo, visíveis lateralmente sobre as mesocoxas. Mesepisterno (Fig. 88) com ângulo interno truncado. Metaventrito com região entre as mesocoxas tão saliente quanto as bordas posteriores do mesoventrito, com pontuação fina e espaçada. Garras tarsais com 3 ou 4 cerdas. Élitros com estrias fortemente marcadas, interestrias achatadas, com pontuação fina, espaçada a densa e simples, gradualmente afilado para os ápices; ápices divergentes com um pequeno espinho sutural. Abdômen com pontuação fina, moderadamente densa e simples, gradualmente afilado posteriormente. Primeiro esternito abdominal com lamelas laterais fortemente esclerotizadas, com órgão luminescente subquadrado, ocupando mais ou menos $1 / 5$ do esternito I. 
Edeago (Figs. 185, 186). Parâmeros com ápices geralmente arredondados, com um espinho látero-dorsal médio; processo da articulação dorsal inteiro; bases medianas ventrais livres. Esclerito dorsal do pênis com prolongamentos basais 1,0-1,1 vez o comprimento da região posterior; margem lateral posterior aos prolongamentos basais com um abaulamento alongado e saliente, recoberto por escamas alongadas; ápice afilado. Esclerito ventral do pênis com aproximadamente $1 / 3$ do esclerito dorsal, com duas pregas laterais, sem escamas.

Fêmea. Igual ao macho, exceto pela antenas mais curtas.

Membrana interconectiva do segmento VIII sem escleritos laterais. Genitália Feminina (Fig. 220). Baculi 1,2-1,3 vezes mais longo que os coxitos. Trato genital. Vagina com glândulas coleteriais mais longas que largas. Região posterior de cada glândula coleterial com uma área triangular formada por microescleritos uniformemente fortemente esclerotizada; região anterior com um esclerito alongado, côncavo, formado por microescleritos. Bursa copulatrix com 2-3 espirais com espinhos alongados. Espermatecas com ápice espiralado

Dimensões. Comprimento total $\overparen{\partial} 26,0-28,0 \mathrm{~mm}$, $\rightarrow$ 27,0-31,0 mm. Comprimento dos élitros em relação ao do protórax: $\widehat{\partial}$ e $\uparrow$ 2,6-2,9. Largura do úmero em relação à do protórax: ^ึ e $\odot$ 1,0-1,1.

Espécies. P. jansonii Candèze, 1863; P. bakewellii Candèze, 1863

Distribuição. Fidji, Vanuatu.

Material examinado. P. jansoni. FIDJI. Sem localidade, sem data, sem coletor, 3 o, 1 ㅇ (BMNH Coll. Janson); idem, 1920, Pemberton, 1 đै (BMNH Coll. Janson); Viti-Levu, sem data, sem coletor, 1 o (MZHF); Tavauni Waiyavo, 16.iii.1924, H. S. Evans col., 2 ภ (BPBM); Navua, 1906, Muir col., 1 우 (BPBM). P. bakewelli. VANUATU. Malekula Is. Lakatoro, 2.ix-19.x.1967, J. \& M. Sedlacek, 1 M (BPBM). Sanma: Santo, Port Olry, 23.x.1981, J. L. Gressitt col., 1 ㅇ. (BPBM); idem, 20-25.x..1981, 1 ô, 1 ㅇ (BPBM); Espirito Santo I. 15.xii.1943, sem coletor, 1 ô (BPBM); idem, 1944, 1 ô (BPBM).

Comentários. Photophorus possui como autapomorfias o protórax e élitros das fêmeas iguais aos do macho, a região posterior ao dente com comprimento médio, as bordas 
posteriores da cavidade mesoventral perpendiculares ao eixo do corpo, o ângulo interno do mesepisterno truncado e os tarsômeros 2-4 com almofada setosa esponjosa pouco desenvolvida e garras tarsais com 4 cerdas na face externa. Esses caracteres (exceto o ângulo externo truncado do mesepisterno) ocorrem, independentemente, em vários outros gêneros de Pyrophorini, mas em seu conjunto distinguem prontamente Photophorus dos demais gêneros da tribo. Photophorus também distingue-se de Hifo, região Australiana, pela presença de vesículas luminescentes no pronoto.

\section{Ignelater Costa, 1975}

(Figs. 7, 8, 49, 85, 87, 187, 188, 221, 246)

Stilpnus Castelnau, 1840: 236 (nome pré-ocupado, Gravenhorst, 1829 Hymenoptera).

Pyrophorus Billberg, 1820: 20 (pars); Candèze, 1863: 30; Schenkling, 1927: 354; Blackwelder, 1944: 285; Costa, 1975b: 105.

Ignelater Costa, 1975: 95, 105; Golbach, 1994: 28; Johnson, 2002: 169.

Redescrição. Macho (Fig. 246). Predominantemente castanhos, geralmente com 1/3 mediano do pronoto mais escuro. Pilosidade curta, densa, amarelada, decumbente. Tegumento brilhante.

Fronte subquadrangular (1,0-1,1 vez mais longa que larga) de lados curvos para dentro, côncava, levemente carenada, com pontuação fina a média, densa e umbilicada. Antenas (Fig. 49) serreadas a partir do quarto antenômero, ultrapassando os ângulos posteriores a partir do $8^{\circ}$ ou do $10^{\circ}$ antenômero; $3^{\circ}$ antenômero $1,0-1,7$ vezes mais longo que o $2^{\circ}, 4^{\circ} 1,8-2,7$ vezes o comprimento do $3^{\circ}$. Olhos de tamanho médio (índice ocular 0,46-0,53), margem ocular levemente emarginada na região posterior. Mandíbula denteada. 
Protórax subquadrado (1,0-1,1 vez mais longo que largo), com lados subparalelos. Pronoto pouco convexo, com pontuação heterogênea, fina a média, espaçada a densa e simples na região discal; mais densa e umbilicada nas laterais, com um par de órgãos luminescentes em forma de vesículas ovais, médias a grandes, achatadas a levemente convexas, localizadas lateralmente, visíveis dos hipômeros. Região mediana posterior com um tubérculo pequeno. Ângulos anteriores agudos e grandes; ângulos posteriores delgados, carenados e divergentes. Prosterno alongado de lados quase retos, com pontuação média a forte e densa, simples ou umbilicada. Processo prosternal com região apical denteada, dente saliente, região posterior ao dente curta (4-5\% do comprimento total do processo). Hipômeros com pontuação fina a média, espaçada, densa e fortemente umbilicada, com ângulo posterior e pequena área glabros, margem posterior truncada, com ou sem dois espinhos.

Mesoventrito. Margem lateral anterior (Fig. 85) com ângulo externo não proeminente, parte ventral fracamente sinuosa a reta, junto à base, parte dorsal não visível. Cavidade mesoventral com bordas posteriores pouco inclinadas a fortemente inclidadas em relação à região anterior, visíveis lateralmente sobre as mesocoxas. Metaventrito com pontuação fina, densa. Élitros com estrias fracamente marcadas, interestrias achatadas, com pontuação fina, espaçada a densa e simples, gradualmente afilado para os ápices; ápices levemente divergentes com um espinho sutural. Abdômen com pontuação fina, moderadamente densa e simples, gradualmente afilado posteriormente. Primeiro esternito abdominal com lamelas laterais fortemente esclerotizadas, com órgão luminescente subquadrado, ocupando mais ou menos $1 / 5$ do esternito I, em algumas espécies parcial a completamente recoberto pelas lamelas laterais.

Edeago (Figs. 187, 188). Parâmeros com ápices geralmente arredondados, com um espinho látero-dorsal médio; processo da articulação dorsal inteiro; bases medianas ventrais livres. Esclerito dorsal do pênis com prolongamentos basais $0,3-0,7$ vez o 
comprimento da região posterior; margem lateral posterior aos prolongamentos basais com um abaulamento alongado e saliente ou com um tubérculo fortemente proeminente, recobertos por escamas curtas a alongadas; ápice afilado. Esclerito ventral do pênis com 1/3 a quase da mesma largura do esclerito dorsal, com duas pregas laterais, com ou sem minúsculas escamas dirigidas posteriormente.

Fêmea. Com protórax levemente mais convexo e mais arredondado, antenas mais curtas.

Membrana interconectiva do segmento VIII com escleritos laterais mais ou menos ovais, grandes. Genitália Feminina (Fig. 221). Baculi 1,2-1,3 vezes mais longo que os coxitos. Trato genital. Vagina com glândulas coleteriais mais longas que largas. Região posterior de cada glândula coleterial com uma área triangular formada por microescleritos uniformemente fortemente esclerotizada; região anterior com um esclerito alongado, côncavo, formado por microescleritos. Bursa copulatrix com 2-3 espirais com espinhos alongados. Espermatecas com ápice espiralado

Dimensões. Comprimento total $\widehat{\jmath} 12,0-29,0 \mathrm{~mm}$, $q$ 19,0-32,0 mm. Comprimento dos élitros em relação ao do protórax: $\bigcirc$ 2,7-3,5, † 2,6-3,9. Largura do úmero em relação à do protórax: ^ึ 1,0-1,2 e 9 0,9-1,1.

Espécies. I. brunneus Costa, 1980; I. caudatus (Champion, 1895); I. glaesum Costa, 1980; I. phosphoreus (Linnaeus, 1758); I .havaniensis (Castelnau, 1840); I. luminosus (Illiger, 1807); I. novoae García \& Piña, 1998; I. paveli García \& Piña, 1998.

Distribuição. Estados Unidos, México, Bahamas, Cuba, Haiti, República Dominicana, Porto Rico, Santa Lúcia, Trinidad \& Tobago, Colômbia. Costa, (1980a), Johnson (2002).

Material examinado. I. bruneus. CUBA. Mts. N de Imias, eastern Oriente (8000-4000ft), 25-28.vii.1936, Darlington col., $\hat{o}$ (Holótipo) (MCZC); idem, 5 ô, 3 \& (Parátipos) (MCZC). I. glaesum. BAHAMAS. Cayman, 17.iv-26.viii.1938, Oxf. Univ. Biol. Exp. Col., ô (Holótipo) (BMNH); idem, 1 ภ, 1 우 (Parátipo) (BMNH). I. havaniensis. MÉXICO. Sem localidade, sem data, sem coletor, 1 đ (MCZC). PORTO RICO. Mayaguez, 04.ii.1969, sem coletor, 1 o, 1 ㅇ (MCZC). CUBA. Trinidad Mts, vi.1929, Darlington col., 2 ô (MCZC); Soledad, 09.vi.1918, sem coletor, 1 đ (MCZC); Soledad (Cienfuegos), iv.1986, Darlington col., 8 
ô, 11 ㅇ (MCZC); Los Indios, sem data, sem coletor, 4 ô, 2 ㅇ (CMNH). BAHAMAS. Sem localidade, 1902, J.

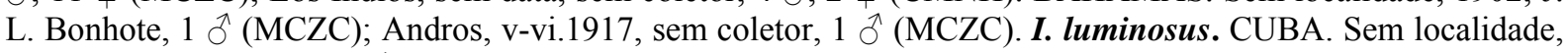
sem data, sem coletor, 1 ô (MCZC). PORTO RICO. Mayaguez, i-iii.1965, R. Landaverde col., 1 ㅇ (MZSP); idem, iv.1966, J. A. Ramos col., 1 ơ (MZSP); El Yunque, v.1938, Darlington col., 2 ô, 2 ㅇ (MCZC); Arecibo, 28.iii.1935, R. C. (?) col., 1 ๙ิ (MCZC); Maricao, 30.v.1938, Darlington col., 5 ô, 1 ㅇ (MCZC); sem localidade, sem data, sem coletor, $7 \hat{\delta}, 4$ q (MNHN). SANTA LÚCIA. 1851, Bonneccour, $1 \overbrace{}^{\lambda}$ (MNHN). I. phosphoreus. CUBA. Sem localidade, sem data, sem coletor, 1 क (DEIC); idem, 3 ㅇ (MNHN). HAITI. Port-au-Prince, 1911,

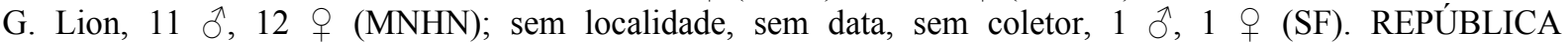
DOMINICANA. Puerto Plata, sem data, sem coletor, 1 q (MCZC); Constanza, viii.1938, Darlington col,., 1 ㅇ (MCZC); San Jose de las Matas, vi.1938, Darlington col., 1 ㅇ (MCZC); S. Domingo, sem data, sem coletor, 3 ${ }^{\dagger}$, 2 ㅇ (ISBN).

Comentários. As espécies descritas recentemente para Cuba, I. novoae e I. paveli, não foram examinadas. Segundo as descrições e ilustrações de García \& Piña (1998) essas espécies são similares a I. bruneus, também de Cuba.

Algumas espécies de Ignelater possuem como autapomorfia a presença de um tubérculo fortemente proeminente na região posterior de cada prolongamento basal do esclerito dorsal do pênis, outras possuem um abaulamento saliente alongado nessa mesma região que parece ser homólogo apenas àquele encontrado em Photophorus, sendo homoplástico em relação às estruturas semelhantes do grupo melanurus e de Lygelater. $\mathrm{Na}$ aparência externa, Ignelater pode ser reconhecido pelas antenas longas, pelo pronoto com 1/3 mediano mais escuro, geralmente com pontuação fina e élitros afilados com ápices divergentes e com um espinho sutural curto ou moderadamente alongado. Por essas características assemelha-se a Opselater lucens, mas este é geralmente menor, possui antenas mais curtas élitros menos afilados.

Gênero E gen. n.

(Figs. 50, 189, 190)

Deilelater Costa, 1975 (pars).

Espécie-tipo: Pyrophorus atlanticus Hyslop, 1917: 8 
Descrição. Macho. Uniformemente castanhos. Pilosidade curta, densa, acizentada, decumbente. Tegumento brilhante.

Fronte subquadrangular (1,0-1,1 vez mais longa que larga) de lados curvos para dentro, côncava, levemente carenada, com pontuação média a forte, densa e umbilicada. Antenas (Fig. 50) fracamente serreadas a partir do quarto antenômero, ultrapassando os ângulos posteriores a partir do $9^{\circ}$ ou $11^{\circ}$ antenômero; $3^{\circ}$ antenômero 1,4 vez mais longo que o $2^{\circ}, 4^{\circ} 1,6-1,7$ vezes o comprimento do $3^{\circ}$. Olhos de tamanho médio (índice ocular 0,45 ), margem ocular levemente emarginada na região posterior. Mandíbula denteada.

Protórax subquadrado (0,9-1,1 vez mais longo que largo), com lados subparalelos. Pronoto levemente convexo, com pontuação fina a forte, densa e simples ou umbilicada na região discal, mais densa e mais umbilicada nas laterais; com um par de órgãos luminescentes em forma de vesículas ovais, médias a grandes, achatadas, localizadas lateralmente. Região mediana posterior sem tubérculo. Ângulos anteriores agudos e grandes; ângulos posteriores delgados, fracamente carenados, pouco divergentes. Prosterno alongado de lados quase retos, com pontuação média, densa e umbilicada. Processo prosternal com região apical denteada, dente saliente, região posterior ao dente curta $(3,0-4,0 \%$ do comprimento total do processo). Hipômeros com pontuação média, densa e fortemente umbilicada, com ângulo posterior e pequena área glabros, margem posterior com ou sem dois espinhos pequenos.

Mesoventrito. Margem lateral anterior com ângulo externo não proeminente, parte ventral quase reta, junto à base, parte dorsal não visível. Cavidade mesoventral com bordas posteriores fortemente inclidadas em relação à região anterior, visíveis lateralmente sobre as mesocoxas. Metaventrito com pontuação fina, densa. Abdômen com pountuação fina, moderadamente densa e simples, gradualmente afilado posteriormente. Primeiro esternito abdominal com lamelas laterais fortemente esclerotizadas, com órgão luminescente pequeno, ocupando mais ou menos $1 / 5$ do esternito I. Élitros com estrias marcadas, 
interestrias levemente convexas, com pontuação fina, espaçada e simples, gradualmente afilado para os ápices; ápices conjuntamante arredondados.

Edeago (Figs. 189, 190). Parâmeros com ápices arredondados, com uma carena látero-dorsal fortemente saliente; processo da articulação dorsal inteiro; bases medianas ventrais livres. Esclerito dorsal do pênis com prolongamentos basais 0,5-0,6 vez o comprimento da região posterior; de lados gradualmente arredondados até o ápice, com poucas escamas curtas nas margens látero-dorsais posteriores. Esclerito ventral do pênis com aproximadamente $2 / 3$ da largura do esclerito dorsal, com ápice arredondado, com duas pregas laterais, com minúsculas escamas dirigidas posteriormente nas margens láteroposteriores.

Fêmea. Não conhecida.

Dimensões. Comprimento total 11,0-19,0 mm. Comprimento dos élitros em relação ao do protórax: 2,5-3,0. Largura do úmero em relação à do protórax: 1,0-1,1 .

Espécies. Gênero E atlanticus (Hyslop, 1917) comb. n.; Gênero E ustulatus (Costa, 1983) comb. n.

Distribuição. Estados Unidos.

Material examinado. Gênero E atlanticus. ESTADOS UNIDOS. Florida: Marion Co. 03.viii.1938, Hubell \& Friaauf col., 1 ○ै (MCZC); Lake Co. Clermont, 20.viii.1966, J. Stibick col., 4 ô (MZSP); Highlands Co. 23.v.1949, B. Patterson col, 1 ○ (FMNH); sem localidade, sem data, sem coletor, 3 ○े (MCZC). Gênero E ustulatus. ESTADOS UNIDOS. Florida: Dunedin, sem data, sem coletor, 7 đै (MCZC); Winter Park, 05.v.1929, sem coletor, 1 § (MCZC); Big Pine Key, 09.v.1966, J. E. Wappes col., 1 đิ (MZSP); Cedar Keys,

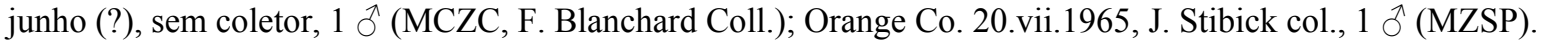

Comentários. O Gênero E é proposto com base nas sinapomorfias compartilhadas por suas duas espécies, carena látero-dorsal fortemente saliente nos ápices dos parâmeros (homoplástica em relação à de algumas espécies de Ignelater) e ausência de tubérculo na base do pronoto (uma reversão para o estado plesiomórfico da tribo, homoplástica em relação ao de algumas espécies do clado 77). Ambas as espécies são muito similares na aparência geral a 
Deilelater, exceto pelas estrias dos élitros mais marcadas, pelas antenas alongadas de Gênero E ustulatus e pelo tamanho menor de Gênero E atlanticus.

\section{Vesperelater Costa, 1975}

(Figs. 51, 58, 62, 65, 107, 191-194, 248)

Pyrophorus Billberg, 1820:20 (pars).

Vesperelater Costa, 1975: 96, 109; Golbach, 1994: 29; Johnson, 2002:169

Espécie-tipo: Pyrophorus ornamentum Germar, 1841 (localidade-tipo: México)

Redescrição. Macho (Fig. 248). Uniformemente castanhos. Pilosidade curta, densa, amarelada ou acizentada. Tegumento brilhante.

Fronte subquadrangular (1,0-1,1 vez mais longa que larga) de lados curvos para dentro, côncava, levemente carenada, com pontuação fina a média, densa e umbilicada. Antenas (Fig. 51) fracamente serreadas a partir do quarto antenômero, atingindo a base dos ângulos posteriores a ultrapassando os ângulos posteriores a partir $11^{\circ}$ antenômero; $3^{\circ}$ antenômero $1,1-1,3$ vezes mais longo que o $2^{\circ}, 4^{\circ} 1,7-2,1$ vezes o comprimento do $3^{\circ}$. Olhos de tamanho médio (índice ocular 0,42-0,49), margem ocular levemente emarginada na região posterior. Mandíbula denteada.

Protórax (Fig. 58, 62) subquadrado (0,9-1,1 vezes mais longo que largo), com lados levemente arredondados, subparalelos a levemente convergentes anteriormente. Pronoto convexo, com pontuação fina a média, densa, simples ou levemente umbilicada na região discal, mais densa e mais umbilicada nas laterais; com um par de órgãos luminescentes em forma de vesículas ovais, médias a grandes, geralmente levemente convexas, localizadas lateralmente. Região mediana posterior com tubérculo pequeno. Ângulos anteriores agudos e grandes; ângulos posteriores delgados, fracamente carenados ou carenados, levemente divergentes. Prosterno (Fig. 65) alongado de lados quase retos, com pontuação média, densa 
e umbilicada. Processo prosternal com região apical denteada, dente saliente, região posterior ao dente curta $(3,0-4,0 \%$ do comprimento total do processo). Hipômeros com pontuação fina a média, densa e fortemente umbilicada, com ângulo posterior e pequena área glabros, margem posterior com ou sem dois espinhos pequenos.

Mesoventrito. Margem lateral anterior com ângulo externo não proeminente, parte ventral quase reta, junto à base, parte dorsal não visível. Cavidade mesoventral com bordas posteriores fortemente inclidadas em relação à região anterior, visíveis lateralmente sobre as mesocoxas. Metaventrito com pontuação fina, densa. Élitros com estrias fracamente marcadas, interestrias achatadas, com pontuação fina, espaçada e simples, gradualmente afilado para os ápices; ápices conjuntamante arredondados. Abdômen com pountuação fina, moderadamente densa e simples, gradualmente afilado posteriormente. Primeiro esternito abdominal (Fig. 107) com lamelas laterais fortemente esclerotizadas, com órgão luminescente subquadrado, ocupando mais ou menos $1 / 5$ do esternito I.

Edeago (Figs.191-194). Parâmeros com ápices geralmente truncados, com um espinho látero-dorsal médio ou com dois espinhos, um látero-dorsal anterior grande e um lateral, apical, pequeno; processo da articulação dorsal inteiro; bases medianas ventrais livres. Esclerito dorsal do pênis com prolongamentos basais $0,6-0,8$ vez o comprimento da região posterior; de lados gradualmente arredondados até o ápice, sem escamas. Esclerito ventral do pênis com aproximadamnte $1 / 3$ da largura do esclerito dorsal, com ápice arredondado, com duas pregas laterais, sem escamas.

Fêmea. Muito similar ao macho, geralmente maior, mais convexa, com antenas mais curtas.

Membrana interconectiva do segmento VIII com escleritos laterais mais ou menos ovais, muito pequenos ou grandes. Genitália Feminina. Baculi 1,0-1,2 vezes mais longo que os coxitos. Trato genital. Vagina com glândulas coleteriais mais longas que largas. Região posterior de cada glândula coleterial com uma área triangular formada por microescleritos, 
geralmente mais esclerotizada na base das glândulas coleteriais; região anterior com um esclerito alongado, côncavo, formado por microescleritos. Bursa copulatrix com 2-3 espirais com espinhos alongados. Espermatecas com ápice espiralado.

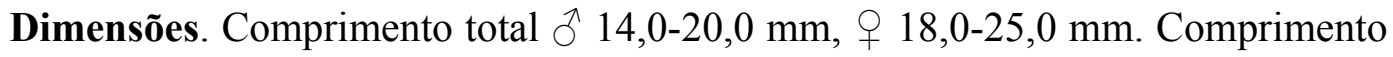
dos élitros em relação ao do protórax: $\widehat{O}$ e $q$ 2,9. Largura do úmero em relação à do protórax: ऽ̄e $\bigcirc$ 1,0-1,1.

Espécies. V. arizonicus (Hyslop, 1917); V. gemmiferus (Germar, 1841); V. occidentalis (Champion, 1895); V. ornamentum (Germar, 1841); V. sirius (Candèze, 1878) comb. $n$.

Distribuição. Estados Unidos, México, Costa Rica.

Material examinado. D. sirius. comb. n. MÉXICO. Sem localidade, sem data, sem coletor, 1 ㅇ (MCZC). Yucatán: Temax, sem data, Gaumar, 5 ô, 2 ㅇ (BMNH); sem localidade, 1952 sem coletor, 1 우 (MNHN, Coll.Oberthur). COSTA RICA. Sem localidade, sem data, sem coletor, 1 ô (CMNH, Coll. Holland). Vesperelater arizonicus. ESTADOS UNIDOS. Arizona: sem localidade, sem data, sem coletor, 1 ô, 1 ㅇ (CISC); Cochise Co., Garden Canyon Huachuca, 19.vii.1950, G. M. Bradt col., 1 ô, 1 ㅇ (AMNH). MÉXICO. Sonora: Alamos (7 mi W), viii.1964, J. A. Chemsak \& J. Powell col., 5 ô, (CISC); Navajoa, 27.vii.1966, J. A. Chemsak, E. G. \& J. M. Linsley col., 4 Oै, (CASC); Minas Nuevas, 07.viii.1952, C. \& P. Vaurie col., 3 Oे, 2 ㅇ (AMNH). Sinaloa: Los Mochis (13 mi N), 07.viii.1964, J. A. Chemsak \& J. Powell col., 3 ठิ (CISC); Mazatlan,

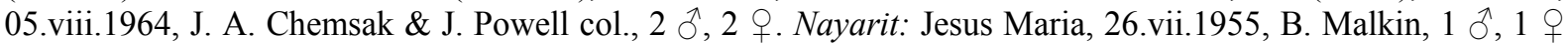
(CASC). Morelos: Alpuyeca, 27.vii.1951, P. D. Hurd col., 1 †, 1 ㅇ (CISC); Vesperelater occidentalis. MÉXICO. Sinaloa: Mazatlan, 22.viii.1965, J. D. Johnson col., 4 §ิ (MZSP). Nayarit: San Juan Peyotan, 02.viii.1955, B. Malkin, 2 ô, 1 † (CISC). Jalisco: Autlan (16 Km N), 12-14.vii.1973, Kovarik, Harrison \& Schaffner col., 4m, 4 क (TAMU); idem (11 Km N), 30.viii.1978, Plitt \& Schaffner col., 3 ô (TAMU); Colima: Manzanillo, 18.vii.1953, C. \& P. Vaurie col., 1 (AMNH). Michoacán de Ocampo: Zamora, 28.viii.1954, Linsley, MacSwain \& Smith col., 1 O , 1 क (CISC); Apatzingan 01-19.viii.1941, H. Hoogstraal, 13 o, 5 o (CNHM). Guerrero: Mexcala, 29.vi.1951, P. D. Hurd col., 6 o (CISC); idem, 09.vii.1955, J. M. Selander col.,

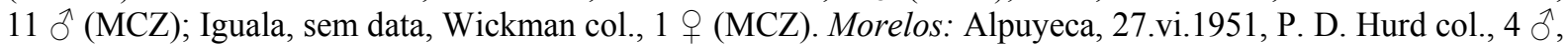
1 (CISC). Puebla: S. Atlixco, 27.vi.1957, J. A. Chemsak \& B. J. Rannells col., 3 ô, 2 क (CISC). V. gemmiferus. MÉXICO. Sem localidade, sem data, sem coletor, 2 ô, 4 ㅇ (BMNH); idem, 2 ô (ISBN); idem, 1835 Chevrolat, 4 ô, 1 + (MNHN). V. ornamentum. MÉXICO. Sinaloa: Mazatlan, 28.vii.1964, J. A. Chemsak \& J. Powell col., 43 ô, 3 ㅇ (CISC). Guerrero: Cacahuamilpa, iv.1956, Halfter col., 1 ô (MZSP). COSTA

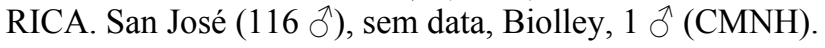

Comentários. Vesperelater possui como autapomorfia o ápice do esclerito dorsal do pênis abruptamente afilado a partir do $1 / 5$ posterior. A maioria das espécies também possui como sinapomorfias o ápice dos parâmeros do edeago com dois espinhos e a área triangular formada por microescleritos da vagina mais esclerotizada na base das glândulas coleteriais. Essas duas últimas não são compartilhadas por V. sirius (Figs. 191, 192), cuja transferência 
para esse gênero, embora pareça ser a melhor solução neste momento, segundo as hipóteses filogenéticas obtidas, deverá ser mais estudada futuramente.

\subsection{Considerações biogeográficas sobre a disjunção entre os gêneros Neotropicais e da}

\section{Oceania}

Pyrophorini ocorre em toda a região Neotropical, no sul da Região Neártica e em algumas ilhas oceânicas do arquipélago de Tonga, de Vanuatu e de Fidji, na região Australiana. A disjunção entre grupos filogeneticamente próximos da Região Neotropical e da Australiana é conhecida em diversos grupos de animais e de plantas (Briggs, 1987) e provavelmente se deve a origem das espécies ancestrais de grupos recentes durante o isolamento da Gondwana no hemisfério sul, no Jurássico Superior, e à sua posterior separação, no final do Mesosóico (Brown \& Lomolino, 1998). A espécie ancestral da tribo Pyrophorini, portanto, provavelmente surgiu durante esse período e já se encontrava bastante diversificada no Terciário, quando ocorreu a separação da Gondwana.

Considerando-se as hipóteses filogenéticas obtidas e a ocorrência atual das espécies de Hifo (Tonga), de Ignelater (América Central e Antilhas) e de Photophorus (Vanuatu e Fidji) pode-se inferir que suas espécies ancestrais, entre o Cretáceo Superior e o Terciário (ca. 100-60 m.a.), estavam predominantemente distribuídas na "Gondwana Tropical”, que incluía o norte da América do Sul, África, Madagascar, Índia, Sudeste da Ásia e Nova Guiné (Amorim \& Tonzoni, 1994) e que sua atual ausência nas regiões Afrotropical e Oriental se deve a extinção. Mas, também é possível e, talvez, mais provável que essas espécies tivessem uma distribuição mais ampla na América do Sul e que tenham se dispersado para a atual região Australiana através da Antártica, durante o final do Cretáceo (ca. 63 m. a.), período em que a África já se encontrava isolada da América do sul e da Antártica (Brown \& Lomolino, 1998; Karol, 2000). A distribuição atual desses gêneros é, em qualquer caso, relictual. 
A dispersão das espécies ancestrais de Hifo e de Photophorus para Tonga, Fidji e Vanuatu deve ter ocorrido muito depois da separação da região Australiana da Gondwana, uma vez que essas ilhas oceânicas provavelmente emergiram entre 5 e 40 milhões de anos atrás. É provável que essa dispersão tenha ocorrido através da Nova Caledônia, ilha continental mais próxima desses arquipélagos, que manteve conexões esporádicas com a Nova Zelândia entre o final do Cretáceo e o a metade do Terciário (Brown e Lomolino, 1998; Bauer \& Jackman, 2006). Vanuatu, Fidji e Tonga têm origem vulcânica e formavam, no Pacifico, um sistema (o Promontório Vanuatu-Fidji-Lau-Tonga) que migrou na direção leste. Durante essa migração é provável que Vanuatu tenha estado muito próximo de Fidji há ca. 20 milhões de anos (Evenhuis \& Bickel, 2005). A espécie ancestral comum a Photophorus bakewelli e a $P$. jansoni provavelmente se dispersou por esses dois arquipélagos durante essa migração. No Oligoceno (37-24 m. a.), transgressões marinhas submergiram a maior parte da Nova Zelândia e da Nova Caledônia, o que pode ter levado à extinção de muitas espécies (Bauer \& Jackman, 2006).

Kroenke (1996, apud Evenhuis \& Bickel, 2005) sugere a possibilidade de uma acresção de parte da Nova Caledônia que se juntou a Tonga e talvez a Fidji, há ca de 6 milhões de anos, hipótese que também pode explicar a dispersão das espécies ancetrais de Hifo e de Photophorus a partir da Nova Caledônia.

A distribuição de Ignelater, assim como dos gêneros Pyrophorus, Lygelater, Deilelater e Vesperelater na América Central, México, sul dos Estados Unidos e Antilhas provavelmente é devida à dispersão das espécies ancestrais desses táxons a partir do norte da região Neotropical durante o estabelecimento da conexão entre a América do sul e a América Central, o que pode ter ocorrido em duas ocasiões: há 10-5 milhões de anos, através do arquipélago da América Central ou há aproximadamente 3,5 milhões de anos, com formação da América Central atual e a elevação do Istmo do Panamá (Brown \& Lomolino, 1998). 


\subsection{Referências}

AMORIM, D. S. \& S. H. S. TozOnI. 1994. Phylogenetic and biogeographic analysis of the Anisopodoidea (Diptera, Bibionomorpha), with an area cladogram for intercontinental relationships. Revista brasileira de Entomologia, 38 (3/4): 517-543.

AMORIM, D.S. 2002. Fundamentos de Sistemática Filogenética. Holos, Editora, Ribeirão Preto, $154 \mathrm{p}$.

ArandA, S. G. 2001. Descripción de tres especies nuevas de Aptopus Eschscholtz, 1829 y redescripción de Aptopus omiltemanus Champion, 1895 (Coleoptera, Elateridae, Cardiophorinae). Revista brasileira de Entomologia, 45(2): 131-137.

Bauer, A. M. \& T. JaCKMan. 2006. Phylogeny and microendemism of the New Caledonian lizard fauna. In M. Vences, J. Köhler, T. Ziegler (eds.). Herpetologia Bonnensis II. Proceedings of the $13^{\text {th }}$ Congress of the Societas Europaea Herpetologica, p. 9-13.

BeCharA, E. J. H. 1988. Luminescent Elaterid Beetles: Biochemical, Biological and Ecological Aspects. Advances in Oxygenated Process, 1: 123-178.

BeCKer, E. C. 1956. Revision of the Nearctic species of Agriotes (Coleoptera: Elateridae). The Canadian entomologist, 88 (supl. 1): 1-101, 74 figs.

BECKER, E. C. 1958. The Phyletic significance of the female internal organs of reproduction in the Elateridae. Proceedings of Tenth International Congress of entomology (1956), 1: 201-205, 17 figs.

Beutel, R. G. 1995. Phylogenetic analysis of Elateriformia (Coleoptera: Polyphaga) based on larval characters. Journal of Zoological Systematics and Evolutionary Research, 33: 145171.

Billberg, G. J. 1820. Enumeratio insectorum in museo Billerg. Stockholm, 138 p. 
Blackwelder, R. E. 1944. Checklist of the Coleopterous Insects of Mexico, Central America. the West Indies and South America. Bulletin of United States National Museum, 185 (2): 280-303.

Bоотн, R. T. G.; M. L. Cox \& R. B. MAdGE. 1990. IIE Guides to Insects of Importance to man. 3. Coleoptera. London, International Institute of Entomology, vi $+384 \mathrm{p}$.

BREMER, K. 1994. Branch support and tree stability. Cladistics 10: 195-304.

Briggs, J. C. 1987. Biogeography and plate tectonics. Elsevier Science Publishers B. V. Amsterdan, 204 p.

Brown, J. H. \& M. V. Lomolino. 1998. Biogeography. 2nd edition. Sinauer Associates, Inc. Publishers, Sunderland, Massachusetts, 692 p.

BURAKOWSKI, B. (1973): Immature stages and biology of Drapetes guttatus (Piller) (Coleoptera, Lissomidae). Annales Zoologici, 30: 335-347.

BuRAKOwsKi, B. (1975). Development, distribution and habits of Trixagus dermestoides (L.), with notes on the Throscidae and Lissomidae (Coleoptera, Elateroidea). Annales Zoologici, 32: $375-405$.

CALDER, A. A. 1996. Click Beetles: Genera of Australian Elateridae (Coleoptera). In: Monographs on Invertebrate Taxonomy. Collingwood, CSIRO Publishing, v. 2, x + 401 p.

Calder, A. A. 1998. Coleoptera: Elateroidea. In: Wells, A. (ed.). Zoological Catalogue of Australia. Melbourne, CSIRO Publishing, v. 29.6, 248 p.

Calder, A. A.; J. F. Lawrence \& J. W. H. Trueman. 1993. Austrelater, gen. nov. (Coleoptera: Elateridae), with description of the larva and coments on elaterid relationships. Invertebrate Taxonomy, 7: 1349-1394.

CAndÈze, E. 1857. Monographie des Élatérides. Tome premier. Mémoires de la Société Royale des Sciences de Liége, 12: 1-400. 
CANDĖZE, E. 1863. Monographie des Élatérides. Tome quatriême. Mémoires de la Société Royale des Sciences de Liége, 17: 1-534.

CANDÈzE, E. 1881. Élatérides nouveaux. Mémoires de la Société Royale des Sciences de Liége, Troisième Fascicule, 6 (2): 1-117.

CANDÈzE, E. 1891. Catalogue Métodique des élatérides connus en 1890. 246 p., Liège.

CANDÈzE, E. 1900. Élatérides nouveaux. Mémoires de la Société Royale des Sciences de Liége, Troisième Fascicule, 44: 77-101.

CASARI, S. A. 2004. Revisión of Loboederus Guérin-Méneville (Coleoptera, Elateridae, Elaterinae, Ampedini). Revista brasileira de Entomologia 48(4): 459-466.

Casari-Chen, S. A. \& C. Costa 1986. Larvas de Coleoptera da Região Neotropical XV. Revisão de Pyrophorini (Elateridae, Pyrophorinae). Revista brasileira de Entomologia, 30 (2): 323-357.

Castelnau, F. L. N. C. Laporte, COMTE DE. 1840. Histoire Naturelle des Insectes Coléoptères. Paris, P. Duménil. 2 v.

Champion, G. C. 1895. Elateridae. In: Biologia Centrali Americana, Insecta, Coleoptera. London, v. 3, pt. 1, p. 297-440.

Coddington, J. \& N. ScharfF. 1994. Problems with zero-length branches. Cladistics, 10: 415-423.

Colepicolo-Neto, P.; C. Costa \& J. H. Bechara. 1986. Luciferin Indentification and Bioluminescence Spectra. Insect Biochemistry, 16 (5): 803-810.

CostA, C. 1969. Gênero Pyrophorus. 2. Redescrição de algumas espécies (Coleoptera, Elateridae). Papéis Avulsos de Zoologia, 22 (24): 249-262.

CostA, C. 1970. Genus Pyrophorus. 3. Life-history, larva and pupa of Pyrophorus punctatissimus Blanchard (Coleoptera, Elateridae). Papéis Avulsos de Zoologia, 23 (8): 69-76. 
CostA, C. 1975a. Notas sobre o gênero Pyroptesis com descrição e dados de P. gilvus, sp. n. (Coleoptera, Elateridae, Pyrophorinae). Papéis Avulsos de Zoologia, 29(1): 1-6.

CostA, C. 1975b. Systematics and evolution of the tribes Pyrophorini and Heligmini with description of Campyloxeninae, new subfamily (Coleoptera, Elateridae). Arquivos de Zoologia, 26 (2): 49-191.

CostA, C. 1976. Speciation and geographical patterns in Pyrophorus Billberg, 1820 (Coleoptera, Elateridae, Pyrophorini). Papéis Avulsos de Zoologia, 29 (18): 141-154.

CostA, C. 1977. Notas sobre o gênero Nyctophyxis e redescrição de N. ocellatus (Germar, 1841) (Coleoptera, Elateridae, Pyrophorinae). Revista brasileira de Entomologia, 21 (3/4): 99-101.

CostA, C. 1978. Sistemática e bionomia de Pyrearinus Costa, 1975 (Coleoptera, Elateridae). Arquivos de Zoologia, 20 (4): 185-236.

CostA, C. 1979. Novas espécies do gênero Hypsiophthalmus Latreille, 1834 e revalidação de Pyrearinus brevicollis (Eschscholtz, 1829), comb. n. (Coleoptera, Elateridae, Pyrophorinae). Papéis Avulsos de Zoologia, 32 (22): 261-276.

CostA, C. 1980a. Novas espécies dos gêneros Ignelater e Opselater (Coleoptera, Elateridae, Pyrophorinae). Papéis Avulsos de Zoologia, 33 (70: 157-176).

CostA, C. 1980b. Novas espécies do gênero Lygelater Costa, 1975 (Elateridae, Pyrophorinae). Papéis Avulsos de Zoologia, 33 (20): 299-307.

CostA, C. 1982. Pyrearinus termitilluminans, sp. n., with description of the mature stages (Coleoptera, Elateridae, Pyrophorinae). Revista brasileira de Zoologia, 1 (1): 23-30.

CostA, C. 1983. Revisão do gênero Deilelater Costa, 1975 (Elateridae, Pyrophorinae), com a descrição de nova espécie. Revista brasileira de Entomologia, 27 (2): 115-124. 
CostA, C. 1984a. Note on the bioluminescence of Balgus schnusei (Heller, 1974) (Trixagidae, Coleoptera). Revista brasileira de Entomologia, 28 (4): 397-398.

Costa, C. 1984b. On the systematic position of Hifo Candèze, 1881 (Elateridae, Coleoptera). Revista brasileira de Entomologia, 28(4): 399-402.

Costa, C. \& CASAri-Chen, S. A. (1993): A review of the Pachyderini (Denticollinae) sensu Stibick, 1979, with the description of Platycrepidiinae trib. n. (Coleoptera, Elateridae, Agrypninae). Revista Brasileira de Entomologia, 37: 61-77.

Costa, C., J. F. Lawrence, S. P. Rosa. (no prelo). Chapter Elateridae. In R. G Beutel \& A. B. Leschen (eds.). Handbook of Zoology/ Handbuch der Zoology. Band IV Arthropoda, Insecta, Teilband, Coleoptera: Evolution and Systematics (Polyphaga Part). Jena, Friedrich-Schiller-Universität Jena.

Costa, C.; S. A. VAnin \& S. A. CASARI-Chen. 1988. Larvas de Coleoptera do Brasil. São Paulo, Museu de Zoologia, vii +282 p.

Crowson, R. A. 1961. On some new characters of classificatory importance in adult of Elateridae (Coleoptera). Entomologist's Monthly Magazine, 96: 158-161.

De PinNA. M. C. C. 1991. Concepts and tests of homology in the cladistic paradigm. Cladistics, 7 : 367-394.

Dolin, V. G. 1975. Wing Venation of click beetles (Coleoptera, Elateridae) and its importance for taxonomy of the family. Zoologicheskii Zhurnal, 54: 1618-1633.

Dolin, V. G. 1978. Phylogeny of click beetles (Coleoptera, Elateridae). Vestinik Zoologii, 1978 (3): $3-12$.

DubOIS, R. 1886. Contribution a l'étude de la production de la lumière par les ètres vivants. Les Elatérides lumineux. Bulletin de la Société Zoologique de France, 11: 1-275, 9 pls. 
EMDEN, F. I. VAN. (1932): Die larven der Callirhipini, eine mutmassliche Cerophytum-larve und familien-bestimmungtabelle der larven der Malacodermata-Soernoxia Reihe (Coleoptera). Bulletin et Annales de la Société Entomologique de Belgique, 72: 199259.

Eschscholtz, J. F. 1829. Eintheilung der Elateriden in Gattungen. In: Thon. Entomologische Archiv. Jena, v.2, p. 31-35.

Evans, M. E. G. 1972. The jump of the click beetle (Coleoptera, Elateridae) - a preliminary study. Journal of Zoology, 167: 319-336.

Evenhuis, N. L. \& D. J. BICKLEL. 2005. The NSF-Fiji terrestrial arthropod survey: overview. Bishop Museum Occasional Papers 82: 3-25.

FARRIS, J. S. 1969. A successive approximations approach to character weighting. Systematic Zoology, 18:374-385.

FARRIS, J. S. 1970. Methods for computing Wagner trees. Systematic Zoology, 34:21-24.

FARRIS, J. S. 1983. The Logical Basis of Phylogenetic Analysis. In: N. Platnick and V. A. Funk (eds), Advances in Cladistics. Proceeding of the second meeting of the Willi Hennig Society. Vol. 2. Columbia University Press, New York, p. 7-36.

FleutiauX, E. (1947): Révision des Élatérides (Coléoptères) de L'Indo-Chine Française. Notes d'Entomologie Chinoise, Shangai, 11-233-420.

GARCÍA, I. F. \& A. L. PIÑA. 1998. Descripción de dos nuevos especies de Ignelater (Coleoptera: Elateridae: Pyrophorinae) de Cuba. Avicennia, 1998 (8/9): 57-60.

Germar, E. F. 1841. Beiträge zu einer Monographie der Gattung Pyrophorus. Zeitschrift für die Entomologie, 1 (2): 193-236.

Golbach, R. 1984. Novedades de la subfamilia Pyrophorinae (Coleoptera, Elateridae). Acta Zoológica Lilloana, 38: 82-85. 
GolBACH, R. 1994. Elateridae (Coleoptera) de la Argentina. Historia, catálogo actualizado hasta 1991 inclusive y clave de subfamilias y de géneros de Centro y Sudamérica. Opera Lilloana, 41: 1-48.

GolobOFF, P. A. 1993. Estimating character weights during tree search. Cladistics, 9: 83-91.

Goloboff. P., J. FARRIS \& K. NiXON. 2003. TNT, Tree Analysis Using New Technology.

GuR'YeVA, Ye. L. 1974. Thoracic structure of click beetles (Coleoptera, Elateridae and the significance of the structural characters for the system of the family. Entomological Review, 53: 67-79.

HARVey, E. N. 1952. Bioluminescence. New York, Academic Press Inc., xvi + 649 p.

Hedges, S. B. 2006. Paleogeography of the Antilles and origin of West Indian terrestrial vertebrates. Annals of the Missouri Botanical Garden, 93: 231-244

HeNNIG, W. 1966. Phylogenetic systematics. Urbana, University of Illinois Press, 263 p.

Hogue, C. L. 1993. Latin American Insects and Entomology. Berkeley, University of California Press, $x i v+536 \mathrm{p}$.

Hyslop, J. A. 1917. The phylogeny of the Elateridae based on larval characters. Annals of the entomological society of America, 10: 241-263.

Hyslop, J. A. 1921. Genotypes of the Elaterid beetles of the world. Proceedings of United States of National Museum, 58: 621-680.

Johnson, P. J. 1995. A new genus of Conoderini, with new generic classifications for Ctenicera sleeperi Becker and Ctenicera pilatei (Champion), and a new species from Jamaica (Coleoptera: Elateridae). The Colleopterists Bulletin, 49(1): 59-71. 
Johnson, P. J. 2002. Elateridae. In: Arnett, R. H. Jr.; M. C. Thomas, P. E. Skelley \& J. H. Frank (eds.). American beetles. Polyphaga: Scarabaeoidea through Curculionoidea. London, CRC Press, v. 2, p. 160-173.

Karol, K. G., Y. Suh, G. E. Schatz \& E. A. Zimmer. 2000. Molecular evidence for the phylogenetic position of Takhtajania in the Winteraceae: inference from nuclear ribosomal and chloroplast gene spacer sequences. Annals of the Missouri Botanical Garden, 87: 414-432.

Kitching, I. J., P. L. Forey, C. J. Humphries \& D. M. Williams. 1998. Cladistics. The Theory and Practice of Parsimony Analysis. Oxford University Press, Oxford. 228 p.

KUKALOVA-PECK, J. \& J. F LAWRENCE. 2004. Relationships among coleopteran suborders and major endoneopteran lineages: Evidence from hind wing characters. European Journal of Entomology, 101 (1): 95-144.

Kukalová-Peck, J. \& J. F. Lawrence. 1993. Evolution of the hind wing in Coleoptera. The Canadian Entomologist, 125 (2): 181-258.

Lacordaire, J. T. 1857. Histoire Naturelle des Insectes. Genera des Coléoptères. Paris, Librairie Encyclopédique de Roret, v. 4, 579 p

Latreille, P. A. 1804. Histoire Naturelle, Génerale et Particulière des Crustacés et des Insectes. Familles Naturelles des Genres. F. Dufart, Paris.

Latreille, P. A. 1825. Familles Naturelles du Régne Animal, Exposées Succinctemente et dans un Ordre Analytique, avec L'Indication de leurs Genres. Baillière, Paris.

LATREILle, P. A. 1834. Distribution méthodique et naturelle des genres de diverses tribus d'insectes coléoptères, de la familia des serricornes. Annales de la Société Entomologique de France, 3: 113-170. 
LAURENT, L. (1961): Sur la suture méso-métasternale chez les Elateridae (Coleoptera). Bulletin de la Société Royale des Sciences de Liège, 30: 68-71.

LAurent, L. (1966): Denticollinae, Pleonominae, Athoomorphinae de la région aethiopienne (Coleoptera, Elateridae). Bulletin de la Société Royale des Sciences de Liège, 35: 801821.

LAWRENCE, J. F. 1987. Rhinorhipidae, a new beetle family from Australia, with comments on the phylogeny of the Elateriformia. Invertebrate Taxonomy, 2: 1-53.

LAwrence J. F. \& A. F. Newton. 1995. Families and subfamilies of Coleoptera (with selected genera, notes, references and data on family-group names). In: Pakaluk, J. \& S. A Slipinski (eds). Biology, Phylogeny, and Classification of Coleoptera. Warszawa, Muzeum i Instytut Zoologii PAN, v. 2, p. 779-1006.

Lawrence J. F. \& E. B. Britton. 1994. Australian Beetles. Victoria, Melbourne University Press, $\mathrm{x}+192$ p., 16 pls.

Lawrence, J. F.; A. M. Hastings; M. J. Dallwitz; T. A. Paine \& E. J. Zurcher. 1999. Beetles of the World: descriptions, illustrations, identification, retrieval for families and subfamilies: version 1.1 for Microsoft Window. Canberra, CSIRO Publishing. (CDROM).

Lawrence, J. F.; N. B. Nitisky \& A. G. KireJTShuk. 1995. Phylogenetic position of Decliniidae (Coleoptera: Scirtoidea) and comments on the classification of Elateriformia (sensu lato). In: Pakaluk, J. \& S. A Slipinski (eds). Biology, Phylogeny, and Classification of Coleoptera. Warszawa, Muzeum i Instytut Zoologii PAN, v. 1, p. 375-410.

LEE, D. \& H. N. BRYANT. 1999. A reconsideration of the coding of inapplicable characters: assumptions and problems.Cladistics,15: 373-378. 
LenKo, K. \& N. PAPAVERo. 1996. Insetos no folclore. $2^{\text {a }}$ ed. rev. e ampl. São Paulo, Ed. Plêiade/FAPESP, 468 p.

LLOYD, E. J. 1971. Bioluminescent comunication in insects. Annual Review of Entomology, 16: 97-114.

LOPES, P. L. 2005. Taxonomia e análise cladística de Mycolybas Crotch, 1876 (Coleoptera, Erotylidae). Dissertação de Mestrado. Instituto de Biociências da USP, São Paulo, 154 p.

MuonA, J. 1995. The phylogeny of Elateroidea (Coleoptera), or which tree is the best? Cladistics, 9: 413-426.

NAKANE, T \& KiSHII, T. (1956): On the subfamilies of Elateridae from Japan (Coleoptera). Kontyû, 24: 201-206, pls. 22-23.

Nelson, G. \& N. PlatnicK. 1981. Systematics and biogeography: Cladistics and vicariance. Columbia University Press, New York, 567 p.

Nixon, K. C. \& J. M. CARPEnTER, 1993. On outgroups. Cladistics 9: 413-426.

OHIRA, H. (1962): Morphological and Taxonomic study on the larvae of Elateridae of Japan (Coleoptera). H. Ohira, Okasaki city, Japan, iv +179 pp., 61 pls.

Page, R. D. M. 2001. Nexus Data Editor (0.5.0).

Perty, J. A. M. 1830. Insecta Brasiliensia. In Delectus animalium articulatorum, fasciculo 1, 60 p.

REDFORD, K. H. 1982. Prey attraction as a possible function of bioluminescence in the larvae of Pyrearinus termitilluminans (Coleoptera, Elateridae). Revista brasileira de Zoologia, 1 (1): $31-34$. 
RosA, S. P. Revisão do gênero Opselater Costa (Coleoptera, Elateridae, Agrypninae). Revista brasileira de Entomologia 48 (2): 203-219.

Sagegami-ObA, R., OBA, Y., OHIRA, H. (2007): Phylogenetic relationships of click beetles (Coleoptera: Elateridae) inferred from 28S ribosomal DNA: Insights into the evolution of bioluminescence in Elateridae, Molecular Phylogenetics and Evolution, 42 (2): $410-421$

Schenkling, S. 1927. Elateridae II. In: Coleopterorum Catalogus. Berlin, W. Junk, pt. 88, n. 11, p. 265-639.

Schneider, M. C., S. P. Rosa, M. C. Almeida, C. Costa \& D. M. Cella (no prelo). Chromosomal similarities and differences among four Neotropical Elateridae (Conoderini and Pyrophorini) and other related species, with comments on the NORs pattern in Coleoptera. Journal of Zoological Systematics and Evolutionary Research.

Schwarz, O. C. E. 1906. Neue Elateriden aus Amerika. Deutsche Entomologische Zeitschrift, 1906: $97-158$.

Seliger, H. H. \& W. L. McElroy. 1965. Light: Physical and Biological Action. New York, Academic Press, 417 p.

SolIER, A. J. J. 1851. Coleoptera: Pentamera \& Heteromera of Chile. In Gay, Historia fisica y politica de Chile. Zoologia, 5: 5-285.

StiBiCK, J. N. L.1979. Classification of the Elateridae (Coleoptera). Relationships and classification of the subfamilies and tribes. Pacific Insects, 20: 145-186.

Strong, E. E. \& D. Lipscomb. 1999. Character coding and inapplicable data. Cladistics, 15: 363371.

VIVIANI, V. L. R.1987. Bioluminescência nos Insetos. Bioikos, 1 (2): 7-19. 
Williams, J. L. 1945. The anatomy of the internal genitalia of some Coleoptera. Proceedings of the Entomological Society of Washington, 47 (4): 73-87.

Zacharuch, R.Y. 1962. Some new larval characters for the classification of Elateridae (Coleoptera) into major groups. Proceedings Royal Society of London (B) 31 (3/4): 29-32. 
ANEXOS 
Anexo 1. Lista dos grupos de espécies incluídos como táxons terminais. As espécies-tipos estão sublinhadas.

Fulgeochlizus Costa, 1975

Grupo Fulgeochlizus

F. bruchi (Candèze, 1896)

F. germari (Candèze, 1863)

Grupo noctivagus

F. noctivagus Costa, 1991

F. pullatus Costa, 1991

\section{Ptesimopsia Costa, 1975}

Grupo Ptesimopsia

P. candezei (Fauvel, 1861)

P. elongata Costa, 1975(Casari-Chen \&

Costa, 1986)

P. gracilis Rosa, 2004

P. lucifuga (Curtis, 1839)

P. luculentus (Germar, 1841)

P. luscinia Costa, 1975 b

P. pyraustes (Germar, 1841)

Grupo parallela

P. parallela (Germar, 1841)

\section{Pyrearinus Costa, 1975}

Grupo Pyrearinus

P. depressicollis (Blanchard, 1843)

P. nyctolampis (Germar, 1841)

P. nyctophilus (Germar, 1841)

P. ruscus Costa, 1978

Grupo pumilus

P. flatus Costa, 1978

P. fragilis Costa, 1978

P. pumilus (Candèze, 1863)
P. scintillula (Candèze, 1881)

P. termitilluminans Costa, 1982

P. vitticollis (Germar,1841)

Grupo sp. $n .1$

P. sp. 1 sp. $n$.

Grupo ferrugineus

P. ferrugineus Costa, 1978

P. fulvescens Costa, 1978

P. fulvus Costa, 1978

Grupo lucernula

$P$. acutus (Candèze, 1863)

P. adustus Costa, 1978

P. alvarengai (Cobos, 1959)

P. baliolus Costa, 1978

P. brunneus Costa, 1978

P. coctilis Costa, 1978

P. lampadion (Illiger, 1807)

P. lucernula (Illiger, 1807)

P. pusillus Costa, 1978

Grupo candelarius

P. amplicollis (Candèze, 1863)

P. candelarius ( Germar, 1841)

P. fulgurans (Candèze, 1863)

$P$. nictitans (Illiger, 1807)

P. retrospiciens (Illiger, 1807)

Grupo lineatus

P. brevicollis (Eschscholtz, 1829)

P. castaneus Costa, 1978

P. cinerarius (Germar, 1841)

P. janus (Herbst, 1806)

P. latus Costa, 1978 
$P$. lineatus (Candèze, 1863)

P. lucidulus (Illiger, 1807)

P. luscinus Costa, 1978

P. micatus Costa, 1978

Grupo basalis

P. basalis (Schwarz, 1902)

Grupo lampyris

P. cereus Costa, 1978

P. lampyris (Candèze, 1863)

P. vesculus Costa, 1978

P. vescus Costa, 1978

Grupo cinnameus

P. sp. 2 sp. n.

P. cinnameus Costa, 1978

\section{Opselater Costa, 1975}

Grupo Opselater

O. helvolus (Germar, 1841)

O. lucens (Illiger, 1807)

O. pyrophanus (Illiger, 1807)

O. quadraticollis (Blanchard, 1843)

Grupo melanurus

O. hebes (Germar, 1841)

O. melanurus (Candèze, 1863)

O. succinus Costa, 1980
Grupo bifossulatus

L. bifossulatus (Candèze, 1865)

Deilelater Costa, 1975

Grupo Deilelater

D. bellamyi (Van Zwaluwenberg, 1936)

D. mexicanus (Champion, 1895)

D. physoderus (Germar, 1841)

D. radians (Champion, 1895)

D. stella (Candèze, 1863)

Grupo sirius

D. sirius (Candèze, 1878)

Grupo atlanticus

D. atlanticus (Hyslop, 1917)

D. ustullatus Costa, 1983

\section{Vesperelater Costa, 1975}

Grupo Vesperelater

V. arizonicus (Hyslop, 1917)

V. occidentalis (Champion, 1895)

V. ornamentum (Germar, 1841)

Grupo gemmiferus

V. gemmiferus (Germar, 1841)

\section{Lygelater Costa, 1975}

Grupo Lygelater Costa, 1975

L. fulgidus (Germar, 1841)

L. ignitus (Fabricius, 1787)

L. indicus (Herbst, 1783)

L. piceus (Schwarz, 1902)

L. succinum Costa, 1980

L. torridus Costa, 1980 


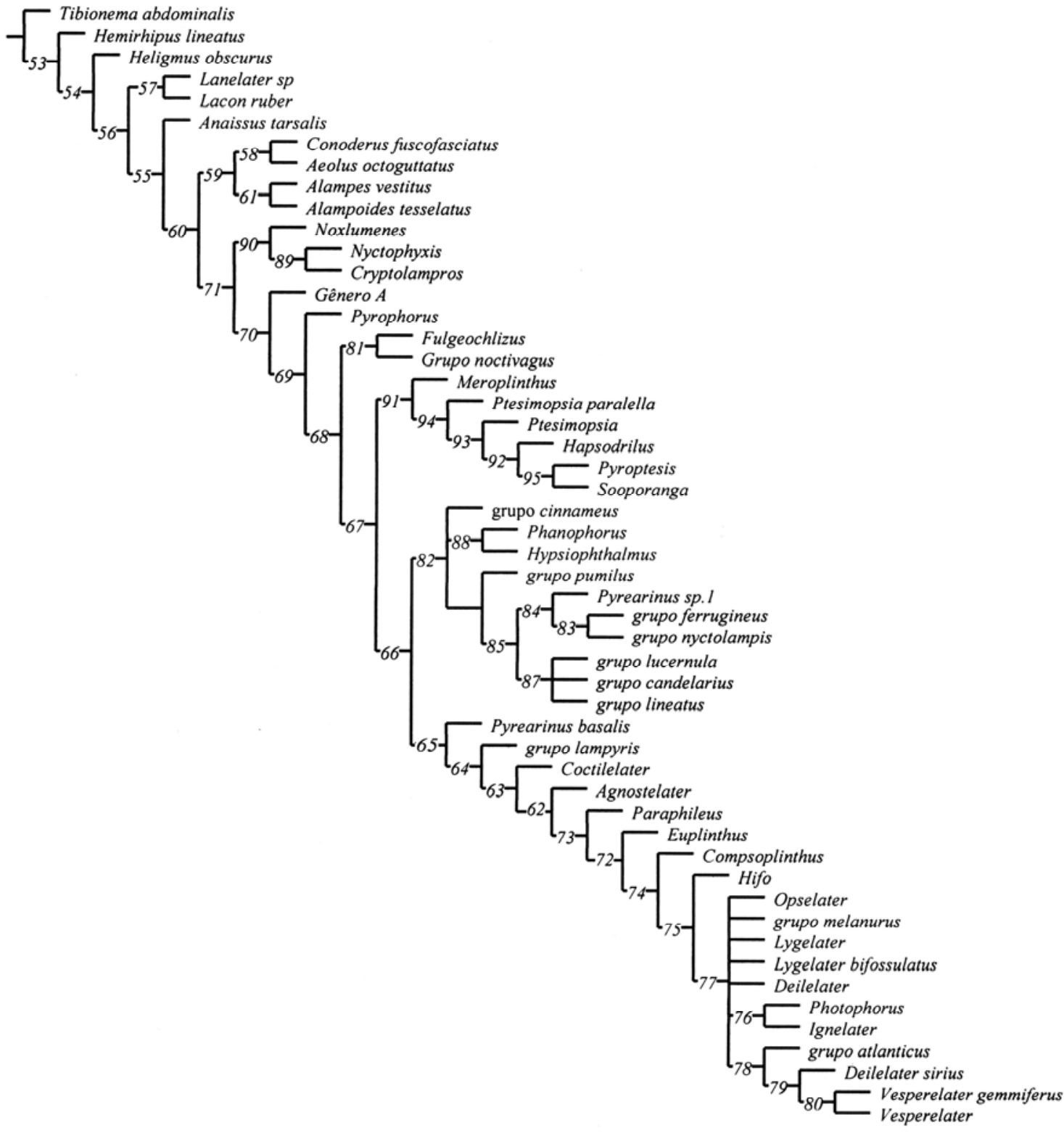

Figura 1. Cladograma de consenso das oito hipóteses filogenéticas mais parcimoniosas para a tribo Pyrophorini. Enraizamento em Tibionema abdominalis; 318 passos, índice de consistência 0,49 e índice de retenção 0,70. Os números indicam nós e clados. 


\section{Clado 82}

resolução 1:

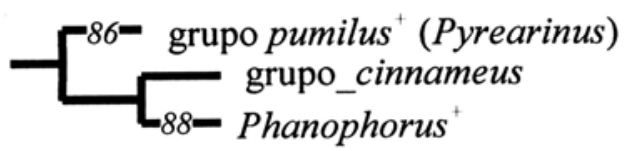

resolução 2:

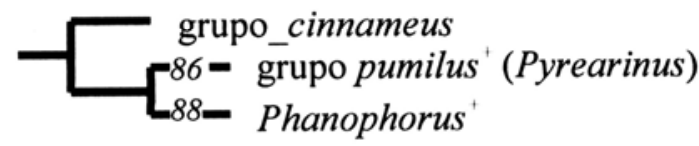

\section{Clado 77}

resolução 1:

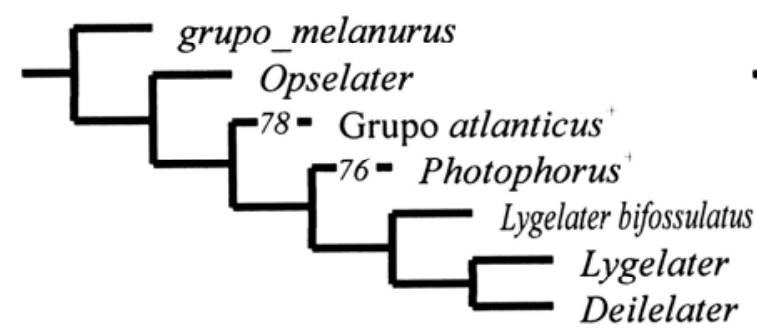

resolução 2:

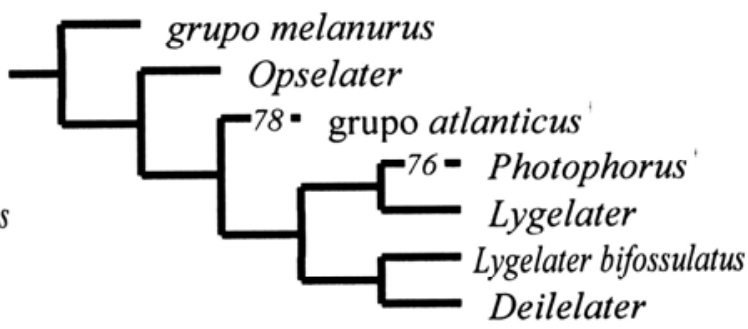

resolução 3:

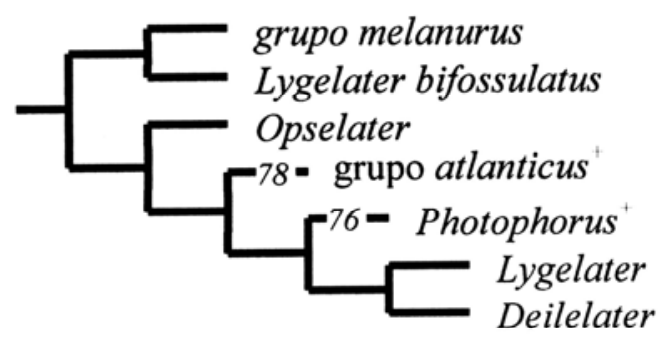

resolução 4:

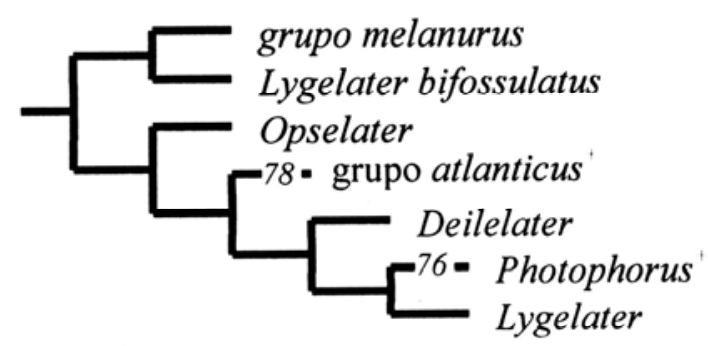

Figura 2. Resoluções alternativas para os clados 82 e 87 do cladograma de consenso de oito árvores mais parcimoniosas. O números indicam nós e clados. 


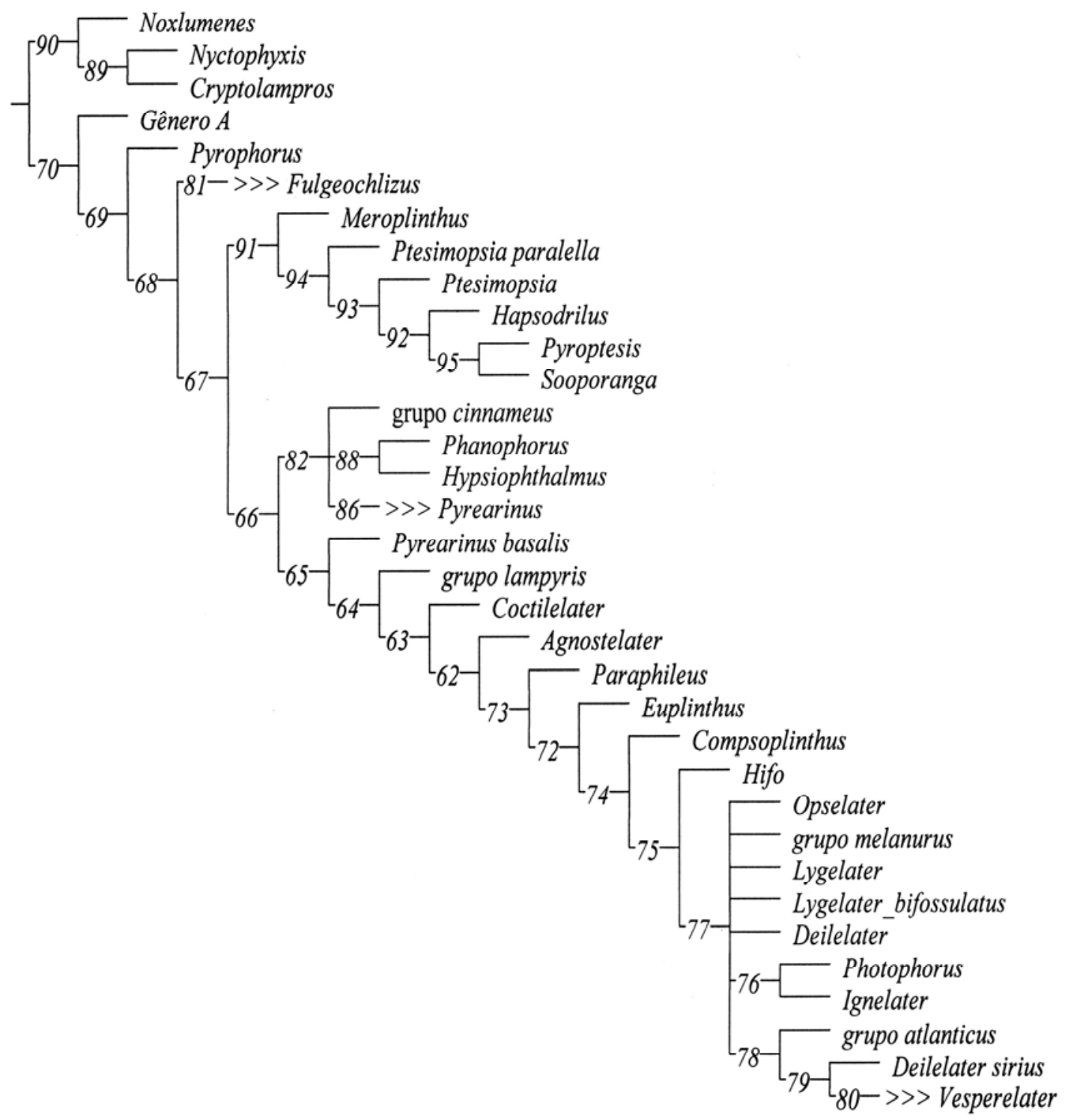

Figura 3. Cladograma de consenso das relações filogenéticas de Pyrophorini. Grupos de espécies monofiléticos colapsados, grupos externos omitidos. Os números indicam nós e clados. 


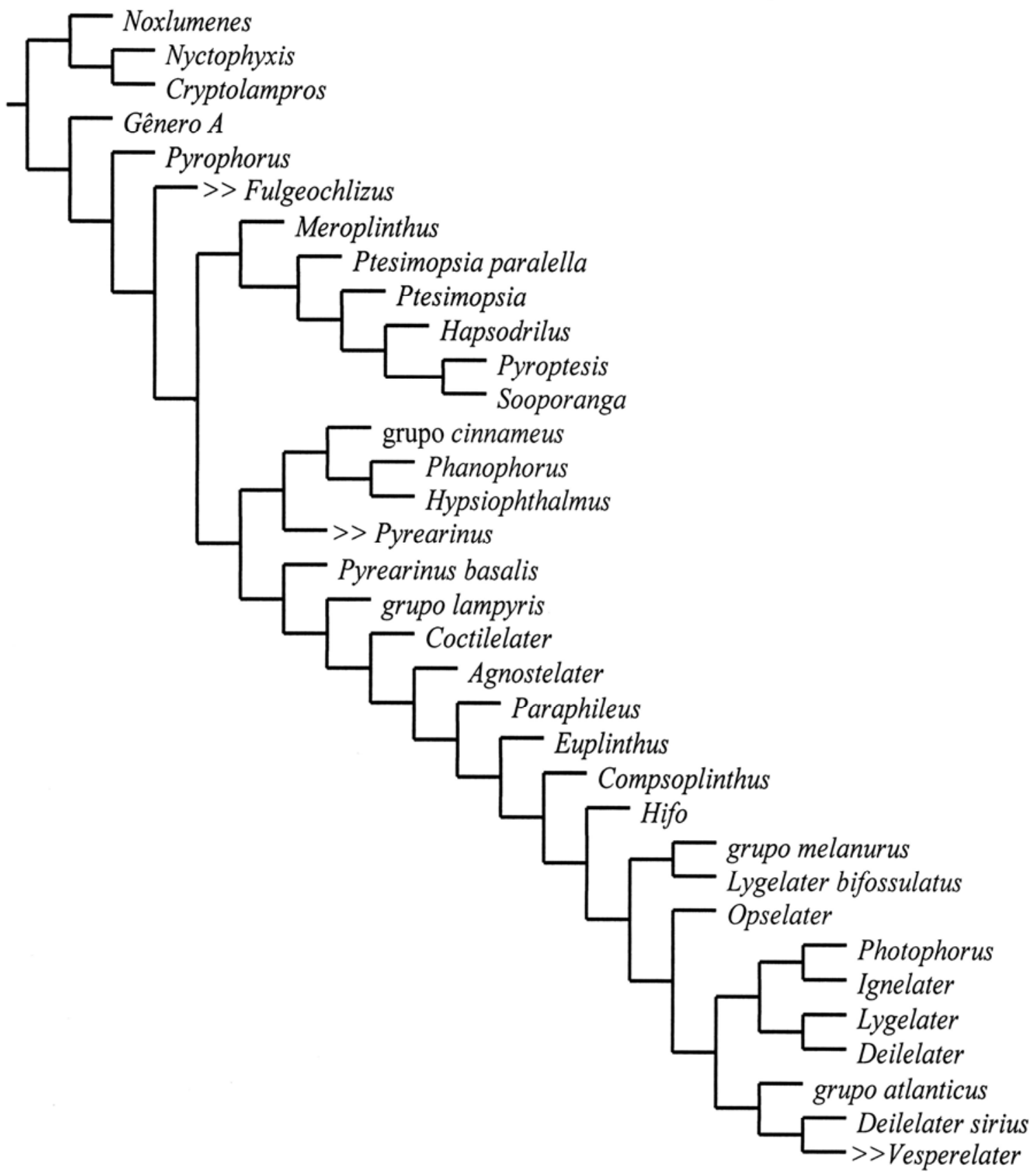

Figura 4. Cladograma das relações filogenéticas de Pyrophorini obtido após a ponderação sucessiva dos caracteres com o índice de adaptabilidade ( $K=3,5,7,21$ e 43). Grupos de espécies monofiléticos colapsados, grupos externos omitidos. 

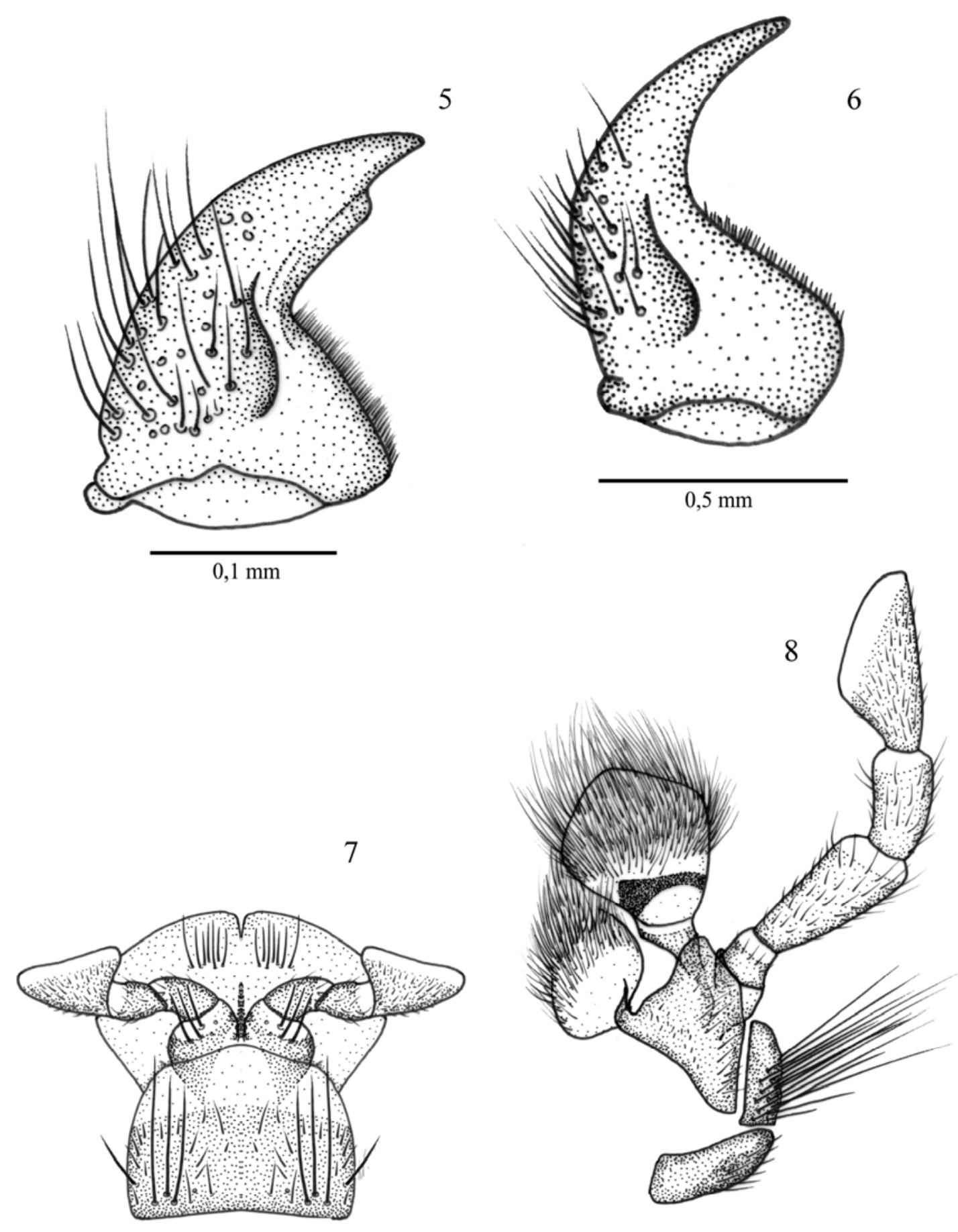

$0,5 \mathrm{~mm}$

Figuras 5-8. Mandíbula (dorsal): 5, Deilelater physoderus; 6, Pyrearinus termitilluminans. Lábio e maxila (ventral): 7, 8, Ignelater havaniensis. 

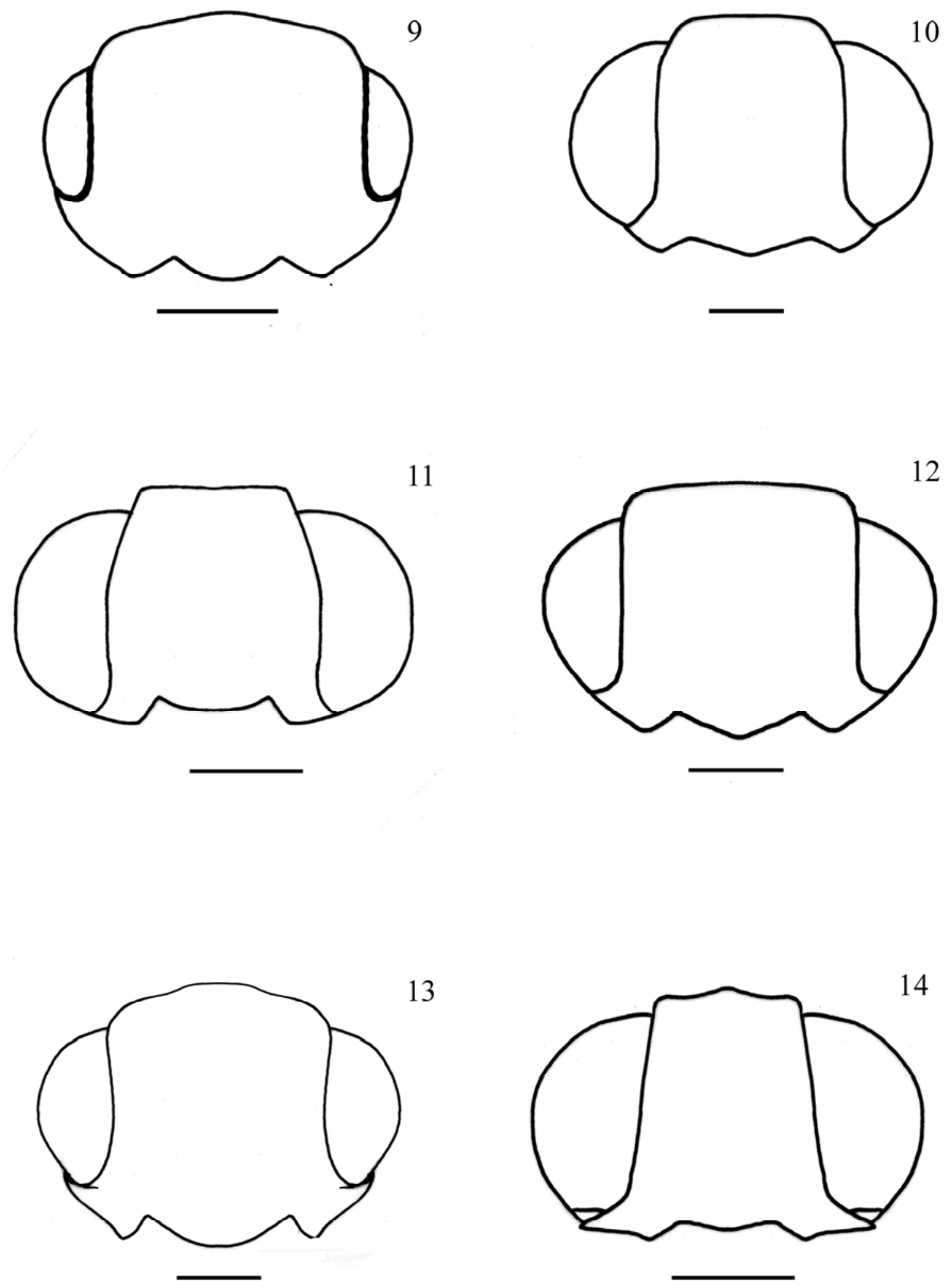

Figuras 9-14. Cabeça (macho, dorsal): 9, Cryptolampros coecus; 10, Pyrophorus noctilucus; 11, Hypsiophthalmus luscius; 12, Fulgeochlizus bruchi; 13, Photophorus jansonii; 14, Pyrearinus candelarius. Escalas: 1,0 mm 

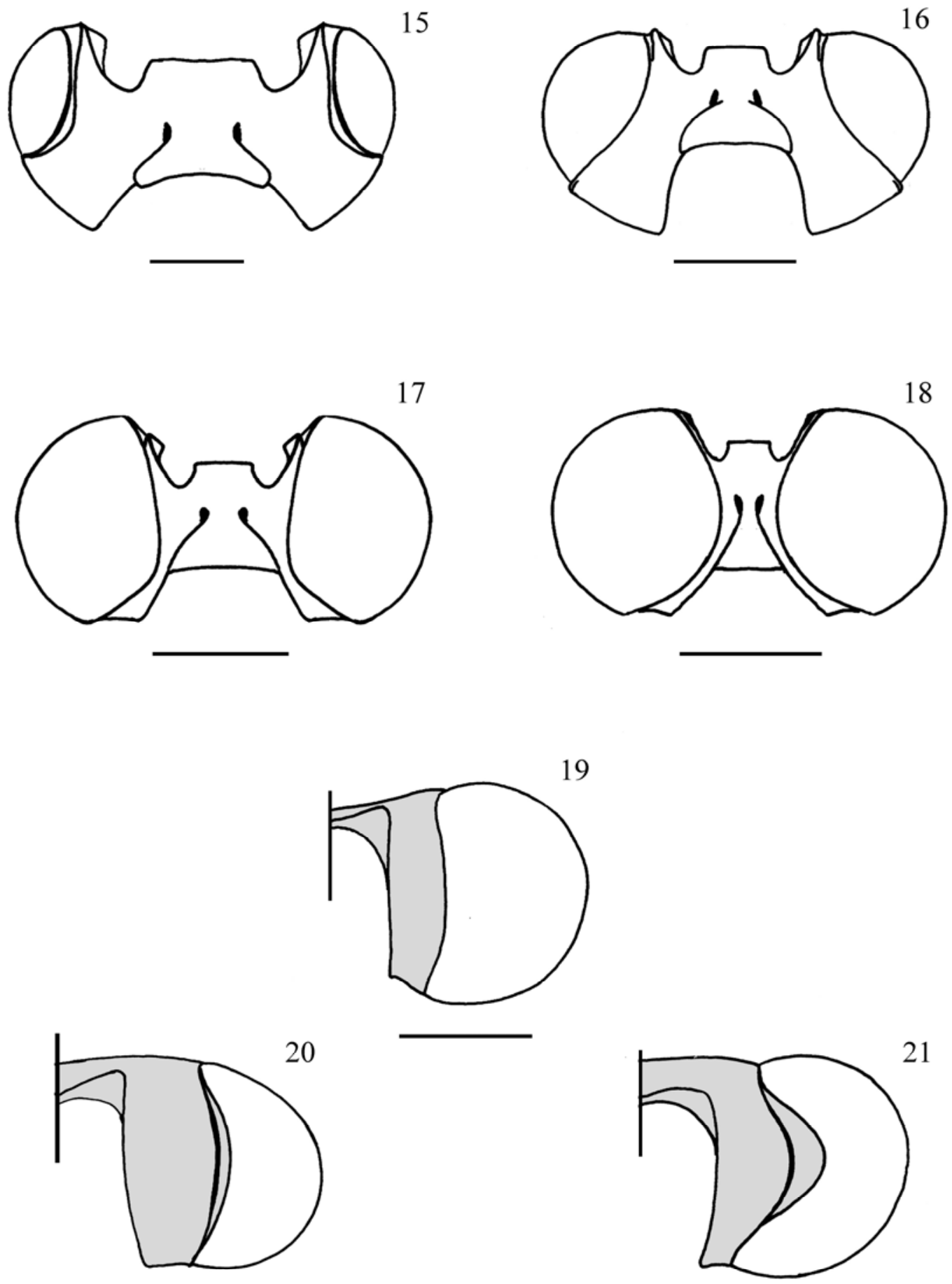

Figuras 15-21. Cabeça (macho, peças bucais removidas, ventral): 15, Cryptolampros coecus; 16, Ptesimopsia luculenta; 17, Pyrearinus fulgurans; 18, Pyrearinus nyctolampis. Cabeça (macho, lado esquerdo omitido; látero-posterior): 19, Hypsiophthalmus luscius; 20, Hapsodrilus ignifer; 21, Pyrearinus brevicollis. Escalas: 1,0 mm. 

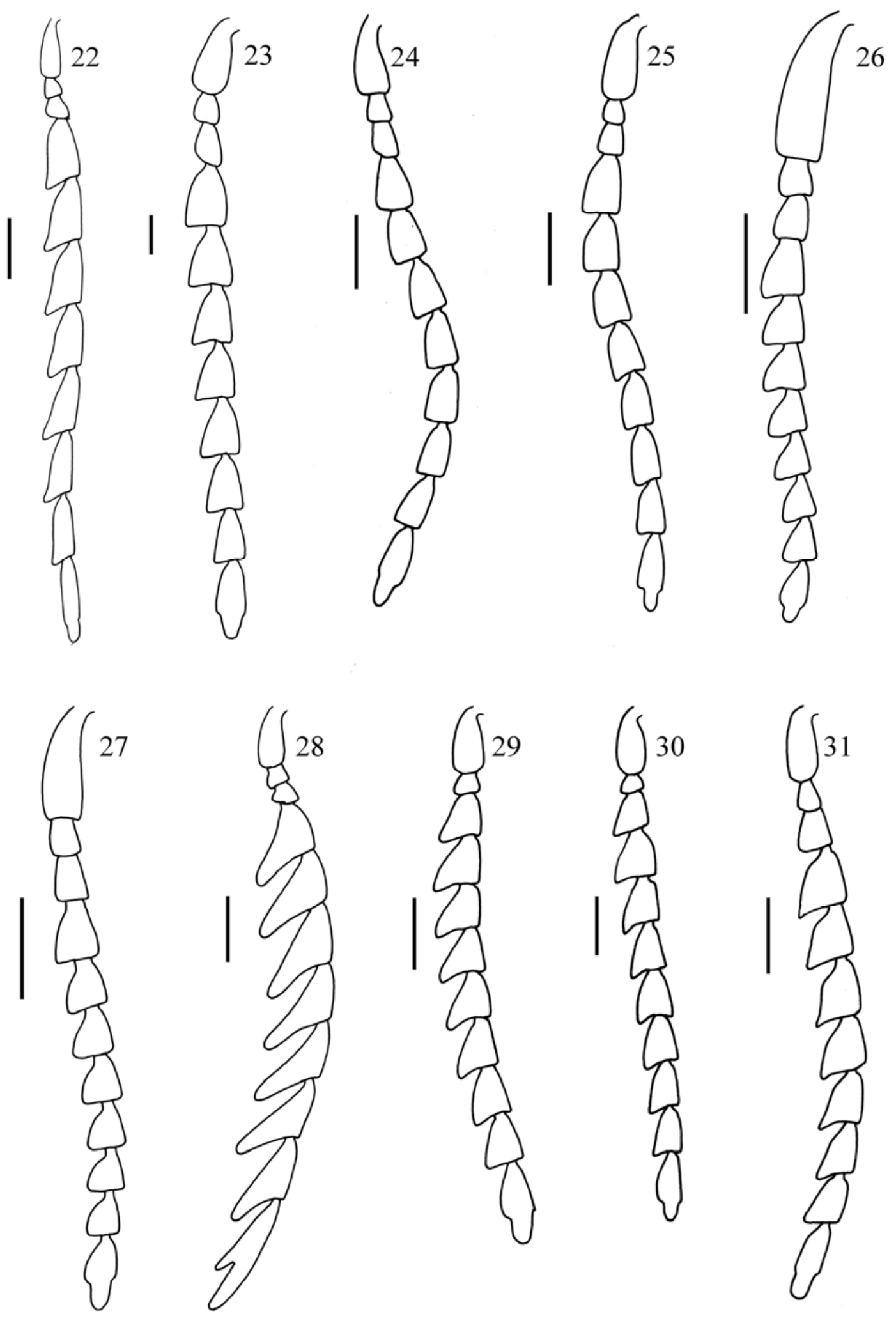

Figuras 22-31. Antenas (macho): 22, Noxlumenes bardus; 23, Nyctophyxis ocellatus; 24, Cryptolampros coecus; 25, Gênero A sp. 1 sp. n.; 26, Pyrophorus noctilucus; 27, Fulgeochlizus bruchi; 28, Fulgeochlizus noctivagus; 29, Meroplinthus trilineatus; 30, Ptesimopsia candezei; 31, Hapsodrilus ignifer. Escalas: 1,0 mm. 

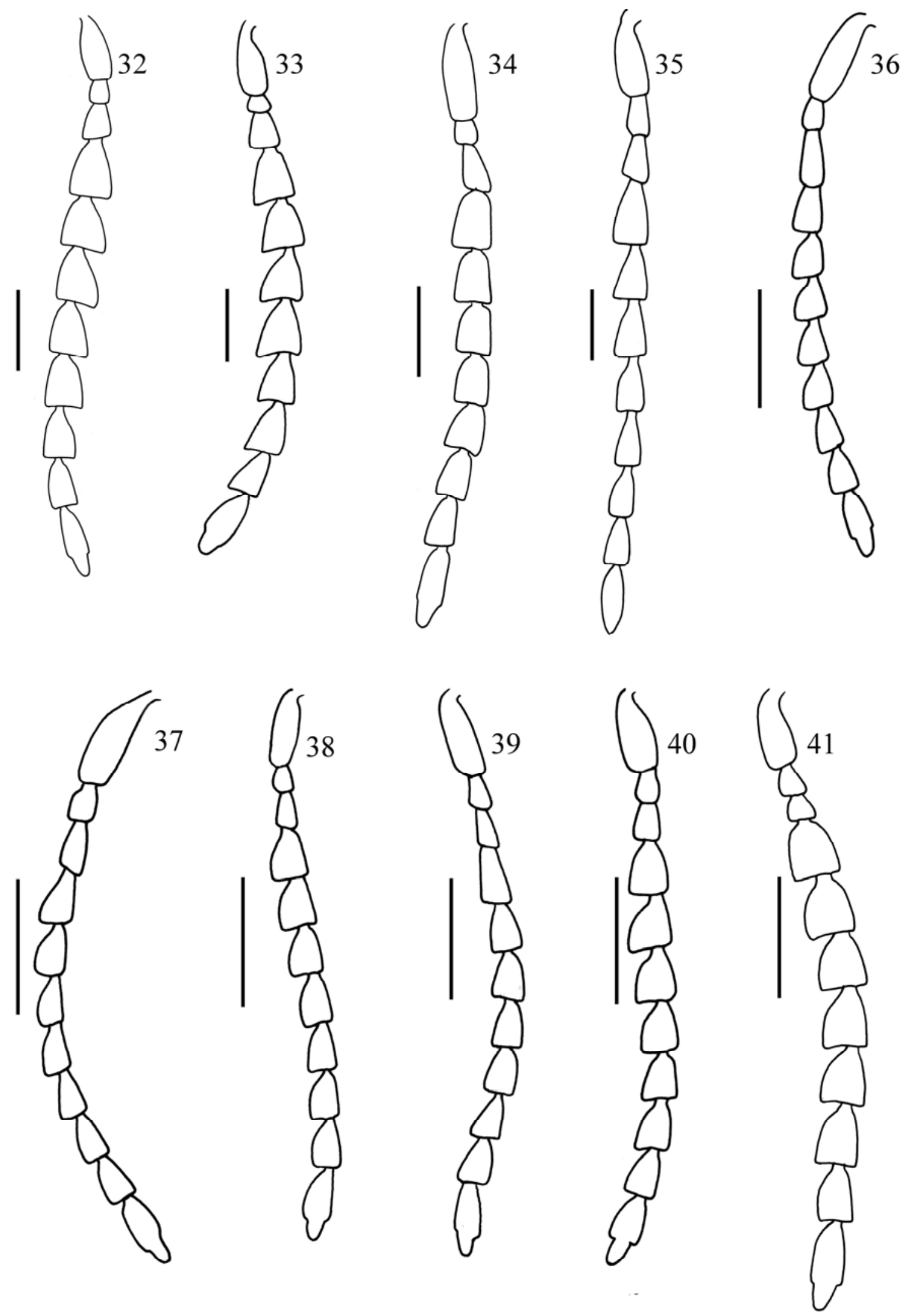

Figuras 32-41. Antenas (macho): 32, Pyroptesis cincticollis; 33, Sooporanga formosa; 34, Gênero B cinnameus comb. n.; 35, Phanophorus perspicax; 36, Hypsiophthalmus boops; 37, Pyrearinus nyctolampis; 38, Gênero C basalis comb. n.; 39, Gênero D vesculus comb. n; 40, Coctilelater corymbitoides; 41, Agnostelater mesochrous. Escalas: 1,0 mm. 

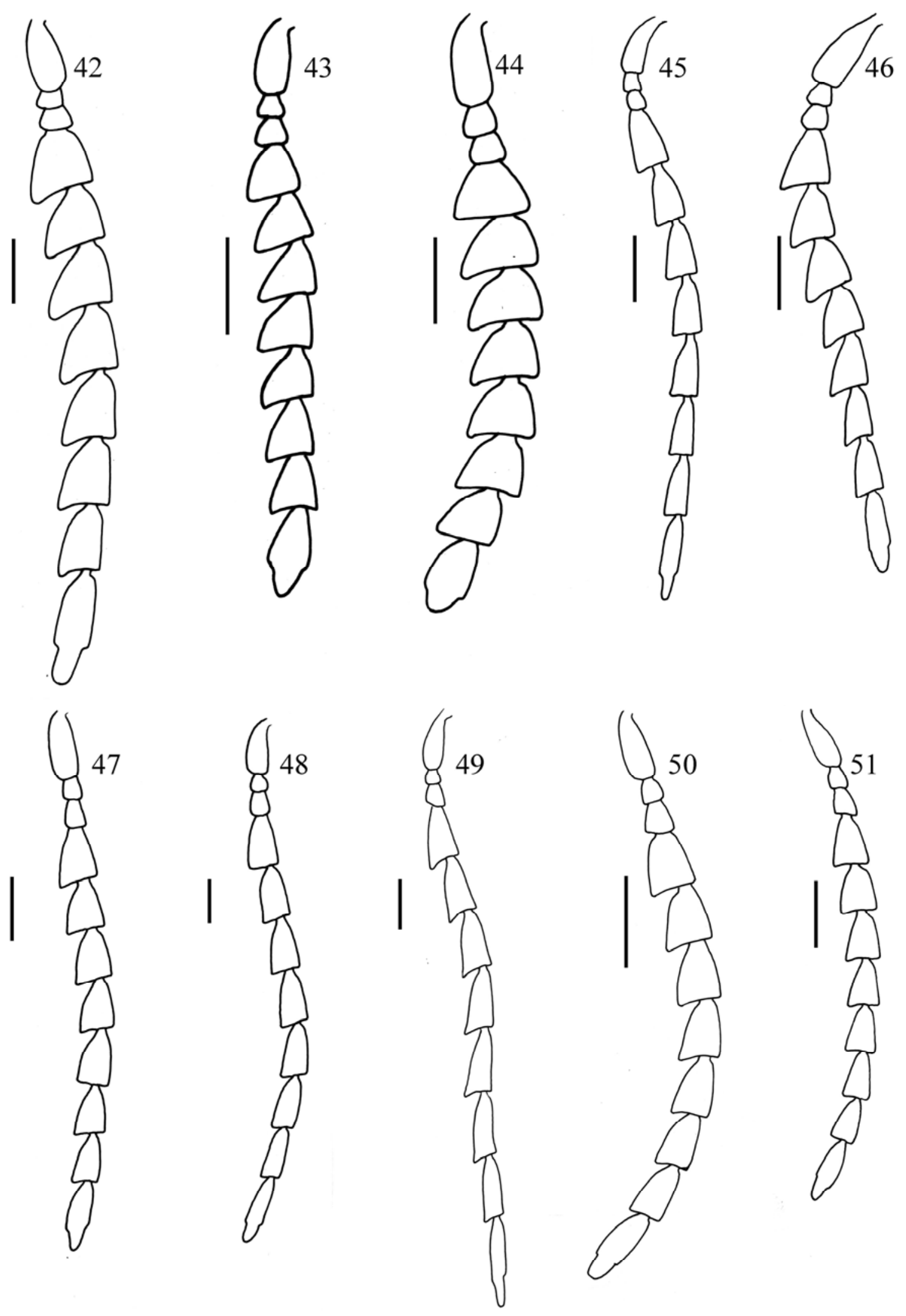

Figuras 42-51. Antenas (macho): 42, Paraphileus thoreyi; 43, Euplinthus ophthalmicus; 44, Compsoplinthus ruber; 45, Lygelater fulgidus; 46, Lygelater bifossulatus; 47, Deilelater physoderus; 48, Photophorus jansonii; 49, Ignelater havaniensis; 50, Deilelater atlanticus; 51, Vesperelater ornamentum. Escalas: $1,0 \mathrm{~mm}$. 

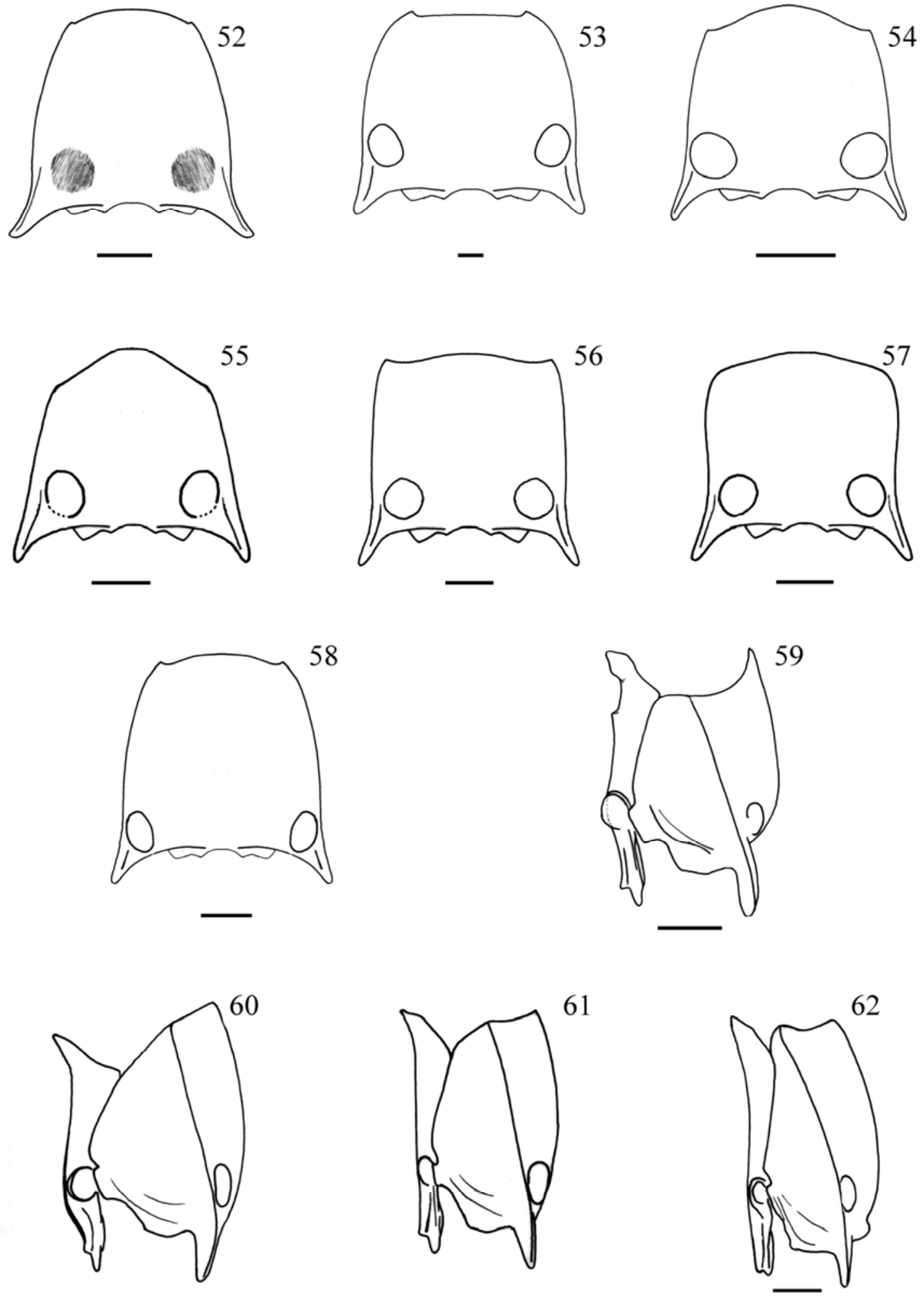

Figuras 52-62. Protórax (macho, dorsal): 52, Noxlumenes bardus; 53, Pyrophorus divergens; 54, Phanophorus perspicax; 55, Hypsiophthalmus boops; 56, Pyrearinus brevicollis; 57, Pyrearinus ruscus; 58, Vesperelater arizonicus. Protórax (macho, lateral): 59, Hypsiophthalmus luscius; 60, Pyrearinus fulvescens; 61, Pyrearinus brevicollis; 62, Vesperelater arizonicus. Escalas: 1,0 mm. 

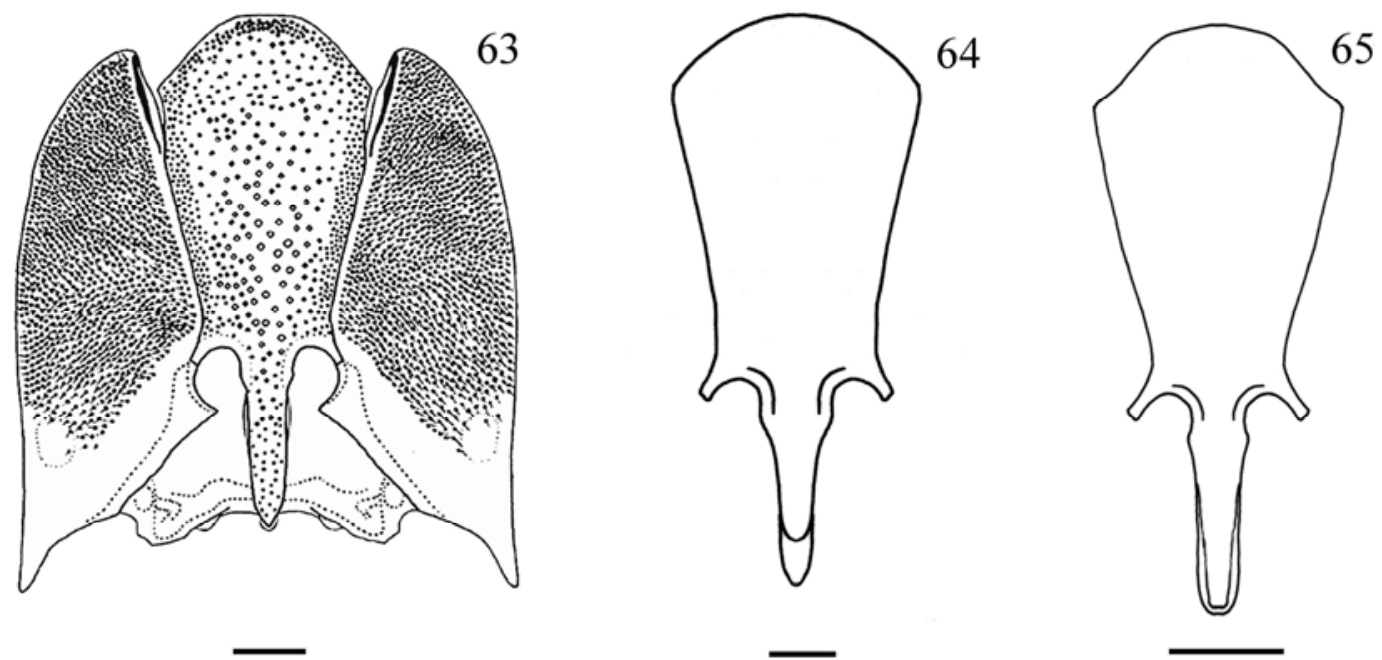

65
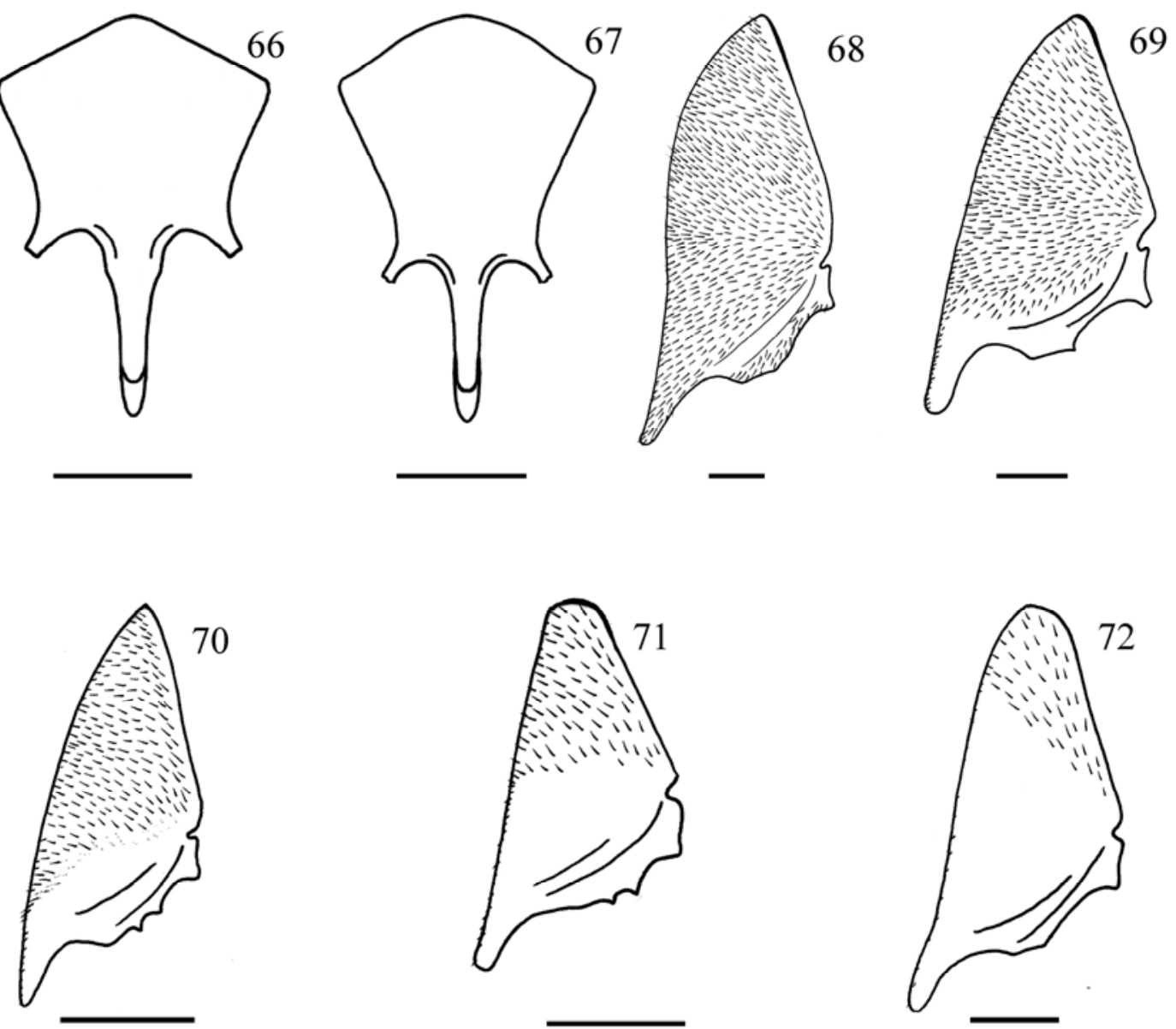

Figuras 63-72. Protórax (macho, ventral): 63, Opselater costae. Prosterno (macho, ventral): 64, Fulgeochlizus bruchi; 65, Vesperelater ornamentum; 66, Pyrearinus ferrugineus; 67, Pyrearinus lineatus. Hipômero (macho, ventral): 68, Gênero A sp. n. 1 sp. n.; 69, Fulgeochlizus bruchi; 70, Gênero C basalis comb. n.; 71, Phanophorus perspicax; 72, Sooporanga formosa. Escalas: 1,0 mm. 

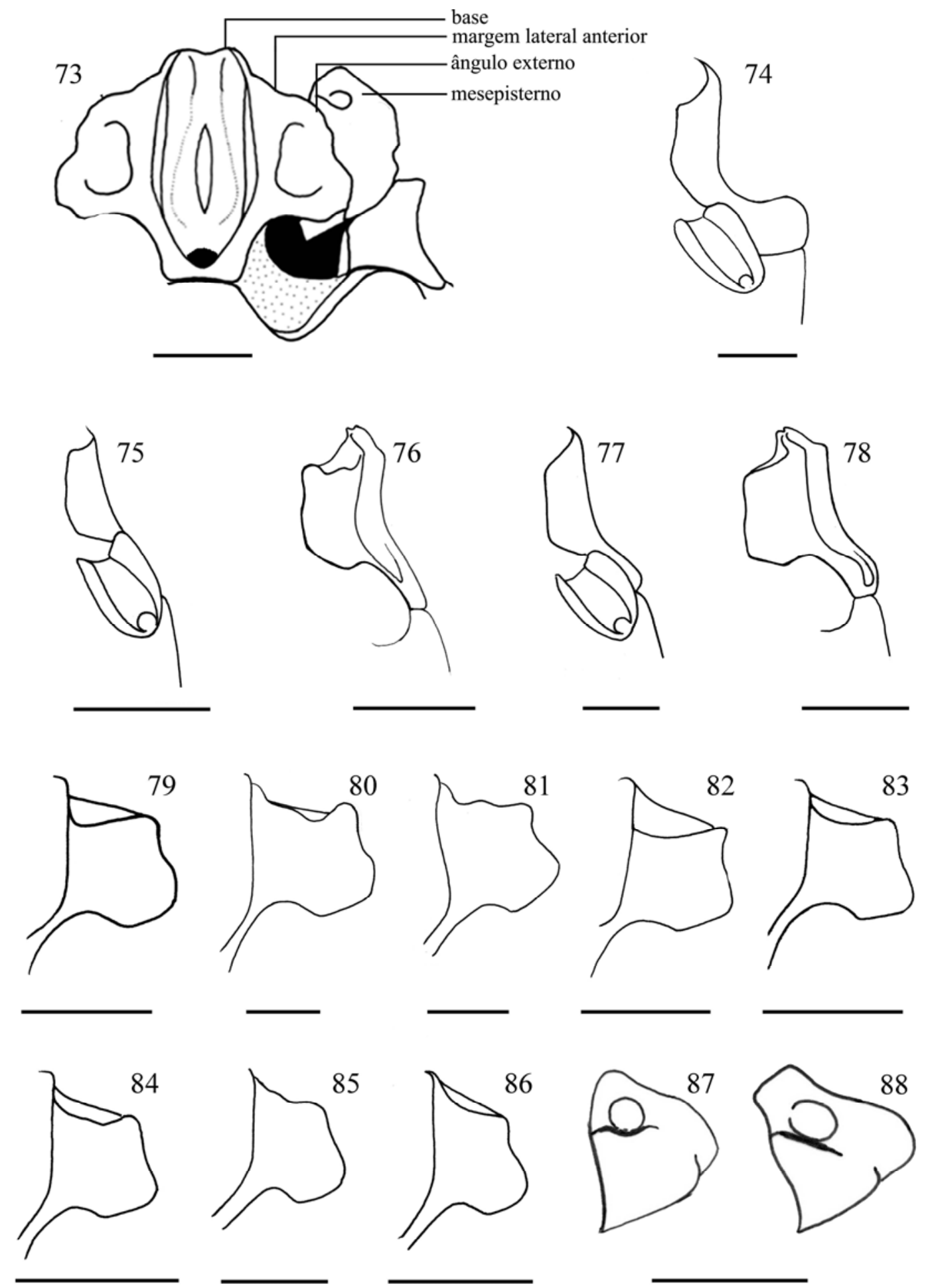

Figuras 73-88. 73, Mesoventrito, mesepisterno, mesepímero e cavidade mesocoxal (macho, ventral): Opselater costae. Mesoventrito (macho): 74, Photophorus jansonii (lateral); 75, Pyrearinus nyctolampis (lateral); 76, Pyrearinus brevicollis (látero-ventral); 77, Ignelater havaniensis (lateral); 78, Opselater pyrophanus (látero-ventral). Margem lateral anterior do mesoventrito (macho, látero-ventral): 79, Noxlumenes bardus; 80, Pyrophorus divergens; 81, Hapsodrilus ignifer; 82, Hypsiophthalmus boops; 83, Pyrearinus fulvescens; 84, Pyrearinus lineatus; 85, Ignelater havaniensis; 86, Coctilelater corymbitoides; 87, Ignelater havaniensis; 88, Photophorus jansonii. Escalas: 1,0 mm. 

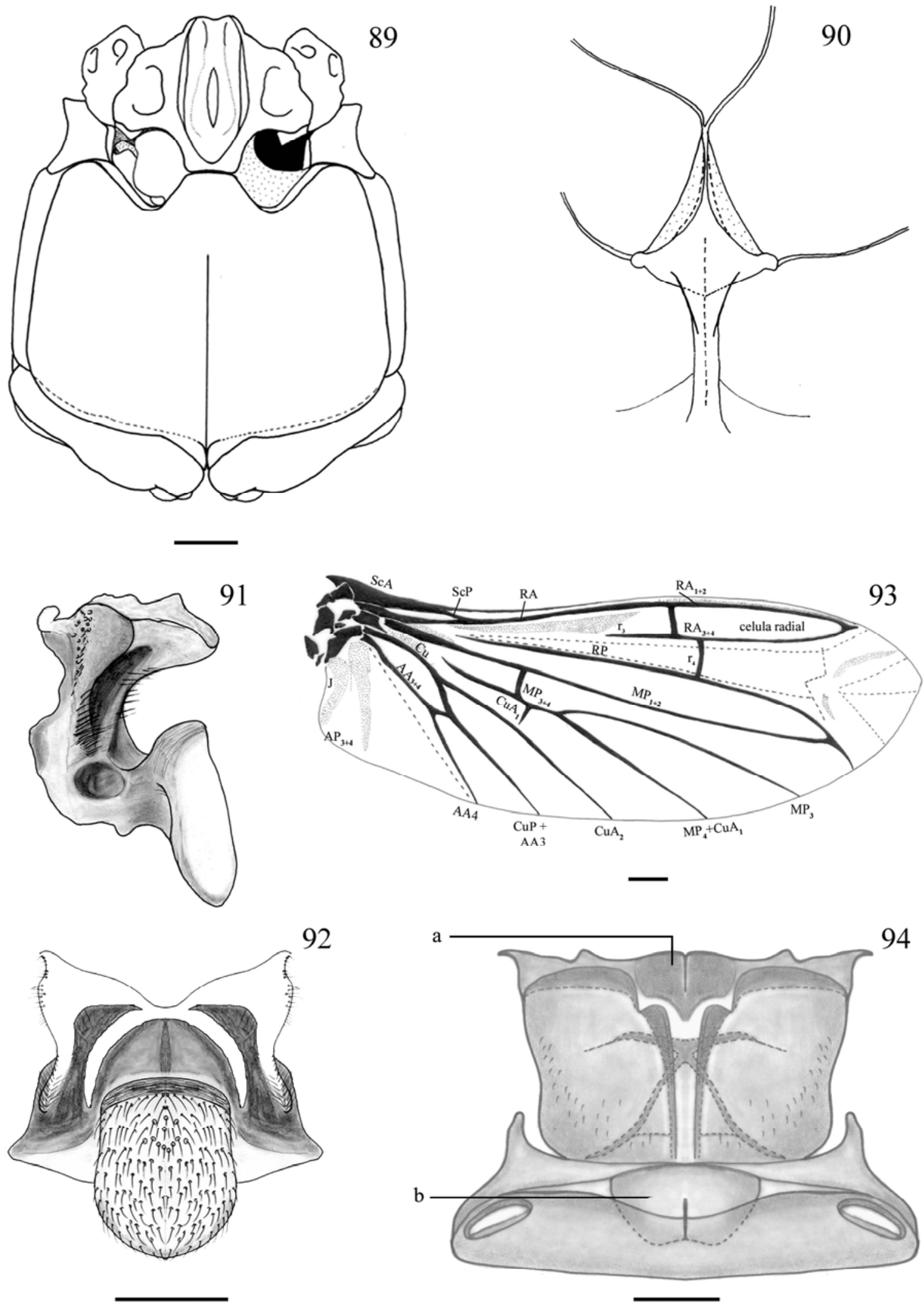

Figuras 89-94. Opselater costae (macho): 89, pterotórax (ventral); 90, metendosternito; 91, 92, escutelo (lateral, dorsal); 93, asa. 94, Vesperelater occidentalis, metanoto (a, região mediana anterior; b, região mediana posterior). Escalas: 1,0 mm. 


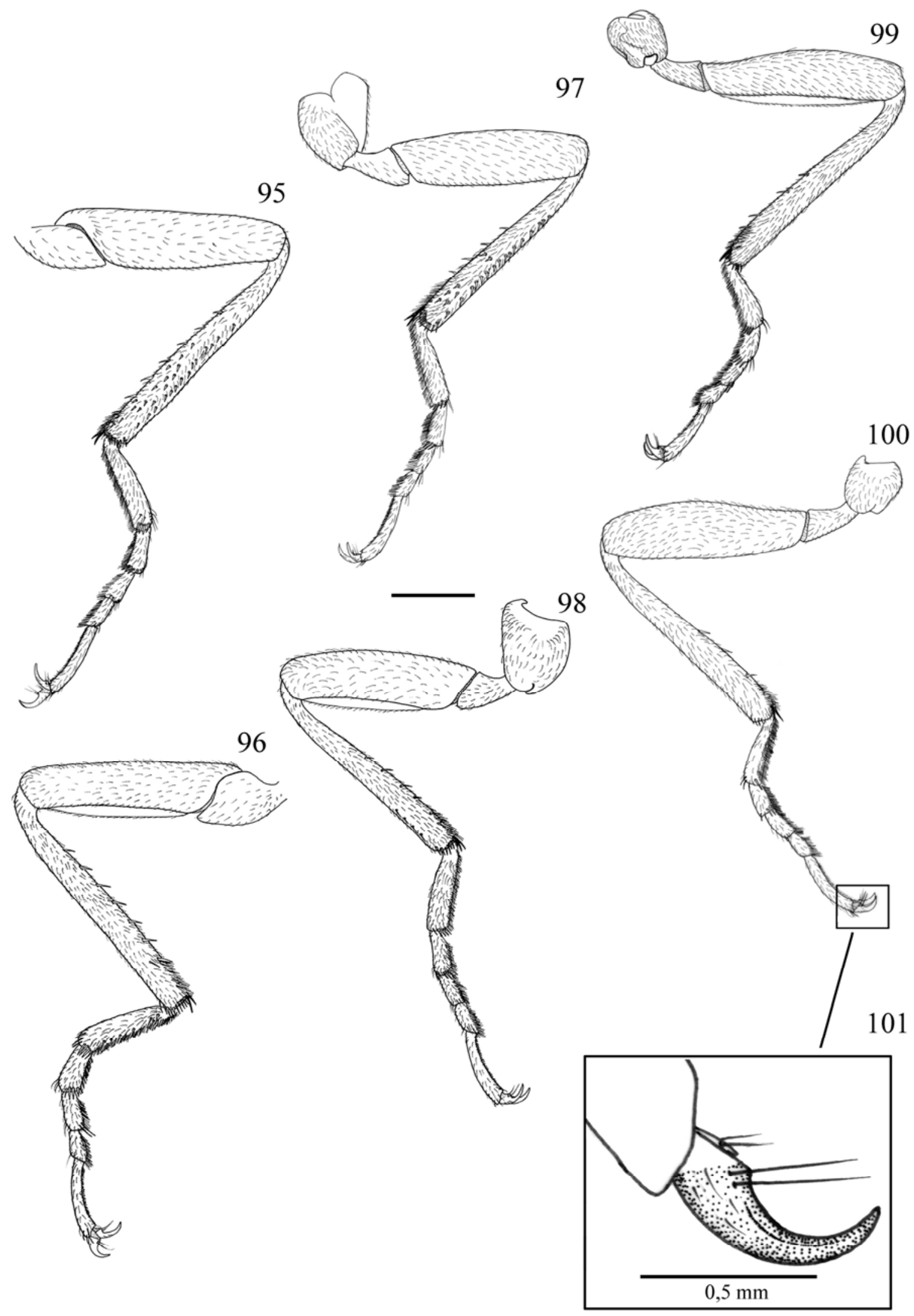

Figuras 95-101. Opselater costae (macho): 95-100, pernas (vista externa e interna): 95, 96 anterior; 97, 98, mediana; 99, 100, posterior. 97, garra tarsal (externa). Escala 95-100: 1,0 $\mathrm{mm}$. 

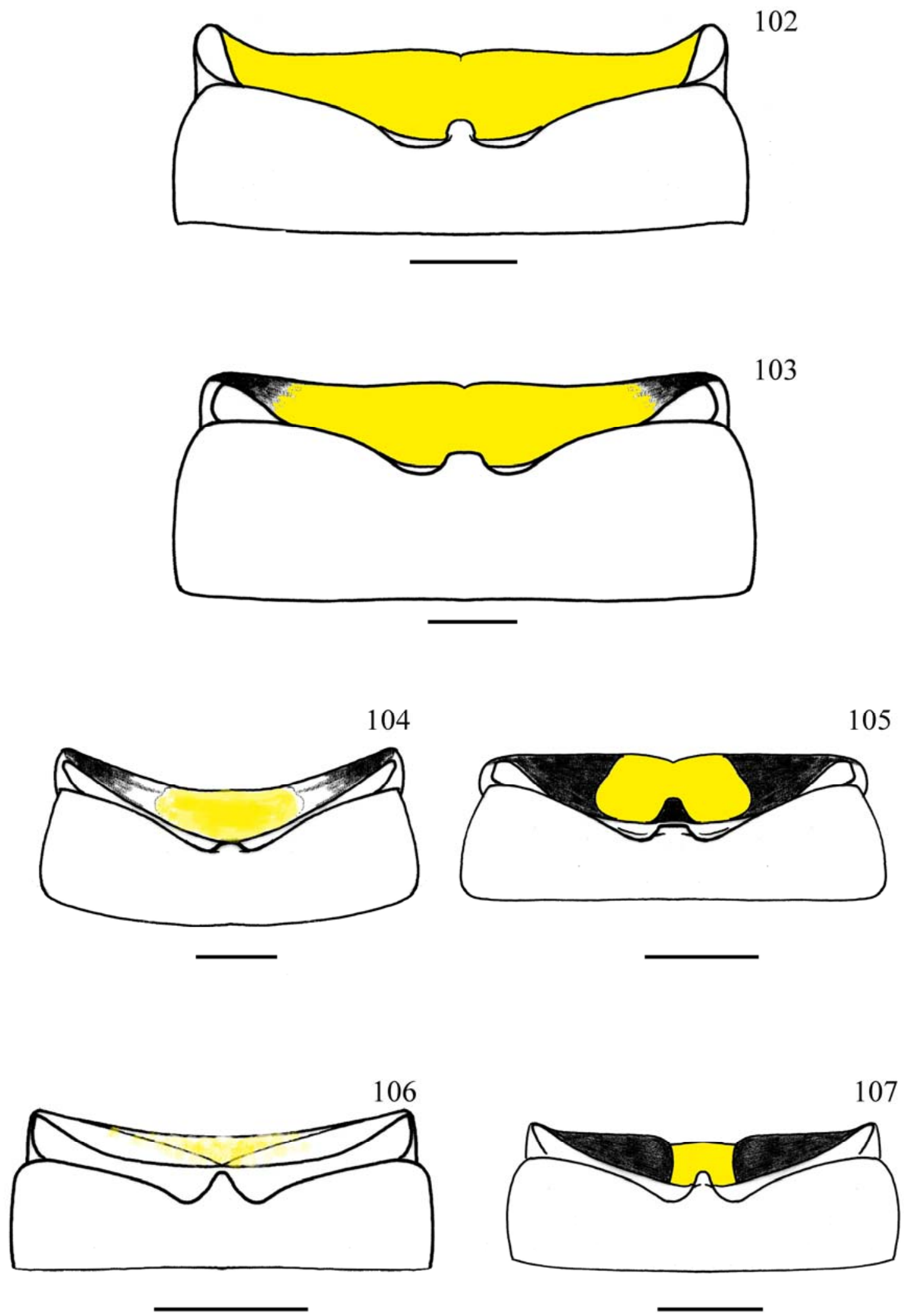

Figuras 102-107. Órgão luminescente abdominal (macho): 102, Fulgeochlizus bruchi; 103, Pyrophorus stupendus; 104, Hapsodrilus ignifer; 105, Hypsiophthalmus charops; 106, Gênero C basalis comb n.; 107, Vesperelater gemmiferus. Escalas: 1,0 mm. 

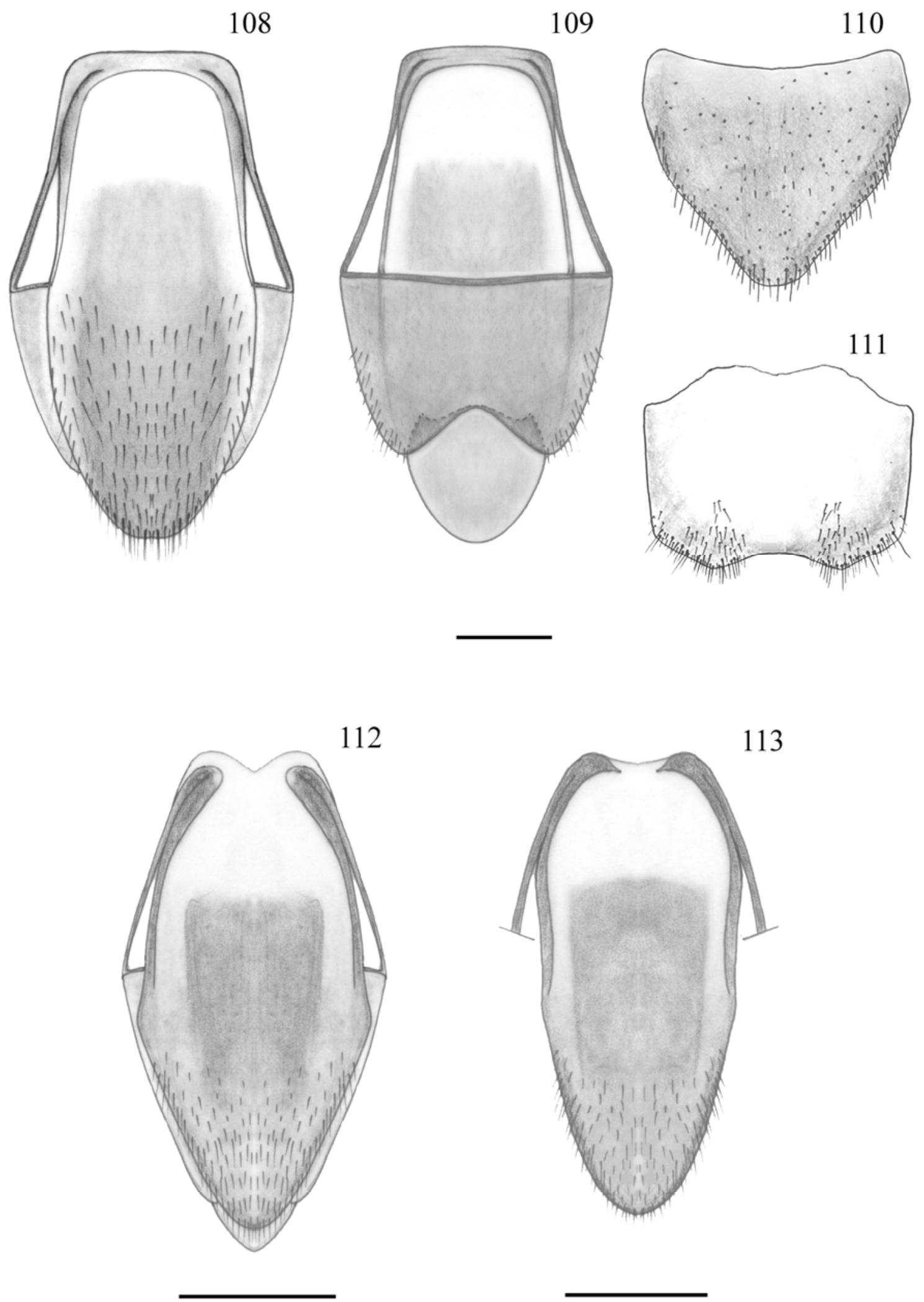

Figuras 108-113. Segmentos VIII-X (macho). 108-111, Opselater pyrophanus: 108, esternito IX; 109, tergitos IX e X; 110, tergito VIII; 111, esternito VIII. 112, Ptesimopsia parallela: esternito IX; 113, Ptesimopsia candezei: esternito IX. Escalas: 1,0 mm. 

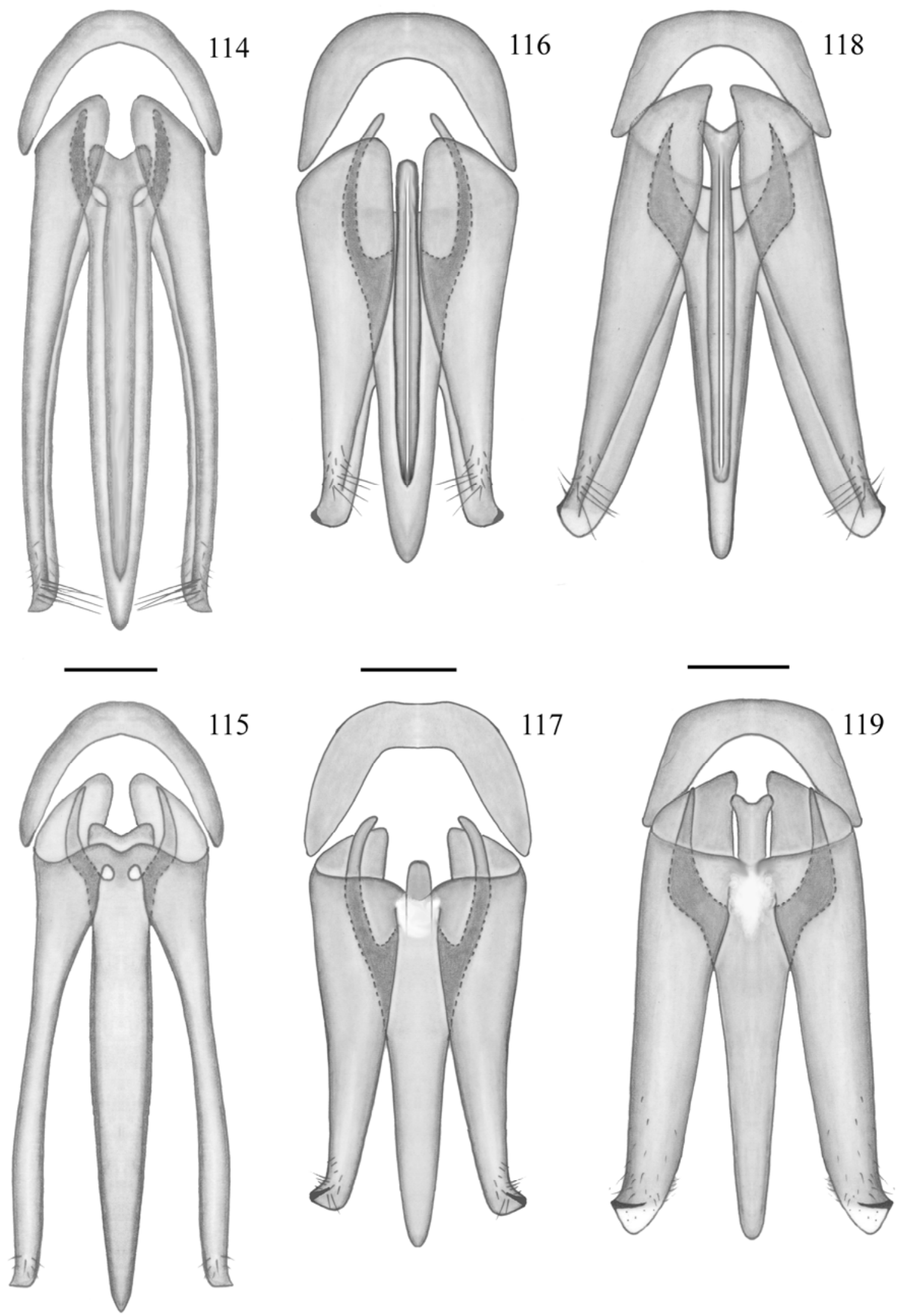

Figuras 113-119. Edeago (ventral, dorsal): 114, 115, Noxlumenes bardus; 116, 117, Nyctophyxis ocellatus; 118, 119, Cryptolampros coecus. Escalas: 0,5 mm. 

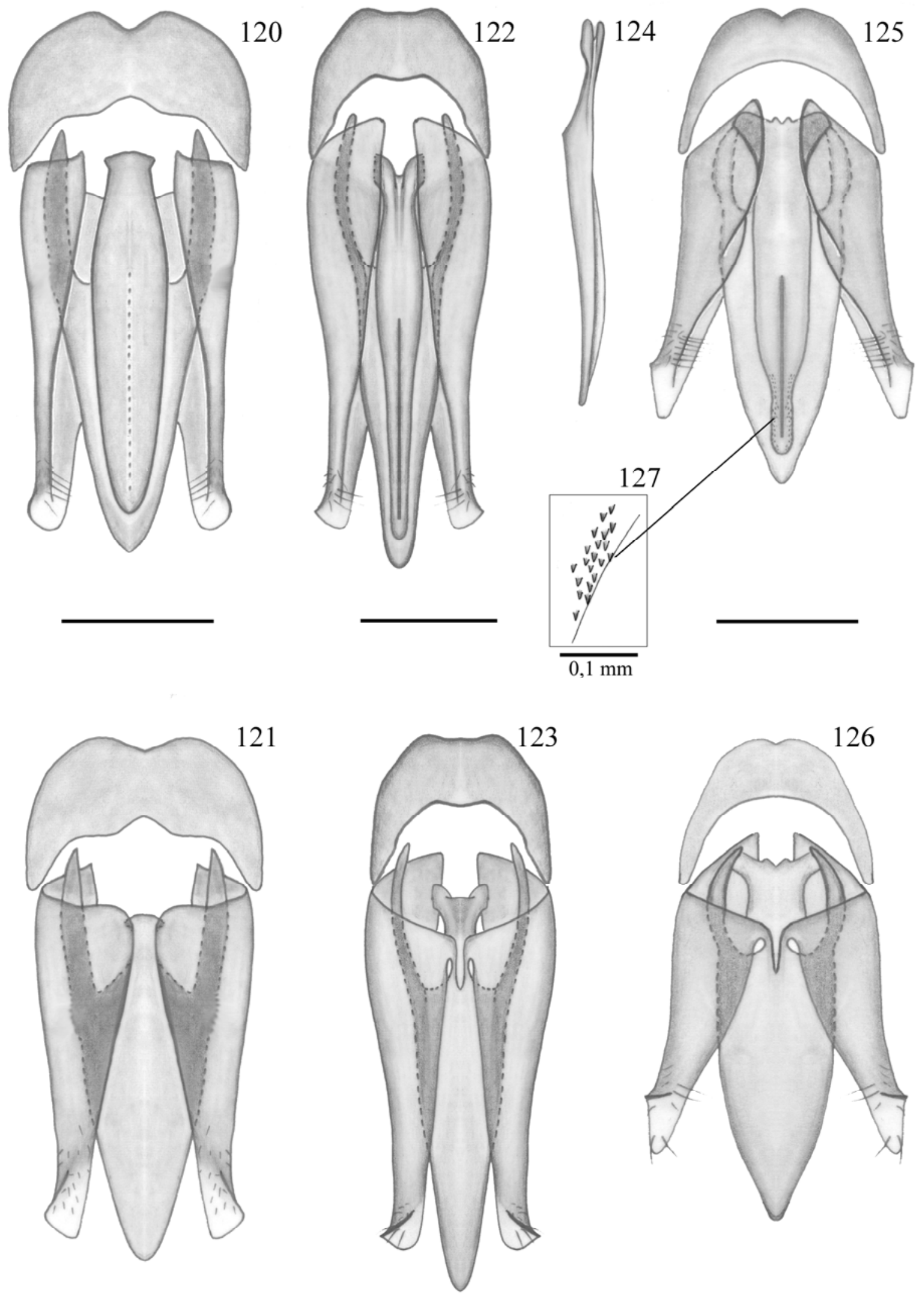

Figuras 120-127. Gênero A sp 1 sp n.: 120, 121, edeago (ventral, dorsal). Pyrophorus divergens: 122, 123, edeago (ventral, dorsal), 124, esclerito ventral (lateral). Pyrophorus noctilucus: 125, 126, edeago (ventral, dorsal), 127, escamas do esclerito ventral. Escalas 120126: $1,0 \mathrm{~mm}$. 

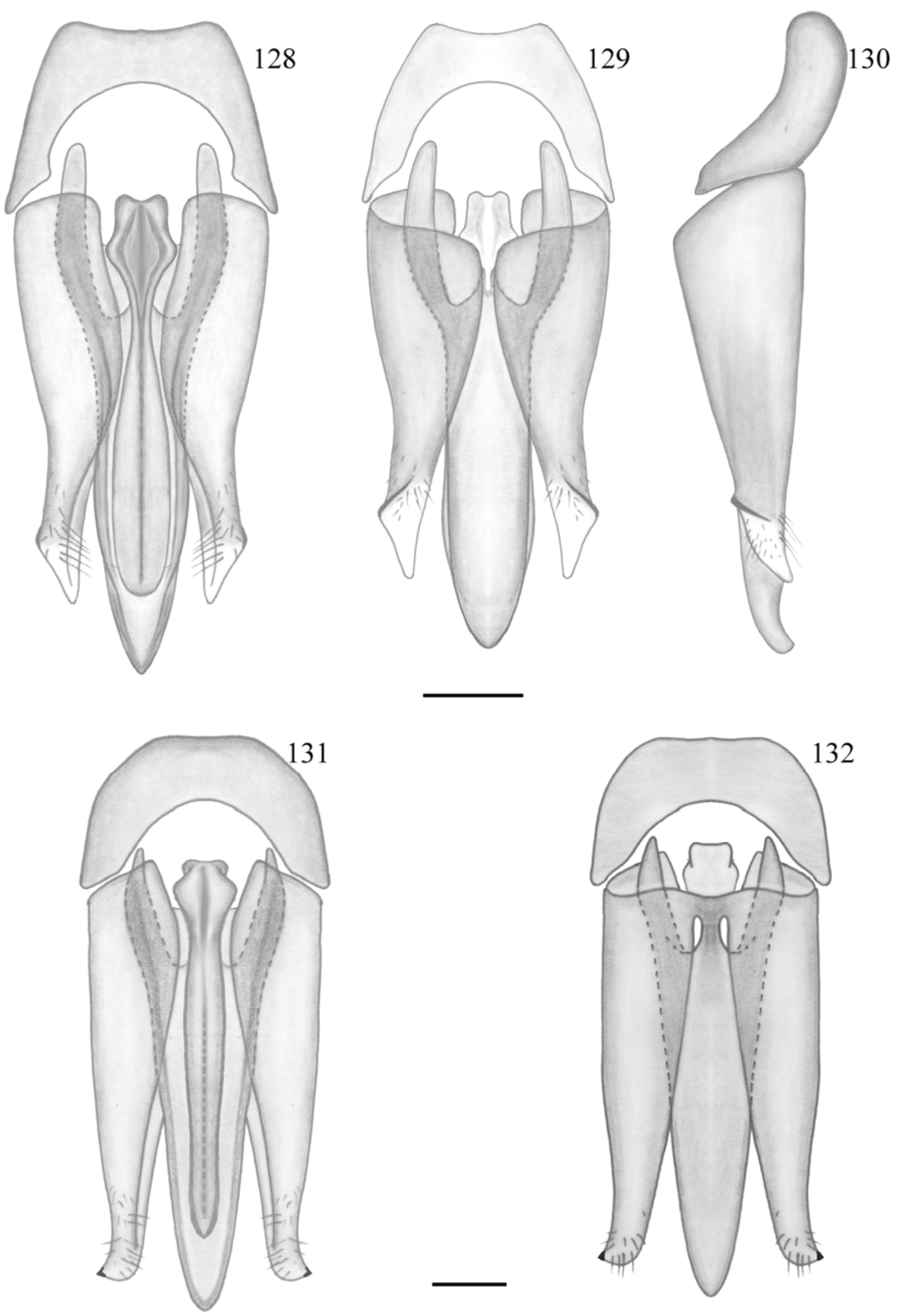

Figuras 128-132. Fulgeochlizus germari: 128-130, edeago (ventral, dorsal, lateral); Fulgeochlizus bruchi: 131, 132, edeago (ventral, dorsal). Escalas: 0,5 mm. 

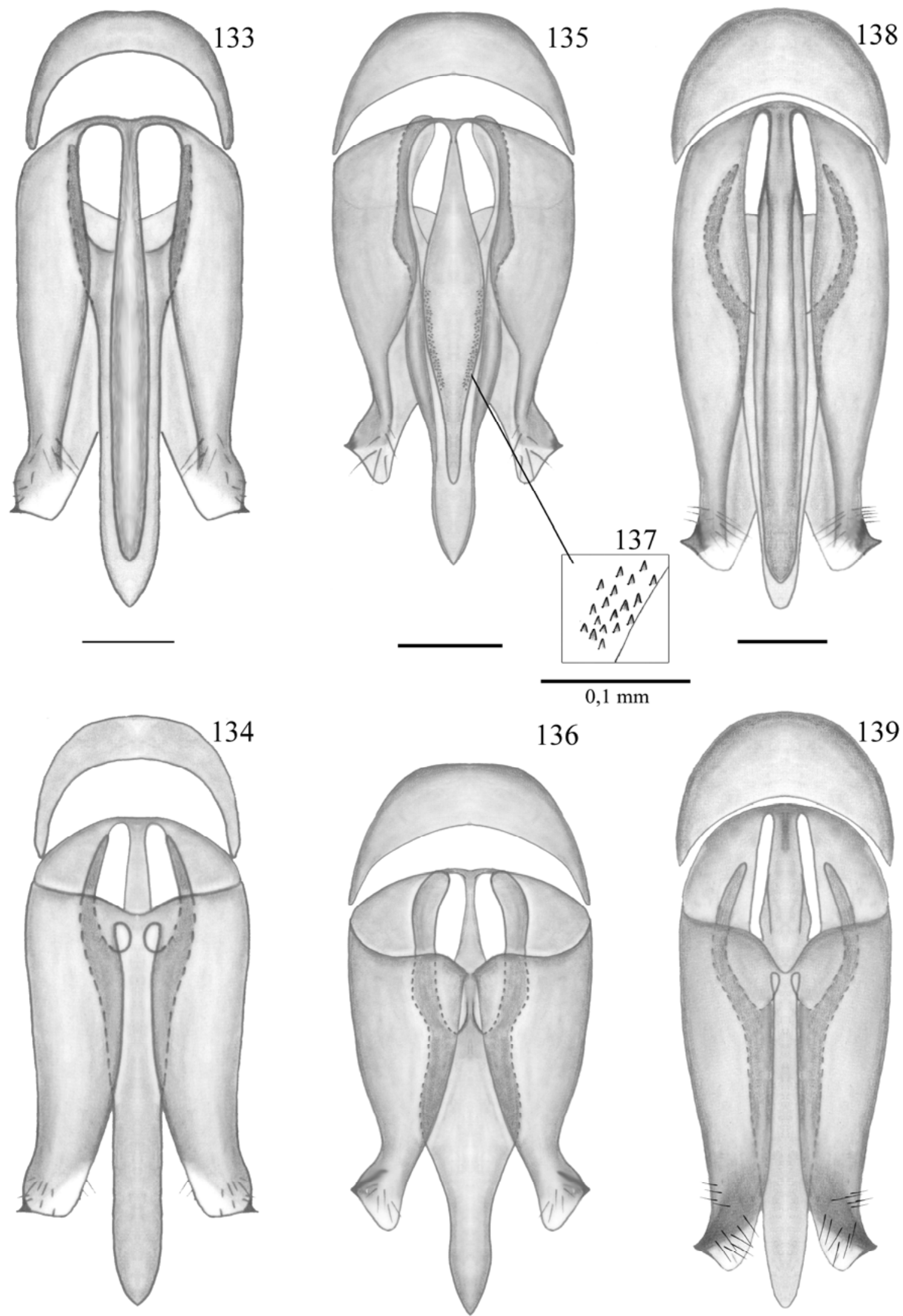

Figuras 133-139. Edeago (ventral, dorsal): 133, 134, Meroplinthus trilineatus; 135, 136, Ptesimopsia parallela (137, escamas do esclerito ventral); 138, 139, Ptesimopsia candezei. Escalas 133-136, 138, 139: 0,5 mm. 


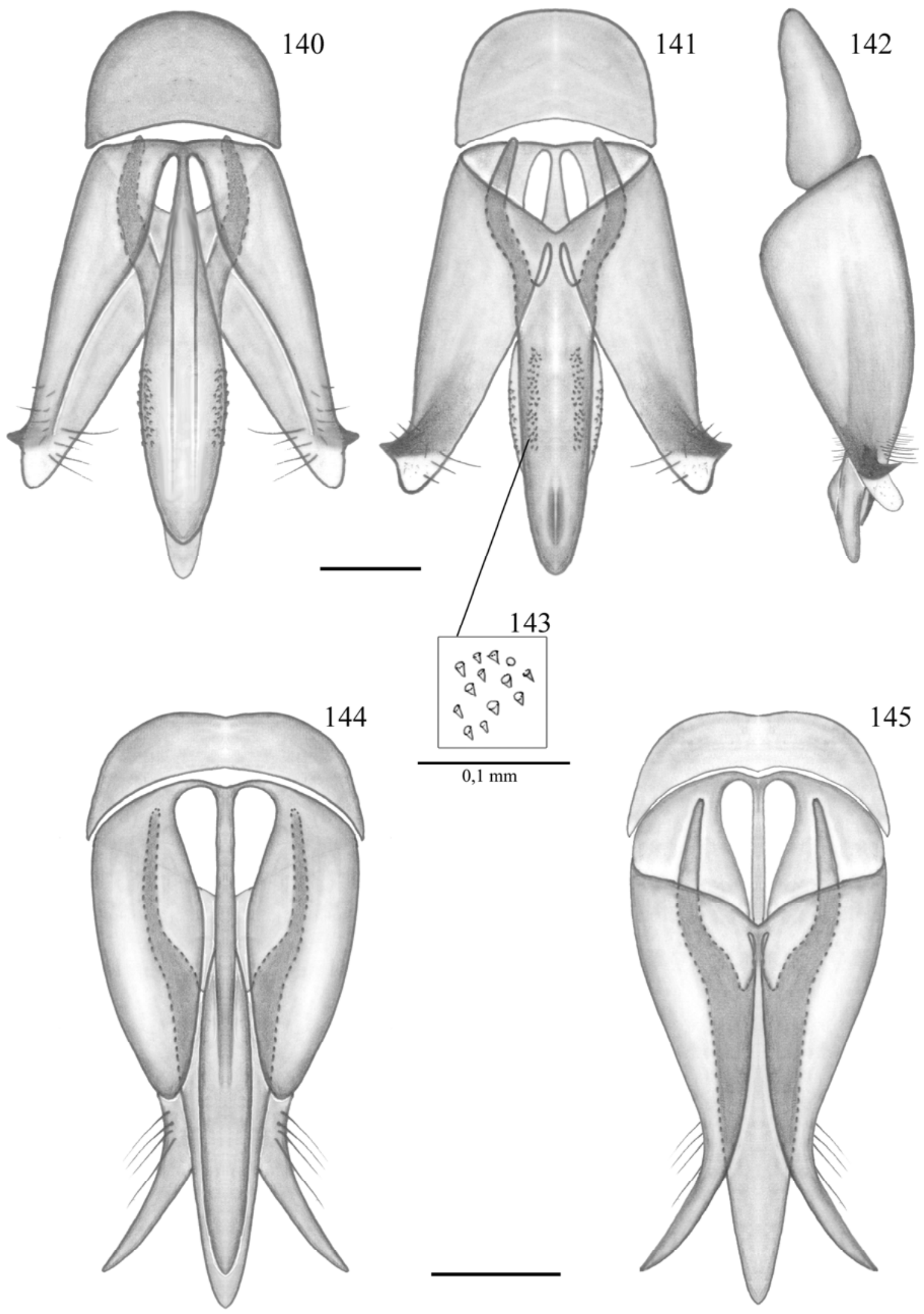

Figuras 140-145. Hapsodrilus ignifer: 140-142, edeago (ventral, dorsal, lateral); 143, espinhos cônicos do esclerito dorsal. Pyroptesis cincticollis: 144, 145, edeago (ventral, dorsal). Escalas 140-142, 144, 145: 0,5 mm. 

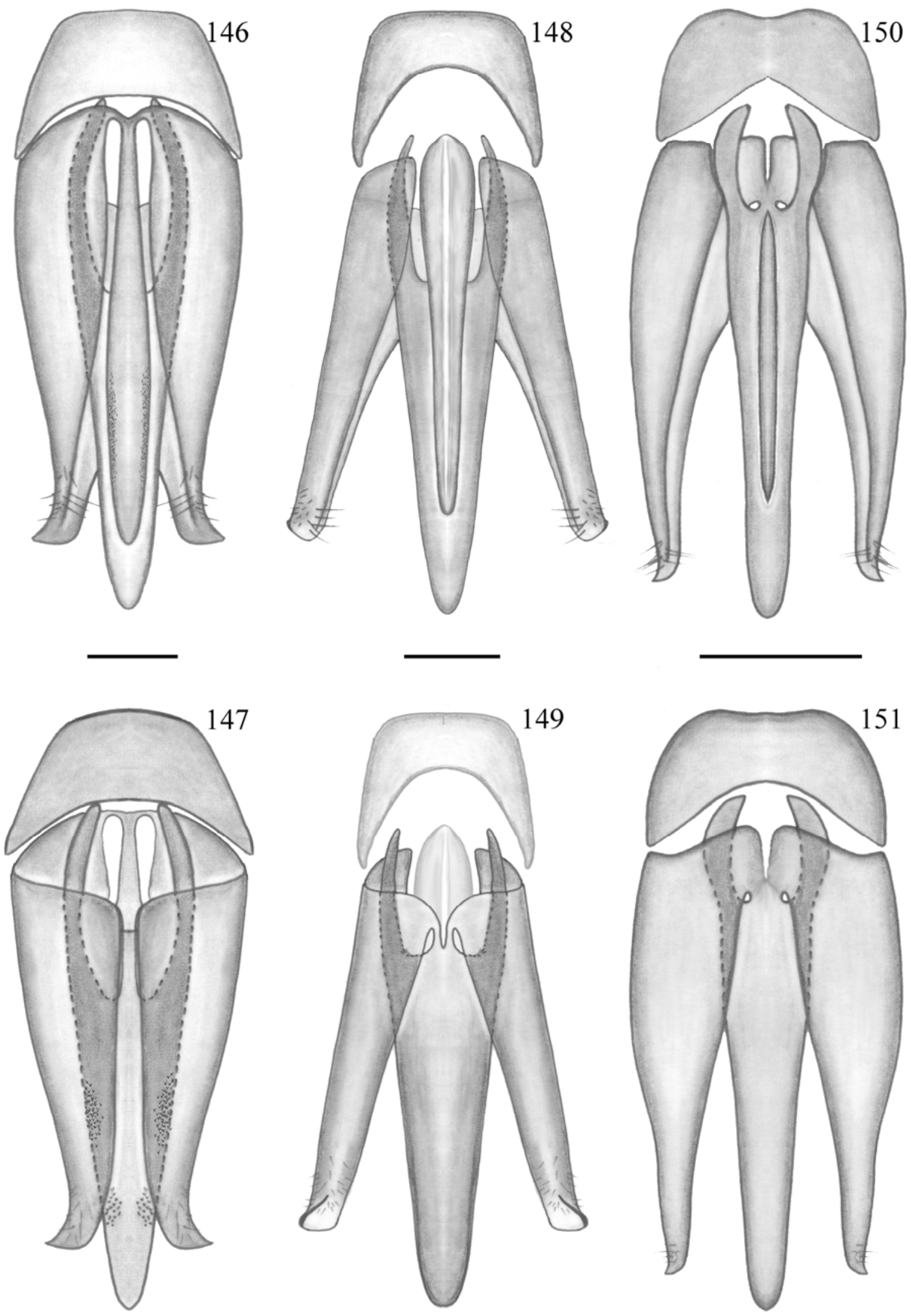

Figuras 146-151. Edeago (ventral, dorsal): 146, 147, Sooporanga formosa; 148, 149, Gênero B cinnameus com n.; 150, 151, Phanophorus perspicax. Escalas: 0,5 mm. 

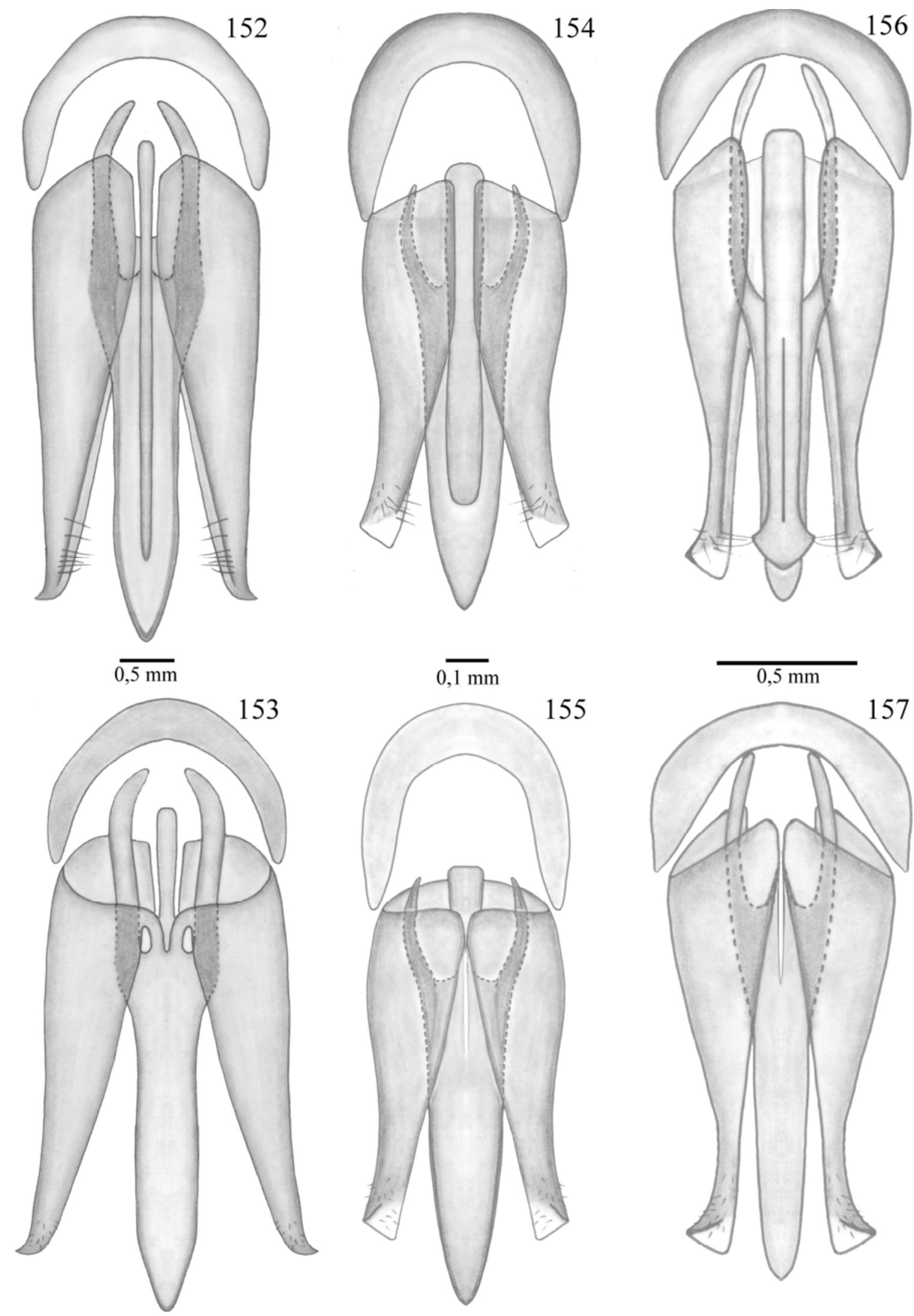

Figuras 152-157. Edeago (ventral, dorsal): 152, 153, Hypsiophthalmus boops; 154, 155, Pyrearinus pumilus; 156, 157, Pyrearinus fulvescens. 

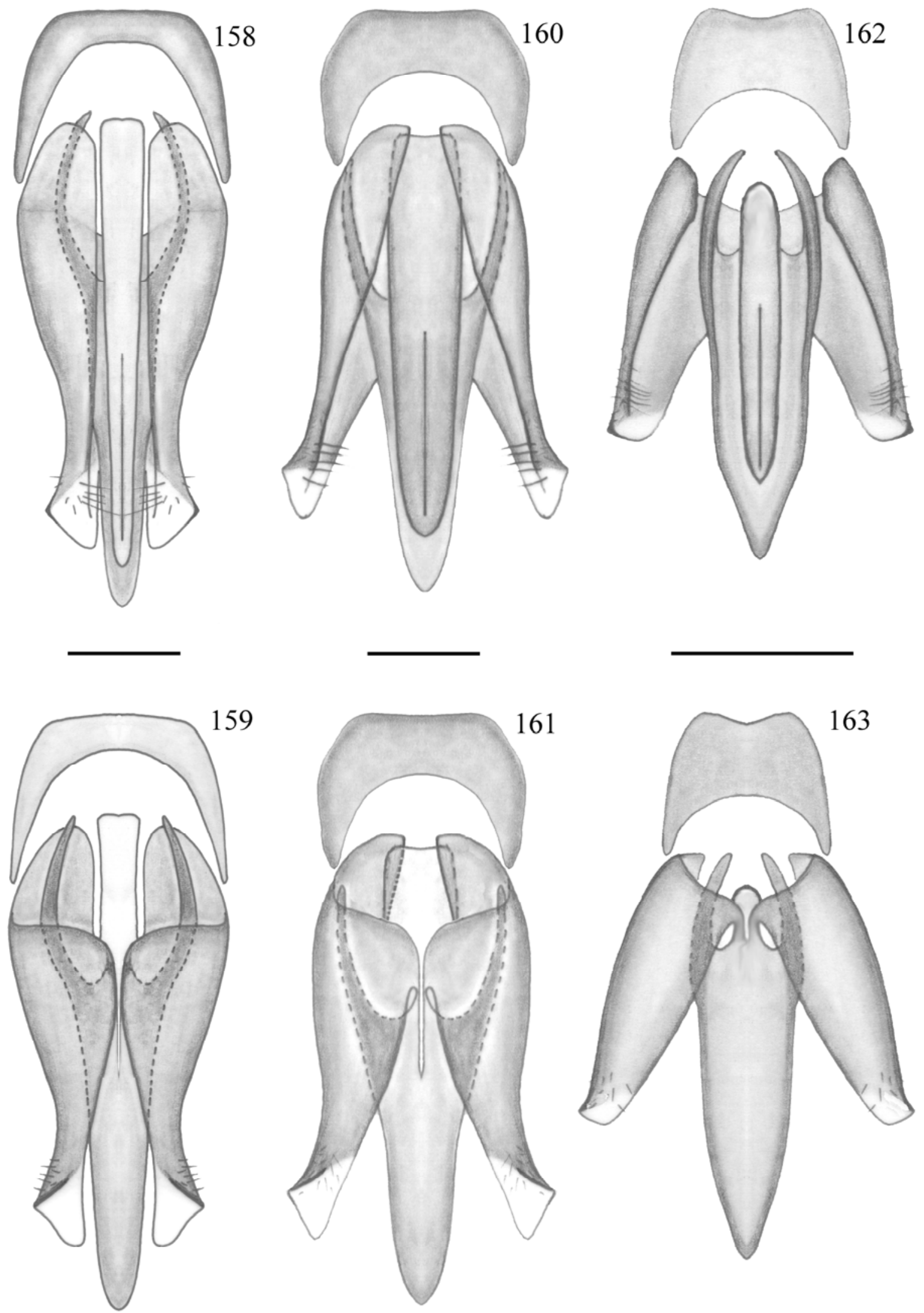

Figuras 158-163. Edeago (ventral, dorsal): 158, 159, Pyrearinus castaneus; 160, 161; Pyrearinus fulgurans; 162, 163, Gênero C basalis comb. n. Escalas: 0,5 mm. 

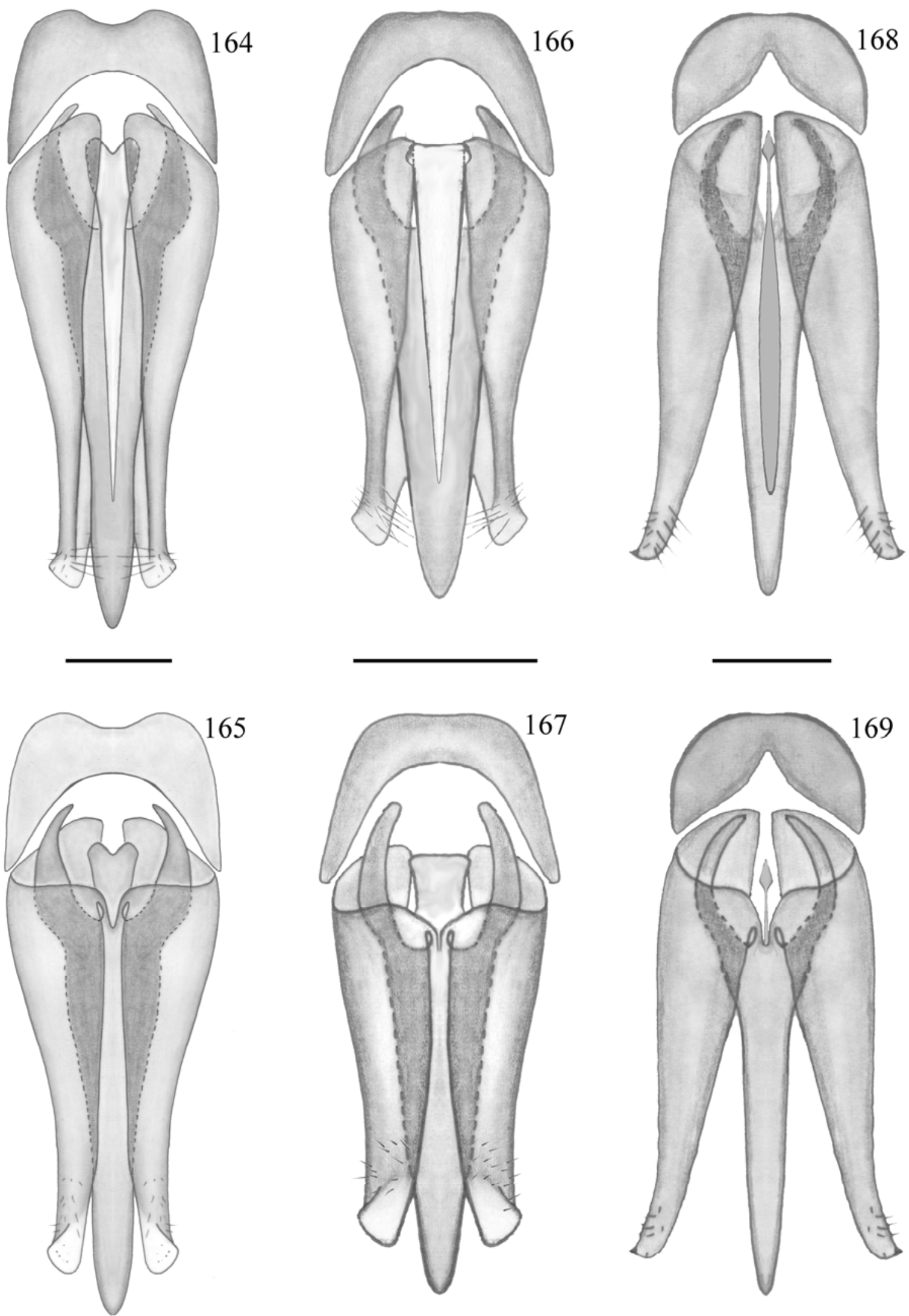

Figuras 164-169. Edeago (ventral, dorsal): 164, 165, Gênero D vescus comb. n.; 166, 167, Coctilelater corymbitoides; 168, 169, Agnostelater mesochrous. Escalas: 0,5 mm. 

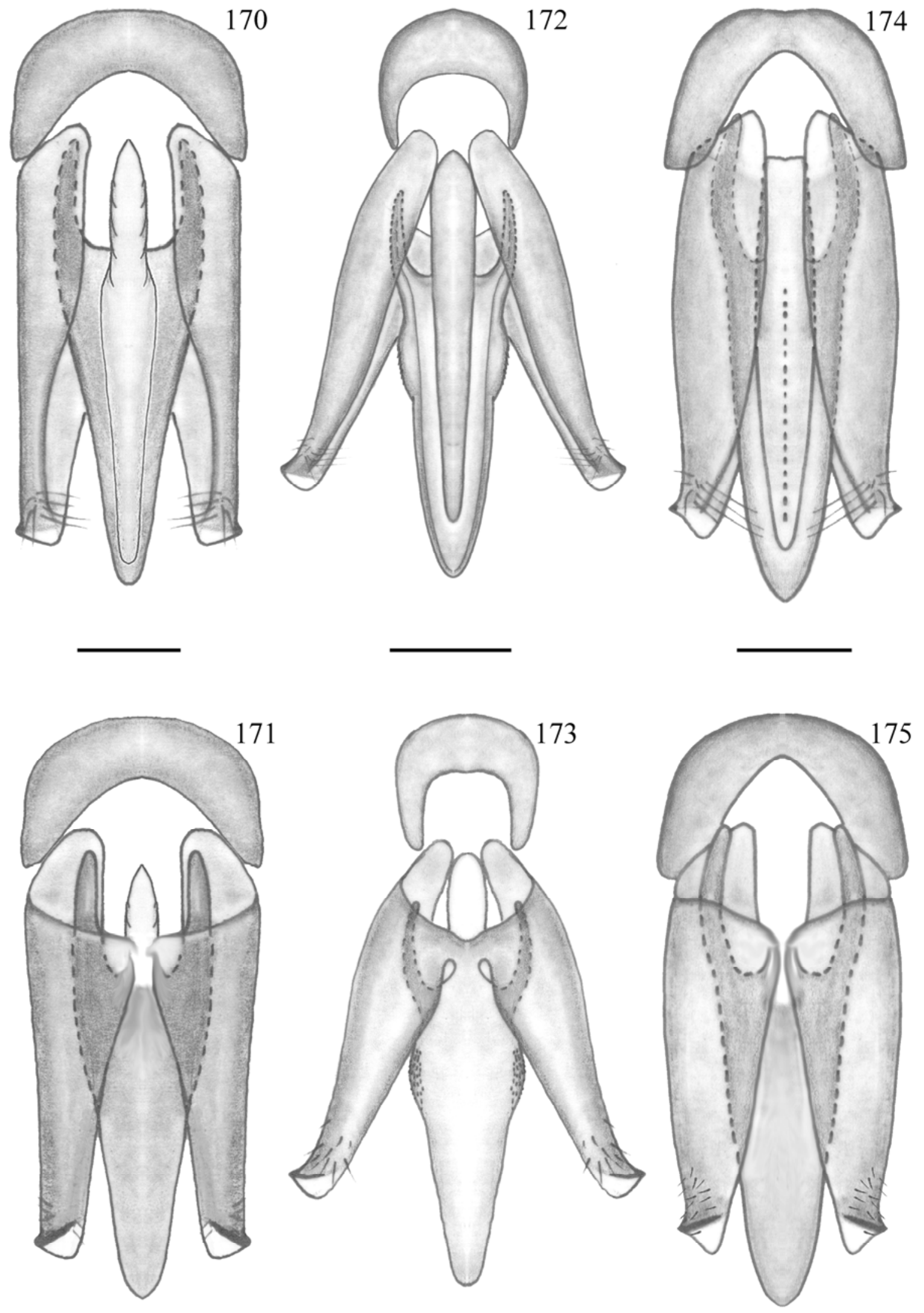

Figuras 170-175. Edeago (ventral, dorsal): 170, 171, Paraphileus thoreyi; 172, 173, Euplinthus ophthalmicus; 174, 175, Compsoplinthus ruber. Escalas: 0,5 mm. 

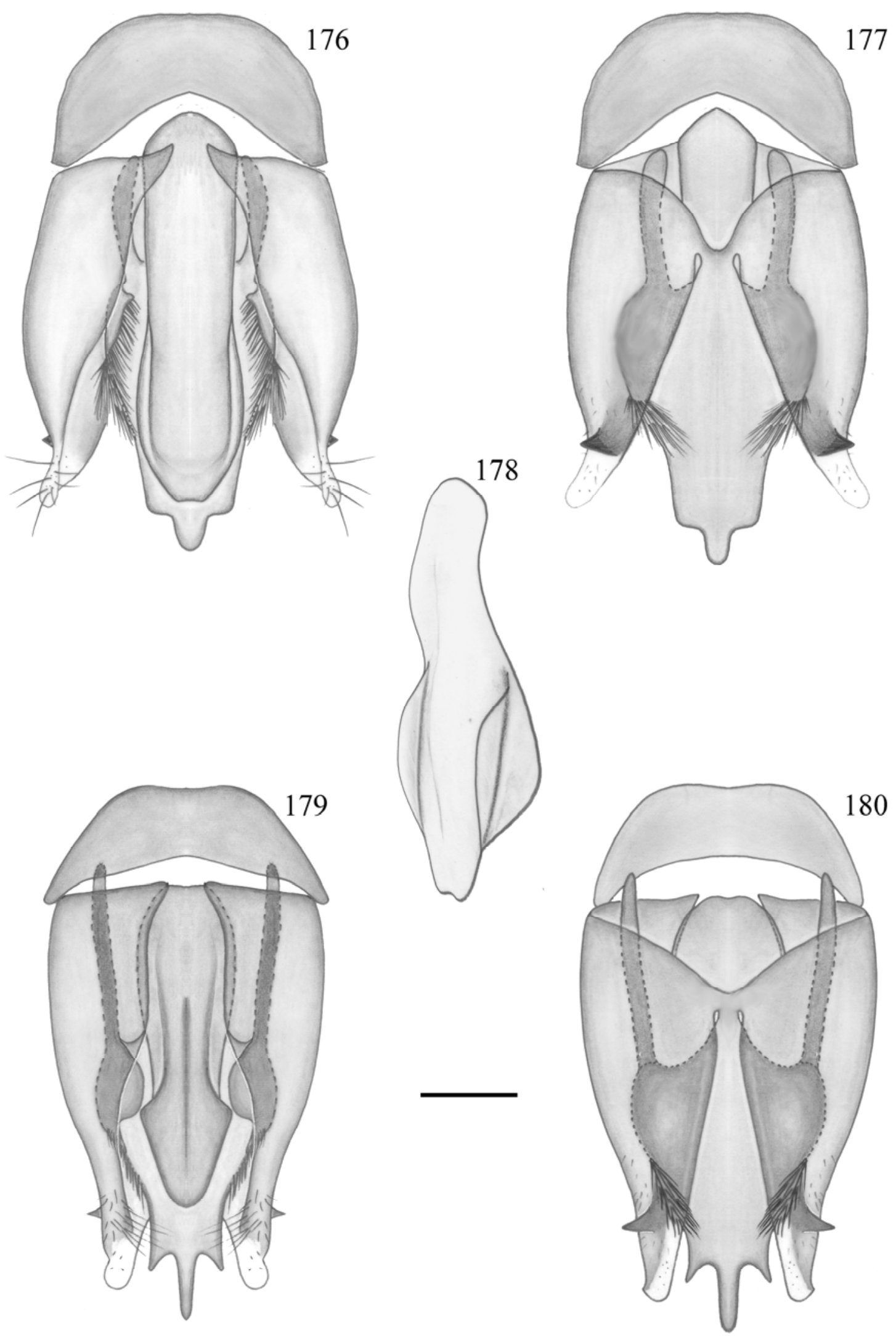

Figuras 176-180. Lygelater fulgidus: 176, 177, edeago (ventral, dorsal); 178, esclerito ventral (látero-ventral). Lygelater indicus: 179, 180, edeago (ventral, dorsal). Escala: 0,5 mm. 

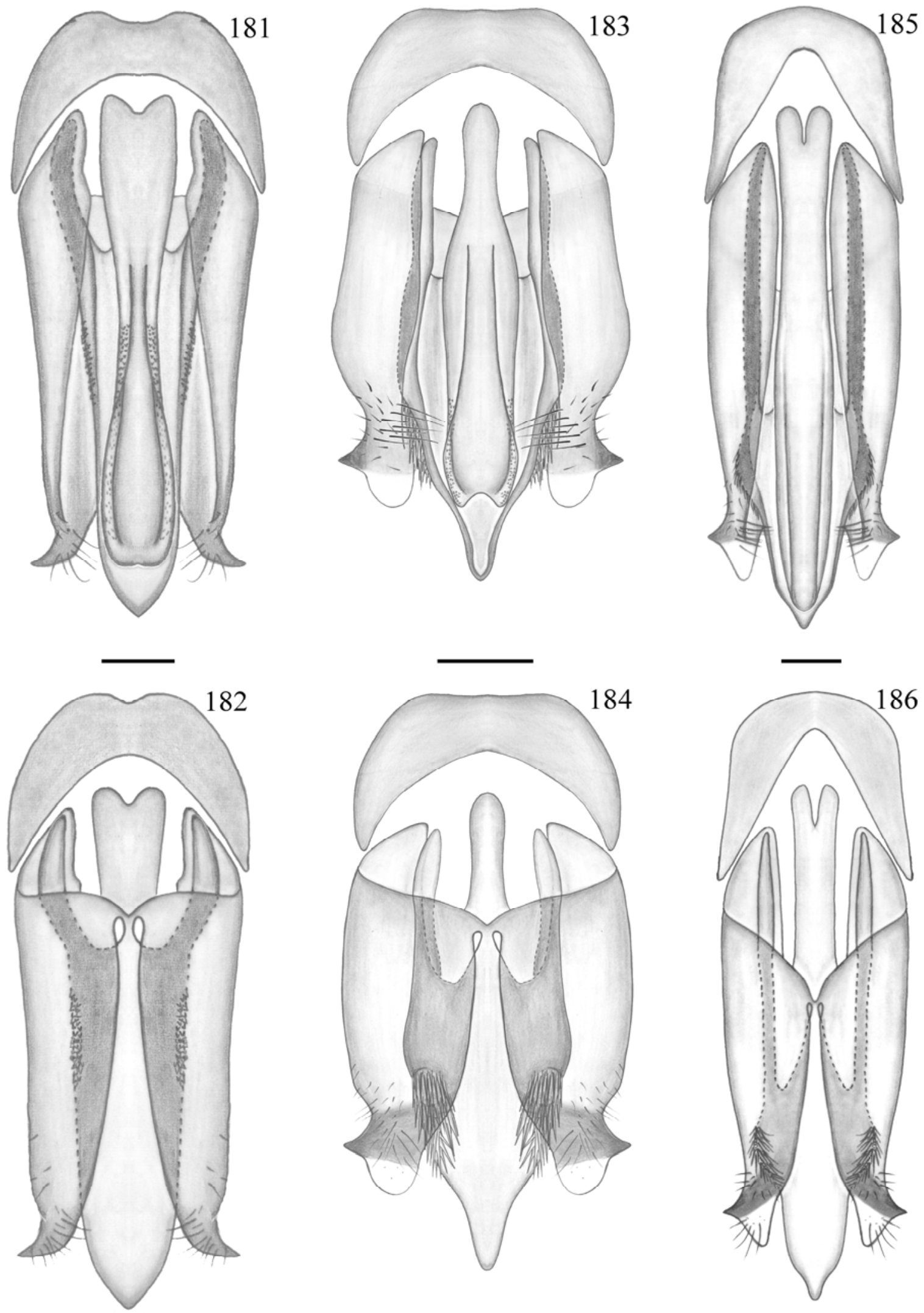

Figuras 181-186. Edeago (ventral, dorsal): 181, 182, Lygelater bifossulatus; 183, 184, Deilelater physoderus; 185, 186, Photophorus jansonii. Escalas: 0,5 mm. 

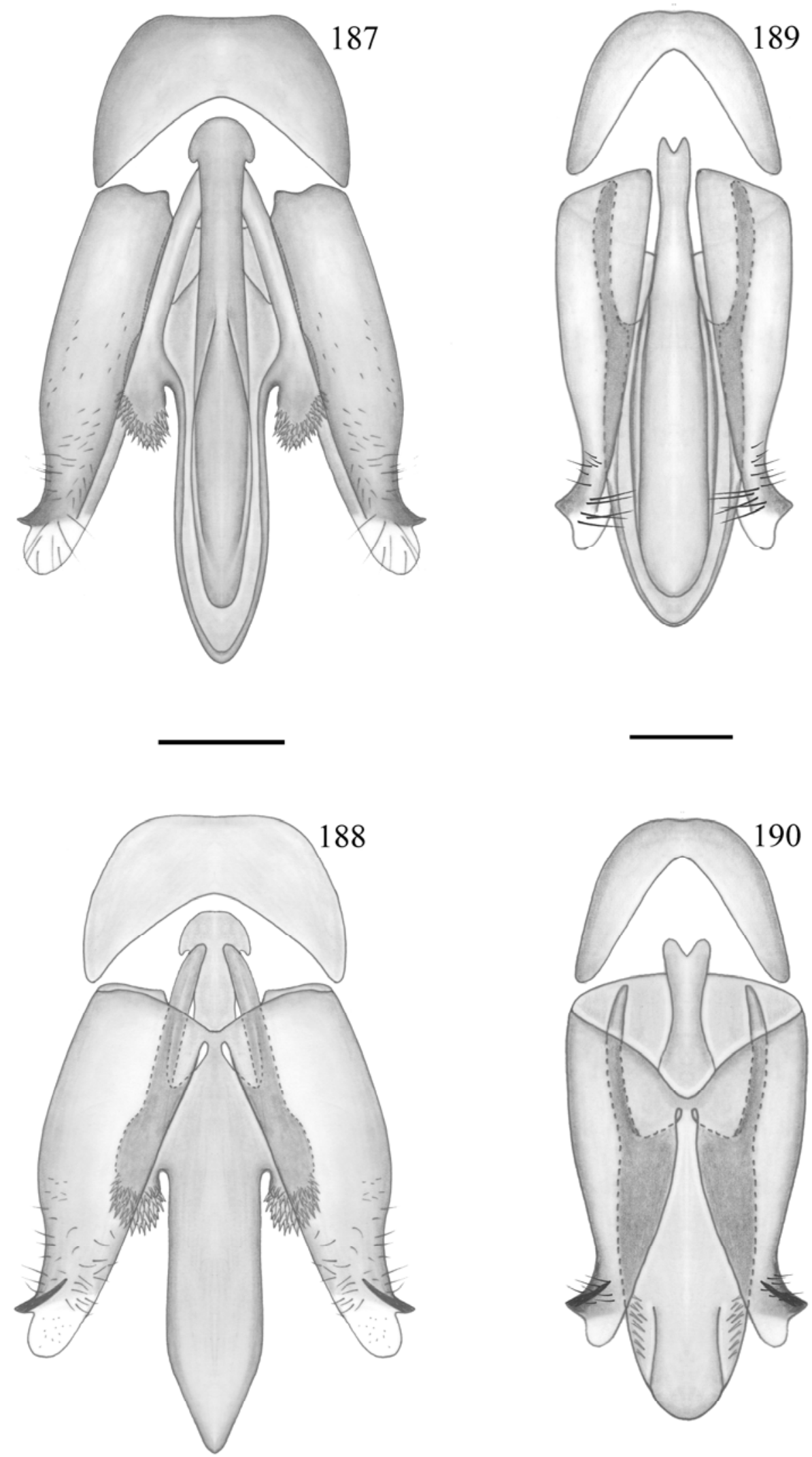

Figuras 187-190. Edeago (ventral, dorsal): 187, 188, Ignelater havaniensis; 189, 190, Gênero E ustulatus comb. n. Escalas: 0,5 mm. 

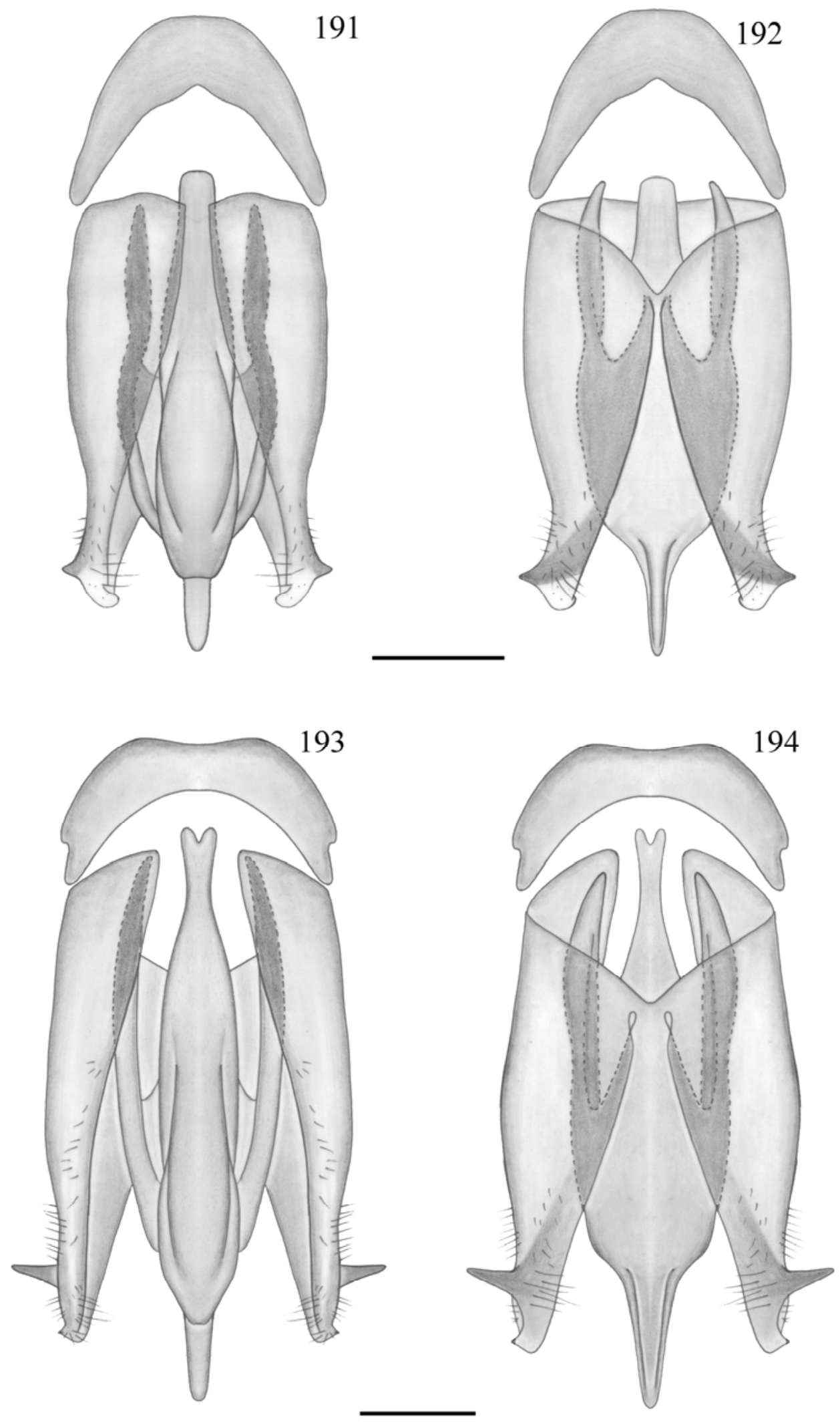

Figuras 191-194. Edeago (ventral, dorsal): 191, 192, Vesperelater sirius comb. n. 193, 194, Vesperelater occidentalis. Escalas: 0,5 mm. 


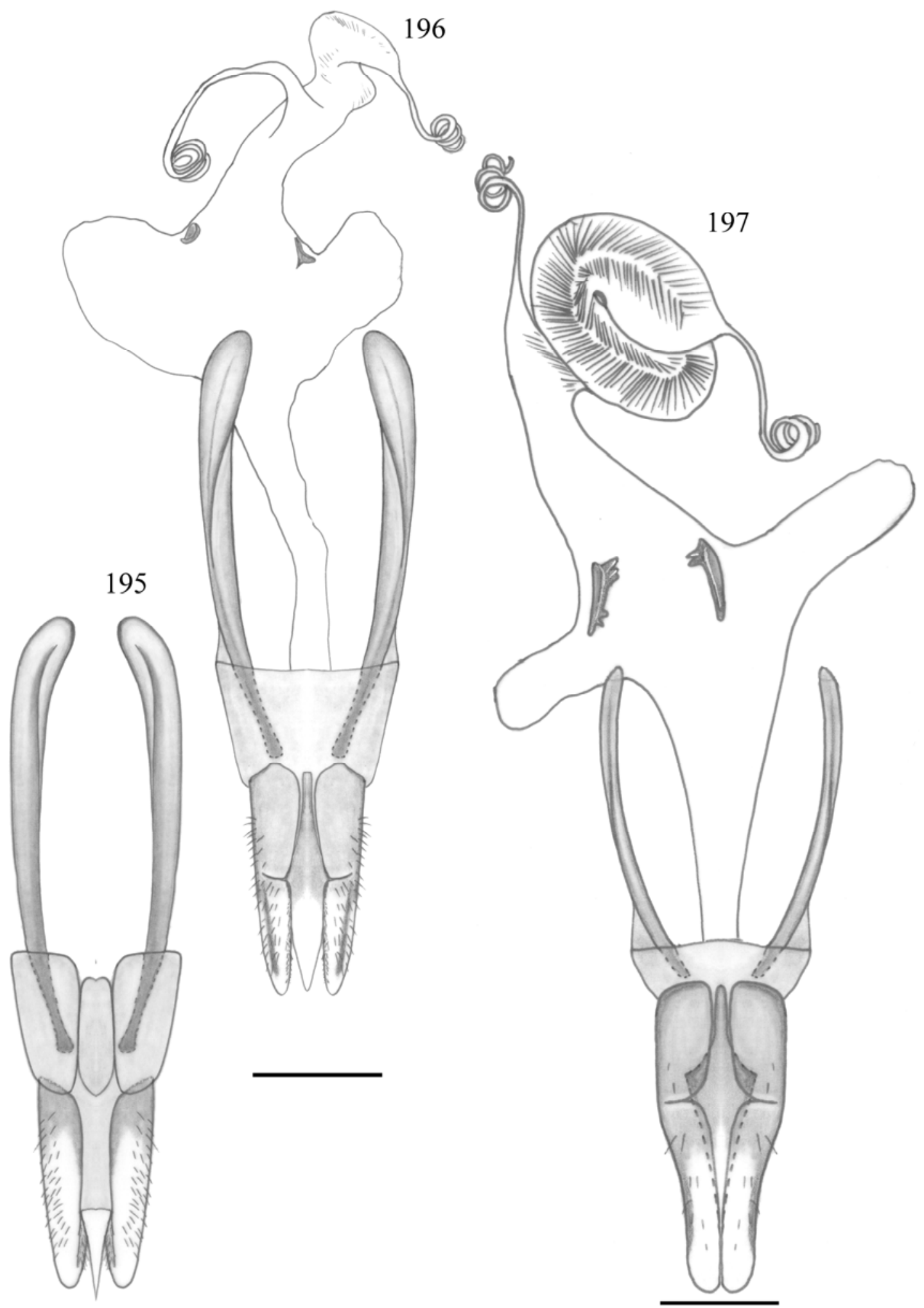

Figuras 195-197. Ovipositor e trato reprodutivo feminino: 195, 196, Nyctophyxis ocellatus (ventral, dorsal); 197, Gênero A sp 1 sp n. (dorsal). Escalas: 1,0 mm. 


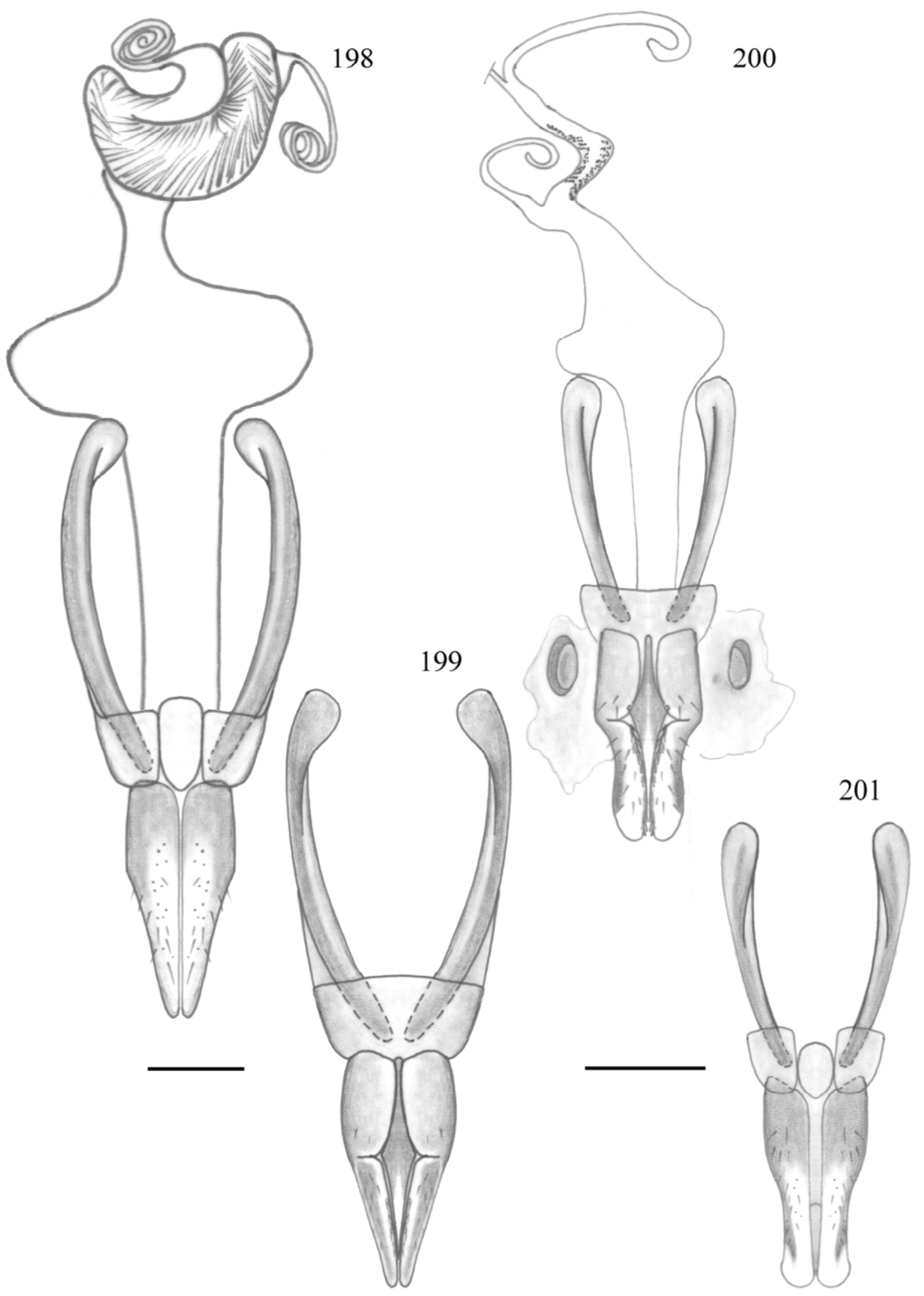

Figuras 198-201. Ovipositor e trato reprodutivo feminino: 198, 199, Fulgeochlizus bruchi (ventral, dorsal); 200, 201, Meroplinthus trilineatus (dorsal, com escleritos da membrana interconectiva do segmento VIII e ventral). Escalas: 1,0 mm. 


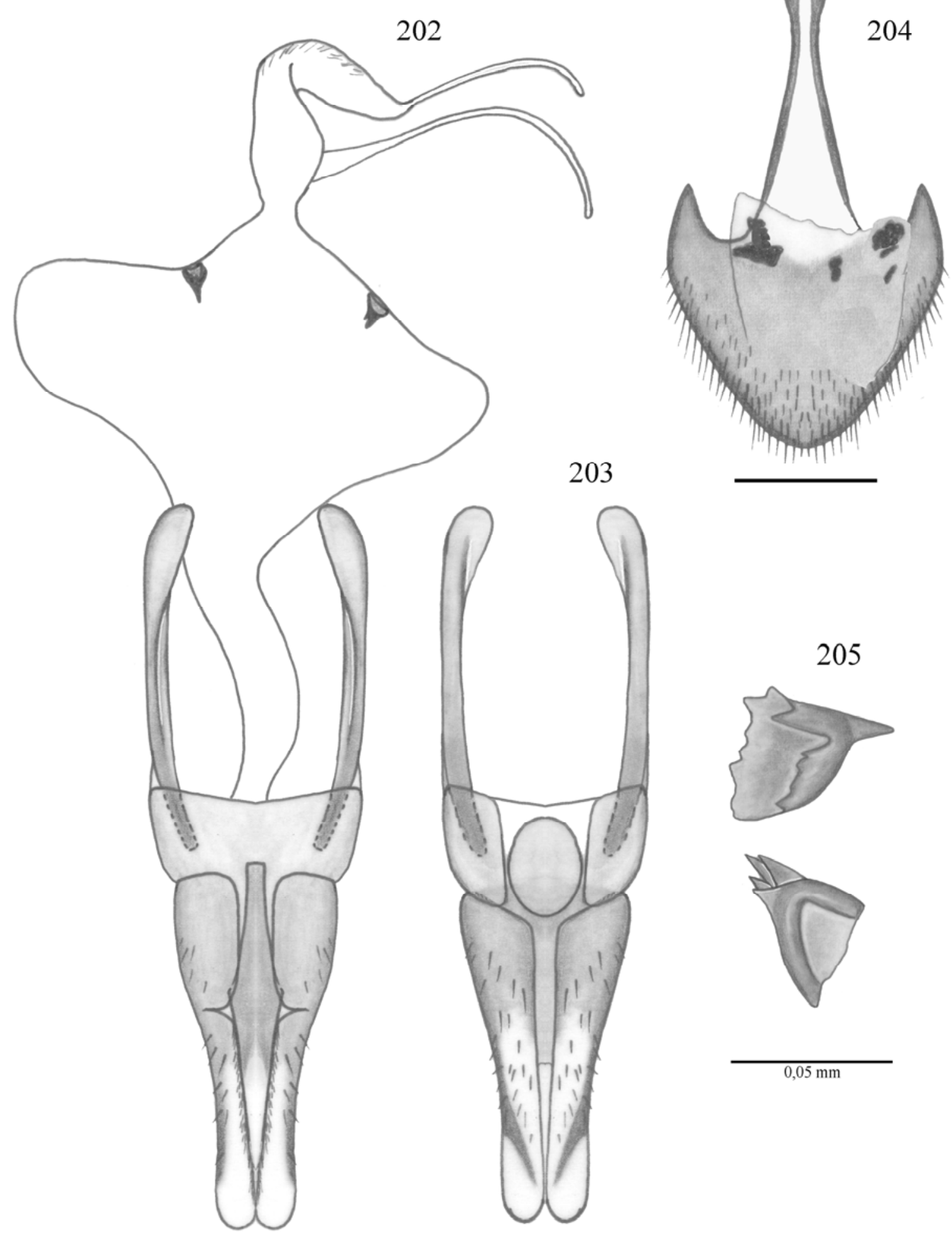

Figuras 202-205. Sooporanga formosa (fêmea): 202, 203, ovipositor e trato reprodutivo (dorsal, ventral); 204, esternito VIII (dorsal, com escleritos da membrana interconectiva do segmento VIII); 205, escleritos da região anterior às glândulas coleteriais. Escalas: 1,0 mm. 


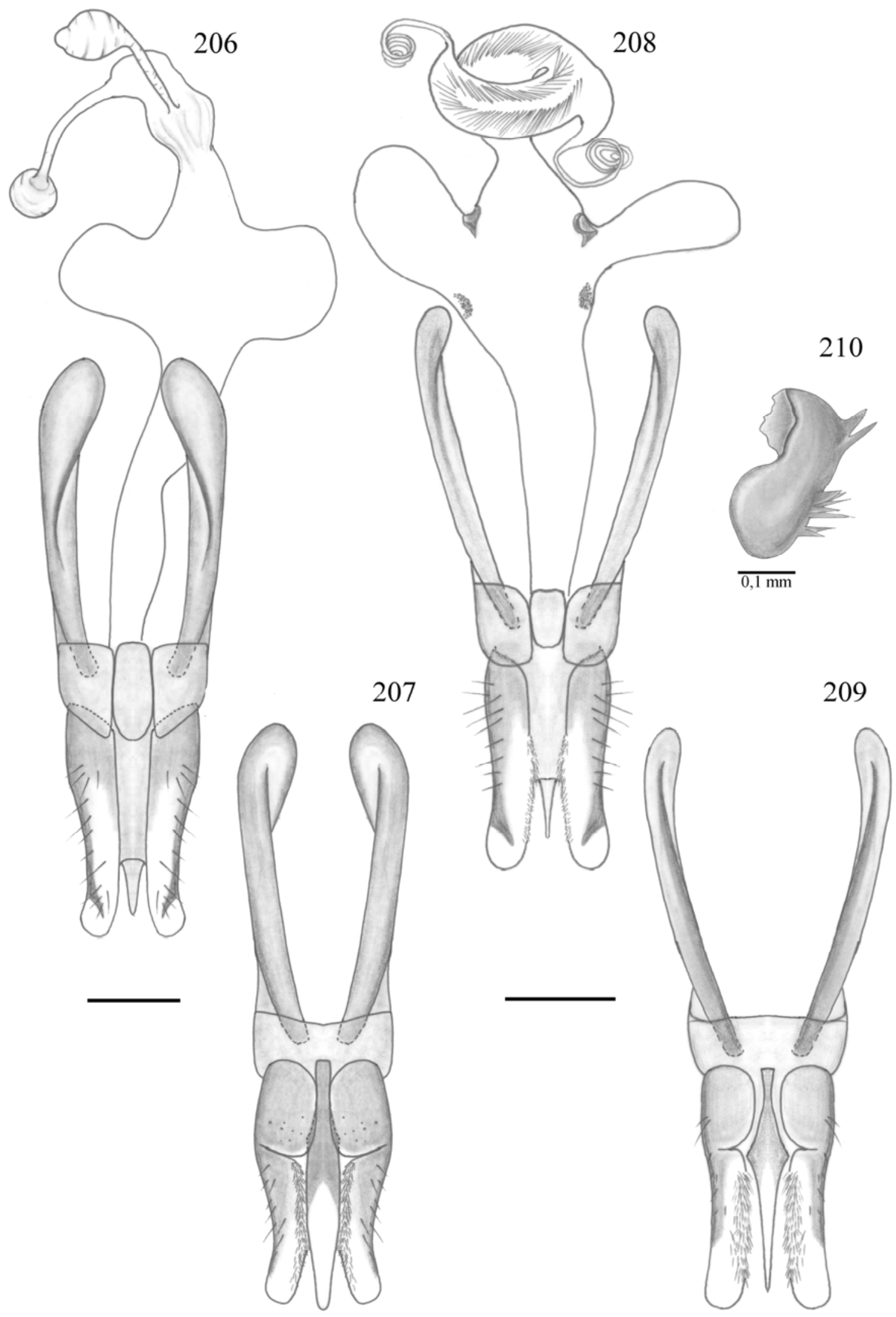

Figuras 206-210. 206-209, ovipositor e trato reprodutivo feminino: 206, 207: Pyrearinus nyctolampis (ventral, dorsal); 208, 209, Pyrearinus fulgurans (ventral, dorsal). Esclerito anterior à glândula coleterial: 210, Pyrearinus fulgurans. Escalas 205-209: 0,5 mm. 

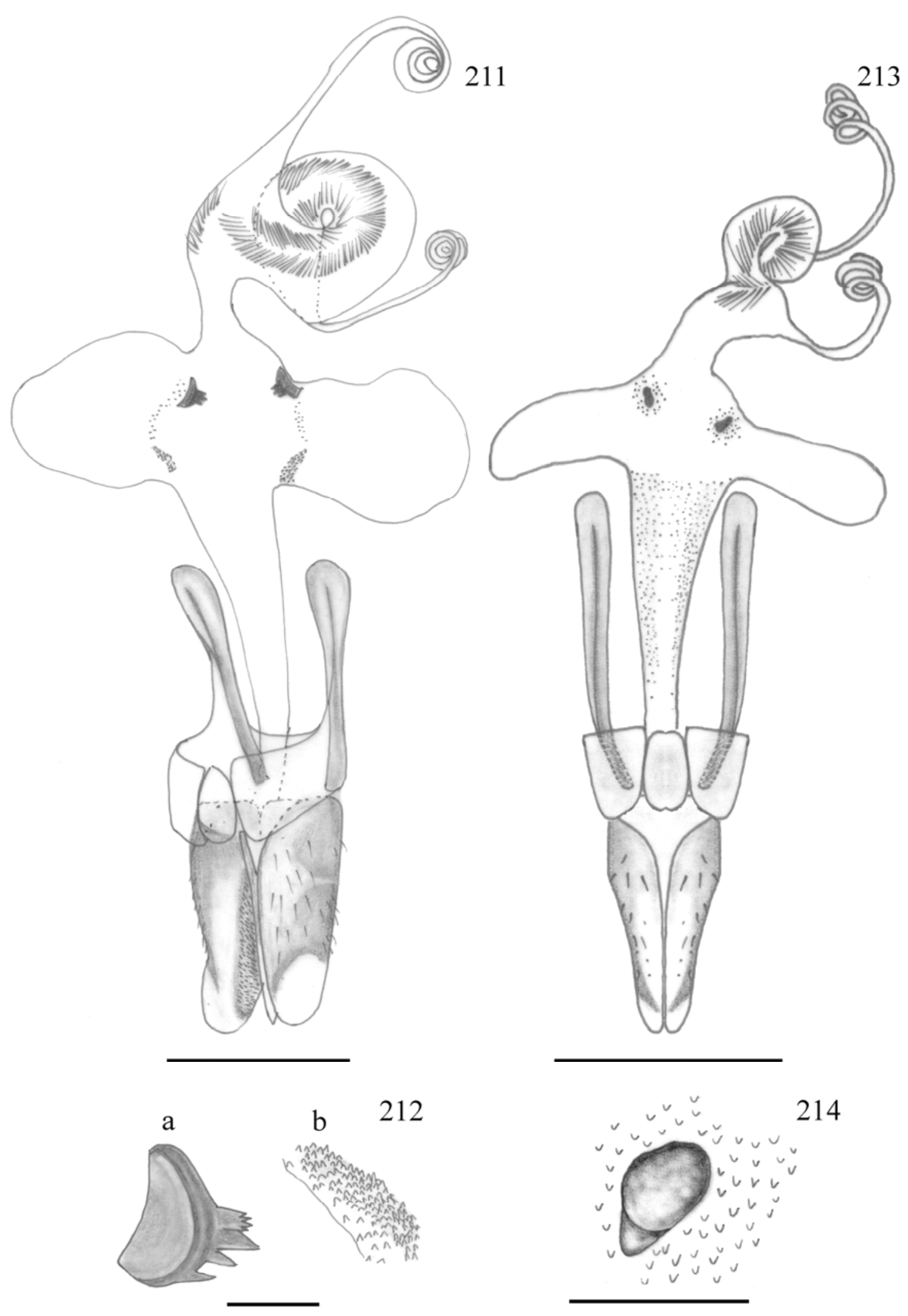

Figuras 211-214. Pyrearinus lineatus: 211, ovipositor e trato reprodutivo feminino (láteroventral); 212 (a, b), escleritos anterior e posterior à glândula coleterial. Euplinthus ophthalmicus: 213, ovipositor e trato reprodutivo feminino (ventral); 214, esclerito anterior à glândula coleterial. Escalas 211, 213: 1,0 mm; 212, 214: 0,1 mm. 

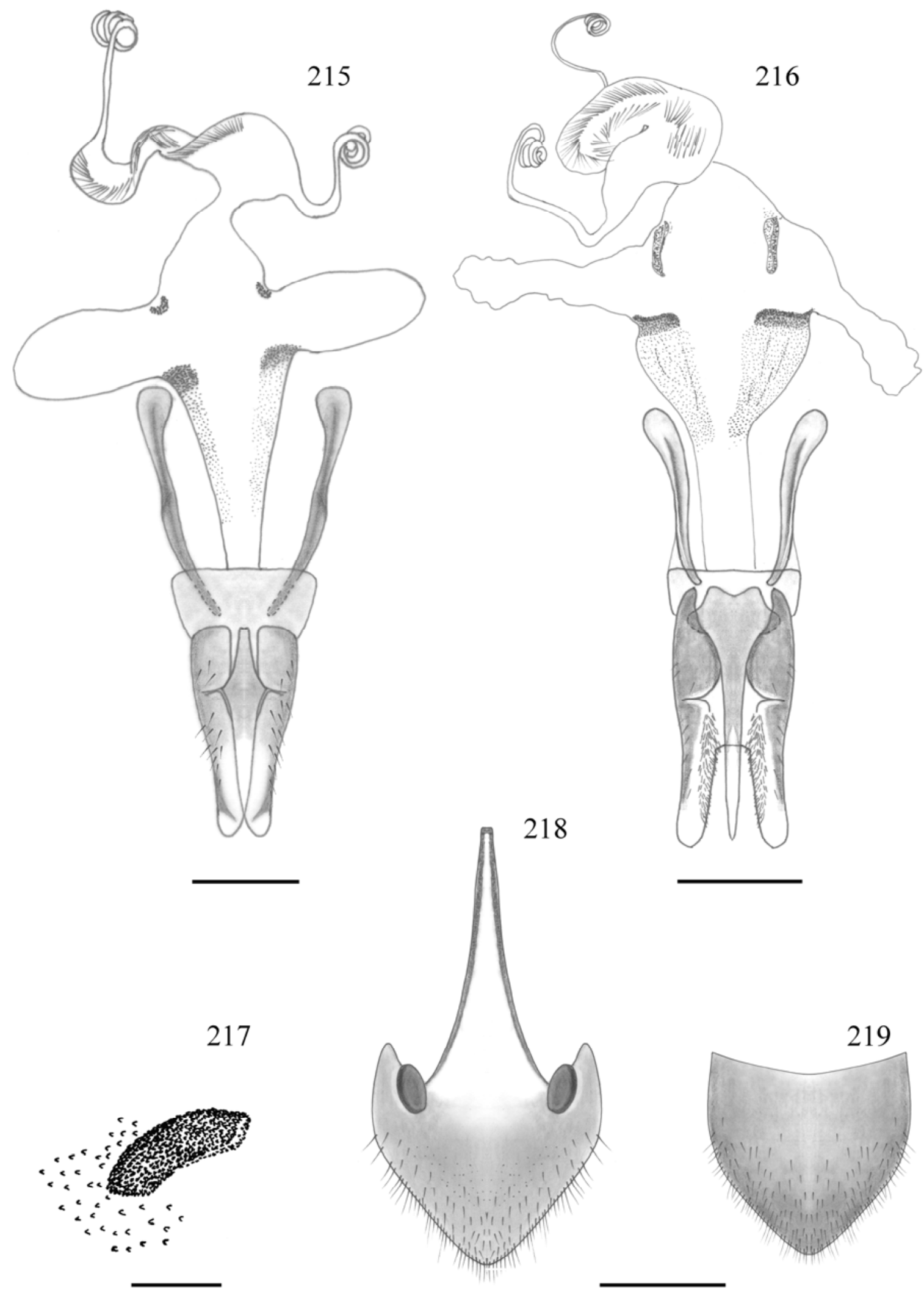

$\overline{0,05 \mathrm{~mm}}$

Figuras 215-219. Ovipositor e trato reprodutivo feminino (dorsal): 215, Compsoplinthus ruber; 216, Lygelater fulgidus. Esclerito anterior à glândula coleterial: 217, Opselater pyrophanus. Lygelater fulgidus (fêmea): 218, esternito VIII (dorsal) com escleritos da membrana interconectiva do segmento VIII; 219, tergito VIII. Escalas 215, 216, 218, 219: 1,0 $\mathrm{mm}$. 


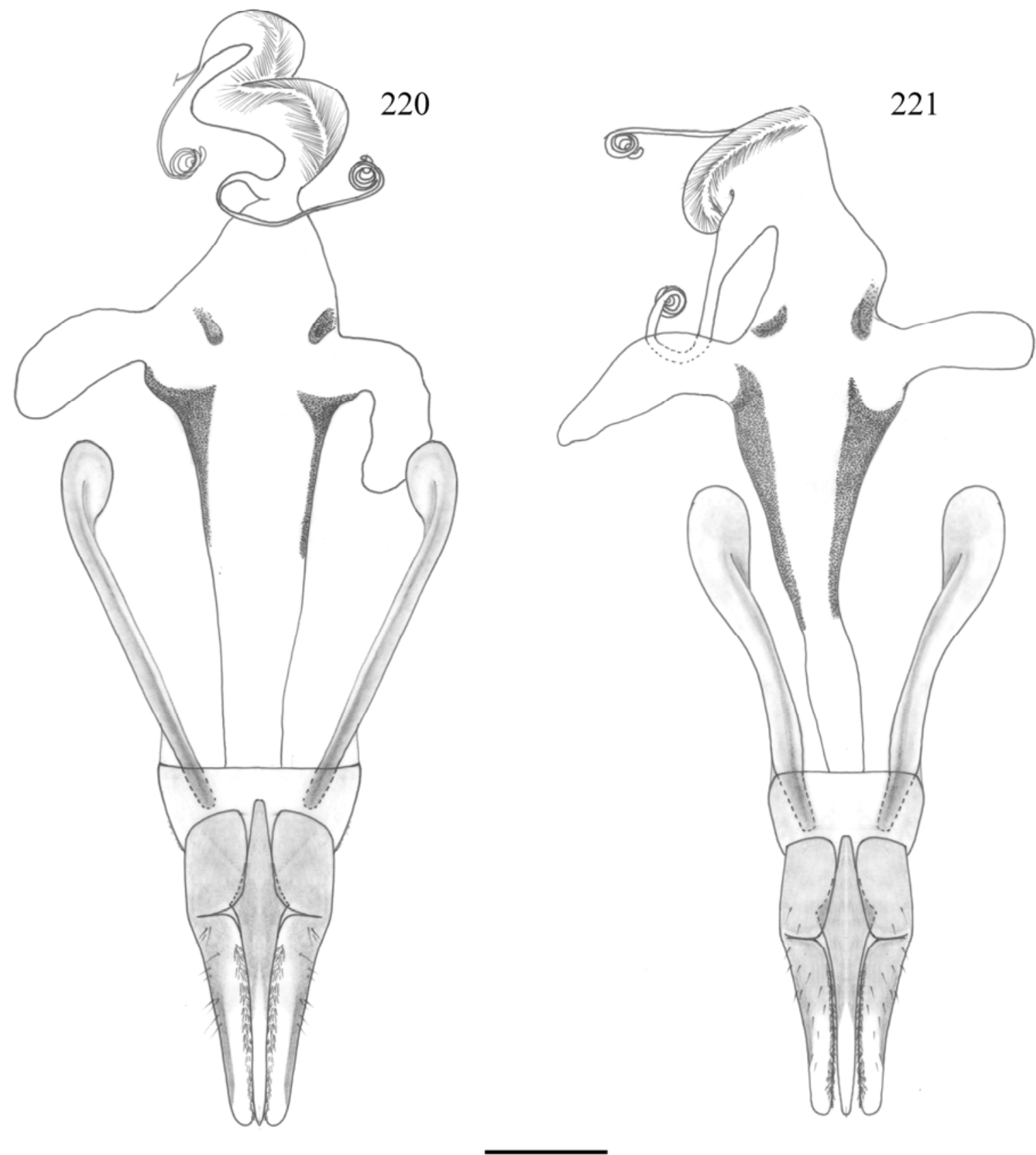

Figuras 220, 221. Ovipositor e trato reprodutivo feminino (dorsal): 220, Photophorus bakewellii; 221, Ignelater havaniensis. Escala: 1,0 mm. 

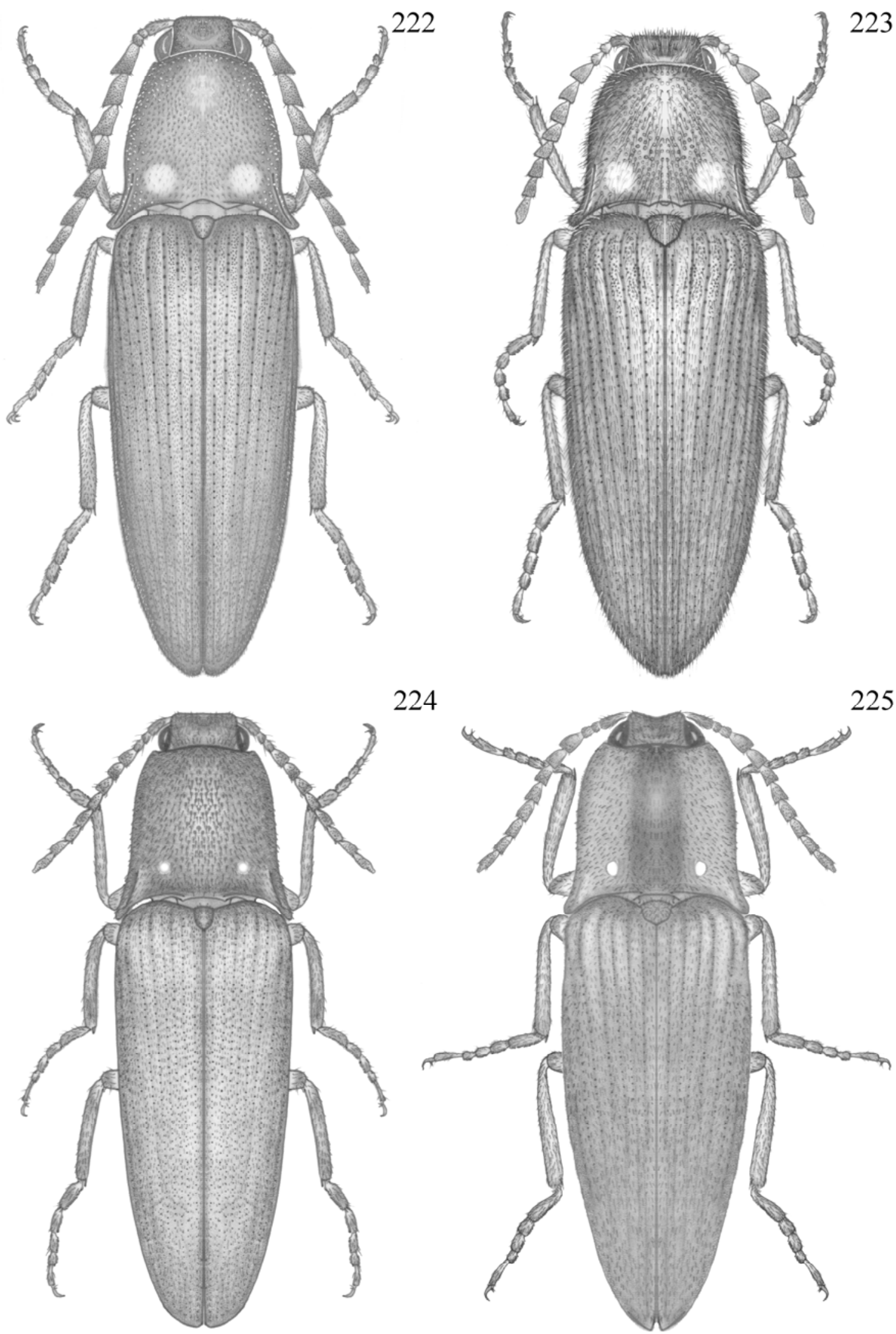

225

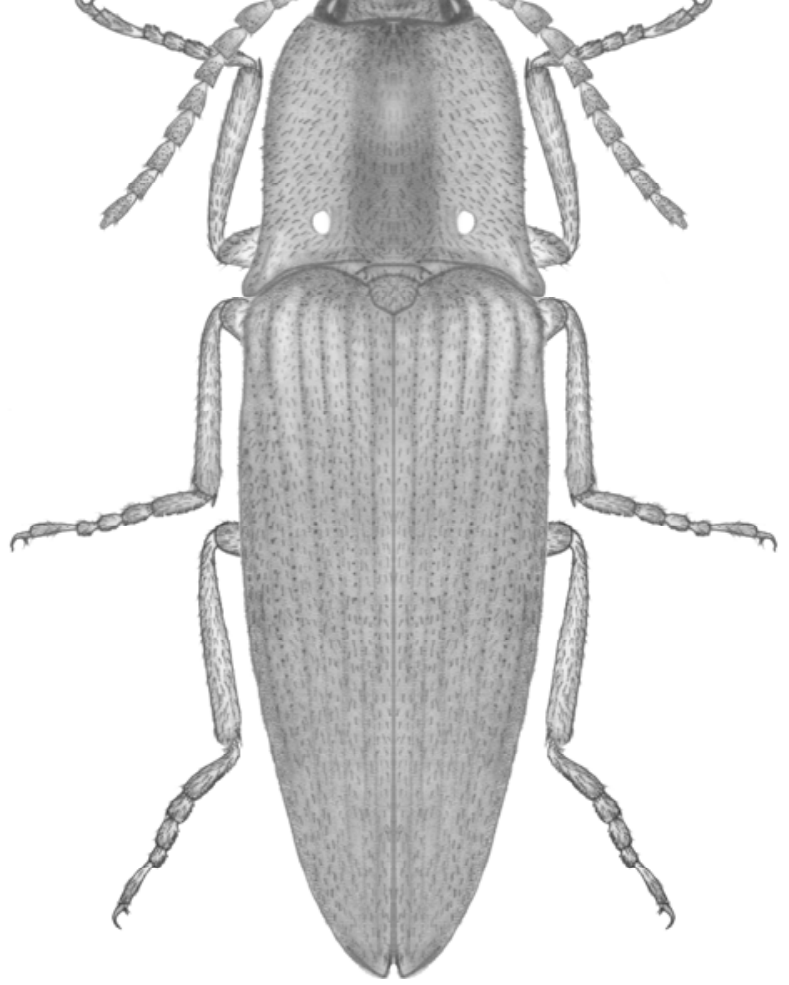

Figuras 222-225. Habitus (macho): 222, Noxlumenes bardus (17,7 mm); 223, Nyctophyxis ocellatus (18,0 mm); 224, Cryptolampros coecus (15,0 mm); 225, Gênero A sp. 1 sp. n (22,0 $\mathrm{mm})$. 


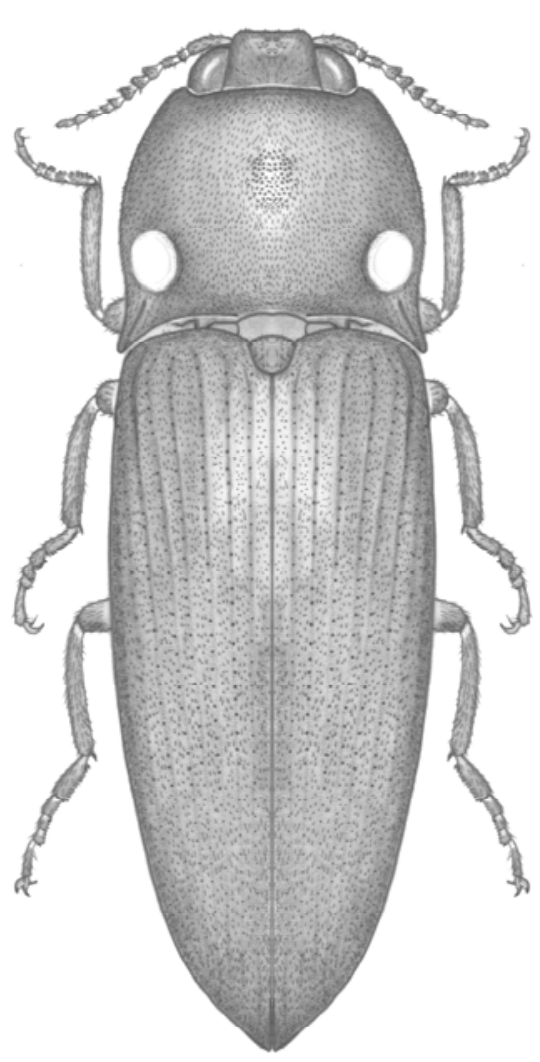

226

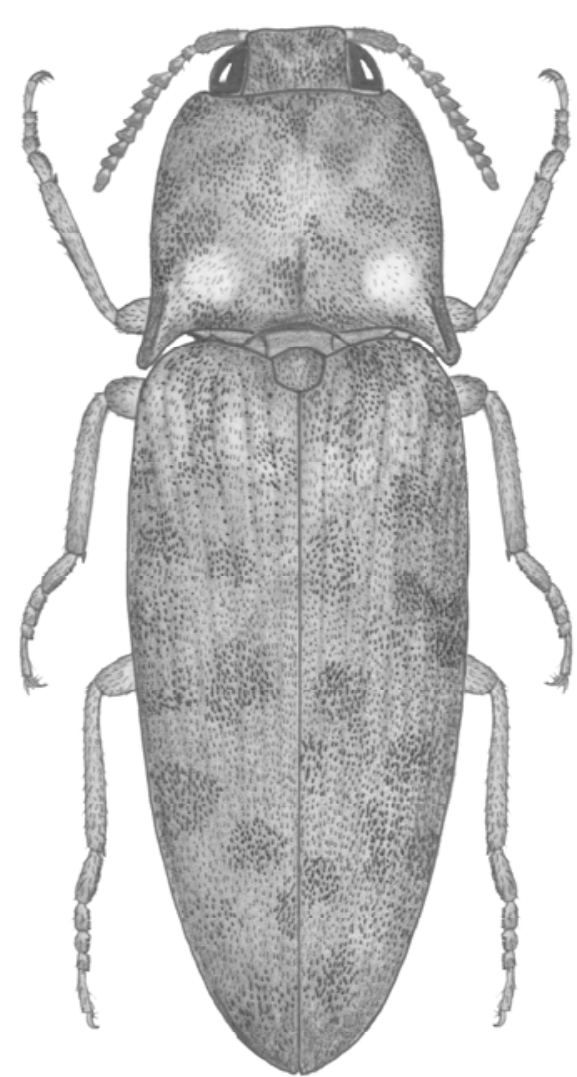

227

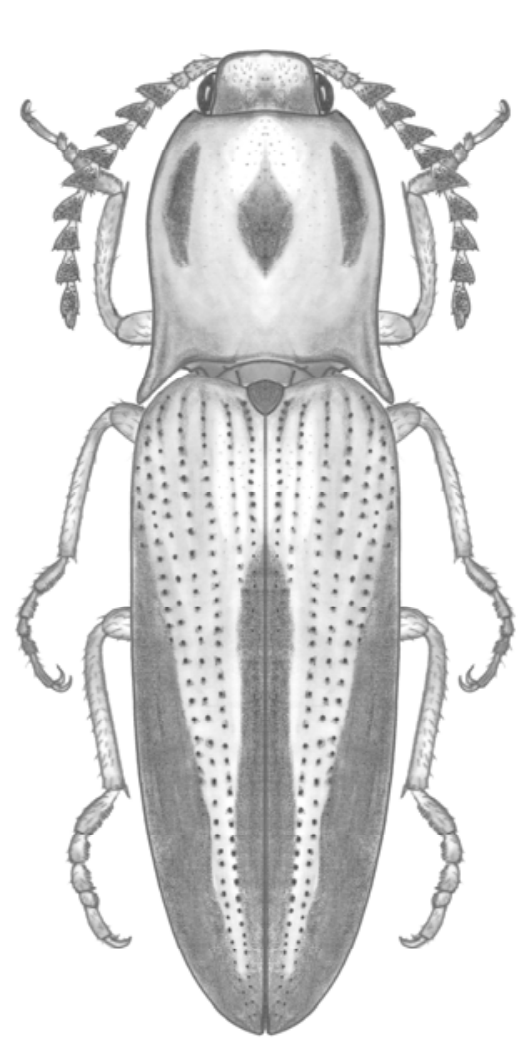

228

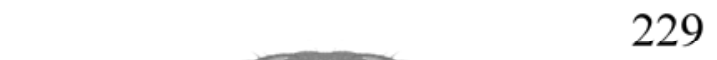

Figuras 226-229. Habitus (macho): 226, Pyrophorus noctilucus (20,0 mm); 227, Fulgeochlizus bruchi (21,3 mm); 228, Meroplinthus trilineatus (17,0 mm); 229, Ptesimopsia candezei $(20,7 \mathrm{~mm})$. 

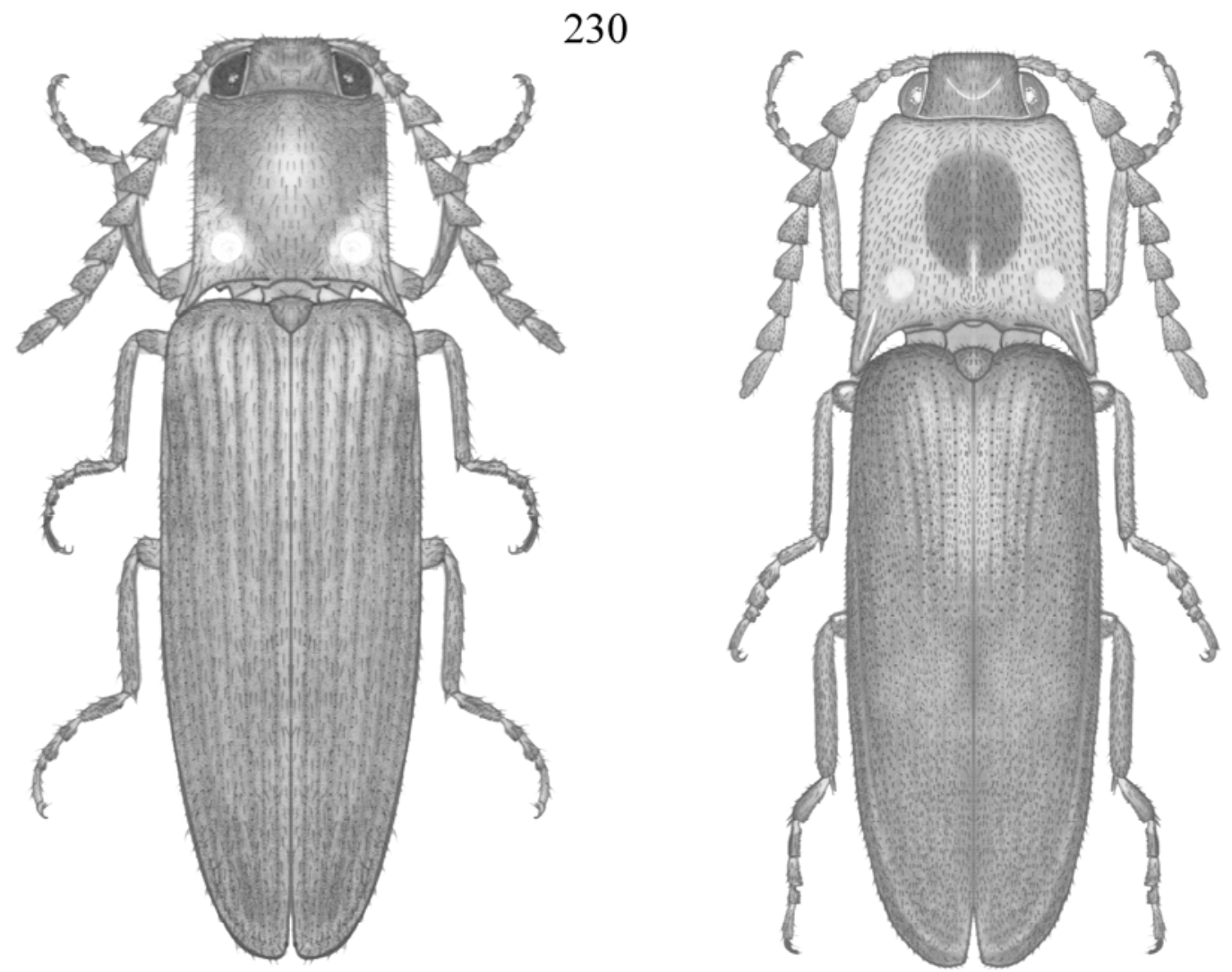

231
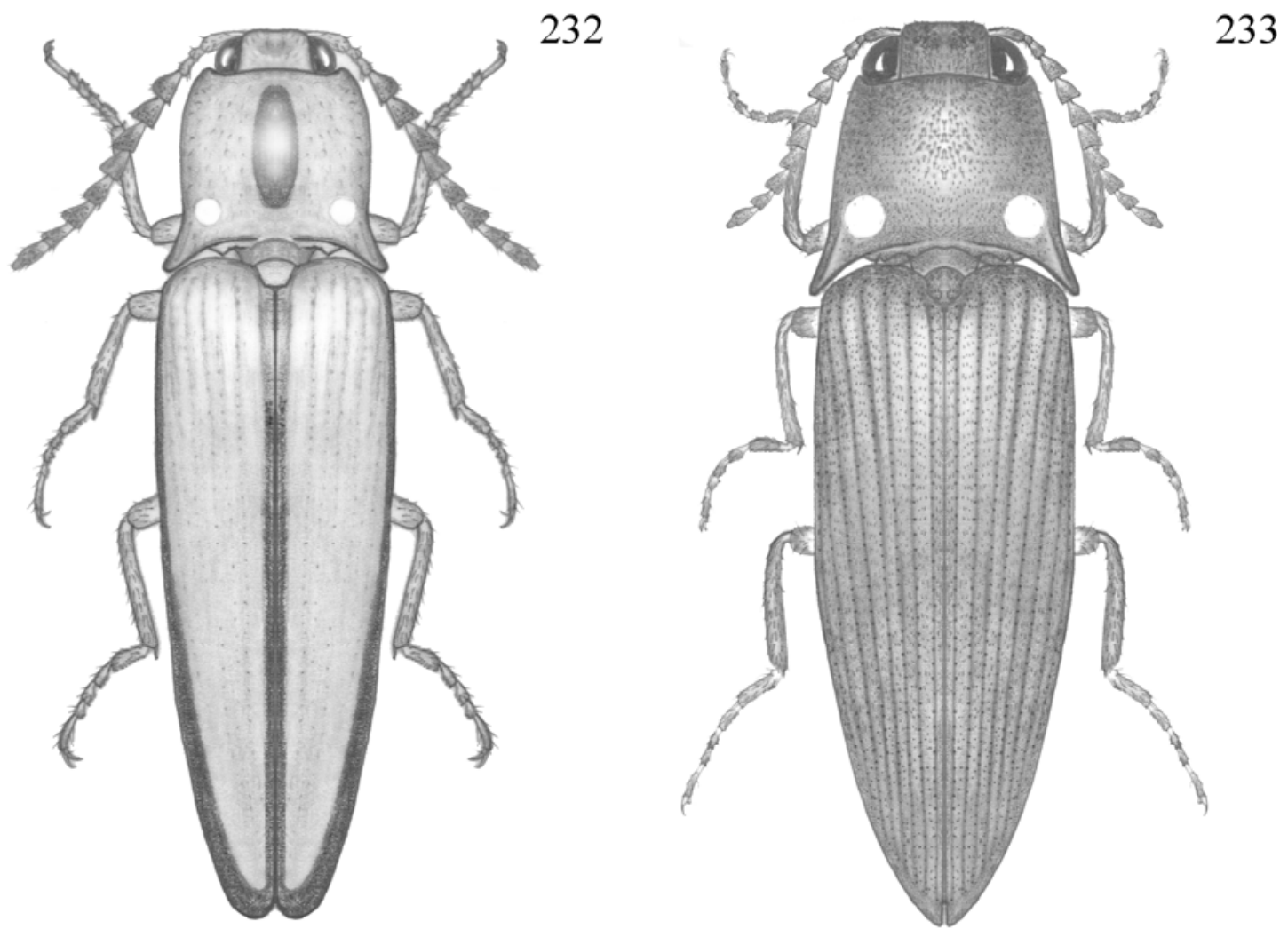

Figuras 230-233. Habitus (macho): 230, Hapsodrilus ignifer (19,5 mm); 231, Pyroptesis cincticollis (15,2 mm); 232, Sooporanga formosa (22,7 mm); 233, Gênero B cinnameus comb. n. $(17,0 \mathrm{~mm})$. 

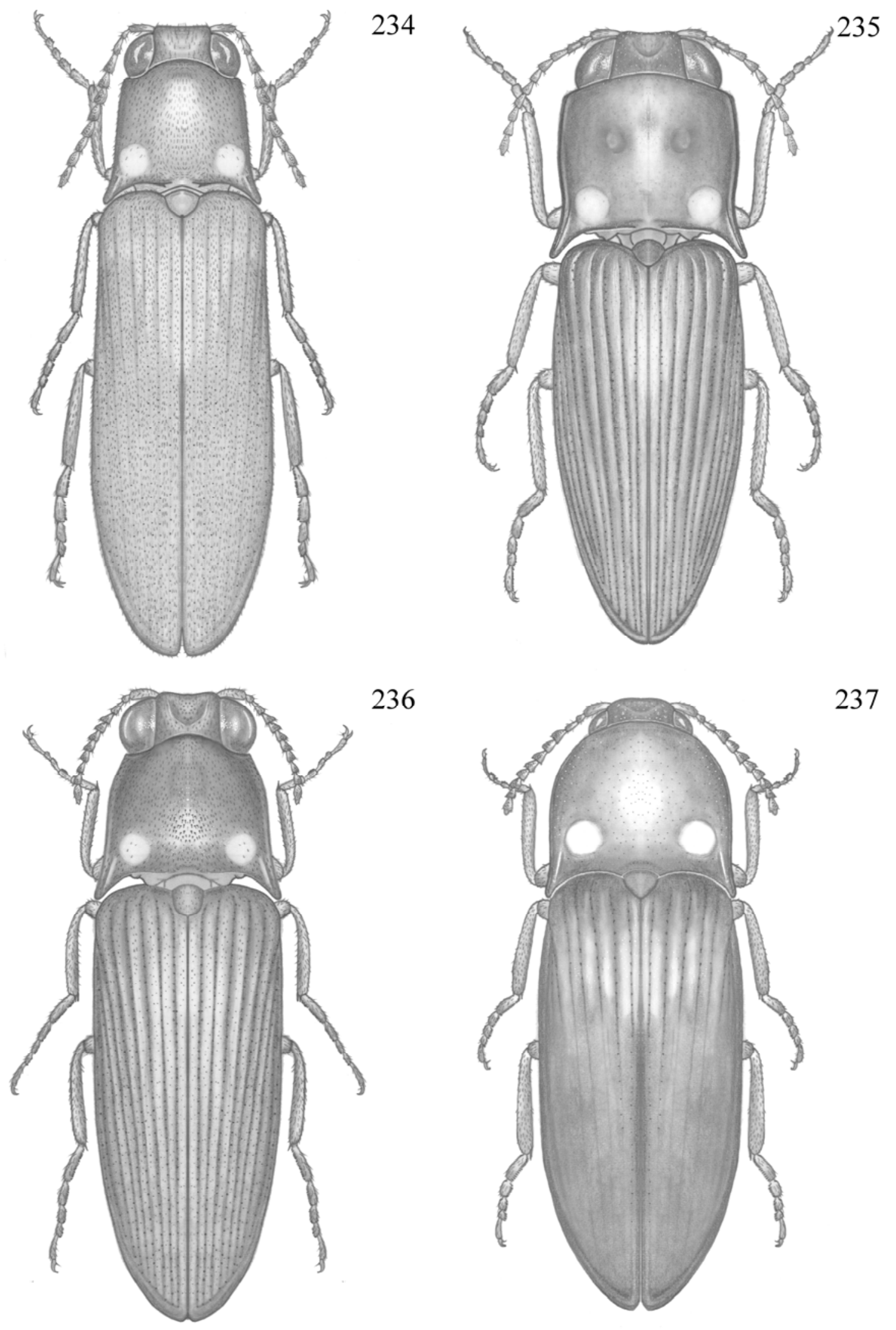

Figuras 234-237. Habitus. Macho: 234, Phanophorus perspicax (11,0 mm); 235, Pyrearinus nyctolampis (13,0 mm); 236, Hypsiophthalmus buphthalmus (14,6 mm). Fêmea: 237, Hypsiophthalmus grossicollis $(17,0 \mathrm{~mm})$. 


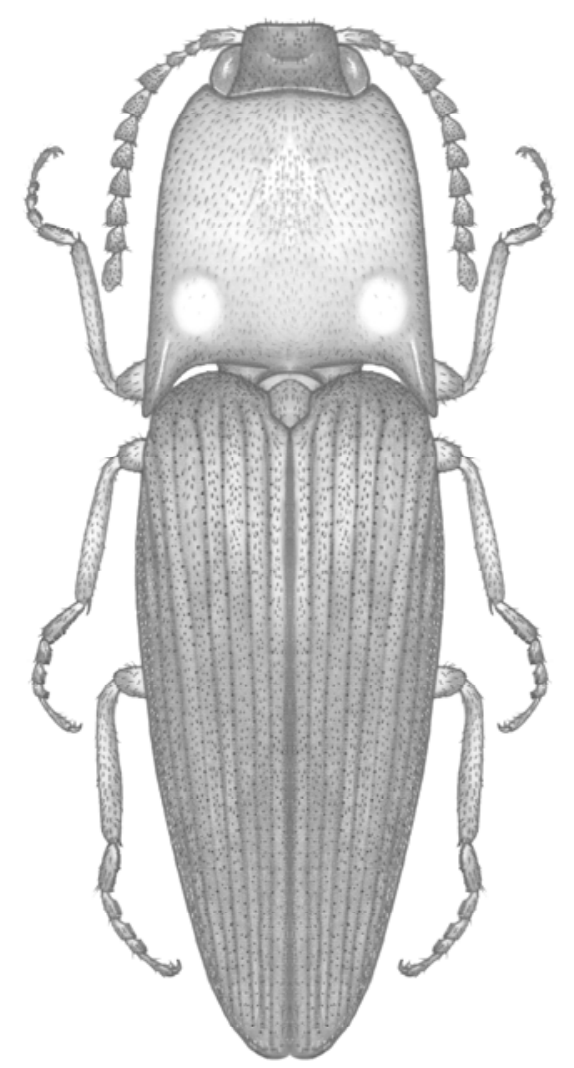

238
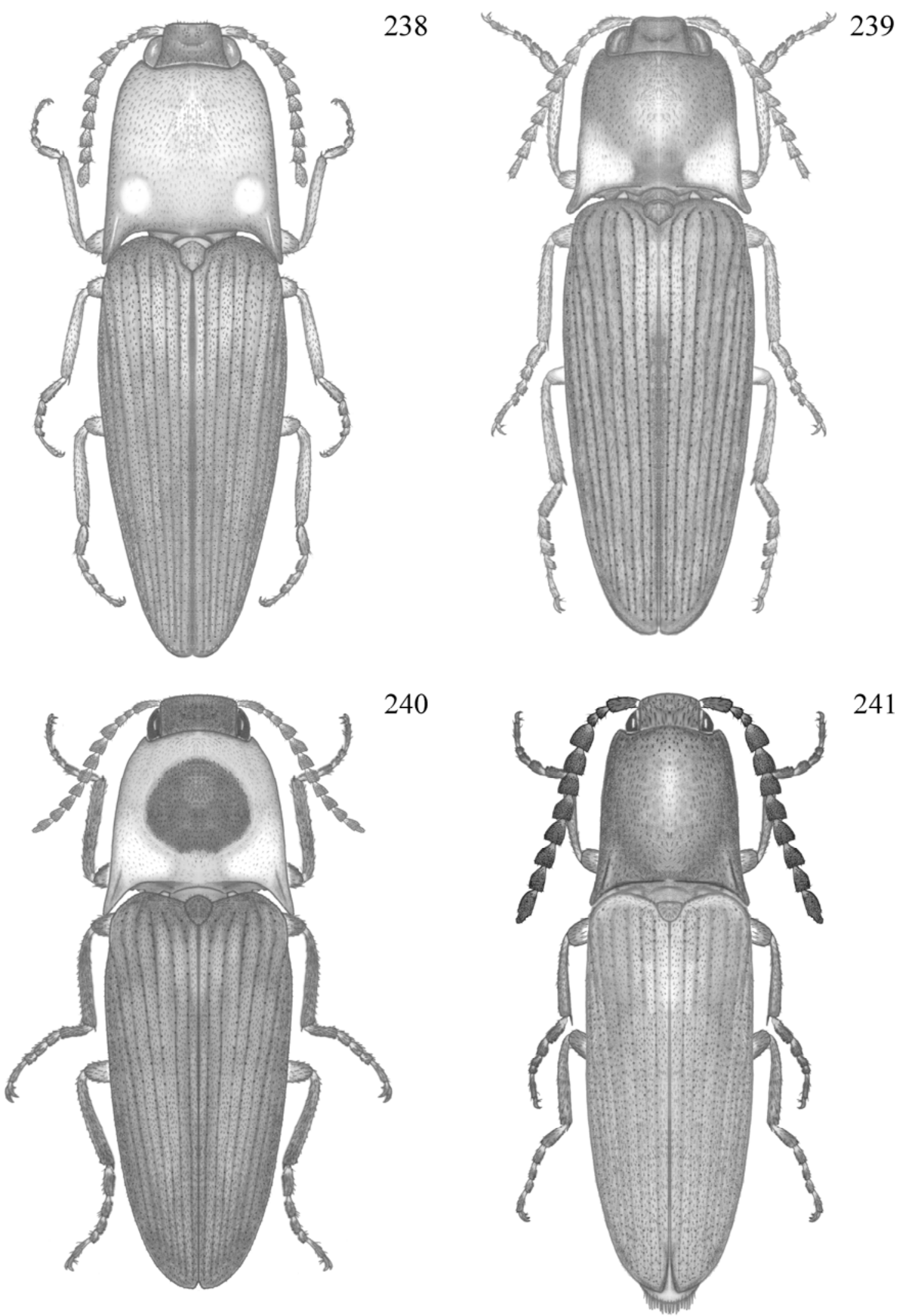

Figuras 238-241. Habitus (macho): 238, Gênero C basalis comb. n. (9,0 mm); 239, Gênero D lampyris comb. n. (15,0 mm); 240, Coctilelater corymbitoides (8,5 mm); 241, Agnostelater mesochrous $(12,0 \mathrm{~mm})$. 

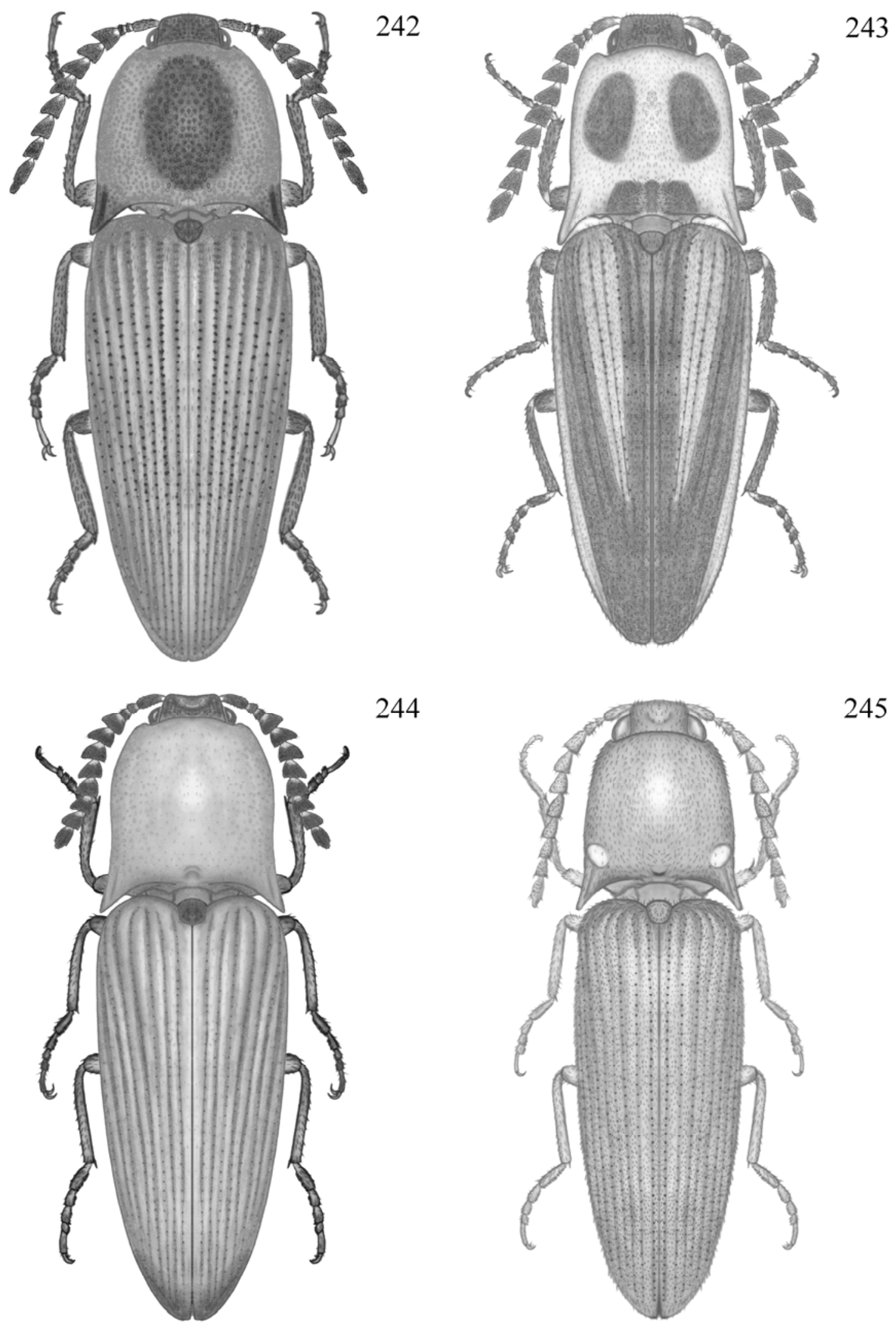

245

Figuras 242-245. Habitus (macho): 242, Paraphileus thoreyi (21,0 mm); 243, Euplinthus ophthalmicus (15,0 mm); 244, Compsoplinthus ruber (16,0 mm); 245, Deilelater physoderus $(18,7 \mathrm{~mm})$. 


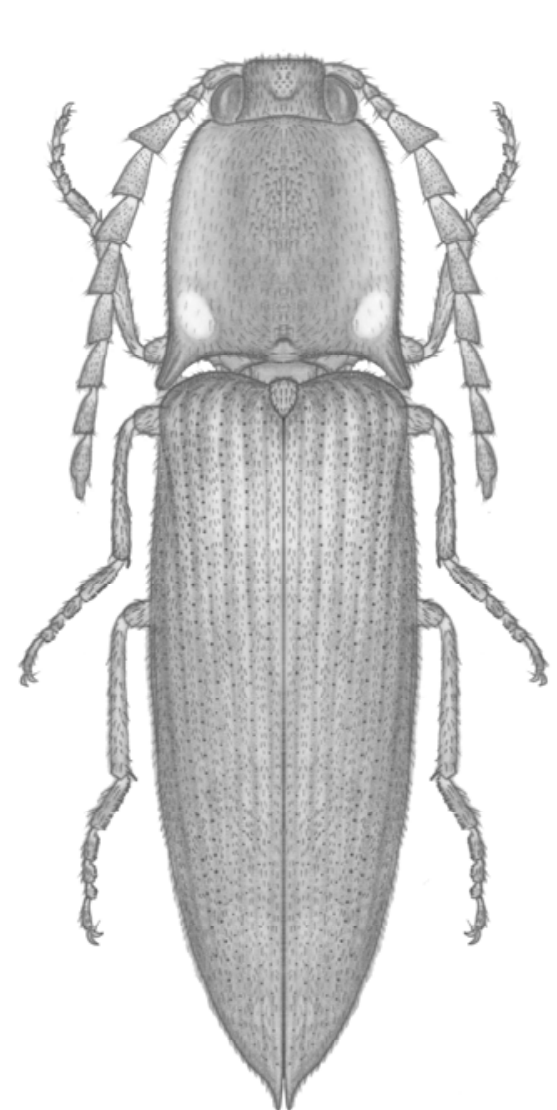

246
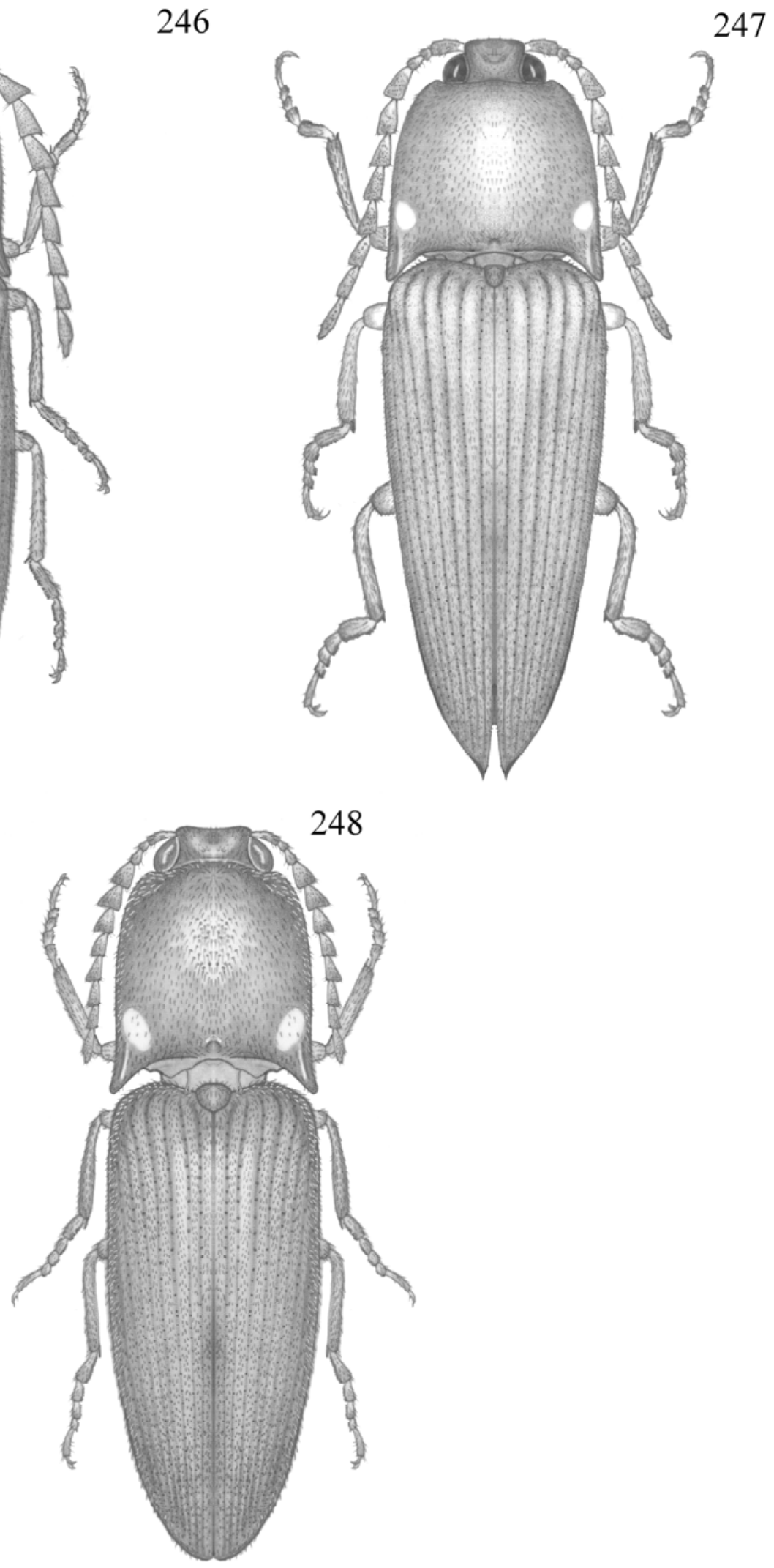

Figuras 246-248. Habitus (macho): 246, Ignelater havaniensis (19,0 mm); 247, Photophorus jansonii (26,0 mm); 248, Vesperelater ornamentum $(14,0 \mathrm{~mm})$. 


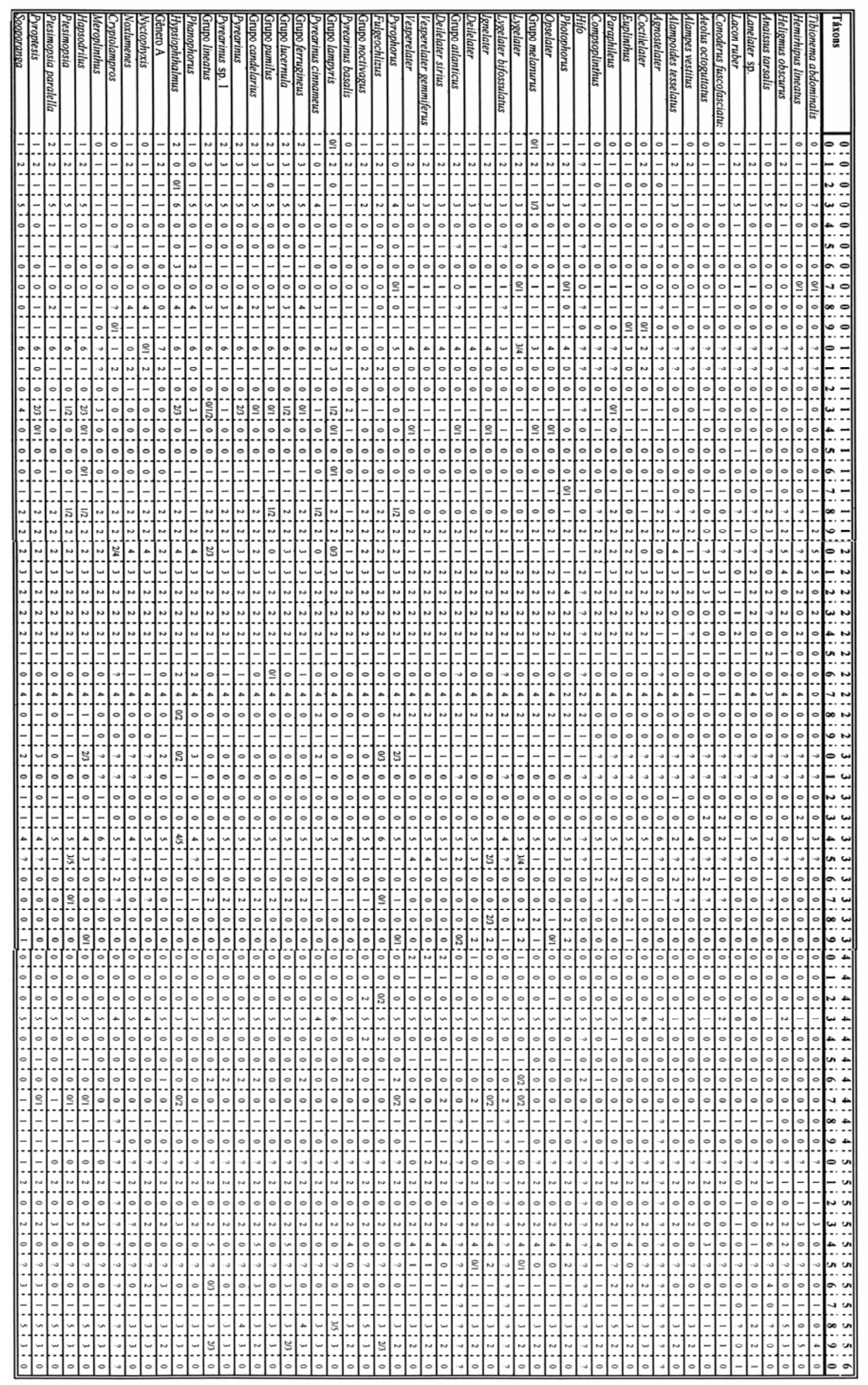

